Cochrane Database of Systematic Reviews

\title{
Interventions for helping to turn term breech babies to head first presentation when using external cephalic version (Review)
}

Cluver C, Gyte GML, Sinclair M, Dowswell T, Hofmeyr GJ

Cluver C, Gyte GML, Sinclair M, Dowswell T, Hofmeyr GJ.

Interventions for helping to turn term breech babies to head first presentation when using external cephalic version. Cochrane Database of Systematic Reviews 2015, Issue 2. Art. No.: CD000184.

DOI: 10.1002/14651858.CD000184.pub4.

www.cochranelibrary.com 
TAB LE OF CONTENTS

HEADER . . . . . . . . . . . . . . . . . . . . . . . . . . . . . . . . . . . . . . . . . .

ABSTRACT . . . . . . . . . . . . . . . . . . . . . . . . . . . . . . . . . . . . . . . . . . . . . . . 1

PLAIN LANGUAGE SUMMARY . . . . . . . . . . . . . . . . . . . . . . . . . . . . . . . . . . . . 2

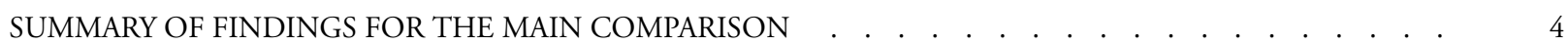

BACKGROUND . . . . . . . . . . . . . . . . . . . . . . . . . . . . . . . . . . . . . . . . . . . . 7

OBJECTIVES . . . . . . . . . . . . . . . . . . . . . . . . . . . . . . . . . . . . . . . . . . . . . . . .

METHODS . . . . . . . . . . . . . . . . . . . . . . . . . . . . . . . . . . . . . . . .

RESULTS . . . . . . . . . . . . . . . . . . . . . . . . . . . . . . . . . . . . . . . . . . .

Figure 1. . . . . . . . . . . . . . . . . . . . . . . . . . . . . . . . . . . . . . . . . . . . . . 14

ADDITIONAL SUMMARY OF FINDINGS . . . . . . . . . . . . . . . . . . . . . . . . . . . . . . . . . .

DISCUSSION . . . . . . . . . . . . . . . . . . . . . . . . . . . . . . . . . . . . . . . 24

AUTHORS' CONCLUSIONS . . . . . . . . . . . . . . . . . . . . . . . . . . . . . . . . . . . . . . . . .

ACKNOWLEDGEMENTS . . . . . . . . . . . . . . . . . . . . . . . . . . . . . . . . . . . . . . . 25

REFERENCES . . . . . . . . . . . . . . . . . . . . . . . . . . . . . . . . . . . . . . . . . .

CHARACTERISTICS OF STUDIES . . . . . . . . . . . . . . . . . . . . . . . . . . . . . . . . . . . . . . . . . . .

DATA AND ANALYSES . . . . . . . . . . . . . . . . . . . . . . . . . . . . . . . . . . . . . . . . . . . . . . . . . . . . .

Analysis 1.1. Comparison 1 Tocolytic drugs (A) vs placebo, Outcome 1 Cephalic presentation at birth (primary). . . 83

Analysis 1.2. Comparison 1 Tocolytic drugs (A) vs placebo, Outcome 2 Failure to achieve cephalic vaginal birth (composite outcome: caesarean section + vaginal breech birth). . . . . . . . . . . . . . . . . . . . . . . . . . . 85

Analysis 1.3. Comparison 1 Tocolytic drugs (A) vs placebo, Outcome 3 Caesarean section (primary). . . . . . . $\quad$. 86

Analysis 1.4. Comparison 1 Tocolytic drugs (A) vs placebo, Outcome 4 Fetal bradycardia (primary). . . . . . . . . $\quad$. 87

Analysis 1.5. Comparison 1 Tocolytic drugs (A) vs placebo, Outcome 5 Failed external cephalic version. . . . . . . $\quad 88$

Analysis 1.6. Comparison 1 Tocolytic drugs (A) vs placebo, Outcome 6 Difficult external cephalic version. . . . . . 90

Analysis 1.7. Comparison 1 Tocolytic drugs (A) vs placebo, Outcome 7 Maternal palpitations. . . . . . . . . . . 91

Analysis 1.8. Comparison 1 Tocolytic drugs (A) vs placebo, Outcome 8 Maternal headaches. . . . . . . . . . . . . 92

Analysis 1.9. Comparison 1 Tocolytic drugs (A) vs placebo, Outcome 9 Maternal hypotension. . . . . . . . . . . .93

Analysis 1.10. Comparison 1 Tocolytic drugs (A) vs placebo, Outcome 10 Operative vaginal birth. . . . . . . . . . 94

Analysis 1.13. Comparison 1 Tocolytic drugs (A) vs placebo, Outcome 13 Perinatal mortality. . . . . . . . . . . . 95

Analysis 1.15. Comparison 1 Tocolytic drugs (A) vs placebo, Outcome 15 Vaginal breech birth. . . . . . . . . . 96

Analysis 1.16. Comparison 1 Tocolytic drugs (A) vs placebo, Outcome 16 Apgar < 7 at 5 minutes (not prespecified). 97

Analysis 1.17. Comparison 1 Tocolytic drugs (A) vs placebo, Outcome 17 Neonatal seizures (not prespecified). $\quad .98$

Analysis 1.18. Comparison 1 Tocolytic drugs (A) vs placebo, Outcome 18 Admission to neonatal unit (not prespecified). 99

Analysis 1.19. Comparison 1 Tocolytic drugs (A) vs placebo, Outcome 19 Birth trauma (not prespecified). . . . . . 100

Analysis 1.20. Comparison 1 Tocolytic drugs (A) vs placebo, Outcome 20 Maternal flushing (not prespecified). $\quad . \quad$. 101

Analysis 2.1. Comparison 2 Tocolytic drug 1 (A) vs tocolytic drug 2 (A), Outcome 1 Cephalic presentation at birth (primary). . . . . . . . . . . . . . . . . . . . . . . . . . . . . . . . . . . . . . . 102

Analysis 2.2. Comparison 2 Tocolytic drug 1 (A) vs tocolytic drug 2 (A), Outcome 2 Failure to achieve cephalic vaginal birth (composite outcome: caesarean section + vaginal breech birth). . . . . . . . . . . . . . . . . . . . . . 103

Analysis 2.3. Comparison 2 Tocolytic drug 1 (A) vs tocolytic drug 2 (A), Outcome 3 Caesarean section (primary)..$\quad 104$

Analysis 2.4. Comparison 2 Tocolytic drug 1 (A) vs tocolytic drug 2 (A), Outcome 4 Fetal bradycardia (primary). $\quad . \quad 105$

Analysis 2.5. Comparison 2 Tocolytic drug 1 (A) vs tocolytic drug 2 (A), Outcome 5 Failed external cephalic version. 106

Analysis 2.6. Comparison 2 Tocolytic drug 1 (A) vs tocolytic drug 2 (A), Outcome 6 Difficult external cephalic version. 107

Analysis 2.7. Comparison 2 Tocolytic drug 1 (A) vs tocolytic drug 2 (A), Outcome 7 Maternal palpitations. $\quad . \quad$. 108

Analysis 2.8. Comparison 2 Tocolytic drug 1 (A) vs tocolytic drug 2 (A), Outcome 8 Maternal headaches. . . . . . 109

Analysis 2.9. Comparison 2 Tocolytic drug 1 (A) vs tocolytic drug 2 (A), Outcome 9 Maternal hypotension. $\quad$. $\quad$. 110

Analysis 2.16. Comparison 2 Tocolytic drug 1 (A) vs tocolytic drug 2 (A), Outcome 16 Apgar $<7$ at 5 minutes (not prespecified). . . . . . . . . . . . . . . . . . . . . . . . . . . . . . . . . . . . .

Analysis 2.18. Comparison 2 Tocolytic drug 1 (A) vs tocolytic drug 2 (A), Outcome 18 Admissions to neonatal unit (not prespecified). . . . . . . . . . . . . . . . . . . . . . . . . . . . . . . . . . . 112

Analysis 3.5. Comparison 3 Vibroacoustic stimulation (B) vs placebo, Outcome 5 Failed external cephalic version. $\quad$. 113

Interventions for helping to turn term breech babies to head first presentation when using external cephalic version (Review)

Copyright () 2016 The Cochrane Collaboration. Published by John Wiley \& Sons, Ltd. 
Analysis 6.1. Comparison 6 Regional analgesia (with or without tocolysis) vs no intervention of regional analgesia (with or without tocolysis), Outcome 1 Cephalic presentation at birth (primary).

Analysis 6.3. Comparison 6 Regional analgesia (with or without tocolysis) vs no intervention of regional analgesia (with or without tocolysis), Outcome 3 Caesarean section (primary). . . . . . . . . . . . . . . . . . . . . .

Analysis 6.4. Comparison 6 Regional analgesia (with or without tocolysis) vs no intervention of regional analgesia (with or without tocolysis), Outcome 4 Fetal bradycardia (primary). . . . . . . . . . . . . . . . . . . 116

Analysis 6.5. Comparison 6 Regional analgesia (with or without tocolysis) vs no intervention of regional analgesia (with or without tocolysis), Outcome 5 Failed external cephalic version. . . . . . . . . . . . . . . . . . . 117

Analysis 6.9. Comparison 6 Regional analgesia (with or without tocolysis) vs no intervention of regional analgesia (with or without tocolysis), Outcome 9 Maternal hypotension. . . . . . . . . . . . . . . . . . . . .

Analysis 6.15. Comparison 6 Regional analgesia (with or without tocolysis) vs no intervention of regional analgesia (with or without tocolysis), Outcome 15 Placental abruption (not prespecified). . . . . . . . . . . . . . . . .

Analysis 6.16. Comparison 6 Regional analgesia (with or without tocolysis) vs no intervention of regional analgesia (with or without tocolysis), Outcome 16 Maternal discomfort (not prespecified). . . . . . . . . . . . . .

Analysis 15.3. Comparison 15 Systemic opioids (E) vs placebo, Outcome 3 Fetal bradycardia (primary). . . . . . .

Analysis 15.4. Comparison 15 Systemic opioids (E) vs placebo, Outcome 4 Caesarean section (primary). . . . . .

Analysis 15.5. Comparison 15 Systemic opioids (E) vs placebo, Outcome 5 Failed external cephalic version. $\quad$. . . . 122

Analysis 15.10. Comparison 15 Systemic opioids (E) vs placebo, Outcome 10 Operative vaginal birth. . . . . . . . 122

Analysis 15.15. Comparison 15 Systemic opioids (E) vs placebo, Outcome 15 Pain score (0-10 scale, lowest best) (nonprespecified).

Analysis 15.16. Comparison 15 Systemic opioids (E) vs placebo, Outcome 16 Maternal satisfaction score (lower score worst) (non-prespecified). . . . . . . . . . . . . . . . . . . . . . . . . . . . . . . . . . .

Analysis 15.17. Comparison 15 Systemic opioids (E) vs placebo, Outcome 17 Nausea and vomiting (non-prespecified).

Analysis 15.18. Comparison 15 Systemic opioids (E) vs placebo, Outcome 18 Dizziness (non-prespecified). . . .

Analysis 15.19. Comparison 15 Systemic opioids (E) vs placebo, Outcome 19 Drowsiness (non-prespecified). . . . .

Analysis 18.2. Comparison 18 Systemic opioids (E) vs regional anaesthesia (C), Outcome 2 Failure to achieve cephalic vaginal birth (composite outcome: caesarean section + vaginal breech birth). . . . . . . . . . . . . . . . . . .

Analysis 18.3. Comparison 18 Systemic opioids (E) vs regional anaesthesia (C), Outcome 3 Caesarean section (primary).

Analysis 18.4. Comparison 18 Systemic opioids (E) vs regional anaesthesia (C), Outcome 4 Fetal bradycardia (primary).

Analysis 18.5. Comparison 18 Systemic opioids (E) vs regional anaesthesia (C), Outcome 5 Failed external cephalic version. . . . . . . . . . . . . . . . . . . . . . . . . . . . . . . . . . . . .

Analysis 21.1. Comparison 21 Tocolytics vs placebo - nullips vs multips, Outcome 1 Cephalic presentation at birth (primary).

Analysis 21.2. Comparison 21 Tocolytics vs placebo - nullips vs multips, Outcome 2 Caesarean section (primary).

Analysis 21.4. Comparison 21 Tocolytics vs placebo - nullips vs multips, Outcome 4 Failed external cephalic version.

Analysis 22.4. Comparison 22 Tocolytic (nifedipine) vs tocolytic (terbutaline) - nullips vs multips, Outcome 4 Failed ECV.

Analysis 23.5. Comparison 23 Hypnosis vs neurolinguistic programming, Outcome 5 Failed external cephalic version.

Analysis 23.15. Comparison 23 Hypnosis vs neurolinguistic programming, Outcome 15 Good pain relief (higher scores better) (non-prespecified).

Analysis 24.5. Comparison 24 Talcum powder vs gel, Outcome 5 Failed external cephalic version (after first round of attempts). . . . . . . . . . . . . . . . . . . . . . . . . . . . . . . . . . . . 


\title{
Interventions for helping to turn term breech babies to head first presentation when using external cephalic version
}

\author{
Catherine Cluver ${ }^{1}$, Gillian ML Gyte ${ }^{2}$, Marlene Sinclair $^{3}$, Therese Dowswell ${ }^{2}$, G Justus Hofmeyr ${ }^{4}$ \\ ${ }^{1}$ Department of Obstetrics and Gynaecology, Faculty of Health Sciences, Stellenbosch University and Tygerberg Hospital, Tygerberg, \\ South Africa. ${ }^{2}$ Cochrane Pregnancy and Childbirth Group, Department of Women's and Children's Health, The University of Liverpool, \\ Liverpool, UK. ${ }^{3}$ Maternal, Fetal and Infant Research Centre, Institute of Nursing Research, University of Ulster, Newtownabbey, UK. \\ ${ }^{4}$ Walter Sisulu University, University of the Witwatersrand, Eastern Cape Department of Health, East London, South Africa \\ Contact address: Catherine Cluver, Department of Obstetrics and Gynaecology, Faculty of Health Sciences, Stellenbosch University \\ and Tygerberg Hospital, PO Box 19063, Tygerberg, Western Cape, 7505, South Africa. cathycluver@hotmail.com.
}

Editorial group: Cochrane Pregnancy and Childbirth Group.

Publication status and date: Edited (no change to conclusions), published in Issue 3, 2016.

Citation: Cluver C, Gyte GML, Sinclair M, Dowswell T, Hofmeyr GJ. Interventions for helping to turn term breech babies to head first presentation when using external cephalic version. Cochrane Database of Systematic Reviews 2015, Issue 2. Art. No.: CD000184. DOI: 10.1002/14651858.CD000184.pub4.

Copyright (C) 2016 The Cochrane Collaboration. Published by John Wiley \& Sons, Ltd.

\begin{abstract}
A B S T R A C T
Background

Breech presentation is associated with increased complications. Turning a breech baby to head first presentation using external cephalic version (ECV) attempts to reduce the chances of breech presentation at birth so as to avoid the adverse effects of breech vaginal birth or caesarean section. Interventions such as tocolytic drugs and other methods have been used in an attempt to facilitate ECV.
\end{abstract}

\section{Objectives}

To assess, from the best evidence available, the effects of interventions such as tocolysis, acoustic stimulation for midline spine position, regional analgesia (epidural or spinal), transabdominal amnioinfusion, systemic opioids and hypnosis, or the use of abdominal lubricants, on ECV at term for successful version, presentation at birth, method of birth and perinatal and maternal morbidity and mortality.

\section{Search methods}

We searched the Cochrane Pregnancy and Childbirth Group's Trials Register (30 September 2014) and the reference lists of identified studies.

\section{Selection criteria}

Randomised and quasi-randomised trials comparing the above interventions with no intervention or other methods to facilitate ECV at term.

\section{Data collection and analysis}

We assessed eligibility and trial quality. Two review authors independently assessed for inclusion all potential studies identified as a result of the search strategy and independently extracted the data using a specially designed data extraction form.

Interventions for helping to turn term breech babies to head first presentation when using external cephalic version (Review)

Copyright ( 2016 The Cochrane Collaboration. Published by John Wiley \& Sons, Ltd. 


\section{Main results}

We included 28 studies, providing data on 2786 women. We used the random-effects model for pooling data because of clinical heterogeneity between studies. A number of trial reports gave insufficient information to allow clear assessment of risk of bias. We used GradePro software to carry out formal assessments of quality of the evidence for beta stimulants versus placebo and regional analgesia with tocolysis versus tocolysis alone.

Tocolytic parenteral beta stimulants were effective in increasing cephalic presentations in labour (average risk ratio (RR) 1.68 , 95\% confidence interval (CI) 1.14 to 2.48 , five studies, 459 women, low-quality evidence) and in reducing the number of caesarean sections (average RR $0.77,95 \%$ CI 0.67 to 0.88 , six studies, 742 women, moderate-quality evidence). Failure to achieve a cephalic vaginal birth was less likely for women receiving a parenteral beta stimulant (average RR 0.75, 95\% CI 0.60 to 0.92, four studies, 399 women, moderate-quality evidence). No clear differences in fetal bradycardias were identified, although this was reported for only one study, which was underpowered for assessing this outcome. Failed external cephalic version was reported in nine studies (900 women), and women receiving parenteral beta stimulants were less likely to have failure compared with controls (average RR $0.70,95 \%$ CI 0.60 to 0.82 , moderate-quality evidence). Perinatal mortality and serious morbidity were not reported. Sensitivity analysis by study quality was consistent with overall findings.

For other classes of tocolytic drugs (calcium channel blockers and nitric oxide donors), evidence was insufficient to permit conclusions; outcomes were reported for only one or two studies, which were underpowered to demonstrate differences between treatment and control groups. Little evidence was found regarding adverse effects, although nitric oxide donors were associated with increased risk of headache. Data comparing different tocolytic drugs were insufficient.

Regional analgesia in combination with a tocolytic was more effective than the tocolytic alone for increasing successful versions (assessed by the rate of failed ECVs; average RR $0.61,95 \%$ CI 0.43 to 0.86 , five studies, 409 women, moderate-quality evidence), and no difference was identified in cephalic presentation in labour (average RR 1.44, 95\% CI 0.78 to 2.66, three studies, 279 women, very low-quality evidence), caesarean sections (average RR $0.74,95 \%$ CI 0.40 to 1.37 , three studies, 279 women, very low-quality evidence) nor fetal bradycardia (average RR 1.48, 95\% CI 0.62 to 3.57, two studies, 210 women, low-quality evidence), although studies were underpowered for assessing these outcomes. Studies did not report on failure to achieve a cephalic vaginal birth (breech vaginal deliveries plus caesarean sections) nor on perinatal mortality or serious infant morbidity.

Data were insufficient on the use of regional analgesia without tocolysis, vibroacoustic stimulation, amnioinfusion, systemic opioids and hypnosis, and on the use of talcum powder or gel to assist external cephalic version, to permit conclusions about their effectiveness and safety.

\section{Authors' conclusions}

Parenteral beta stimulants were effective in facilitating successful ECV, increasing cephalic presentation in labour and reducing the caesarean section rate, but data on adverse effects were insufficient. Data on calcium channel blockers and nitric acid donors were insufficient to provide good evidence.

The scope for further research is clear. Possible benefits of tocolysis in reducing the force required for successful version and possible risks of side effects need to be addressed further. Further trials are needed to compare the effectiveness of routine versus selective use of tocolysis and the role of regional analgesia, fetal acoustic stimulation, amnioinfusion and abdominal lubricants, and the effects of hypnosis, in facilitating ECV. Although randomised trials of nitric oxide donors are small, the results are sufficiently negative to discourage further trials. Intervention fidelity for ECV can be enhanced by standardisation of the techniques and processes used for clinical manipulation of the fetus in the abdominal cavity and ought to be the subject of further research.

\section{PLAIN LANGUAGE SUMMARY}

\section{Ways to help turn a breech baby to head first presentation at the end of pregnancy}

Babies born in the breech position (bottom first) are at increased risk of complications at birth because of a delay in birth of the head. Turning a breech baby to head first in late pregnancy may reduce these complications. A procedure called 'external cephalic version (ECV)' describes when practitioners use their hands on the woman's abdomen to gently try to turn the baby from the breech position to head first. A number of treatments may help the success of ECV. These include using tocolytic drugs (drugs like beta stimulants and calcium channel blockers that relax the womb), stimulating the baby with sound through the mother's abdomen (acoustic stimulation),

Interventions for helping to turn term breech babies to head first presentation when using external cephalic version (Review)

Copyright ( 2016 The Cochrane Collaboration. Published by John Wiley \& Sons, Ltd. 
increasing the fluid surrounding the baby (transabdominal amnioinfusion), injecting pain-relieving drugs into the mother's lower back to produce regional analgesia (epidural or spinal analgesia), giving the mother opioid drugs to help her relax, using hypnosis and applying gel or talcum powder to the mother's abdomen.

This review of trials found 28 randomised controlled studies involving 2786 women. Most studies looked at the effects of tocolytic beta stimulant drugs. Results showed that babies are more likely to turn head first during ECV and to remain head first for the start of labour, if women receive beta stimulants. These drugs also reduced the number of caesarean sections, but insufficient data on possible adverse effects were collected. Little information on other types of tocolytic drugs was available, although nitric oxide donors were associated with an increase in headaches. In addition, too little evidence was available to show whether the other ways of trying to help ECV are effective. Further research is needed if we are to increase the success of ECV. 


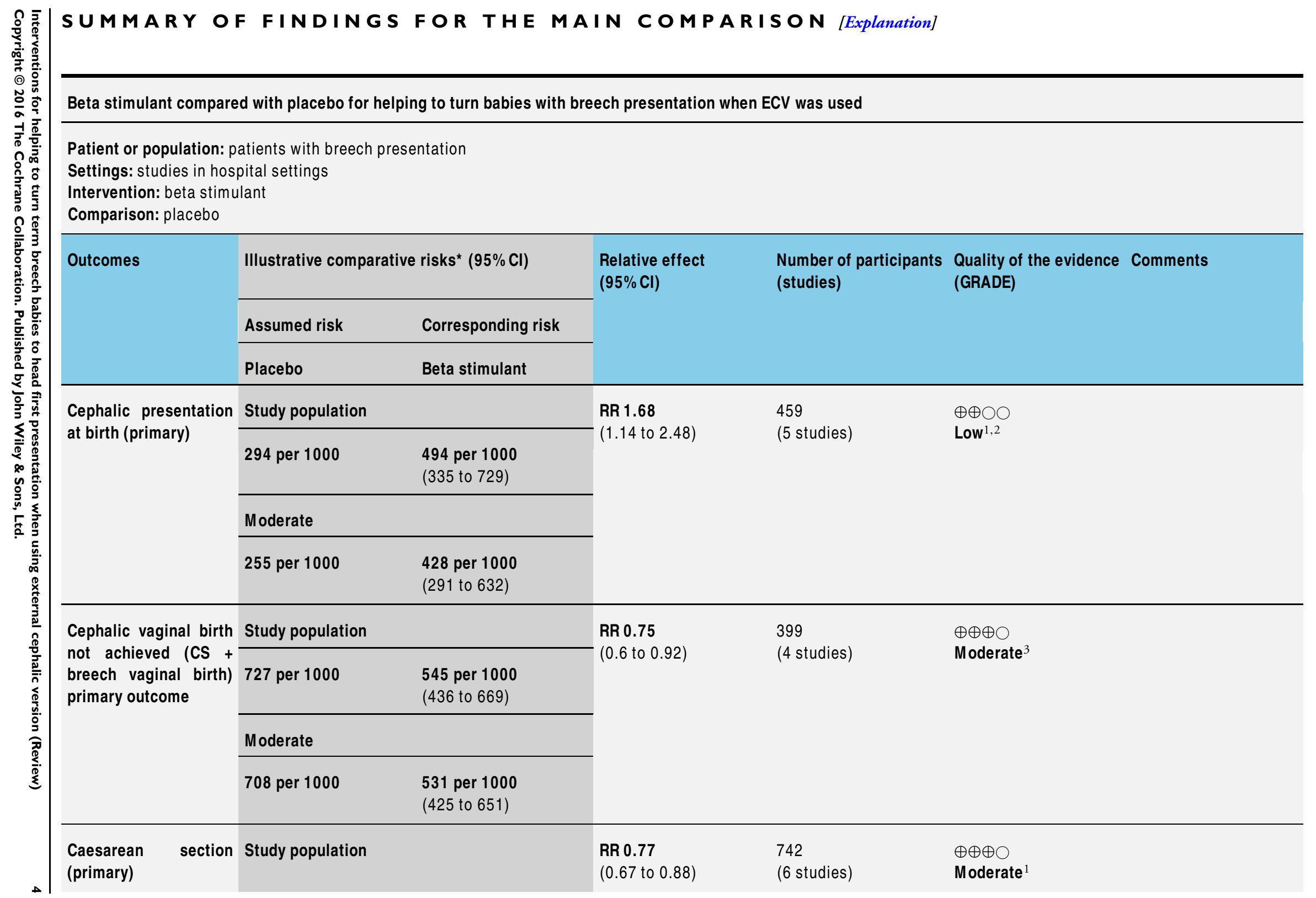




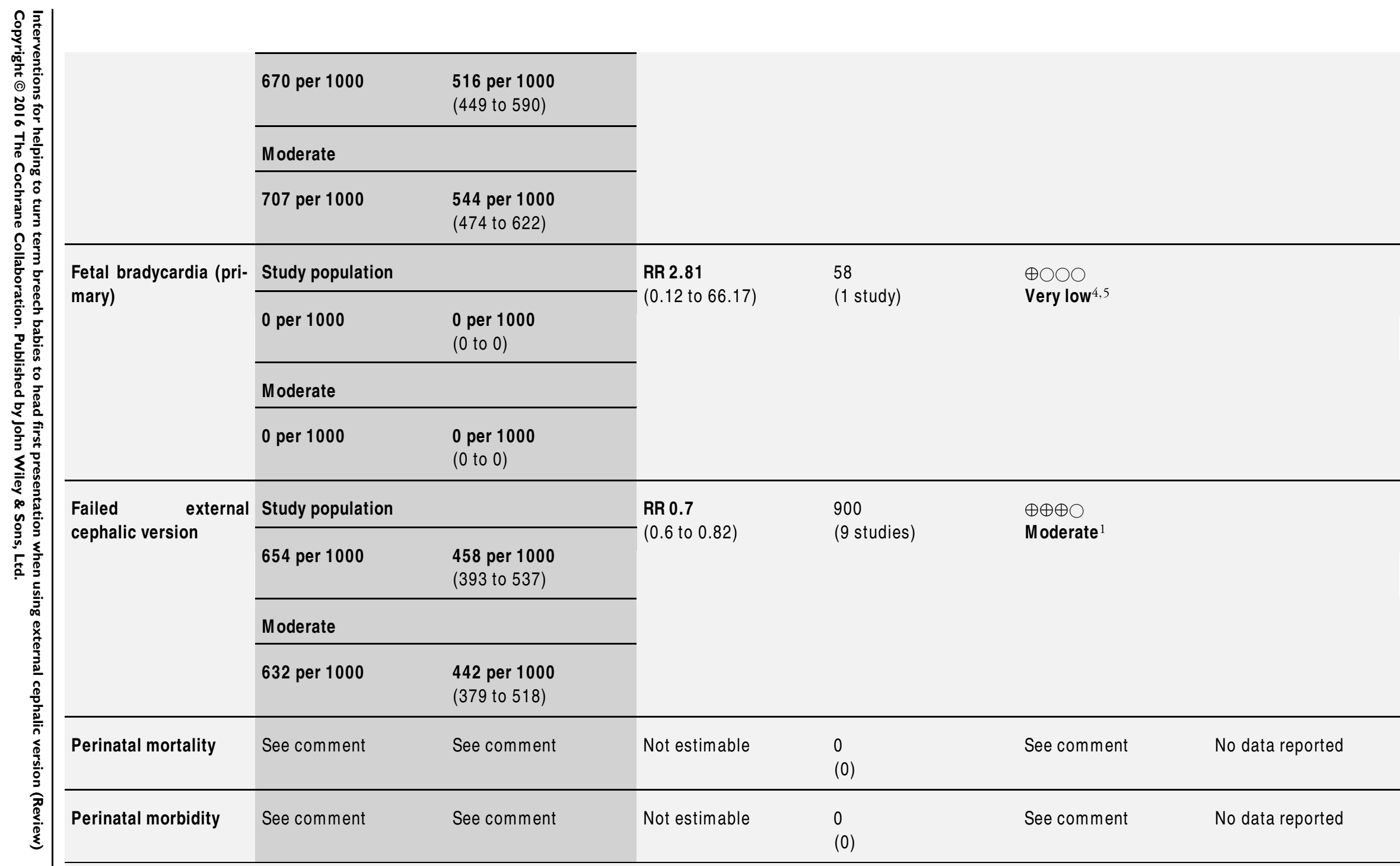

*The basis for the assumed risk (e.g. median control group risk across studies) is provided in footnotes. The corresponding risk (and its $95 \%$ confidence interval) is based on the assumed risk in the comparison group and the relative effect of the intervention (and its $95 \% \mathrm{Cl}$ ).

Cl: Confidence interval; RR: Risk ratio. 
GRADE Working Group grades of evidence.

High quality: Further research is very unlikely to change our confidence in the estimate of effect.

Moderate quality: Further research is likely to have an important impact on our confidence in the estimate of effect and may change the estimate.

Low quality: Further research is very likely to have an important impact on our confidence in the estimate of effect and is likely to change the estimate.

Very low quality: We are very uncertain about the estimate.

1. Most studies contributing data had design limitations.

2. $1^{2}>60 \%$. Effect size varied considerably.

3. All studies providing data had design limitations.

4. The one study included is of poor quality, as it is an unblinded quasi-RCT.

5. Wide $95 \% \mathrm{Cl}$ crossing the line of no effect; small sample size and low event rate. 


\section{B A C K G R O U N D}

\section{Description of the condition}

Breech presentation occurs when the baby is positioned bottom first. It is more common in early pregnancy, and the incidence decreases with increasing gestational age. The incidence at term is about 3\% to $4 \%$ (Hickok 1992). Breech presentation may be caused by an underlying fetal or maternal abnormality, it may be an apparently chance occurrence or it may be related to an otherwise benign variant such as cornual placental position (the placenta situated in an upper lateral corner of the uterus). In the latter two instances, breech presentation places a healthy baby and mother at increased risk of a complicated vaginal birth or caesarean section. Therefore, it is understandable that obstetricians, midwives and consumer groups take considerable interest in this topic. Prevention of harm with reduction of risk for mother and baby is a quantifiable outcome of carefully gathering this research evidence. Knowing what works best for whom and in what circumstances is the concern of clinical researchers working in this field.

Considerable disagreement surrounds the management of breech (bottom first) presentation, with respect to both the place of external cephalic version (ECV) and the type of birth. Interpretation of the findings of non-randomised trials is confounded by the fact that breech presentation per se appears to be a marker for poor perinatal outcome. For example, the incidence of childhood handicap following breech presentation has been found to be high (16\%) for both babies born vaginally and those born by caesarean section (Danielian 1996). Randomised trials of planned mode of birth for vaginal breech birth have shown short-term benefit for the breech presenting baby managed by planned caesarean section compared with planned vaginal birth, although the impact on future pregnancies remains uncertain (Hofmeyr 2003). Two-year outcomes of one of these randomised trials showed no significant difference in the combined risk of death/neurodevelopmental delay between planned vaginal and planned caesarean groups (Whyte 2004). Despite this, these results have had a profound effect on clinical practice, and in many institutions, caesarean section for breech presentation has become routine. Under these circumstances, the impact of ECV on caesarean section rates would be expected to be greater than was the case in previous trials in institutions in which vaginal breech birth was common. The increased rate of caesarean section for breech presentation has decreased the rate of vaginal breech births, and concern has arisen that practitioners are losing the skill of supporting women who have vaginal breech births.

Breech presentation can be classified as complete, frank or incomplete. A complete breech occurs when the baby's hips and knees are flexed, with feet near the buttocks. A frank breech presentation is seen when the baby's legs are extended up to its head. Incomplete breech presentations include a footling breech, in which one or both legs are extended below the baby's bottom, and a kneeling breech, whereby the knees are the presenting part of the breech.
Although underlying reasons may explain the breech presentation, the baby may have a more difficult vaginal birth because of the delay in birth of the head.

\section{Description of the intervention}

\section{External cephalic version}

During an ECV, practitioners use their hands on the woman's abdomen to gently try to turn the baby from the breech position to the head-down position. A video of the procedure can be viewed at https://www.youtube.com/watch?v=fKaNZfUno50.

External cephalic version before term became a part of routine obstetrical practice on the basis of the self-evident immediate effectiveness of the procedure, as well as reassuring results from several non-randomised trials, and in spite of the negative results of the only randomised trial reported before 1980 (Brosset 1956). The popularity of ECV before term waned after the mid-1970s, in part because of reports of an increase in perinatal mortality associated with the procedure (Bradley-Watson 1975), which, in retrospect, may have been due to application of undue force and the increasing perception of caesarean section as a safer option than ECV or breech birth.

Before the mid-1970s, ECV was usually attempted before term because of the belief that the procedure would seldom be successful at term. Subsequent studies showed that with the use of tocolysis, ECV could be achieved in a substantial proportion of women with breech presentation at term (37 or more completed weeks of pregnancy). Predictors of unsuccessful version include engaged presenting part, fetal head not easily palpable and tense uterus (Lau 1997).

Initially, successful ECV at a late stage of pregnancy was considered to have become possible only because of the use of tocolytic drugs to relax the uterus. However, later studies showed that ECV at term was frequently possible without tocolysis. The overall success rate was $60 \%$ in a systematic review of randomised controlled trials in which some trials included facilitation and others did not (Hofmeyr 1996).

The question, therefore, arose as to whether tocolysis should be used routinely for ECV at term, or only in those cases in which difficulty is anticipated or initial attempts fail.

A number of interventions to try to make ECV easier and more successful have been suggested, including use of tocolytic drugs, vibroacoustic stimulation, regional analgesia, amnioinfusion, maternal hydration, systemic opioid drugs, hypnosis and abdominal lubricants.

\section{How the intervention might work}




\section{Tocolysis to facilitate ECV at term}

1. Beta stimulants, such as salbutamol, ritodrine, hexoprenaline or terbutaline, are widely used tocolytics. They are usually given intravenously. Possible side effects for mother and baby include tachycardia (increase in heart rate).

2. Calcium channel blockers, like nifedipine, can be administered orally (Smith 2000). These drugs can be associated with hypotension (fall in blood pressure).

3. Nitric oxide donors, such as intravenous nitroglycerine (Belfort 1993) or sublingual glyceryl trinitrate/nitroglycerine spray (Reddick 1997; Yanny 2000), have been suggested as alternative tocolytics.

\section{Vibroacoustic stimulation to facilitate ECV at term}

This procedure is performed when the baby is stimulated using sound applied to the mother's abdomen to provoke the baby to move out of the midline position. It has been studied in one small trial, which is included in this review (Johnson 1995).

\section{Regional analgesia to facilitate ECV at term}

Regional analgesia includes spinal and epidural anaesthesia. Epidural analgesia is provided when an anaesthetic drug is infused into the epidural space. Spinal analgesia is given when an anaesthetic drug is injected into the cerebrospinal fluid. In a retrospective cohort study, ECV at term was successful in 59\% of 32 women with epidural analgesia, and in $24 \%$ of 37 women without (Carlan 1994). In an uncontrolled study, ECV under epidural analgesia was successful in nine of 16 women $(56 \%)$ in whom initial attempts had failed (Neiger 1998a; Neiger 1998b). Common adverse effects of these analgesics include hypotension and headache.

\section{Amnioinfusion to facilitate ECV at term}

An amnioinfusion is a procedure whereby saline is infused into the amniotic sac to increase the volume of fluid to enable the baby to turn more easily. Amnioinfusions can be done transabdominally or transvaginally. In an uncontrolled study, six women with failed ECV had a successful repeat attempt following transabdominal amnioinfusion with $700 \mathrm{~mL}$ to $900 \mathrm{~mL}$ warmed saline (Benifla 1995). To our knowledge, no randomised trials have determined the effectiveness of this intervention.

\section{Systemic opioids to facilitate ECV at term}

Systemic opioids may facilitate ECV by relaxing the mother and reducing her sense of discomfort during the procedure.

\section{Hypnosis to facilitate ECV at term}

Different types of hypnosis may facilitate ECV by promoting relaxation, thereby potentially reducing the woman's sense of discomfort during the procedure.

\section{Talcum powder and gel to facilitate ECV at term}

Powder or gel applied to the woman's abdomen may act as a lubricant, possibly allowing smoother hand movements during attempts to turn the baby.

\section{Why it is important to do this review}

It is important to assess whether various interventions do increase the effectiveness of ECV in turning a breech baby to head first presentation and to help guide their use in clinical practice. Many of these interventions are commonly used, and it is important for doctors to be able to apply evidence-based medicine in this setting to offer the mother the greatest chance of success when undergoing an ECV. It must also be determined whether any of these interventions is associated with possible harm to mother or fetus.

Readers are referred to previous reviews of the topic (Hofmeyr 1989; Hofmeyr 1991; Hofmeyr 1992; Hofmeyr 1993; Hofmeyr 2014; Zhang 1993) - see also related Cochrane reviews: 'Cephalic version by postural management for breech presentation' ( Hofmeyr 2012b); 'Cephalic version by moxibustion for breech presentation' (Coyle 2012); 'External cephalic version for breech presentation at term' (Hofmeyr 2012a); and 'External cephalic version for breech presentation before term' (Hutton 2006).

\section{O B J E C T I VES}

To assess, from the best evidence available, the effects of interventions such as tocolysis, acoustic stimulation for midline spine position, regional analgesia (epidural or spinal), transabdominal amnioinfusion, systemic opioids and hypnosis, or the use of abdominal lubricants, on ECV at term for successful version, presentation at birth, method of birth and perinatal and maternal morbidity and mortality.

\section{METHODS}

\section{Criteria for considering studies for this review}

\section{Types of studies}

Clinical trials comparing the effects of interventions such as routine tocolysis versus selective or no use of tocolysis, or different tocolytics, epidural or spinal analgesia, amnioinfusion, maternal hydration, systemic opioids and fetal acoustic stimulation in midline fetal spine positions or hypnosis or abdominal lubricants on 
clinically meaningful outcomes, with random or quasi-random allocation to treatment and control groups and with violations of allocated management and exclusions after allocation not sufficient to materially affect outcomes.

\section{Types of participants}

Women with singleton breech presentations at term and no contraindications to ECV or the intervention being studied, with or without previous failed ECV.

\section{Types of interventions}

A. Tocolytic drugs.

B. Vibroacoustic stimulation in midline fetal spine positions.

C. Regional analgesia.

D. Amnioinfusion.

E. Systemic opioids.

To avoid duplication of data, we have listed the interventions under study in order, from A to E. Each intervention will be compared with placebo and with only those interventions above it on the list. Thus, the intervention 'Regional analgesia' (C) will be compared with placebo, then with tocolytic drugs (A), then with vibroacoustic stimulation (B) and finally with other regional analgesia $(\mathrm{C})$. When $\mathrm{C}$ is compared with $\mathrm{C}$, different types of regional analgesia are compared with each other, so epidural may be compared with spinal analgesia as an intervention to facilitate ECV. Interventions identified in the future will be added to the end of the list.

In this update we identified trials examining other types of interventions used to facilitate ECV.

F. Hypnosis*.

G. Abdominal lubricants* (talcum powder versus gel).

*We decided to include these interventions, although they were not prespecified in the original protocol.

\section{Types of outcome measures}

\section{Primary outcomes}

1. Cephalic presentation at labour and at birth.

2. Failure to achieve cephalic vaginal birth (composite outcome: caesarean section plus vaginal breech birth)*

3. Caesarean section.

4. Fetal bradycardia or prolonged decelerations as defined by trial authors.

\section{Secondary outcomes}

1. Failed external cephalic version.

2. Difficult external cephalic version.

3. Maternal palpitations.

4. Maternal headaches.
5. Maternal hypotension.

6. Operative vaginal birth.

7. Maternal mortality.

8. Maternal morbidity.

9. Perinatal mortality.

10. Perinatal morbidity.

We have included other outcomes, not specified here, when they were reported in the studies and when we considered them to be clinically important: vaginal breech birth, Apgar less than seven at five minutes, neonatal seizures, admission to neonatal unit, birth trauma, flushing in women, placental abruption, maternal discomfort, pain scores, maternal satisfaction with the procedure and maternal side effects (nausea and vomiting, dizziness and drowsiness).

*In this version of the review, a new primary outcome has been added. The purpose of ECV is to avoid breech presentation, which increases the risk of caesarean section and of breech vaginal delivery. For this reason, and to increase consistency with other related Cochrane reviews, we have added a composite outcome "Failure to achieve cephalic vaginal birth," which represents caesarean section plus vaginal breech births.

\section{Search methods for identification of studies}

The following methods section of this review is based on a standard template used by the Cochrane Pregnancy and Childbirth Group.

\section{Electronic searches}

We contacted the Trials Search Co-ordinator to search the Cochrane Pregnancy and Childbirth Group's Trials Register (30 September 2014).

The Cochrane Pregnancy and Childbirth Group's Trials Register is maintained by the Trials Search Co-ordinator and contains trials identified from:

1. monthly searches of the Cochrane Central Register of Controlled Trials (CENTRAL);

2. weekly searches of MEDLINE (Ovid);

3. weekly searches of Embase (Ovid);

4. handsearches of 30 journals and the proceedings of major conferences;

5. weekly current awareness alerts for a further 44 journals plus monthly BioMed Central email alerts.

Details of the search strategies for CENTRAL, MEDLINE and Embase, the list of handsearched journals and conference proceedings, and the list of journals reviewed via the current awareness service can be found in the 'Specialized Register' section within the editorial information about the Cochrane Pregnancy and Childbirth Group.

Trials identified through the searching activities described above are each assigned to a review topic (or topics). The Trials Search 
Co-ordinator searches the register for each review using the topic list rather than keywords.

\section{Searching other resources}

We searched the reference lists of retrieved studies.

We did not apply any language or date restrictions.

\section{Data collection and analysis}

For this update, we used the following methods. These methods are based on a standard template used by the Cochrane Pregnancy and Childbirth Group.

\section{Selection of studies}

Two review authors independently assessed for inclusion all potential studies identified as a result of the search strategy. We resolved disagreements through discussion, or, if required, we consulted the other review authors to achieve consensus.

\section{Data extraction and management}

We designed a form on which to record extracted data. For eligible studies, two review authors extracted data using the agreed upon form. We resolved discrepancies through discussion, or, if required, we consulted the third review author. We entered the data into Review Manager software (RevMan 2014) and checked them for accuracy.

When information in trial reports was unclear, we planned to contact report authors to request further details.

\section{Assessment of risk of bias in included studies}

Two review authors independently assessed risk of bias for each study using the criteria outlined in the Cochrane Handbook for Systematic Reviews of Interventions (Higgins 2011). We resolved disagreements by discussion with the other review authors.

\section{(I) Random sequence generation (checking for possible selection bias)}

We described for each included study the method used to generate the allocation sequence in sufficient detail to allow an assessment of whether it should produce comparable groups.

We assessed the method as:

- low risk of bias (any truly random process, e.g. random number table; computer random number generator);

- high risk of bias (any non-random process, e.g. odd or even date of birth; hospital or clinic record number); or

- unclear risk of bias.
(2) Allocation concealment (checking for possible selection bias)

We described for each included study the method used to conceal allocation to interventions before assignment and assessed whether intervention allocation could have been foreseen in advance of, or during, recruitment, or changed after assignment.

We assessed the methods as:

- low risk of bias (e.g. telephone or central randomisation; consecutively numbered sealed opaque envelopes);

- high risk of bias (open random allocation; unsealed or nonopaque envelopes, alternation; date of birth); or

- unclear risk of bias.

\section{(3.I) Blinding of participants and personnel (checking for possible performance bias)}

We described for each included study the methods used, if any, to blind study participants and personnel from knowledge of which intervention a participant received. We considered that studies were at low risk of bias if they were blinded, or if we judged that lack of blinding was unlikely to affect results. We assessed blinding separately for different outcomes or classes of outcomes.

We assessed the methods as:

- low, high or unclear risk of bias for participants; and

- low, high or unclear risk of bias for personnel.

(3.2) Blinding of outcome assessment (checking for possible detection bias)

We described for each included study the methods used, if any, to blind outcome assessors from knowledge of which intervention a participant received. We assessed blinding separately for different outcomes or classes of outcomes.

We assessed methods used to blind outcome assessment as:

- low, high or unclear risk of bias.

(4) Incomplete outcome data (checking for possible attrition bias due to the quantity, nature and handling of incomplete outcome data)

We described for each included study, and for each outcome or class of outcomes, the completeness of data including attrition and exclusions from the analysis. We stated whether attrition and exclusions were reported and the numbers included in the analysis at each stage (compared with the total number of randomly assigned participants), reasons for attrition or exclusion when reported and whether missing data were balanced across groups or were related to outcomes. When sufficient information was reported, or could be supplied by the trial authors, we planned to reinclude missing data in the analyses that we undertook.

We assessed methods as:

- low risk of bias (e.g. no missing outcome data; missing outcome data balanced across groups); 
- high risk of bias (e.g. numbers or reasons for missing data imbalanced across groups; 'as treated' analysis done with substantial departure of intervention received from that assigned at randomisation); or

- unclear risk of bias.

\section{(5) Selective reporting (checking for reporting bias)}

We described for each included study how we investigated the possibility of selective outcome reporting bias and what we found. We assessed these methods as:

- low risk of bias (when it is clear that all of the study's prespecified outcomes and all expected outcomes of interest to the review have been reported);

- high risk of bias (when not all of the study's prespecified outcomes have been reported; one or more reported primary outcomes were not prespecified; outcomes of interest were reported incompletely and so cannot be used; study failed to include results of a key outcome that would have been expected to have been reported); or

- unclear risk of bias

(6) Other bias (checking for bias due to problems not covered by the methods listed above)

We described for each included study any important concerns we had about other possible sources of bias.

\section{(7) Overall risk of bias}

We made explicit judgements about whether studies were at high risk of bias, according to criteria given in the Cochrane Handbook for Systematic Reviews of Interventions (Higgins 2011). With reference to the methods listed above, we planned to assess the likely magnitude and direction of bias and whether we considered it likely to impact the findings. When sufficient data were available, we explored the impact of the level of bias by undertaking sensitivity analyses - see Sensitivity analysis.

For this update, we assessed the quality of the evidence using the GRADE approach (Schunemann 2009) to assess the quality of the body of evidence related to the following outcomes.

1. Cephalic presentation at labour and at birth.

2. Failure to achieve cephalic vaginal birth.

3. Caesarean section.

4. Fetal bradycardia or prolonged decelerations as defined by trial authors.

5. Failed external cephalic version.

6. Perinatal mortality.

7. Perinatal morbidity.

We graded the evidence and included 'Summary of findings' tables for two comparisons.

1. Tocolytics (parenteral beta stimulants) versus placebo.

2. Regional analgesia with tocolysis versus tocolysis alone.
The GRADE profiler (Grade 2014) was used to import data from Review Manager 5.3 (RevMan 2014) to create 'Summary of findings' tables. We produced a summary of the intervention effect and a measure of quality for each of the above outcomes by using the GRADE (Grades of Recommendation, Assessment, Development and Evaluation) approach. The GRADE approach uses five considerations (study limitations, consistency of effect, imprecision, indirectness and publication bias) to assess the quality of the body of evidence for each outcome. Evidence can be downgraded from 'high quality' by one level for serious, or by two levels for very serious, limitations depending on assessments for risk of bias, indirectness of evidence, serious inconsistency, imprecision of effect estimates or potential publication bias.

\section{Measures of treatment effect}

\section{Dichotomous data}

For dichotomous data, we have presented results as summary risk ratios with $95 \%$ confidence intervals.

\section{Continuous data}

We used mean differences if outcomes were measured in the same way between trials. We used standardised mean differences to combine trials that measured the same outcome but used different methods.

\section{Unit of analysis issues}

\section{Cluster-randomised trials}

We planned to include cluster-randomised trials in the analyses along with individually randomised trials if they were otherwise eligible. For this version of the review, we identified no such trials; if they are included in future updates, we will adjust sample sizes using the methods described in the Cochrane Handbook for Systematic Reviews of Interventions based on an estimate of the intracluster correlation co-efficient (ICC) derived from the trial (if possible), from a similar trial or from a study of a similar population. If we use ICCs from other sources, we will report this and will conduct sensitivity analyses to investigate the effects of variation in the ICC. If we identify both cluster-randomised trials and individually randomised trials, we plan to synthesise relevant information. We will consider it reasonable to combine the results from both if little heterogeneity is noted between study designs, and if the interaction between effects of the intervention and choice of the randomisation unit is considered unlikely.

We will also acknowledge heterogeneity in the randomisation unit and will perform a sensitivity analysis to investigate the effects of the randomisation unit. 


\section{Cross-over trials}

We did not plan to include trials with a cross-over design. One of the trials that was otherwise eligible for inclusion randomly assigned women to two groups (parallel design), but if after two attempts the randomised ECV method was not successful, the trial protocol allowed the alternative method to be used (Vallikkannu 2014). We treated this study as a parallel-group randomised controlled trial and used only data collected before any cross-over to the alternative method.

\section{Other unit of analysis issues}

We excluded trials including multiple pregnancies. In this version of the review, we did not include trials with multiple treatment arms; if we identify such trials for inclusion in future updates, we will use the methods set out in the Cochrane Handbook for Systematic Reviews of Interventions for analysis.

\section{Dealing with missing data}

For included studies, we noted levels of attrition. In future updates, if more eligible studies are included, review authors will explore the impact of including studies with high levels of missing data in the overall assessment of treatment effect by using sensitivity analysis.

For all outcomes, we carried out analyses, as far as possible, on an intention-to-treat basis (i.e. we attempted to include in the analyses all participants randomly assigned to each group). The denominator for each outcome in each trial was the number randomly assigned minus the number of participants whose outcomes were known to be missing.

\section{Assessment of heterogeneity}

We assessed statistical heterogeneity in each meta-analysis using the $\mathrm{Tau}^{2}, \mathrm{I}^{2}$ and $\mathrm{Chi}^{2}$ statistics. We regarded heterogeneity as substantial if $\mathrm{I}^{2}$ was greater than $30 \%$ and either $\mathrm{Tau}^{2}$ was greater than zero or the $\mathrm{P}$ value $(<0.10)$ in the $\mathrm{Chi}^{2}$ test for heterogeneity was low. If we identified substantial heterogeneity (> 30\%), we planned to explore this by performing prespecified subgroup analysis.

\section{Assessment of reporting biases}

In future updates, if 10 or more studies are included in the metaanalysis, we plan to investigate reporting biases (such as publication bias) using funnel plots. We will assess funnel plot asymmetry visually. If asymmetry is suggested by a visual assessment, we will perform exploratory analyses to investigate this.

\section{Data synthesis}

We carried out statistical analysis using the Review Manager software (RevMan 2014). We used the random-effects model for pooling data because of clinical heterogeneity in the included studies in various comparisons. The random-effects summary represents the average range of possible treatment effects, and we have discussed the clinical implications of differing treatment effects between trials. If the average treatment effect was not considered clinically meaningful, we did not combine trials. We have presented results as the average treatment effect with $95 \%$ confidence intervals, and when heterogeneity between trials was noted, with estimates of $\mathrm{Tau}^{2}$ and $\mathrm{I}^{2}$.

\section{Subgroup analysis and investigation of heterogeneity}

If we identified substantial heterogeneity, we investigated this by using subgroup analyses.

When data were available, we planned to carry out the following analysis.

1. nulliparous versus multiparous women.

We restricted subgroup analysis to the review's primary outcomes. We assessed subgroup differences by performing interaction tests available within RevMan (RevMan 2014). We reported the results of subgroup analyses by quoting the $\mathrm{Chi}^{2}$ statistic and the $\mathrm{P}$ value, and results of the interaction test by reporting the $\mathrm{I}^{2}$ value.

\section{Sensitivity analysis}

We explored heterogeneity by performing sensitivity analysis, looking at primary outcomes only, and by excluding trials with greater risk of bias. We considered studies at low risk of bias when they had low risk of bias in generation of the randomisation sequence, concealment of allocation and loss to follow-up.

\section{R E S U L T S}

\section{Description of studies}

\section{Results of the search}

In total the search identified 56 reports corresponding to 36 studies. In the previous published review (Cluver 2012), 25 studies met the inclusion criteria, and in this update, we have included three additional trials (Munoz 2014; Reinhard 2012; Vallikkannu 2014). The 28 included studies involved a total of 2786 women. We have set out information about all of the included trials in the Characteristics of included studies tables. 


\section{Included studies}

We found 17 studies involving 1876 women that assessed tocolytic drugs (Bujold 2003a; Bujold 2003b; Chung 1996; Collaris 2009; El-Sayed 2004; Fernandez 1997; Hilton 2009; Impey 2005; Kok 2008; Marquette 1996; Nor Azlin 2005; Nor Azlin 2008; Robertson 1987; Stock 1993; Tan 1989; Vani 2009; Yanny 2000). These drugs included beta stimulants (salbutamol, ritodrine, hexoprenaline and terbutaline), a calcium channel blocker (nifedipine) and a nitric oxide donor (nitroglycerine/glyceryl trinitrate).

We found one study involving 26 women that assessed vibroacoustic stimulation (Johnson 1995).

We found six studies involving 554 women that assessed regional analgesia (Delisle 2001; Dugoff 1999; Mancuso 2000; Schorr 1997; Weiniger 2007; Weiniger 2010). Five of these studies used a tocolytic drug as well in both groups (Dugoff 1999; Mancuso 2000; Schorr 1997; Weiniger 2007; Weiniger 2010), and one study allowed doctors to use a tocolytic at their discretion (Delisle 2001). None of the studies looked at regional analgesia alone.

We found no studies on amnioinfusion.

We found one study involving 95 women that compared regional analgesia with systemic opioids, with both groups also receiving a tocolytic drug (Sullivan 2009).

One study with 60 women examined a systemic opioid (remifen- tanil) compared with placebo (Munoz 2014).

One study involving 80 women compared two types of hypnosis/relaxation (Reinhard 2012), and one (with 95 women) looked at the application of talcum powder versus gel to assist ECV (Vallikkannu 2014). In this final study after two failed attempts at ECV, cross-over to the other method occurred, and although analysis was done by intention-to-treat (according to original allocation), a proportion of women in both groups received both methods, making interpretation of results difficult; for this reason we have included in the review only data related to the period before the cross-over.

Three studies are awaiting classification (Andarsio 2000; Hollard 2003; Tan 2008) - see Characteristics of studies awaiting classification - and two are ongoing (Burgos 2012; Passerini 2013) - see Characteristics of ongoing studies.

\section{Excluded studies}

We excluded three studies (Dockeray 1984; Guittier 2013; Wallace 1984) - see Characteristics of excluded studies.

\section{Risk of bias in included studies}

See the table of Characteristics of included studies and Figure 1. 
Figure I. Risk of bias summary: review authors' judgements about each risk of bias item for each included study.

\begin{tabular}{|c|c|c|c|c|c|c|c|}
\hline & 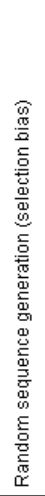 & 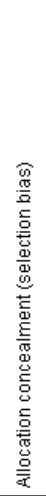 & 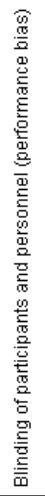 & 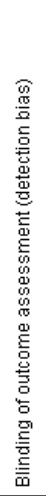 & 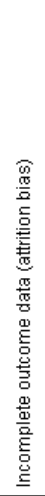 & 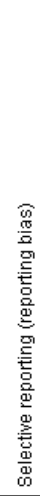 & 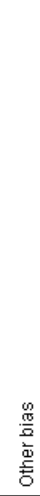 \\
\hline Bujold 2003a & († & $\odot$ & $\odot$ & ๑ & $\odot$ & $?$ & O \\
\hline Bujold 2003b & + & + & + & + & + & $?$ & $?$ \\
\hline Chung 1996 & (†) & - & $?$ & $?$ & † & $?$ & $?$ \\
\hline Collaris 2009 & $\odot$ & $\odot$ & $\odot$ & ? & $\odot$ & ? & $\odot$ \\
\hline Delisle 2001 & ? & ? & ○ & ? & ? & ? & $\theta$ \\
\hline Dugoff 1999 & $\odot$ & $?$ & ? & ? & $\odot$ & $?$ & $\odot$ \\
\hline El-Sayed 2004 & + & + & ○ & ? & $\odot$ & $?$ & $\odot$ \\
\hline Fernandez 1997 & $\odot$ & ? & ๑ & $\odot$ & $\odot$ & $?$ & + \\
\hline Hilton 2009 & + & + & $\odot$ & $\odot$ & $\odot$ & $?$ & + \\
\hline Impey 2005 & + & $\odot$ & $?$ & $?$ & $\odot$ & $?$ & $\odot$ \\
\hline Johnson 1995 & $\odot$ & $\odot$ & $?$ & $?$ & $\odot$ & $?$ & ? \\
\hline Kok 2008 & $\odot$ & $\odot$ & $\odot$ & + & $\odot$ & $?$ & ? \\
\hline Mancuso 2000 & $\odot$ & $\odot$ & - & - & $\odot$ & $?$ & 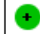 \\
\hline Marquette 1996 & ? & $?$ & $\odot$ & $\odot$ & $\odot$ & ? & $?$ \\
\hline Munoz 2014 & $\odot$ & ๑ & $\odot$ & $\odot$ & + & $\odot$ & $\odot$ \\
\hline Nor Azlin 2005 & $\odot$ & + & $\odot$ & $\odot$ & $\odot$ & $?$ & $?$ \\
\hline Nor Azlin 2008 & $\odot$ & $\odot$ & ? & ? & $\Theta$ & $?$ & $\odot$ \\
\hline Reinhard 2012 & $\odot$ & $?$ & $\odot$ & $\odot$ & $\odot$ & $?$ & $\odot$ \\
\hline Robertson 1987 & $\Theta$ & ○ & ○ & ○ & $\odot$ & $?$ & + \\
\hline Schorr 1997 & $\odot$ & $\odot$ & 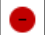 & $\theta$ & $\odot$ & $?$ & $\odot$ \\
\hline Stock 1993 & ? & ? & $\odot$ & $\odot$ & $\odot$ & $?$ & $\theta$ \\
\hline Sullivan 2009 & ๑) & - & $\odot$ & $\odot$ & + & $?$ & 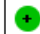 \\
\hline Tan 1989 & $?$ & ○ & 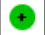 & $\odot$ & $\odot$ & $?$ & $?$ \\
\hline Vallikkannu 2014 & + & $?$ & $\theta$ & ○ & $\odot$ & $?$ & ? \\
\hline Vani 2009 & $\odot$ & $\odot$ & $\theta$ & $\theta$ & $\odot$ & $?$ & $?$ \\
\hline Weiniger 2007 & ? & $?$ & $\theta$ & $\theta$ & $\odot$ & $?$ & $?$ \\
\hline Weiniger 2010 & ? & $?$ & $\theta$ & $\theta$ & + & $?$ & $?$ \\
\hline Yanny 2000 & $\odot$ & $\odot$ & $?$ & $?$ & $\odot$ & $?$ & ๑ \\
\hline
\end{tabular}




\section{Allocation}

We judged 16 studies to be at low risk of bias for both adequate sequence generation and adequate allocation concealment (Bujold 2003a; Bujold 2003b; Collaris 2009; El-Sayed 2004; Hilton 2009; Impey 2005; Johnson 1995; Kok 2008; Mancuso 2000; Munoz 2014; Nor Azlin 2005; Nor Azlin 2008; Schorr 1997; Sullivan 2009; Vani 2009; Yanny 2000). We considered one study to be at high risk of bias for both sequence generation and allocation concealment (Robertson 1987). The remaining studies were unclear, or we observed a mixture of low, high and unclear risk of bias (Figure 1).

\section{Blinding}

We judged 11 studies to be adequately blinded with low risk of bias for both performance bias (women and staff blinded) and detection bias (outcome assessors blinded) (Bujold 2003a; Bujold 2003b; Fernandez 1997; Hilton 2009; Kok 2008; Marquette 1996; Munoz 2014; Nor Azlin 2005; Reinhard 2012; Stock 1993; Tan 1989). Eight studies were at high risk of bias for both performance and detection bias (Mancuso 2000; Robertson 1987; Schorr 1997; Sullivan 2009; Vallikkannu 2014; Vani 2009; Weiniger 2007; Weiniger 2010). For the remaining studies, blinding was not clearly reported or performance or detection bias was noted (Figure 1).

\section{Incomplete outcome data}

We considered 26 studies at low risk of bias when considering attrition. In one study, risk of bias was unclear for this domain (Delisle 2001), and in another study, loss to follow-up meant that for some outcomes the study was at high risk of bias (Nor Azlin 2008) (Figure 1).

\section{Selective reporting}

We classified all but one of the studies as unclear because we did not assess the trial protocols (Figure 1).

\section{Other potential sources of bias}

We considered 14 studies at low risk of bias in terms of other potential sources of bias, and three at high risk. The remaining studies were unclear on this (Figure 1).

\section{Effects of interventions}

See: Summary of findings for the main comparison Beta stimulant compared with placebo for helping to turn babies with breech presentation when ECV was used; Summary of findings
2 Regional analgesia (with tocolysis) versus no intervention of regional analgesia (with or without tocolysis) for breech presentation

We included 28 studies, involving 2786 women (Characteristics of included studies).

\section{Comparison I. Tocolysis versus placebo for external cephalic version (ECV) at term ( 13 studies with 1 5,468 women)}

Thirteen studies involving 1548 women looked at this comparison using various tocolytic drugs (Bujold 2003a; Chung 1996; Fernandez 1997; Hilton 2009; Impey 2005; Kok 2008; Marquette 1996; Nor Azlin 2005; Robertson 1987; Stock 1993; Tan 1989; Vani 2009; Yanny 2000).

Beta stimulants: Nine studies looked at beta stimulants. Six studies involving 639 women looked at parenteral ritodrine (Chung 1996; Impey 2005; Marquette 1996; Nor Azlin 2005; Robertson 1987; Stock 1993); two studies involving 174 women looked at oral and parenteral salbutamol (Tan 1989; Vani 2009); and one study involving 103 women looked at parenteral terbutaline (Fernandez 1997).

Calcium channel blockers: One study involving 320 women looked at oral nifedipine (Kok 2008).

Nitric oxide donors: Three studies involving 282 women looked at parenteral or sublingual nitroglycerine/glyceryl nitrate (Bujold 2003a; Hilton 2009; Yanny 2000).

The overall quality of the studies was reasonable. We judged seven studies to have low risk of bias for both sequence generation and allocation concealment (Bujold 2003a; Hilton 2009; Impey 2005; Kok 2008; Nor Azlin 2005; Vani 2009; Yanny 2000) and eight studies to have adequate blinding (Bujold 2003a; Fernandez 1997; Hilton 2009; Kok 2008; Marquette 1996; Nor Azlin 2005; Stock 1993; Tan 1989). See Figure 1.

We have used random-effects models throughout these comparisons because of the clinical heterogeneity observed between studies. We have presented data for different classes of tocolytics together in the same forest plots, but we have not pooled results. Findings for different classes of tocolytic drugs are also reported separately in the text, as different classes of drugs have different mechanisms of action. For most outcomes, evidence mainly relates to beta stimulants.

\section{Primary outcomes}

We found a statistically significant increase in cephalic presentation at labour and at birth with the use of parenteral beta stimulants (average risk ratio (RR) 1.68, 95\% confidence interval (CI) 1.14 to 2.48, five studies, 459 women, random-effects $\mathrm{Tau}^{2}=$ 
$0.12, \mathrm{I}^{2}=64 \%, \mathrm{Chi}^{2} \mathrm{P}$ value 0.03 , evidence graded as low quality; Analysis 1.1). Relatively little evidence was found for other classes of tocolytic drugs. One study with 310 women examined the use of a calcium channel blocker and did not demonstrate a difference between intervention and control groups for cephalic presentation at birth (RR $1.13,95 \%$ CI 0.87 to 1.48 ); single studies examining parenteral and sublingual nitric oxide donors also showed no statistically significant differences between intervention and control groups (RR $1.58,95 \%$ CI 0.91 to 2.76 , participants $=125$, and, RR 0.74 , 95\% CI 0.52 to 1.05 , participants $=99$, respectively).

Failure to achieve a cephalic vaginal birth was less likely for women receiving a beta stimulant (average RR $0.75,95 \%$ CI 0.60 to 0.92 , four studies, 399 women, evidence graded as moderate quality; Analysis 1.2). One study examined the use of a sublingual nitric oxide donor and reported no clear evidence of differences between groups (RR 1.22, 95\% CI 0.86 to 1.72 , participants $=99$ ).

We noted a significant reduction in caesarean sections with the use of beta stimulants to facilitate ECV (average RR 0.77, 95\% CI 0.67 to 0.88 , participants $=742$, six studies, $\mathrm{I}^{2}=25 \%$; Analysis 1.3). Evidence on the impact of calcium channel blockers and parenteral nitric oxide donors was limited and showed no clear difference in the rates of caesarean section between treatment and control groups (calcium channel blocker: RR 1.11, 95\% CI 0.88 to 1.40 , one study, participants $=310$; parenteral nitric oxide donor: RR 0.83 , 95\% CI 0.67 to 1.02 , one study, participants $=125$ ).

We identified no significant difference in fetal bradycardia in any of the studies reporting this outcome (beta stimulants: RR 2.81, 95\% CI 0.12 to 66.17 , participants $=58$, one study, evidence graded as very low quality; calcium channel blocker: RR 1.11, $95 \%$ CI 0.50 to 2.43 , participants $=310$, one study; oral nitric oxide donor: RR $0.39,95 \%$ CI 0.08 to 1.93 , participants $=99$, one study; Analysis 1.4).

Only one class of tocolytic drugs, the beta stimulants, had a reasonable number of trials to allow firm conclusions regarding primary outcomes (see Summary of findings for the main comparison).

\section{Secondary outcomes}

We found a statistically significant reduction in failure of ECV when parenteral beta stimulant drugs were used (average RR 0.70, $95 \%$ CI 0.60 to 0.82 , participants $=900$, nine studies, $\mathrm{I}^{2}=34 \%$, evidence graded as moderate quality; Analysis 1.5). For other types of tocolytics (oral beta stimulants, oral calcium channel blockers, parenteral or sublingual nitric oxide donors), evidence was insufficient to demonstrate any differences between groups for failure of ECV (RR $1.00,95 \%$ CI 0.56 to 1.79 , participants $=45$, one study; RR $0.93,95 \%$ CI 0.78 to 1.11 , participants $=310$, one study; RR $0.86,95 \%$ CI 0.70 to 1.06 , participants $=126$, one study; average RR $1.04,95 \%$ CI 0.55 to 1.96 , participants $=156$, two studies, respectively).

Too few studies assessed most of our other secondary outcomes to reveal clear differences between groups. No statistically signifi- cant differences between groups were identified for difficult ECV (parenteral beta stimulants: RR $0.50,95 \%$ CI 0.16 to 1.54 , participants =63, one study; Analysis 1.6); maternal palpitation (parenteral beta stimulants: RR 5.00, 95\% CI 0.25 to 101.89 , participants = 114, one study; parenteral nitric oxide donors: RR 0.49 , $95 \%$ CI 0.05 to 5.27, participants $=117$, one study; Analysis 1.7 ); or maternal hypotension, which was reported for single studies examining parenteral and sublingual nitric oxide donors (RR 1.47, $95 \%$ CI 0.26 to 8.50 , participants $=117$, and, RR 5.88, $95 \% \mathrm{CI}$ 0.73 to 47.07, participants $=99$, respectively; Analysis 1.9).

Two studies examining the use of parenteral or sublingual nitric oxide donors reported maternal headaches, and women receiving active treatment were more likely to experience headache compared with those given placebo (RR 18.68, 95\% CI 1.11 to 313.77 , participants $=117$, and, RR $10.29,95 \%$ CI 2.55 to 41.56 , participants = 99, respectively; Analysis 1.8).

Other outcomes were not reported or were reported in single studies, and evidence was insufficient to reveal differences between groups receiving tocolysis versus placebo.

1. Operative vaginal birth (calcium channel blocker: RR 0.34, 95\% CI 0.09 to $1.22,310$ women; Analysis 1.10).

2. Maternal mortality (not reported).

3. Maternal morbidity (not reported).

4. Perinatal mortality (calcium channel blocker: 310 participants, no events; Analysis 1.13).

5. Perinatal morbidity (not reported).

In this version of the review, we added the outcome vaginal breech birth, which was reported in one study with no evidence of a difference between groups (RR 1.00, 95\% CI 0.30 to 3.28, one study, 124 women; Analysis 1.15).

\section{Non-prespecified outcomes}

An additional six outcomes were reported that we had not specified in the protocol: Apgar less than seven at five minutes (beta stimulants: no events, two studies, 227 infants), neonatal seizures (beta stimulants: no events, one study, 124 infants), admission to neonatal unit (beta stimulants: average RR 1.00, 95\% CI 0.30 to 3.36, two studies, 238 infants; Analysis 1.18), birth trauma (beta stimulant: no events, one study, 144 women) and flushing in women (calcium channel blocker: RR 23.30, 95\% CI 1.38 to 391.91, one study, 310 women; Analysis 1.20). We found too few data on these outcomes to report findings with confidence.

\section{Subgroup analysis by parity}

Six studies reported the data by parity (Chung 1996; Hilton 2009; Impey 2005; Nor Azlin 2005; Stock 1993; Tan 1989), but only two reported data on our primary outcomes (Hilton 2009; Impey 2005). Interaction tests showed no differences between nulliparous and multiparous women. Cephalic presentation in labour and at birth was not statistically significant, but the numbers of women 
were small (average RR 1.89, 95\% CI 0.98 to 3.62, two studies, 249 women, interaction test $\mathrm{Chi}^{2}=0.00, \mathrm{df}=1, \mathrm{P}$ value 0.95 ; Analysis 21.1). We observed a significant reduction in caesarean sections (average RR 0.84, 95\% CI 0.74 to 0.95 , two studies, 249 women, interaction test $\mathrm{Chi}^{2}=0.68, \mathrm{df}=1, \mathrm{P}=0.41$; Analysis 21.2 ) and in failed ECV (average RR $0.78,95 \%$ CI 0.66 to 0.92 , six studies, 513 women, interaction test $\mathrm{Chi}^{2}=2.07, \mathrm{df}=1, \mathrm{P}=$ 0.08 , Analysis 21.4 ), with no differences between nulliparous and multiparous women.

\section{Subgroup analysis by study quality}

We considered two studies to be at high risk of bias in terms of randomisation, concealment of allocation or completeness of data (Fernandez 1997; Robertson 1987); both of these studies examined parenteral beta stimulants. Even with these studies temporarily excluded, parenteral beta stimulants still appeared to be effective in achieving cephalic presentation at birth (average RR 2.03, 95\% CI 1.49 to 2.77 , three studies, 289 women). Findings for the outcome of failure to achieve cephalic vaginal birth remained non-significant for parenteral beta stimulants (average RR 0.65, 95\% CI 0.38 to 1.11 , two studies, 238 women). There remained a significant reduction in caesarean sections for parenteral beta stimulants when studies at high risk of bias were temporarily removed (average RR 0.75, 95\% CI 0.63 to 0.89 , four studies, 581 women). Fetal bradycardia remained as showing no significant difference identified.

\section{Comparison 2. Tocolytics versus other tocolytics (four studies with 344 women)}

Four studies, or parts of studies, involving 344 women looked at these comparisons.

Calcium channel blockers (A2) versus beta stimulants (A1): Two studies involving 176 women made this comparison (Collaris 2009; Nor Azlin 2008).

Nitric oxide donors (A3) versus beta stimulants (A1): Two studies involving 168 women made this comparison (Bujold 2003b; El-Sayed 2004).

Nitric oxide donors (A3) versus calcium channel blockers (A2): No studies looked at this comparison.

One study involving 63 women included three groups and compared two different beta stimulants - hexoprenaline and ritodrine - versus placebo (Stock 1993). We are not comparing different drugs within the same class, so these data are omitted from this section (although the data are included in the section on tocolysis versus placebo).

The overall quality of the studies was reasonable. All four studies were assessed as being at low risk of bias in terms of both sequence generation and allocation concealment (Bujold 2003b; Collaris 2009; El-Sayed 2004; Nor Azlin 2008). Blinding was considered adequate in one study, in which women, staff and outcome assessors were blinded (Bujold 2003b). (See Figure 1.)

\section{Primary outcomes}

We obtained too few data on these outcomes to report findings with confidence.

\section{Cephalic presentation at birth}

1. Calcium channel blockers versus beta stimulants (RR 0.62, 95\% CI 0.39 to 0.98 , one study, 90 women; Analysis 2.1).

2. Nitric oxide donors versus beta stimulants (RR 0.56, 95\% CI 0.29 to 1.09 , one study, 74 women; Analysis 2.1.2).

\section{Cephalic vaginal birth not achieved}

1. Nitric oxide donors versus beta stimulants (RR 1.13, 95\% CI 0.88 to 1.47 , one study, 74 women; Analysis 2.2).

\section{Caesarean section}

1. Calcium channel blockers versus beta stimulants (average RR $1.28,95 \%$ CI 1.03 to 1.59 , two studies, 170 women; Analysis 2.3).

\section{Fetal bradycardia}

1. Calcium channel blockers versus beta stimulants (average RR $1.17,95 \%$ CI 0.46 to 3.03, two studies, 170 infants; Analysis 2.4).

2. Nitric oxide donors versus beta stimulants (RR 1.06, 95\% CI 0.16 to 7.10 , one study, 74 infants; Analysis 2.4.1).

\section{Secondary outcomes}

\section{Failed ECV}

1. Calcium channel blockers versus beta stimulants (average RR $1.41,95 \%$ CI 1.06 to 1.86 , two studies, 176 women; Analysis 2.5.1).

2. Nitric oxide donors versus beta stimulants (average RR $1.48,95 \%$ CI 1.13 to 1.94 , two studies, 133 women; Analysis 2.5.2).

\section{Difficult ECV}

1. Calcium channel blockers versus beta stimulants (RR 5.22, 95\% CI 0.26 to 105.81 , one study, 90 women; Analysis 2.6).

\section{Non-prespecified outcomes}

Other non-prespecified outcomes (maternal palpitations, headache, hypotension and infant admission to neonatal intensive care unit) were reported in single studies with small sample sizes, and evidence was insufficient to allow firm conclusions. 


\section{Subgroup analysis by parity}

One small study involving 86 women compared nifedipine versus terbutaline and reported data by parity (Nor Azlin 2008). Failed ECV, the only outcome reported by parity, did not show a significant difference between the two tocolytic drugs, although the interaction tests showed no differences between nulliparous and multiparous women (RR 1.38, 95\% CI 0.90 to 2.13, one study, 86 women interaction test $\mathrm{Chi}^{2}=0.35, \mathrm{df}=1, \mathrm{P}$ value 0.55 ; Analysis 22.4).

\section{Sensitivity analyses by study quality}

Studies were insufficient for this analysis.

\section{Comparison 3. Vibroacoustic stimulation in midline fetal spine positions versus placebo (one study, 26 women)}

One study involving 26 women (of whom 23 provided data) looked at this comparison and reported only on the number of women in whom ECV failed (Johnson 1995). The quality of the study was reasonable, but only 26 women were included. So the finding of a statistically significant reduction in failed ECV cannot be relied upon (RR $0.09,95 \%$ CI 0.01 to 0.60 , one study, 23 women; Analysis 3.5).

Other primary and secondary outcomes were not reported.

\section{Comparison 4. Vibroacoustic stimulation versus tocolytics}

We found no studies assessing this comparison.

\section{Comparison 5. Comparison of different types of vibroacoustic stimulation}

We found no studies assessing this comparison.

\section{Comparison 6. Regional analgesia versus placebo (six studies, 554 women)}

Six studies involving 554 women looked at this comparison. Four of these studies addressed the effect of spinal analgesia on ECV (Delisle 2001; Dugoff 1999; Weiniger 2007; Weiniger 2010); two studies assessed the effect of epidural analgesia (Mancuso 2000; Schorr 1997).

All studies except one (Delisle 2001) used a tocolytic drug as well in both arms; the one exception allowed clinicians to choose to use a tocolytic drug if they wished (Delisle 2001). This study reported on very few of our prespecified outcomes. We have analysed separately the use of regional analgesia with or without tocolysis. Findings for primary outcomes for regional analgesia (with tocolysis) are set out in Summary of findings 2.
The quality of the studies was generally unclear. Only two studies were considered to have low risk of bias in terms of sequence generation and allocation concealment (Mancuso 2000; Schorr 1997). The remainder of the studies were mostly unclear around risk of bias (Figure 1).

\section{Primary outcomes}

For regional analgesia with tocolysis versus tocolysis alone, we found no statistically significant differences identified for the primary outcomes: cephalic presentation at labour and at birth (average RR $1.44,95 \%$ CI 0.78 to 2.66 , three studies, 279 women, random-effects, $\mathrm{Tau}^{2}=0.24, \mathrm{I}^{2}=80 \%, \mathrm{Chi}^{2} \mathrm{P}$ value 0.006 ; Analysis 6.1); caesarean section (average RR $0.74,95 \%$ CI 0.40 to 1.37 , three studies, 279 women, random-effects, $\mathrm{Tau}^{2}=0.26 \mathrm{I}^{2}=88 \%$, $\mathrm{Chi}^{2} \mathrm{P}$ value 0.0003; Analysis 6.3); and fetal bradycardia (average RR $1.48,95 \%$ CI 0.62 to 3.57 , two studies, 210 women, randomeffects, $\mathrm{Tau}^{2}=0.05, \mathrm{I}^{2}=8 \%, \mathrm{Chi}^{2} \mathrm{P}$ value 0.30; Analysis 6.4). Failure to achieve cephalic vaginal delivery was not reported.

\section{Secondary outcomes}

We did identify a significant reduction in the number of failures of ECV with regional analgesia with tocolysis (RR 0.61, 95\% CI 0.43 to 0.86 , participants $=409$, five studies, $\mathrm{I}^{2}=56 \%$; Analysis 6.5). This outcome was also reported in the single study examining regional analgesia without tocolysis versus no intervention, and no evidence suggested a difference between groups (RR 0.89, $95 \%$ CI 0.70 to 1.14 , participants $=141)$. None of our other secondary outcomes were reported (operative vaginal birth, maternal mortality, maternal morbidity, perinatal mortality, perinatal morbidity).

\section{Outcomes not prespecified}

Some studies assessed placental abruption and maternal discomfort but identified no differences with regional analgesia. Three studies examined maternal hypotension, and regional analgesia with tocolysis was associated with increased risk of hypotension (average RR 11.58, 95\% CI 1.53 to 87.50 , participants $=280$, three studies, $\mathrm{I}^{2}=0 \%$; Analysis 6.9).

\section{Subgroup analysis by parity}

Six studies reported data by parity, but it was not possible to undertake any subgroup analysis.

\section{Sensitivity analysis by study quality}

Good quality data were insufficient for subgroup sensitivity analysis for this comparison, as only two (Mancuso 2000; Schorr 1997) of the six identified were considered to have low risk of bias in 
terms of randomisation, concealment of allocation or completeness of data.

\section{Comparison 7. Regional analgesia versus tocolytics}

We found no studies assessing this comparison.

\section{Comparison 8. Regional analgesia versus vibroacoustic stimulation}

We found no studies assessing this comparison.

\section{Comparison 9. Comparison of different types of regional analgesia}

We found no studies assessing this comparison.

\section{Comparison 10. Amnioinfusion versus placebo}

We found no studies assessing this comparison.

\section{Comparison I I. Amnioinfusion versus tocolytics}

We found no studies assessing this comparison.

\section{Comparison I2. Amnioinfusion versus vibroacoustic stimulation}

We found no studies assessing this comparison.

\section{Comparison 13. Amnioinfusion versus regional analgesia}

We found no studies assessing this comparison.

\section{Comparison 14. Comparison of different types of amnioinfusion}

We found no studies assessing this comparison.

\section{Comparison I5. Systemic opioids versus placebo (one study, 60 women)}

One study with 60 women was included in this comparison (Munoz 2014); in this trial intravenous patient-controlled remifentanil was compared with an intravenous placebo.

\section{Primary outcomes}

Presentation at birth was not reported. Trialists reported "transient" fetal bradycardia, but the study was underpowered to demonstrate a statistically significant difference between groups (RR 0.31, 95\% CI 0.09 to 1.04; Analysis 15.3). The frequency of caesarean section was very similar in the two groups (RR 0.99, 95\% CI 0.63 to 1.57 ) (Analysis 15.4).

\section{Secondary outcomes}

No clear evidence was found of a difference between groups in failure of ECV (RR $0.77,95 \%$ CI 0.47 to 1.26 ; Analysis 15.5) nor in frequency of operative vaginal birth (RR $0.94,95 \%$ CI 0.20 to 4.27; Analysis 15.10).

Other secondary outcomes were not reported.

\section{Other outcomes}

Several non-prespecified outcomes were reported in this trial. Women receiving the opioid had lower pain scores compared with control participants (mean difference (MD) -1.80 (on a 10-point scale), 95\% CI -3.04 to -0.56; Analysis 15.15), and maternal satisfaction with the procedure was increased in the group receiving remifentanil (MD 2.60, 95\% CI 1.25 to 3.95; Analysis 15.16). No significant difference between groups was found in maternal side effects (nausea and vomiting, dizziness and drowsiness), although the study was underpowered to demonstrate differences for most outcomes (Analysis 15.17; Analysis 15.18; Analysis 15.19).

\section{Comparison 16. Systemic opioids versus tocolytics}

We found no studies assessing this comparison.

\section{Comparison 17. Systemic opioids versus vibroacoustic stimulation}

We found no studies assessing this comparison.

\section{Comparison I8. Systemic opioids versus regional analgesia}

One study, involving 95 women, assessed this comparison ( Sullivan 2009). The quality of the study was good; only lack of blinding might contribute to bias. The remaining assessments were consistent with low risk of bias (Figure 1).

\section{Primary outcomes}

The rate of cephalic presentation at birth was not reported. No significant differences between groups were reported for the outcome failure to achieve vaginal cephalic birth (RR $1.18,95 \% \mathrm{CI}$ 0.90 to 1.54 ). Also no clear difference between groups was seen 
in terms of the numbers of women undergoing caesarean section (RR 1.18, 95\% CI 0.90 to 1.54 , 95 women; Analysis 18.3). A similar rate of fetal bradycardia was observed in the two groups (RR 0.71, 95\% CI 0.24 to 2.09, 94 women; Analysis 18.4).

\section{Secondary outcomes}

No statistically significant difference was observed in frequency of failure of ECV when a systemic opioid was compared with regional analgesia (RR 1.29, 95\% CI 0.93 to $1.80,95$ women; Analysis 18.5).

\section{Comparison 19. Systemic opioids versus amnioinfusion}

We found no studies assessing this comparison.

\section{Comparison 20. Comparison of different systemic opioids}

We found no studies assessing this comparison.

\section{Comparison 23. Hypnosis versus neurolinguistic programming (one study, 80 women)}

One study with 80 women compared two types of hypnosis.

\section{Primary outcomes}

No primary outcomes were reported.

\section{Secondary outcomes}

No significant evidence suggested that one hypnosis technique was more effective than the other (RR 1.08 , 95\% CI 0.74 to 1.57; Analysis 23.5), and women in both groups reported a similar degree of pain relief during the procedure, as measured on a scale of one to 10 (MD $0.10,95 \%$ CI -0.87 to 0.67 , one study, 80 women (non-prespecified outcome); Analysis 23.15).

\section{Comparison 24. Talcum powder versus gel to assist with ECV (one study, 95 women)}

One study compared the use of talcum powder versus gel applied to the woman's abdomen to assist with ECV. If after one round of attempts (two attempts) using the allocated method, ECV was not successful, the alternative method could be tried. This meant that many of the women in the trial with initial failed ECV crossed over to the other method; outcome data were very difficult to interpret because although analysis was performed according to original allocation, women may have received both methods. We therefore report here only the secondary outcome related to failure of ECV after the first round of attempts (using the allocated method). There was insufficient evidence to demonstrate whether talcum was more or less effective than gel in assisting version (RR 1.26, $95 \%$ CI 0.84 to 1.89 , one study, 80 women; Analysis 24.5 ). 


\begin{tabular}{|c|c|c|c|c|c|c|c|}
\hline \multicolumn{8}{|c|}{ tervention of regional analgesia (with or without tocolysis) for breech presentation } \\
\hline 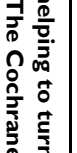 & \multicolumn{7}{|c|}{$\begin{array}{l}\text { Patient or population: patients with breech presentation } \\
\text { Settings: studies in hospital settings } \\
\text { Intervention: regional analgesia (with tocolysis) versus no intervention of regional analgesia (with or without tocolysis) }\end{array}$} \\
\hline 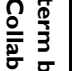 & \multirow[t]{3}{*}{ Outcomes } & \multicolumn{2}{|c|}{ Illustrative comparative risks* $(95 \% \mathrm{Cl})$} & \multirow{3}{*}{$\begin{array}{l}\text { Relative effect } \\
(95 \% \mathrm{Cl})\end{array}$} & \multirow{3}{*}{$\begin{array}{l}\text { Number of participants } \\
\text { (studies) }\end{array}$} & \multirow{3}{*}{$\begin{array}{l}\text { Quality of the evidence } \\
\text { (GRADE) }\end{array}$} & \multirow{3}{*}{ Comments } \\
\hline 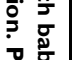 & & Assumed risk & Corresponding risk & & & & \\
\hline 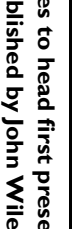 & & Control & $\begin{array}{l}\text { Regional analge- } \\
\text { sia (with tocolysis) vs } \\
\text { no intervention of re- } \\
\text { gional analgesia (with } \\
\text { or without tocolysis) }\end{array}$ & & & & \\
\hline 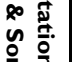 & \multirow{4}{*}{$\begin{array}{l}\text { Cephalic presentation } \\
\text { at birth (primary) }\end{array}$} & \multicolumn{2}{|c|}{ Study population } & \multirow{4}{*}{$\begin{array}{l}\text { RR } 1.63 \\
-(0.75 \text { to } 3.53)\end{array}$} & \multirow{4}{*}{$\begin{array}{l}279 \\
\text { (3 studies) }\end{array}$} & \multirow{4}{*}{\multicolumn{2}{|c|}{$\begin{array}{l}\oplus \bigcirc \bigcirc \bigcirc \\
\text { Very low }\end{array}$}} \\
\hline . & & 393 per 1000 & $\begin{array}{l}640 \text { per } 1000 \\
(295 \text { to } 1000)\end{array}$ & & & & \\
\hline $\begin{array}{l}0 \\
0 \\
0 \\
0\end{array}$ & & \multicolumn{2}{|l|}{ Moderate } & & & & \\
\hline$\frac{2}{\frac{2}{2}}$ & & 352 per 1000 & $\begin{array}{l}574 \text { per } 1000 \\
(264 \text { to } 1000)\end{array}$ & & & & \\
\hline$\frac{1}{3}$ & \multirow{4}{*}{$\begin{array}{l}\text { Cephalic vaginal birth } \\
\text { not achieved (CS + } \\
\text { breech vaginal birth) } \\
\text { (primary) }\end{array}$} & \multicolumn{2}{|c|}{ Study population } & \multirow{4}{*}{$\begin{array}{l}\text { RR } 0.65 \\
-(0.47 \text { to } 0.89)\end{array}$} & \multirow{4}{*}{$\begin{array}{l}108 \\
\text { (1 study) }\end{array}$} & \multirow{4}{*}{\multicolumn{2}{|c|}{$\begin{array}{l}\oplus \oplus \bigcirc \bigcirc \\
\text { Low }^{4,5}\end{array}$}} \\
\hline 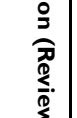 & & 741 per 1000 & $\begin{array}{l}481 \text { per } 1000 \\
\text { (348 to } 659)\end{array}$ & & & & \\
\hline & & \multicolumn{2}{|l|}{ Moderate } & & & & \\
\hline$N$ & & 741 per 1000 & $\begin{array}{l}482 \text { per } 1000 \\
(348 \text { to } 659)\end{array}$ & & & & \\
\hline
\end{tabular}




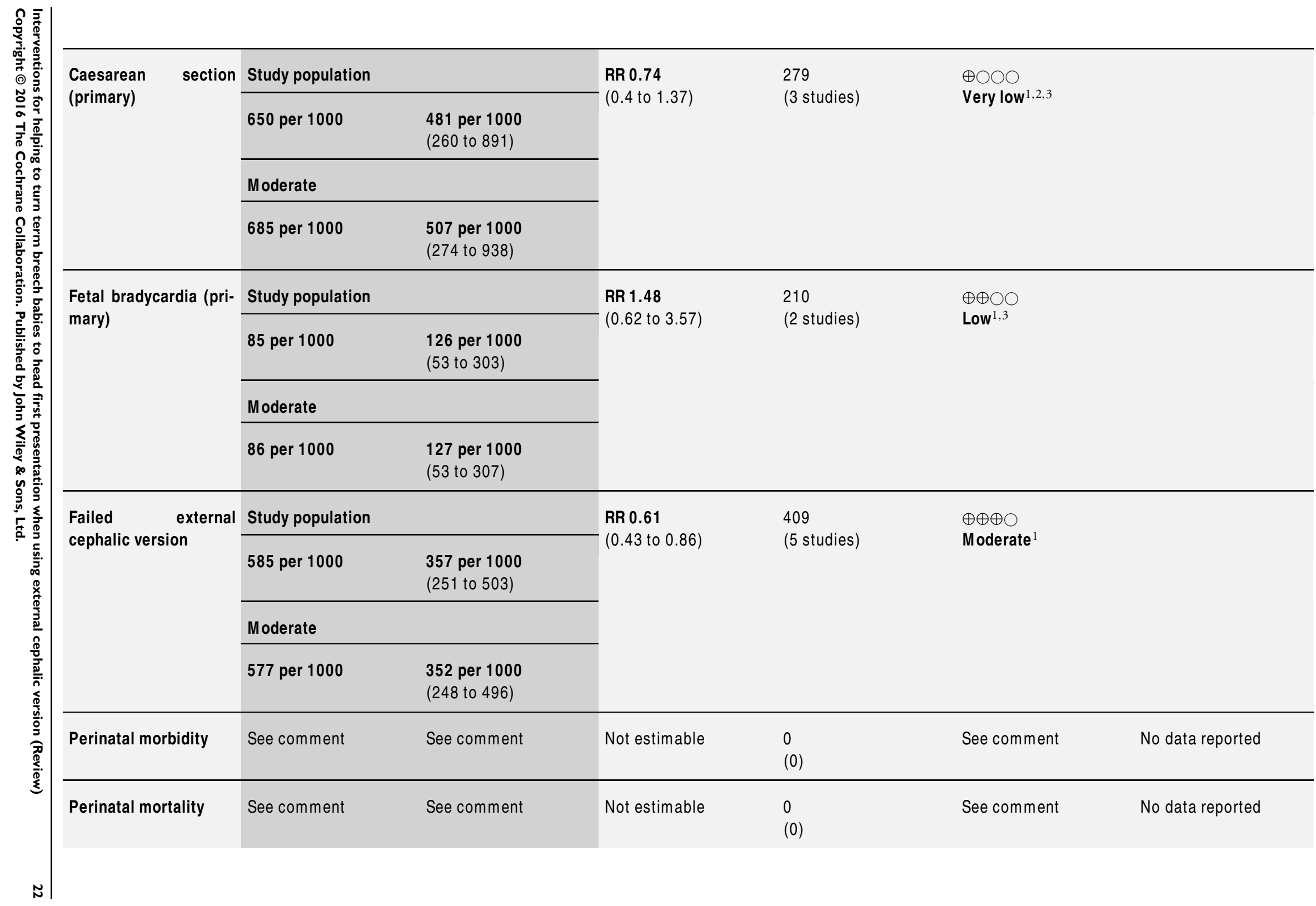


*The basis for the assumed risk (e.g. median control group risk across studies) is provided in footnotes. The corresponding risk (and its $95 \%$ confidence interval) is based on the assumed risk in the comparison group and the relative effect of the intervention (and its $95 \% \mathrm{Cl}$ ).

Cl: Confidence interval; RR: Risk ratio.

GRADE Working Group grades of evidence.

High quality: Further research is very unlikely to change our confidence in the estimate of effect.

Moderate quality: Further research is likely to have an important impact on our confidence in the estimate of effect and may change the estimate.

Low quality: Further research is very likely to have an important impact on our confidence in the estimate of effect and is likely to change the estimate.

Very low quality: We are very uncertain about the estimate.

1. All studies contributing data had design limitations.

2. $I^{2}>60 \%$; direction and size of effect inconsistent.

3. Wide $95 \% \mathrm{Cl}$ crossing the line of no effect and small sample size.

4. Study contributing data had design limitations.

5. Estimate based on small sample size. 
DISCUSSION

\section{Summary of main results}

Parenteral beta stimulants, used to help external cephalic version of breech babies, were effective in increasing the number of women going into labour with their baby in a cephalic presentation and in reducing the number of women undergoing caesarean section. However, data on possible adverse effects are insufficient. Data derived by comparison of other classes of tocolytic drugs (calcium channel blockers and nitric acid donors) were also insufficient. We identified no difference in response between nulliparous women and multiparous women in terms of successful external cephalic version (ECV), babies in the cephalic presentation during labour and caesarean section.

Use of regional analgesia, in combination with a tocolytic drug, to facilitate ECV was effective in terms of increasing successful versions, but the data show no benefit in terms of babies in the cephalic presentation during labour or reduction in caesarean sections.

Data were insufficient on the use of vibroacoustic stimulation, amnioinfusion, systemic opioids, hypnosis or abdominal lubricants for helping to turn breech babies using ECV techniques.

\section{Overall completeness and applicability of evidence}

Available evidence does not describe many of the prespecified outcomes, in particular, possible adverse effects.

\section{Quality of the evidence}

The overall quality of the evidence was reasonable, with studies on regional analgesia unable to be blinded. However, several assessments will have yielded insufficient data to provide an answer with any degree of assurance. We carried out formal assessments of quality of the evidence using GRADEpro for parenteral beta stimulants and regional analgesia with tocolysis. For both of these comparisons, the evidence was graded from moderate to very low quality.

\section{Potential biases in the review process}

Evidence in this review was derived from studies identified in a detailed search process. Trials comparing interventions to help external cephalic version of breech babies at term that have not been published may not have been identified. We attempted to minimise bias in the review process by having two review authors independently extract data.

\section{Agreements and disagreements with other studies or reviews}

We are not aware of any other systematic reviews on this topic. Studies within the review seem to be in reasonable agreement.

\section{AUTHORS' CONCLUSIONS}

\section{Implications for practice}

Beta stimulant tocolytics, given parenterally to facilitate external cephalic version of breech babies, increased the number of babies in the cephalic presentation during labour and birth, and reduced the number of caesarean sections performed. However, insufficient data were collected on possible adverse effects on mother or baby. Other groups of tocolytics, calcium channel blockers and nitric acid donors yielded insufficient data to provide good evidence. Data on other possible facilitators of external cephalic version (ECV) were insufficient to provide useful evidence.

Use of regional analgesia in combination with tocolytic drugs increased the rate of success of ECV, but data were insufficient to indicate whether this was associated with an increase in cephalic presentation at birth or a change in the rate of caesarean section.

\section{Implications for research}

Future research needs to carefully assess any potential adverse effects on both mother and baby.

\section{Routine tocolysis for ECV at term}

Further controlled trials of routine tocolysis for ECV at term are needed. In particular, possible benefits of routine tocolysis used to reduce the force required for successful ECV, and possible risks of maternal cardiovascular side effects, need to be addressed further. Additional trials are also needed to compare the effectiveness of routine versus selective use of tocolysis; investigators should include short-term and long-term outcome measures that assess morbidity according to type of birth.

Although randomised trials of nitroglycerine have been small, the results are sufficiently negative to discourage further trials.

\section{Fetal acoustic stimulation for ECV at term}

The results presented in this review are sufficiently encouraging to justify further trials of this procedure. Short-term and long-term outcomes must be assessed.

\section{Regional analgesia for ECV at term}

Further trials are needed. The effect of vaginal displacement of the presenting part should be assessed. Fluid received by the regional 
analgesia group and by the control group should be similar, and whether tocolytic agents should be used adjunctively needs further investigation.

\section{Amnioinfusion for ECV at term}

Transabdominal amnioinfusion to increase amniotic fluid volume might facilitate ECV and should be investigated.

\section{Hydration to increase amniotic fluid volume for ECV at term}

Intravenous or oral hydration before ECV attempts to increase amniotic fluid volume should be investigated as a separate intervention (Hofmeyr 2002).

\section{Systemic opioids for ECV at term}

Given the general adverse effects of opioids (Bricker 2002), research might be better focused on other possible facilitators for ECV of breech babies.

\section{Other interventions}

Evidence on other interventions such as hypnosis or abdominal lubricants is insufficient; adequately designed and powered trials may throw light on whether such interventions are worthwhile.

\section{ACKNOWLEDGEMENTS}

We thank the Cochrane Pregnancy and Childbirth team for technical support, in particular Steve Milan for assisting with data extraction in the previously published version of this review (Cluver 2012).

We thank the NIHR Programme Grant, which enabled Therese Dowswell (TD) to join our review team for this update. TD is supported by the NIHR Cochrane Programme Grant Project: 13/ 89/05 - Pregnancy and childbirth systematic reviews to support clinical guidelines.

\section{R E F E R E N C E S}

\section{References to studies included in this review}

Bujold 2003a \{published data only\}

* Bujold E, Boucher M, Rinfret D, Berman S, Ferreira E, Marquette GP. Sublingual nitroglycerin versus placebo as a tocolytic for external cephalic version: a randomized controlled trial in parous women. American Journal of Obstetrics and Gynecology 2003;189:1070-3.

Bujold E, Boucher M, Rinfret D, Marquette G. Sublingual nitroglycerin versus placebo as a tocolytic for external cephalic version: a randomized controlled trial in parous women [abstract]. American Journal of Obstetrics and Gynecology 2002;187(6 Pt 2):S103.

Bujold 2003b \{published data only\}

Bujold E, Marquette GP, Ferreira E, Gauthier RJ, Boucher M. Sublingual nitroglycerin versus intravenous ritodrine as tocolytic for external cephalic version: a double-blind randomized trial. American Journal of Obstetrics and Gynecology 2003;188(6):1454-7; discussion 1457-9.

\section{Chung 1996 \{published data only\}}

* Chung T, Neale E, Lau TK, Rogers M. A randomized, double blind, controlled trial of tocolysis to assist external cephalic version in late pregnancy. Acta Obstetricia et Gynecologica Scandinavica 1996;75:720-4.

Neale EJ, Lau TK, Chung A, Cohn M, Baldwin S, Rogers $\mathrm{M}$. A randomized double blind controlled trial of tocolysis to assist external cephalic version in late pregnancy. 27th British Congress of Obstetrics and Gynaecology; 1995 July 4-7; Dublin, Ireland. 1995:76.
Collaris 2009 \{published data only\}

Collaris R, Tan PC. Oral nifedipine versus subcutaneous terbutaline tocolysis for external cephalic version: a doubleblind randomised trial. BJOG: an international journal of obstetrics and gynaecology 2009;116(1):74-81.

Delisle 2001 \{published data only\} Delisle MF, Kamani A, Douglas J, Bebbington M. Antepartum external cephalic version under spinal anesthesia: a randomized controlled trial. American Journal of Obstetrics and Gynecology 2001;185(6 Suppl):S115.

Dugoff 1999 \{published data only\}

Dugoff L, Jones OW, Stamm C, Mohling S, Hawkins J. A prospective, randomized trial evaluating the use of spinal anesthesia in external cephalic version. American Journal of Obstetrics and Gynecology 1998;178(1):S71.

* Dugoff L, Stamm CA, Jones OW, Mohling SI, Hawkins JL. The effect of spinal anesthesia on the success rate of external cephalic version: a randomized trial. Obstetrics \& Gynecology 1999;93(3):345-9.

El-Sayed 2004 \{published data only\} El-Sayed Y, Chitkara U, Reley ET, Cohen SE, Holbrook RH, Druzin M. Nitroglycerin versus terbutaline for external cephalic version. American Journal of Obstetrics and Gynecology 1998;178(1):S71.

* El-Sayed YY, Pullen K, Riley ET, Lyell D, Druzin ML, Cohen SE, et al. Randomized comparison of intravenous nitroglycerin and subcutaneous terbutaline for external cephalic version under tocolysis. American Journal of Obstetrics and Gynecology 2004;191:2051-5. 
Fernandez 1997 \{published data only\}

Fernandez CO, Bloom S, Wendel G. A prospective, randomized, blinded comparison of terbutaline versus placebo for singleton, term external cephalic version. American Journal of Obstetrics and Gynecology 1996;174: 326.

* Fernandez CO, Bloom SL, Smulian JC, Ananth CV, Wendel GD Jr. A randomized placebo-controlled evaluation of terbutaline for external cephalic version. Obstetrics \& Gynecology 1997;90(5):775-9.

Hilton 2009 \{published data only\}

Hilton J. Intravenous nitroglycerin for external cephalic versions trial (INVERT): a randomized, double-blinded placebo-controlled trial. JOGC: Journal of Obstetrics and Gynaecology Canada 2007;29(6 Suppl 1):S16.

* Hilton J, Allan B, Swaby C, Wah R, Jarrell J, Wood S, et al. Intravenous nitroglycerin for external cephalic version: a randomized controlled trial. Obstetrics \& Gynecology 2009; 114(3):560-7.

Impey 2005 \{published data only\}

Impey L, Pandit M. Tocolysis for repeat external cephalic version in breech presentation at term: a randomised, double-blinded, placebo-controlled trial. BJOG: an international journal of obstetrics and gynaecology 2005;112: 627-31.

Johnson 1995 \{published data only\}

Johnson RL, Elliot JP. Fetal acoustic stimulation, an adjunct to external cephalic version: a blinded, randomized crossover study. American Journal of Obstetrics and Gynecology 1995;173:1369-72.

Kok 2008 \{published data only\}

Kok M. Management of breech presentation: external cephalic version with tocolysis: a multicentre randomised controlled trial, 2005. Netherlands Trial Register (http:// www.trialregister.nl) (accessed 1 November 2005).

* Kok M, Bais JM, Van Lith JM, Papatsonis DM, Kleiverda G, Hanny D, et al. Nifedipine as a uterine relaxant for external cephalic version: a randomized controlled trial. Obstetrics \& Gynecology 2008;112(2 Pt 1):271-6.

Mancuso 2000 \{published data only\} Mancuso KM, Yancey MK, Murphy JA, Markenson GR. Epidural analgesia for cephalic version: a randomized trial. Obstetrics \& Gynecology 2000;95(5):648-51.

Marquette 1996 \{published data only\}

Marquette GP, Boucher M, Theriault D, Rifret D. Does the use of a tocolytic agent affect the success rate of external cephalic version?. American Journal of Obstetrics and Gynecology 1996;175:859-61.

Munoz 2014 \{published data only\}

Munoz H, Guerra S, Perez-Vaquero P, Valero C, Aizpuru F, Lopez-Picado A. Remifentanil versus placebo for analgesia during external cephalic version: a randomised clinical trial. International Journal of Obstetric Anesthesia 2014;23(1): 52-7.

Valero CA. Remifentanil versus paracetamol for pain treatment external cephalic versions, 2010.
ClinicalTrials.gov (http://clinicaltrials.gov/) (accessed 21 May 2013).

Nor Azlin 2005 \{published data only\} Nor Azlin MI, Haliza H, Mahdy ZA, Anson I, Fahya MN, Jamil MA. Tocolysis in term breech external cephalic version. International Journal of Gynecology \& Obstetrics 2005;88:5-8.

Nor Azlin 2008 \{published data only\} Nor Azlin MI, Maryasalwati I, Norzilalwati MN, Zaleha AM, Mohammad AJ, Zainul RMR. Nifedipine versus terbutaline for tocolysis in external cephalic version. International Journal of Gynecology \& Obstetrics 2008;102 (3):263-6.

Reinhard 2012 \{published data only\}

Reinhard J, Peiffer S, Reichenbach L, Tottel E, Reitter A, Sinanovic B, et al. The effects of clinical hypnosis versus neuro-linguistic programming (NLP) before external cephalic version (ECV) - a prospective off-centre randomised double blind controlled trial. Archives of Gynecology and Obstetrics 2012;286(Suppl 1):S213-S214. Reinhard J, Peiffer S, Reichenbach L, Tottel E, Reitter A, Yuan J, et al. Clinical hypnosis before external cephalic version. Archives of Gynecology and Obstetrics 2012;286 (Suppl 1):S215.

* Reinhard J, Peiffer S, Snger N, Herrmann E, Yuan J, Louwen F. The effects of clinical hypnosis versus neurolinguistic programming (NLP) before external cephalic version (ECV): a prospective off-centre randomised, doubleblind, controlled trial. Evidence-based Complementary and Alternative Medicine 2012;2012:Article ID 626740.

Reinhard J, Sanger N, Hanker L, Reichenbach L, Yuan J, Herrmann E, et al. Delivery mode and neonatal outcome after a trial of external cephalic version (ECV): a prospective trial of vaginal breech versus cephalic delivery. Archives of Gynecology and Obstetrics 2013;287(4):663-8.

Robertson 1987 \{published data only\}

Robertson AW, Kopelman JN, Read JA, Duff P, Magelssen DJ, Dashow EE. External cephalic version at term: is a tocolytic necessary?. Obstetrics \& Gynecology 1987;70: 896-9.

Schorr 1997 \{published data only\} Schorr SJ, Speights SE, Ross EL, Bofill JA, Rust OA, Norman PF, et al. A randomized trial of epidural anesthesia to improve external cephalic version success. American Journal of Obstetrics and Gynecology 1997;177(5):1133-7.

Stock 1993 \{published data only\}

Stock A, Chung T, Rogers M, Ming WW. Comparison of placebo, ritodrine and hexoprenaline for external cephalic version at term. Proceedings of 2nd International Scientific Meeting of the Royal College of Obstetricians and Gynaecologists; 1993 Sept 7-10; Hong Kong. 1993:141. * Stock A, Chung T, Rogers M, Ming WW. Randomized, double blind, placebo controlled comparison of ritodrine and hexoprenaline for tocolysis prior to external cephalic version at term. Australian and New Zealand Journal of Obstetrics and Gynaecology 1993;3:265-8. 
Sullivan 2009 \{published data only\}

Bauchat JR, Grobman WA, Sullivan JT, McCarthy RJ, Fitzgerald PC, Wong CA. Effect of combined spinalepidural analgesia versus systemic opioid analgesia on fetal heart rate for external cephalic version. Anesthesiology 2007; 106(Suppl 1):17.

Sullivan JT, Bauchat JR, Grobman WA, McCarthy RJ, Wong CA. Impact of CSE versus systemic opioid on fetal heart rate pattern during external cephalic version. Anesthesiology 2007;107:Abstract no: A772.

* Sullivan JT, Grobman WA, Bauchat JR, Scavone BM, Grouper S, McCarthy RJ, et al. A randomized controlled trial of the effect of combined spinal-epidural analgesia on the success of external cephalic version for breech presentation. International Journal of Obstetric Anesthesia 2009;18(4):328-34.

Sullivan JT, Patel R, Robles C, Grouper S, Wong CA. The impact of combined spinal-epidural analgesia on success of external cephalic version. Anesthesiology 2006;105:A917. Sullivan JT, Scavone BM, Grouper S, Patel R, Robles C, McCarthy RJ, et al. A randomized controlled trial of the impact of combined spinal-epidural analgesia on the success of external cephalic version for breech presentation. Anesthesiology 2006;104(Suppl 1): 10.

Tan 1989 \{published data only\}

Tan GWT, Jen SW, Tan SL, Salmon YM. A prospective randomised controlled trial of external cephalic version comparing two methods of uterine tocolysis with a nontocolysis group. Singapore Medical Journal 1989;30:155-8.

Vallikkannu 2014 \{published data only\} Vallikkannu N, Nadzratulaiman WN, Omar SZ, Si Lay $\mathrm{K}$, Tan PC. Talcum powder or aqueous gel to aid external cephalic version: a randomised controlled trial. $B M C$ Pregnancy and Childbirth 2014;14(1):49.

Vani 2009 \{published data only\}

Vani S, Lau SY, Lim BK, Omar SZ, Tan PC. Intravenous salbutamol for external cephalic version. International Journal of Gynecology \& Obstetrics 2009;104(1):28-31.

Weiniger 2007 \{published data only\}

Weiniger CF. Spinal analgesia versus no analgesia: study for external cephalic version (ongoing trial), 2006.

ClinicalTrials.gov (http://clinicaltrials.gov/) (accessed 21 March 2006).

* Weiniger CF, Ginosar Y, Elchalal U, Sharon E, Nokrian M, Ezra Y. External cephalic version for breech presentation with or without spinal analgesia in nulliparous women at term: a randomized controlled trial. Obstetrics \& Gynecology 2007;110(6):1343-50.

Weiniger CF, Ginosaur Y, Elchalal U, Einav S, Nucrietin $\mathrm{M}$, Guage P, et al. Prospective randomised study of external cephalic version for breech presentation at term in nulliparous women: spinal analgesia versus no analgesia. International Journal of Obstetric Anesthesia 2007;16(Suppl 1):S21.
Weiniger 2010 \{published data only\}

Weiniger C, Ginosar Y, Sela H, Elchalal U, Weissman C, Ezra Y. External cephalic version at term in multiparous women with or without spinal analgesia: randomized controlled trial. American Journal of Obstetrics and Gynecology 2008;199(6 Suppl 1):S34.

* Weiniger CF, Ginosar Y, Elchalal U, Sela HY, Weissman C, Ezra Y. Randomized controlled trial of external cephalic version in term multiparae with or without spinal analgesia. British Journal of Anaesthesia 2010;104(5):613-8.

Yanny 2000 \{published data only\}

Yanny H, Johanson R, Baldwin K, Lucking L, Fitzpatrick $\mathrm{R}$, Jones P. Double-blind randomised controlled trial of glyceryl trinitrate spray for external cephalic version. British Journal of Obstetrics and Gynaecology 2000;107:562-4.

\section{References to studies excluded from this review}

Dockeray 1984 \{published data only\} Dockeray CJ, Gleeson RP. An evaluation of perinatal outcome following external cephalic version under general anaesthesia. Irish Journal of Medical Science 1984; Vol. 153:325.

Guittier 2013 \{published data only\} Guittier MJ, Guillemin F, Farinelli EB, Irion O, Boulvain M, de Tejada BM. Hypnosis for the control of pain associated with external cephalic version: a comparative study. Journal of Alternative \& Complementary Medicine 2013;19(10):820-6.

Wallace 1984 \{published data only\} Wallace RL, Van Dorsten JP, Eglinton GS. External cephalic version with tocolysis. Observations and continuing experience at the Los Angeles County/University of Southern California Medical Center. Journal of Reproductive Medicine 1984;29:745-8.

\section{References to studies awaiting assessment}

Andarsio 2000 \{published data only\} Andarsio F, Feng TI. External cephalic version: nitroglycerin versus terbutaline. American Journal of Obstetrics and Gynecology 2000;182(1 Pt 2):S161.

Hollard 2003 \{published data only\} Hollard A, Lyons C, Rumney P, Hunter M, Reed E, Nageotte $M$. The effect of intrathecal anesthesia on the success of external cephalic version (ECV). American Journal of Obstetrics and Gynecology 2003;189(6):S140.

\section{Tan 2008 \{published data only\}}

Tan PC. A double-blind randomised trial of $250 \mu \mathrm{g}$ versus $500 \mu \mathrm{g}$ bolus dose of terbutaline as a tocolytic agent in external cephalic version, 2008. Current Controlled Trials (www.controlled-trials.com) (accessed 12 May 2010).

\section{References to ongoing studies}

\section{Burgos 2012 \{published data only\}}

* Burgos J. Open randomized controlled trial to evaluate the efficacy and safety of remifentanil versus nitrous oxide in 
external cephalic version at term in singleton pregnancy in breech presentation (REMIVER), 2012. ClinicalTrials.gov (http://clinicaltrials.gov/) (accessed 21 May 2013).

Del-Rey L. Clinical trial to evaluate the efficacy and safety of two drugs for pain relieve for pregnant women whose fetus is breech, to attempt to turn the baby, 2011. EU Clinical Trials Register (accessed 31 May 2013).

\section{Passerini 2013 \{published data only\}}

Passerini CG. Maternal oral hydration and external cephalic version, 2013. ClinicalTrials.gov (http://clinicaltrials.gov/) (accessed 5 February 2014).

\section{Additional references}

\section{Belfort 1993}

Belfort MA. Intravenous nitroglycerin as a tocolytic agent for intrapartum external cephalic version. South African Medical Journal 1993;83:656.

\section{Benifla 1995}

Benifla JL, Goffinet F, Bascou V, Darai E, Proust A, Madelenat $P$. Transabdominal amnio-infusion facilitates external version maneuver after initial failure. Six successful attempts. Journal de Gynecologie, Obstetrique et Biologie de la Reproduction 1995;24:319-22.

\section{Bradley-Watson 1975}

Bradley-Watson PJ. The decreasing value of external cephalic version in modern obstetric practice. American Journal of Obstetrics and Gynecology 1975;123:237-40.

\section{Bricker 2002}

Bricker L, Lavender T. Parenteral opioids for labor pain relief: a systematic review. American Journal of Obstetrics and Gynecology 2002;186(5 Suppl):S94-S109.

\section{Brosset 1956}

Brosset A. The value of prophylactic external version in cases of breech presentation. Acta Obstetricia et Gynecologica Scandinavica 1956;35:555-62.

\section{Carlan 1994}

Carlan SJ, Dent JM, Huckaby T, Whittington EC, Shaefer $D$. The effect of epidural anesthesia on safety and success of external cephalic version at term. Anesthesia and Analgesia 1994;79:525-8.

\section{Coyle 2012}

Coyle ME, Smith CA, Peat B. Cephalic version by moxibustion for breech presentation. Cochrane Database of Systematic Reviews 2012, Issue 5. DOI: 10.1002/ 14651858.CD003928.pub3

\section{Danielian 1996}

Danielian PJ, Wang J, Hall MH. Long term outcome by method of delivery of fetuses in breech presentation at term: population based follow up. BMJ 1996;312:1451-3.

\section{Grade 2014 [Computer program]}

McMaster University. GRADEpro. [Computer program on www.gradepro.org]. Version 2014. McMaster University,

\section{Hickok 1992}

Hickok DE, Gordon DC, Milberg JA, Williams MA, Daling JR. The frequency of breech presentation by gestational age at birth: a large population-based study. American Journal of Obstetrics and Gynecology 1992;166(3):851-2.

Higgins 2011

Higgins JPT, Green S, editors. Cochrane Handbook for Systematic Reviews of Interventions Version 5.1.0 [updated March 2011]. Available from The Cochrane Collaboration, 2011. www.cochrane-handbook.org.

\section{Hofmeyr 1989}

Hofmeyr GJ. Breech presentation and abnormal lie in late pregnancy. In: Chalmers I, Enkin MW, Keirse MJNC editor(s). Effective Care in Pregnancy and Childbirth. Oxford: Oxford University Press, 1989:653-65.

\section{Hofmeyr 1991}

Hofmeyr GJ. External cephalic version at term: how high are the stakes?. British Journal of Obstetrics and Gynaecology 1991; 98:1-3.

\section{Hofmeyr 1992}

Hofmeyr GJ. Breech presentation and shoulder dystocia in childbirth. Current Opinion in Obstetrics and Gynecology 1992;4:807-12.

\section{Hofmeyr 1993} Hofmeyr GJ. External cephalic version at term. Fetal Maternal Medicine Review 1993;5:213-22.

\section{Hofmeyr 1996} Hofmeyr GJ, Kulier R. External cephalic version for breech presentation at term. Cochrane Database of Systematic Reviews 1996, Issue 1. DOI: 10.1002/ 14651858.CD000083

\section{Hofmeyr 2002} Hofmeyr GJ, Gülmezoglu AM. Maternal hydration for increasing amniotic fluid volume in oligohydramnios and normal amniotic fluid volume. Cochrane Database of Systematic Reviews 2002, Issue 1. DOI: 10.1002/ 14651858.CD000134

\section{Hofmeyr 2003}

Hofmeyr GJ, Hannah ME. Planned caesarean section for term breech delivery. Cochrane Database of Systematic Reviews 2003, Issue 2. DOI: 10.1002/ 14651858.CD000166

\section{Hofmeyr 2012a}

Hofmeyr GJ, Kulier R. External cephalic version for breech presentation at term. Cochrane Database of Systematic Reviews 2012, Issue 10. DOI: 10.1002/ 14651858.CD000083.pub2

\section{Hofmeyr 2012b} Hofmeyr GJ, Kulier R. Cephalic version by postural management for breech presentation. Cochrane Database of Systematic Reviews 2012, Issue 10. DOI: 10.1002/ 14651858.CD000051.pub2

\section{Hofmeyr 2014}

Hofmeyr GJ. External cephalic version. UpToDate, Waltham, Post TW (Ed), UptoDate, MA (Accessed October 2014). 


\section{Hutton 2006}

Hutton EK, Hofmeyr GJ. External cephalic version for breech presentation before term. Cochrane Database of Systematic Reviews 2006, Issue 1. DOI: 10.1002/ 14651858.CD000084.pub2

\section{Lau 1997}

Lau TK, Lo KW, Wan D, Rogers MS. Predictors of successful external cephalic version at term: a prospective study. British Journal of Obstetrics and Gynaecology 1997; 104(7):798-802.

\section{Neiger 1998a}

Neiger R, Hennessy M, Patel M. Reattempting failed external cephalic version under epidural anesthesia. American Journal of Obstetrics and Gynecology 1998;178(1): S71.

\section{Neiger 1998b}

Neiger R, Hennessy MD, Patel M. Reattempting failed external cephalic version under epidural anesthesia. American Journal of Obstetrics and Gynecology 1998;179(5): 1136-9.

\section{Reddick 1997}

Reddick LF, Livingston E, Bell E. Sublingual aerosol nitroglycerin for uterine relaxation in attempted external version. American Journal of Obstetrics and Gynecology 1997; 176:496-7.

\section{RevMan 2014 [Computer program]}

The Cochrane Collaboration. Review Manager (RevMan). Version 5.3. Copenhagen, The Nordic Cochrane Centre: The Cochrane Collaboration, 2014.

\section{Schunemann 2009}

Schunemann HJ. GRADE: from grading the evidence to developing recommendations. A description of the system and a proposal regarding the transferability of the results of clinical research to clinical practice [GRADE: Von der Evidenz zur Empfehlung. Beschreibung des Systems und Losungsbeitrag zur Ubertragbarkeit von Studienergebnissen]. Zeitschrift fur Evidenz, Fortbildung und Qualitat im Gesundheitswesen 2009;103(6):391-400. [PUBMED: 19839216]

\section{Smith 2000}

Smith P, Anthony J, Johanson R. Nifedipine in pregnancy. British Journal of Obstetrics and Gynaecology 2000;107(3): 299-307.

\section{Valero 2010}

Valero CA. Remifentanil versus paracetamol for pain treatment external cephalic versions, 2010. ClinicalTrials.gov (http://clinicaltrials.gov/) (accessed 21 May 2013).

Whyte 2004

Whyte H, Hannah ME, Saigal S, Hannah WJ, Hewson $\mathrm{S}$, Amankwah K, et al. Outcomes of children at 2 years after planned cesarean birth versus planned vaginal birth for breech presentation at term: the International Randomized Term Breech Trial. American Journal of Obstetrics and Gynecology 2004;191(3):864-71.

\section{Zhang 1993}

Zhang J, Bowes WA, Fortney JA. Efficacy of external cephalic version: a review. Obstetrics and Gynecology 1993; 82:306-12.

\section{References to other published versions of this review}

\section{Cluver 2012}

Cluver CA, Hofmeyr GJ, Gyte GML, Sinclair M. Interventions for helping to turn term breech babies to head first presentation when using external cephalic version. Cochrane Database of Systematic Reviews 2012, Issue 1. DOI: 10.1002/14651858.CD000184.pub3

\section{Hofmeyr 1995}

Hofmeyr GJ. Routine tocolysis for external cephalic version at term. [revised 04 October 1993]. In: Enkin MW, Keirse MJNC, Renfrew MJ, Neilson JP, Crowther C (eds.) Pregnancy and Childbirth Module. In: The Cochrane Pregnancy and Childbirth Database [database on disk and CDROM]. The Cochrane Collaboration; Issue 2, Oxford: Update Software; 1995.

\section{Hofmeyr 2004}

Hofmeyr GJ, Gyte GML. Interventions to help external cephalic version for breech presentation at term. Cochrane Database of Systematic Reviews 2004, Issue 1. DOI: 10.1002/14651858.CD000184.pub2

* Indicates the major publication for the study 


\section{CHARACTERISTICS OF STUDIES}

\section{Characteristics of included studies [ordered by study ID]}

Bujold 2003a

\begin{tabular}{|c|c|}
\hline Methods & RCT. \\
\hline Participants & $\begin{array}{l}\text { Inclusion criteria: women with singleton breech pregnancy at } 36 \text { to } 40 \text { weeks' gestation } \\
\text { Women also given NST and US evaluation for EFW, fetal morphologic features, AFI and } \\
\text { placental location. After NST, if women met criteria, clinician verified breech mobility } \\
\text { by abdominal palpation. N = } 99 \\
\text { Exclusion criteria: IUGR (defined as an EFW (determined by US examination, < 10th } \\
\text { percentile for GA), oligohydramnios (defined as AFI } \leq 5 \mathrm{~cm} \text { ), presence of a placenta pre- } \\
\text { via or an abruptio placenta, a previous uterine scar other than a low transverse caesarean } \\
\text { delivery, active labour, rupture of membranes, fetal anomalies incompatible with life, a } \\
\text { non-mobile breech by abdominal palpation, any contraindication to vaginal delivery, a } \\
\text { medical/allergic contraindication to nitroglycerine }\end{array}$ \\
\hline
\end{tabular}

Interventions

Intervention: tocolysis: nitroglycerine - nitric oxide donor (A3) - sublingual.

2 sublingual sprays of 400 micrograms nitroglycerine given 3 minutes before $\mathrm{ECV}$. $\mathrm{N}=$ 50

Comparison: placebo: 2 sublingual sprays of placebo given 3 minutes before ECV. $\mathrm{N}=$ 49

Outcomes

ECV success (at end of procedure); vertex presentation at labour and at birth; vaginal birth; CS; headache; blood pressure; maternal tachycardia; birthweight

Notes Sainte-Justine Hospital, April 1999 to August 2002.

\section{Risk of bias}

\begin{tabular}{l|l|l}
\hline Bias & Authors' judgement & Support for judgement \\
\hline $\begin{array}{l}\text { Random sequence generation (selection } \\
\text { bias) }\end{array}$ & Low risk & Computerised randomisation table. \\
\hline $\begin{array}{l}\text { Allocation concealment (selection bias) } \\
\text { Blinding of participants and personnel } \\
\text { (performance bias) } \\
\text { All outcomes }\end{array}$ & Low risk & Placebo-controlled trial with identical preparations. \\
\hline $\begin{array}{l}\text { Blinding of outcome assessment (detection } \\
\text { bias) } \\
\text { All outcomes }\end{array}$ & Low risk & $\begin{array}{l}\text { Participants, clinician and assessor were blinded. Intravenous } \\
\text { ritodrine and placebo were supplied in identical form; sublingual } \\
\text { nitroglycerine and placebo were also supplied in identical form } \\
\text { by the hospital pharmacy }\end{array}$ \\
\hline & & $\begin{array}{l}\text { Participants, clinician and assessor were blinded. Intravenous } \\
\text { ritodrine and placebo were supplied in identical form; sublingual } \\
\text { nitroglycerine and placebo were also supplied in identical form } \\
\text { by the hospital pharmacy }\end{array}$ \\
\hline
\end{tabular}


Bujold 2003a (Continued)

\begin{tabular}{|c|c|c|}
\hline $\begin{array}{l}\text { Incomplete outcome data (attrition bias) } \\
\text { All outcomes }\end{array}$ & Low risk & $\begin{array}{l}\text { No indication of loss of participants. } \\
\text { Not mentioned whether the analysis was intention-to-treat; ap- } \\
\text { pears that a total of } 99 \text { women were randomly assigned and all } \\
\text { completed }\end{array}$ \\
\hline Selective reporting (reporting bias) & Unclear risk & $\begin{array}{l}\text { We did not assess the trial protocol, but the trial authors said } \\
\text { they would compare the rate of vertex presentation at time of } \\
\text { birth and the rate of vertex vaginal birth. They reported only } \\
\text { that there was no difference and have not provided data. Other } \\
\text { outcomes may also be left out }\end{array}$ \\
\hline Other bias & High risk & $\begin{array}{l}\text { Halfway through the trial, an interim analysis was performed by } \\
\text { the data safety monitoring board. This board decided to stop the } \\
\text { trial because of a statistically significant (P value }<0.01 \text { ) higher } \\
\text { rate of side effects and a trend toward a lower rate of successful } \\
\text { ECV in } 1 \text { group. This decision was based on the likelihood (< } \\
1 \% \text { ) that that group would ultimately show a significant increase } \\
\text { in the success rate of ECV, and the likelihood ( }>95 \%) \text { that the } \\
\text { subsequently randomly assigned women would be exposed to } \\
\text { increased risk of adverse outcomes without potential benefit if } \\
\text { the trial was completed. Investigators were informed, and the } \\
\text { trial was stopped } \\
\text { No statistically significant differences were observed between the } \\
2 \text { groups with regard to maternal age, GA, EFW, AFI, placental } \\
\text { location and type of breech }\end{array}$ \\
\hline
\end{tabular}

Bujold 2003b

Methods

Participants
RCT.

Inclusion: women with singleton breech pregnancy at 36 to 40 weeks' gestation. $\mathrm{N}=$ 74

Exclusion criteria: IUGR, oligohydramnios, placenta praevia, placenta abruptio, uterine scar other than low transverse CS, active labour, ruptured membranes, fetal anomalies incompatible with life, any contraindication to vaginal birth, contraindications to trial medications, non-reactive CTG. CTG and US performed

Interventions

Intervention: tocolysis - nitroglycerine - nitric oxide donor (A3) - sublingual.

Nitroglycerine, 2 sublingual sprays of 400 micrograms nitroglycerine plus IV placebo. $\mathrm{N}=38$

Comparison: tocolysis - ritodrine - beta stimulant (A1) - parenteral.

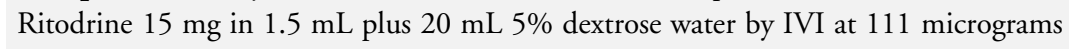
per minute, plus placebo sublingual spray. $\mathrm{N}=36$

Maximum 4 ECV attempts with US control.

Outcomes

Rate of successful ECV; headaches; blood pressure; maternal heart rate; palpitations, hypotension and prolonged fetal heart rate decelerations (fetal bradycardia) 
Bujold 2003b (Continued)

\begin{tabular}{|c|c|c|}
\hline Notes & \multicolumn{2}{|c|}{ Sainte-Justine Hospital, April 1999 to August 2001.} \\
\hline \multicolumn{3}{|l|}{ Risk of bias } \\
\hline Bias & Authors' judgement & Support for judgement \\
\hline $\begin{array}{l}\text { Random sequence generation (selection } \\
\text { bias) }\end{array}$ & Low risk & $\begin{array}{l}\text { Computerised table of randomisation. For every } 6 \text { women who } \\
\text { were entered, } 3 \text { women were assigned to the ritodrine group and } \\
3 \text { women were assigned to the nitroglycerine group }\end{array}$ \\
\hline Allocation concealment (selection bias) & Low risk & Placebo-controlled trial with identical preparations. \\
\hline $\begin{array}{l}\text { Blinding of participants and personnel } \\
\text { (performance bias) } \\
\text { All outcomes }\end{array}$ & Low risk & $\begin{array}{l}\text { IV ritodrine and placebo were supplied by the hospital pharmacy } \\
\text { in identical form; sublingual nitroglycerine and placebo were } \\
\text { also supplied by the hospital pharmacy in identical form. The } \\
\text { nurse and the attending physician were blinded to the contents } \\
\text { of the infusion or the sublingual spray }\end{array}$ \\
\hline $\begin{array}{l}\text { Blinding of outcome assessment (detection } \\
\text { bias) } \\
\text { All outcomes }\end{array}$ & Low risk & $\begin{array}{l}\text { IV ritodrine and placebo were supplied by the hospital pharmacy } \\
\text { in identical form; sublingual nitroglycerine and placebo were } \\
\text { also supplied by the hospital pharmacy in identical form. Staff } \\
\text { were blinded }\end{array}$ \\
\hline $\begin{array}{l}\text { Incomplete outcome data (attrition bias) } \\
\text { All outcomes }\end{array}$ & Low risk & $\begin{array}{l}\text { No indication suggested that any women were excluded after } \\
\text { randomisation or were lost to follow-up }\end{array}$ \\
\hline Selective reporting (reporting bias) & Unclear risk & We did not assess the trial protocol. \\
\hline Other bias & Unclear risk & $\begin{array}{l}\text { Study stopped after } 74 \text { women were enrolled because ritodrine } \\
\text { was withdrawn from the market in July } 2001 \text { - not because of } \\
\text { benefit } \\
\text { No statistically significant differences between the } 2 \text { groups with } \\
\text { regard to maternal age, GA, maternal weight, AFI and Frank } \\
\text { breech. However, a significant difference was observed between } \\
\text { the } 2 \text { groups at admission with respect to mean blood pressure } \\
\text { (mm Hg)* at admission for the ritodrine group: } 98(67-125) \text {; } \\
\text { mean blood pressure }(\mathrm{mm} \mathrm{Hg})^{*} \text { at admission for the nitroglyc- } \\
\text { erine group: } 90(75-106)(\mathrm{P} \mathrm{value} 0.03)\end{array}$ \\
\hline
\end{tabular}

Chung 1996

\begin{tabular}{ll}
\hline Methods & RCT, stratified by parity. \\
\hline Participants & $\begin{array}{l}\text { Inclusion criteria: women with singleton breech presentation, as confirmed by US, at } \\
36 \text { to } 38 \text { weeks' gestation. } \mathrm{N}=51 \text { recruited but } 50 \text { analysed } \\
\text { Exclusion criteria: contraindication to tocolytic therapy, scarred uterus, antepartum } \\
\text { haemorrhage, hypertension, impaired fetal growth, oligohydramnios, vaginal delivery }\end{array}$
\end{tabular}

Interventions for helping to turn term breech babies to head first presentation when using external cephalic version (Review) 
contraindicated, abnormal umbilical artery Doppler flow pattern

Interventions

Intervention: tocolytic: ritodrine - beta stimulant (A1) - parenteral

IVI of ritodrine $0.4 \mathrm{mg} / \mathrm{mL}$ in $5 \%$ dextrose at $1.5 \mathrm{~mL} / \mathrm{min}$ via an infusion pump, for 15 minutes before and during ECV attempt. If uterine contractions appeared to be preventing successful version, the infusion rate was increased in steps of $0.75 \mathrm{~mL} / \mathrm{min}$. Compared with matching 5\% dextrose infusion. ECV attempted by 2 investigators, followed by repeat US scan and CTG. $\mathrm{N}=25$

Comparison: placebo: $\mathrm{N}=25$.

Outcomes

Failed ECV attempt. Other data presented according to successful or failed ECV attempt: non-cephalic presentation at birth (1/24 vs 23/26); CS (5/24 vs 19/26). 1 intrauterine death occurred 4 weeks after successful ECV (group not stated)

Subgroup analysis showed that statistically significant benefit was limited to nulliparous women

Notes

Paired sequential analysis reached significance after 10 pairs. Trial was continued because of erroneous statistical calculations. Thereafter little benefit was seen from tocolysis. Study authors suggest that tocolysis is helpful only during the learning phase of the technique. A subsequent trial (published earlier) from the same group showed no benefit of tocolysis (Stock 1993).

Nulliparous and parous women randomly assigned separately.

\section{Risk of bias}

\begin{tabular}{|c|c|c|}
\hline Bias & Authors' judgement & Support for judgement \\
\hline $\begin{array}{l}\text { Random sequence generation (selection } \\
\text { bias) }\end{array}$ & Low risk & $\begin{array}{l}\text { Computer-generated random numbers: sequential paired } \\
\text { design. }\end{array}$ \\
\hline Allocation concealment (selection bias) & High risk & $\begin{array}{l}\text { Randomisation code was known to } 1 \text { of the authors who } \\
\text { attended each woman throughout the procedure and for } 20 \\
\text { minutes thereafter. He did not take part in version attempts. } \\
\text { It is not clear whether allocation in pairs may have enabled } \\
\text { the unblinded study author to know the next allocation in } \\
\text { some cases, which could introduce selection bias, as could the } \\
\text { study author knowing the code even if he did not undertake } \\
\text { the procedure }\end{array}$ \\
\hline
\end{tabular}

Blinding of participants and personnel Unclear risk (performance bias)

All outcomes

Blinding of outcome assessment (detection Unclear risk bias)

All outcomes
Participant was blinded; 2 doctors who attempted the version were blind to randomisation throughout, but the code was known to a third review author, who was in attendance throughout

Participant was blinded; 2 doctors who attempted the version were blind to randomisation throughout, but the code was known to a third review author, who was in attendance throughout 


\begin{tabular}{l|l|l}
\hline $\begin{array}{l}\text { Incomplete outcome data (attrition bias) } \\
\text { All outcomes }\end{array}$ & Low risk & $\begin{array}{l}1 \text { woman was excluded because of absent end-diastolic flow } \\
\text { in the umbilical artery before commencement of the proce- } \\
\text { dure (unclear whether they were excluded before randomi- } \\
\text { sation) } \\
\text { Unclear whether the analysis was intention-to-treat. }\end{array}$ \\
\hline Selective reporting (reporting bias) & Unclear risk & We did not assess the trial protocol. \\
\hline Other bias & Unclear risk & $\begin{array}{l}\text { Groups judged by study authors to be similar in age, parity } \\
\text { and mean gestation (Table 1, page 721) }\end{array}$ \\
\hline
\end{tabular}

\section{Collaris 2009}

\begin{tabular}{ll}
\hline Methods & RCT. \\
\hline Participants & $\begin{array}{l}\text { Inclusion criteria: woman not in labour, with singleton pregnancy in breech or transverse } \\
\text { lie at } 36 \text { to } 41 \text { weeks' gestation. } \mathrm{N}=90 \\
\text { Exclusion criteria: in keeping with recommendations of the American College of Ob- } \\
\text { stetricians and Gynecologists on ECV }\end{array}$ \\
\hline Interventions & $\begin{array}{l}\text { Intervention: tocolytic: nifedipine - calcium channel blocker (A2) - oral. } \\
\text { Oral nifedipine (10 mg) and SQ saline placebo. N = 44. } \\
\text { Comparison: tocolytic: terbutaline - beta stimulant (A1) - parenteral. } \\
\text { Subcutaenous terbutaline (250 micrograms) with oral placebo. N = 46 }\end{array}$ \\
\hline Outcomes & $\begin{array}{l}\text { Primary outcomes were successful ECV and CS. } \\
\text { Secondary outcomes were cephalic fetal presentation at delivery, numerical rating score } \\
\text { for satisfaction with ECV, preference for injection or tablet, post ECV. Also, CTG } \\
\text { assessment, labour onset, prelabour membrane rupture and various neonatal outcomes }\end{array}$ \\
\hline Notes & $\begin{array}{l}\text { Women who had a failed ECV on first attempt could be re-randomised. Study authors } \\
\text { did a primary analysis on } 90 \text { women, but then undertook a secondary analysis by adding } \\
\text { in repeat ECV attempts. We will consider only the primary analysis data }\end{array}$ \\
\hline
\end{tabular}

\section{Risk of bias}

\section{Bias \\ Authors' judgement Support for judgement}

Random sequence generation (selection Low risk bias)

Allocation concealment (selection bias) Low risk

Blinding of participants and personnel Low risk (performance bias)

All outcomes
Computer-generated, variable blocks of 8 or 12 .

No indication that this was an issue; did use sequential opening of sealed opaque envelopes

Participants and providers blinded; unclear whether outcome assessor was blinded 
Collaris 2009 (Continued)

\begin{tabular}{|c|c|c|}
\hline $\begin{array}{l}\text { Blinding of outcome assessment (detection } \\
\text { bias) } \\
\text { All outcomes }\end{array}$ & Unclear risk & $\begin{array}{l}\text { Participants and providers blinded; unclear whether outcome } \\
\text { assessor was blinded }\end{array}$ \\
\hline $\begin{array}{l}\text { Incomplete outcome data (attrition bias) } \\
\text { All outcomes }\end{array}$ & Low risk & $\begin{array}{l}\text { For some outcomes, data were collected only for a subset of } \\
\text { participants; CTGs of } 7 \text { women }(7 \%) \text { were missing from the } \\
\text { files } \\
\text { Analysis of participants at primary enrolment was performed } \\
\text { on an intention-to-treat basis. All women received treatment as } \\
\text { allocated }\end{array}$ \\
\hline Selective reporting (reporting bias) & Unclear risk & We did not assess the trial protocol. \\
\hline Other bias & Low risk & $\begin{array}{l}\text { No significant differences were noted in baseline criteria; no } \\
\text { other biases were apparent }\end{array}$ \\
\hline
\end{tabular}

Delisle 2001

\begin{tabular}{ll}
\hline Methods & RCT. \\
\hline Participants & $\begin{array}{l}\text { Inclusion criteria: singleton non-vertex; age } 18 \text { or older; GA } 36 \text { weeks or more; intact } \\
\text { membranes; reactive CTG. } \mathrm{N}=141\end{array}$ \\
\hline Interventions & $\begin{array}{l}\text { Intervention: regional analgesia (C). } \\
\text { Spinal analgesia with bupivacaine } 0.25 \% 1 \mathrm{~mL} \text { plus } 20 \text { mcg fentanyl vs control; } 4 \text { ECV } \\
\text { attempts. } \mathrm{N}=73 \\
\text { Comparison: standard care. } \mathrm{N}=68 . \\
\text { Nitroglycerine tocolysis was used per operator preference. }\end{array}$ \\
\hline Outcomes & ECV failure; non-reassuring CTG (1/73 vs 0/68). \\
\hline Notes & Conference abstract, August 1998 to June 2001. \\
\hline
\end{tabular}

Risk of bias

Bias

Random sequence generation (selection Unclear risk bias)

Allocation concealment (selection bias) Unclear risk No information given.

Blinding of participants and personnel High risk (performance bias)

Participants and clinicians were not blinded; unclear whether All outcomes outcome assessor was blinded 
Delisle 2001 (Continued)

\begin{tabular}{|c|c|c|}
\hline $\begin{array}{l}\text { Blinding of outcome assessment (detection } \\
\text { bias) } \\
\text { All outcomes }\end{array}$ & Unclear risk & $\begin{array}{l}\text { Participants and clinicians were not blinded; unclear whether } \\
\text { outcome assessor was blinded }\end{array}$ \\
\hline $\begin{array}{l}\text { Incomplete outcome data (attrition bias) } \\
\text { All outcomes }\end{array}$ & Unclear risk & Little information given. \\
\hline Selective reporting (reporting bias) & Unclear risk & We did not assess the trial protocol. \\
\hline Other bias & High risk & $\begin{array}{l}\text { Baseline data: reported as similar in maternal age, GA at time } \\
\text { of ECV, parity and birthweight. However, clinicians, who were } \\
\text { not blinded to the intervention, were able to give IV tocolysis } \\
\text { by choice; this could lead to an imbalance between groups. No } \\
\text { information on this is given in the Conference abstract, but this } \\
\text { is a potential source of bias }\end{array}$ \\
\hline
\end{tabular}

\section{Dugoff 1999}

Methods

Participants

Interventions

RCT.

Inclusion criteria: breech presentation, 36 weeks or more, reactive CTG, intact membranes, minimum $2 \times 2 \mathrm{~cm}$ pocket of amniotic fluid. $\mathrm{N}=102$ in the main paper (in abstract, reported as 101 women)

Exclusion criteria: gross fetal anomaly, uterine malformation, EFW $>4000 \mathrm{~g}$, fetal growth restriction, placenta praevia, third-trimester vaginal bleeding, labour, contraindications to spinal analgesia or terbutaline

Intervention: regional analgesia $(\mathrm{C})+$ tocolytic.

Spinal analgesia with $10 \mathrm{mcg}$ sufentanil and $1 \mathrm{~mL} 0.25 \%$ bupivacaine and $500 \mathrm{~mL}$ lactated Ringer's prehydration. $\mathrm{N}=50$ (49 in abstract; we will use detail from the detailed publication)

Comparison: standard care + tocolytic. $\mathrm{N}=52$.

ECV with terbutaline $0.25 \mathrm{mg}$ was attempted usually by 2 operators, and was stopped for fetal bradycardia, maternal discomfort. Up to 4 attempts were allowed. Vaginal elevation of the presenting part not used

\begin{tabular}{ll}
\hline Outcomes & Successful ECV; breech delivery; CS. \\
\hline Notes & $\begin{array}{l}\text { University of Colorado Health Sciences Centre and Denver Health Medical Centre, } \\
\text { USA. October } 1993 \text { to August } 1997\end{array}$ \\
\hline
\end{tabular}

\section{Risk of bias}

\begin{tabular}{l|l|l} 
Bias & Authors' judgement & Support for judgement \\
\hline $\begin{array}{l}\text { Random sequence generation (selection } \\
\text { bias) }\end{array}$ & Low risk & Randomised, computer-generated sequence.
\end{tabular}

Interventions for helping to turn term breech babies to head first presentation when using external cephalic version (Review) 


\begin{tabular}{|c|c|c|}
\hline Allocation concealment (selection bias) & Unclear risk & $\begin{array}{l}\text { Allocation by cards in sealed envelopes. Cards designating } \\
\text { "spinal" or "no spinal" were placed in sealed opaque envelopes } \\
\text { that were opened after women signed informed consent forms }\end{array}$ \\
\hline $\begin{array}{l}\text { Blinding of participants and personnel } \\
\text { (performance bias) } \\
\text { All outcomes }\end{array}$ & Unclear risk & $\begin{array}{l}\text { Likely that the women and the clinician were not blinded to } \\
\text { whether or not women received an epidural }\end{array}$ \\
\hline $\begin{array}{l}\text { Blinding of outcome assessment (detection } \\
\text { bias) } \\
\text { All outcomes }\end{array}$ & Unclear risk & No mention of whether investigators were blinded. \\
\hline $\begin{array}{l}\text { Incomplete outcome data (attrition bias) } \\
\text { All outcomes }\end{array}$ & Low risk & $\begin{array}{l}\text { Spontaneous version occurred before ECV in } 4 \text { women in the } \\
\text { spinal group (after the spinal was given) and in } 1 \text { woman in the } \\
\text { no spinal group. These women were included in the intention- } \\
\text { to-treat analysis }\end{array}$ \\
\hline Selective reporting (reporting bias) & Unclear risk & We did not assess the trial protocol. \\
\hline Other bias & Low risk & No differences in baseline characteristics were noted. \\
\hline
\end{tabular}

\section{El-Sayed 2004}

\begin{tabular}{|c|c|}
\hline Methods & RCT - with cross-over for some unsuccessful ECVs. \\
\hline Participants & $\begin{array}{l}\text { Inclusion criteria: term singleton pregnancy with breech presentation. } \mathrm{N}=59 \text {. } \\
\text { Exclusion criteria: Maternal exclusion criteria included chronic hypertension, } \\
\text { preeclampsia, placental abruption, placenta praevia, maternal cardiac disease, chorioam- } \\
\text { nionitis and previous uterine surgery } \\
\text { Fetal exclusion criteria included ruptured membranes, IUGR (EFW }<10 \text { th centile for } \\
\text { GA by US), decreased AFI or oligohydramnios, fetal anomalies incompatible with life } \\
\text { and an extended fetal head }\end{array}$ \\
\hline Interventions & $\begin{array}{l}\text { Intervention: tocolytic: nitroglycerine - nitric oxide donor (A3) - parenteral. } \\
\text { IV nitroglycerin }(100 \mu \mathrm{g} I V \times 2) . \mathrm{N}=30 \text {. } \\
\text { Comparison: tocolytic: terbutaline - beta stimulant (A1) - parenteral. } \\
\text { Terbutaline }(0.25 \mathrm{mg} \mathrm{SQ}) . \mathrm{N}=29 \text {. } \\
\text { After successful } \mathrm{ECV} \text {, the decision to induce then or wait for spontaneous labour was } \\
\text { left to the doctor. After failed } \mathrm{ECV} \text {, the options were intervention with the other drug } \\
\text { in the trial, discharge with appointment for CS or immediate CS; the decision was left } \\
\text { to the doctor }\end{array}$ \\
\hline Outcomes & $\begin{array}{l}\text { Successful ECV; difficult ECV; palpitations; headaches; method of delivery; light-head- } \\
\text { edness; flushing; reversion (back to breech after ECV) }\end{array}$ \\
\hline Notes & $\begin{array}{l}\text { We have used only data on initial "Failed ECV" because of the cross-over element of this } \\
\text { study. We are contacting study authors to clarify the other outcome data }\end{array}$ \\
\hline
\end{tabular}


El-Sayed 2004 (Continued)

\section{Risk of bias}

\begin{tabular}{|c|c|c|}
\hline Bias & Authors' judgement & Support for judgement \\
\hline $\begin{array}{l}\text { Random sequence generation (selection } \\
\text { bias) }\end{array}$ & Low risk & $\begin{array}{l}\text { Randomisation done by a third party not } \\
\text { involved in the trial. } 30 \text { labels bearing the } \\
\text { word 'nitroglycerin' and } 30 \text { labels bearing } \\
\text { the word 'terbutaline.' Labels were placed } \\
\text { on } 60 \text { unmarked opaque envelopes, which } \\
\text { were sealed, shuffled thoroughly and num- } \\
\text { bered sequentially }\end{array}$ \\
\hline Allocation concealment (selection bias) & Low risk & $\begin{array}{l}\text { Labels were placed on } 60 \text { unmarked opaque } \\
\text { envelopes, which were sealed and num- } \\
\text { bered sequentially }\end{array}$ \\
\hline
\end{tabular}

Blinding of participants and personnel High risk (performance bias)

No blinding of participant or doctor. Dif-

All outcomes

fering routes of administration of drugs, IV or SQ, meant that people would know which drug was being administered

Blinding of outcome assessment (detection Unclear risk

Unclear whether the assessor was blinded.

bias)

All outcomes

Incomplete outcome data (attrition bias) Low risk

All outcomes
1 woman was assigned to terbutaline before it was confirmed that the baby was breech; excluded as fetus had a cephalic presentation. This was considered insufficient to influence the analysis

\begin{tabular}{l|l|l}
\hline Selective reporting (reporting bias) & Unclear risk & We did not assess the trial protocol. \\
\hline Other bias & Low risk & $\begin{array}{l}\text { No statistically significant differences in } \\
\text { pretreatment maternal or fetal characteris- } \\
\text { tics (see Table 1, on p 2053). These were } \\
\text { maternal age, GA at ECV, multiparity, }\end{array}$ \\
& $\begin{array}{l}\text { EFW, body mass index, anterior placenta } \\
\text { and ECV by maternal-fetal medicine at- } \\
\text { tending }\end{array}$ \\
\hline
\end{tabular}


Fernandez 1997

\begin{tabular}{|c|c|c|}
\hline Methods & \multicolumn{2}{|l|}{ RCT. } \\
\hline Participants & \multicolumn{2}{|c|}{$\begin{array}{l}\text { Inclusion criteria: singleton, non-cephalic pregnancy; > } 36 \text { weeks' gestation. } \mathrm{N}=103 \\
\text { Exclusion criteria: younger than } 17 \text { years of age, prior uterine surgery, ruptured mem- } \\
\text { branes, placenta praevia, anomalous fetus, multiple gestation, sensitivity to terbutaline, } \\
\text { other maternal medical complications }\end{array}$} \\
\hline Interventions & \multicolumn{2}{|c|}{$\begin{array}{l}\text { Intervention: tocolytic: terbutaline - beta stimulant }(\mathrm{A} 1) \text { - parenteral. } \\
\text { Terbutaline } 0.25 \mathrm{mg} \text { in unlabelled insulin syringe given SQ } 15 \text { to } 30 \text { minutes before } \\
\text { ECV attempts. Forward then backward roll attempted. } \mathrm{N}=52 \\
\text { Comparison: placebo. } \mathrm{N}=51 \text {. }\end{array}$} \\
\hline Outcomes & \multicolumn{2}{|l|}{ Successful ECV; CS. } \\
\hline Notes & \multicolumn{2}{|c|}{ Parkland Memorial Hospital, Dallas, Texas, USA. January 1994 to June 1995} \\
\hline \multicolumn{3}{|l|}{ Risk of bias } \\
\hline Bias & Authors' judgement & Support for judgement \\
\hline $\begin{array}{l}\text { Random sequence generation (selection } \\
\text { bias) }\end{array}$ & Low risk & $\begin{array}{l}\text { Randomised computer tables - randomisation by pharmacy us- } \\
\text { ing computer-generated random sequence }\end{array}$ \\
\hline Allocation concealment (selection bias) & Unclear risk & No mention in article. \\
\hline $\begin{array}{l}\text { Blinding of participants and personnel } \\
\text { (performance bias) } \\
\text { All outcomes }\end{array}$ & Low risk & $\begin{array}{l}\text { Terbutaline or placebo obtained from pharmacy in unlabelled } \\
\text { syringe. Placebo was an equal volume of normal saline }\end{array}$ \\
\hline $\begin{array}{l}\text { Blinding of outcome assessment (detection } \\
\text { bias) } \\
\text { All outcomes }\end{array}$ & Low risk & Placebo-controlled trial with blinding of staff. \\
\hline $\begin{array}{l}\text { Incomplete outcome data (attrition bias) } \\
\text { All outcomes }\end{array}$ & Low risk & $\begin{array}{l}\text { No exclusion of women or loss to follow-up. Appears to be an } \\
\text { intention-to-treat analysis }\end{array}$ \\
\hline Selective reporting (reporting bias) & Unclear risk & We did not assess the trial protocol. \\
\hline Other bias & Low risk & $\begin{array}{l}\text { With exception of maternal age, the } 2 \text { groups did not differ at } \\
\text { baseline. Mean age for terbutaline group: } 23.4 \text {. Mean age for } \\
\text { placebo group: } 25.7\end{array}$ \\
\hline
\end{tabular}


Hilton 2009

\begin{tabular}{ll}
\hline Methods & RCT, stratified by parity and hospital. \\
\hline Participants & $\begin{array}{l}\text { Inclusion criteria: non-cephalic singleton pregnancies over } 37 \text { weeks with normal AFI. } \\
\text { Participants split into nulliparous }(\mathrm{N}=82) \text { and multiparous }(\mathrm{N}=44) . \mathrm{N}=126\end{array}$ \\
$\begin{array}{l}\text { Exclusion criteria: labour, ruptured membranes, history of third-trimester bleeding, } \\
\text { any preexisting uterine scar, pregnancy-induced hypertension or gestational diabetes, } \\
\text { oligohydramnios, hydramnios, IUGR, macrosomia, maternal hypotension, inability to } \\
\text { comprehend the consent form }\end{array}$ \\
\hline
\end{tabular}

\begin{tabular}{ll} 
Interventions & $\begin{array}{l}\text { Intervention: tocolytic: nitroglycerine - nitric oxide donor (A3) parenteral. } \\
\text { IV nitroglycerine }(10 \mathrm{~mL} \text { of } 100 \text { micrograms } / \mathrm{mL}) \cdot \mathrm{N}=65 \text { (nulliparous }=42, \text { multiparous } \\
=23) \\
\text { Comparison: placebo. } \mathrm{N}=61 \text { (nulliparous }=40 \text {, multiparous }=21) .\end{array}$ \\
\hline Outcomes & $\begin{array}{l}\text { ECV success; cephalic presentation at delivery; } \mathrm{CS} \text { rate; maternal discomfort; headaches; } \\
\text { flushing; hypotension; palpitations; fetal heart rate abnormalities }\end{array}$ \\
\hline Notes & $\begin{array}{l}\text { Nulliparous group: } 4 \text { women excluded after randomisation. In experimental group, } 1 \\
\text { excluded for pregnancy-induced hypertension, and } 1 \text { excluded for decreased AFI. Con- } \\
\text { trol group: } 1 \text { excluded as woman was in labour, and } 1 \text { excluded because of cephalic } \\
\text { presentation. } 1 \text { woman in placebo group lost to follow-up } \\
\text { Multiparous group: } 3 \text { women excluded after randomisation. In experimental group, } 2 \\
\text { excluded as presentation was cephalic at the time of version. In placebo group, } 1 \text { woman } \\
\text { excluded as presentation was cephalic at time of version }\end{array}$
\end{tabular}

Risk of bias

\begin{tabular}{l|l|l}
\hline Bias & Authors' judgement & Support for judgement \\
\hline $\begin{array}{l}\text { Random sequence generation (selection } \\
\text { bias) }\end{array}$ & Low risk & Randomisation tables used. \\
\hline Allocation concealment (selection bias) & Low risk & $\begin{array}{l}\text { Using separate randomisation sequences for } \\
\text { nulliparous and multiparous women at each } \\
\text { hospital site, participants were assigned a study } \\
\text { number from sequentially numbered opaque } \\
\text { envelopes. The study number was forwarded to } \\
\text { the pharmacy, and allocated treatment was pro- } \\
\text { vided on the basis of the corresponding study } \\
\text { number from randomisation tables kept in the } \\
\text { pharmacy. No further details provided on ran- } \\
\text { domisation sequences used }\end{array}$ \\
\hline Group of allocation was unknown to obstetri- \\
cian, nurse, anaesthesiologist and woman
\end{tabular}

Blinding of participants and personnel Low risk (performance bias)

All outcomes
Treatment was prepared as $10 \mathrm{~mL}$ of clear fluid in a $10 \mathrm{~mL}$ syringe with $10 \mathrm{~mL}$ of $100 \mathrm{mi}$ crograms $/ \mathrm{mL}$ of nitroglycerin for women in the nitroglycerin group, or $10 \mathrm{~mL}$ of normal 
Hilton 2009 (Continued)

saline for women in the placebo group. Syringes for nitroglycerine and placebo were visually indistinguishable. Group for allocation was unknown to obstetrician, nurse, anaesthesiologist and woman

Blinding of outcome assessment (detection Low risk bias)

All outcomes
Treatment was prepared as $10 \mathrm{~mL}$ of clear fluid in a $10 \mathrm{~mL}$ syringe with $10 \mathrm{~mL}$ of $100 \mathrm{mi}$ crograms $/ \mathrm{mL}$ of nitroglycerin for women in the nitroglycerin group, or $10 \mathrm{~mL}$ of normal saline for women in the placebo group. Syringes for nitroglycerine and placebo were visually indistinguishable. Group for allocation was unknown to obstetrician, nurse, anaesthesiologist and woman

1 woman lost to follow-up.

No apparent exclusion of women after randomisation.

7 women did not undergo ECV, but their outcomes were included in the analysis

Nulliparous group: 2 in nitroglycerine group excluded: 1 had pregnancy-induced hypertension, 1 had a decreased AFI

Nulliparous group: 2 in placebo group excluded: 1 cephalic, 1 lost to follow-up

Multiparous group: 2 in nitroglycerine group excluded: had cephalic presentations

Multiparous group: 1 in placebo group excluded: had cephalic presentation

Data on fetal heart rate abnormalities were available for 61 women in nitroglycerine group and 58 in placebo group; for side effects, the numbers were 59 and 58 , respectively

We did not assess the trial protocol.

Selective reporting (reporting bias)

Unclear risk

Baseline data: similar for maternal age, GA and anterior placenta in nulliparous and multiparous trials

Impey 2005

\section{Methods}

Participants

\section{RCT.}

Inclusion criteria: nulliparous women, singleton breech presentation at 36 weeks, or multiparous at 37 or more weeks. Eligible for inclusion if an unsuccessful attempt at ECV (without tocolysis) was reported, with normal CTG. $\mathrm{N}=144$ 
Exclusion criteria: preexisting indication for CS, unstable lie, fetal compromise (abdominal circumference below 3rd centile, either umbilical artery resistance index above 97 th centile or deepest amniotic fluid pocket $2 \mathrm{~cm}$, rhesus isoimmunisation

\begin{tabular}{ll} 
Interventions & $\begin{array}{l}\text { Intervention: tocolytic: ritodrine - beta stimulant (A1) - parenteral. } \\
\text { Tocolysis administered as ritodrine hydrochloride (Yutopar infusion of } 50 \mathrm{mg}(10 \mathrm{mg} / \\
\mathrm{mL}) \text { ) added to } 12 \mathrm{~mL} \text { dextrose saline (total } 17 \mathrm{~mL} \text { of ritodrine } 3 \mathrm{mg} / \mathrm{mL}) . \mathrm{N}=62 \\
\text { Comparison: placebo: } 17 \mathrm{~mL} \text { dextrose saline infusion by the same route at the same } \\
\text { rate. } \mathrm{N}=62\end{array}$ \\
\hline Outcomes & $\begin{array}{l}\text { Primary outcome cephalic presentation at birth. } \\
\text { Secondary outcomes: incidence of successful ECV, CS, length of hospital inpatient stay, } \\
\text { incidence of neonatal Apgar scores < } 7 \text { at } 5 \text { minutes, neonatal admission, rare neonatal } \\
\text { outcomes and mean cord arterial } \mathrm{pH} \text {. McGill pain scale was used to measure intensity } \\
\text { of pain }\end{array}$ \\
\hline
\end{tabular}
and other local hospitals were referred in at 36 or 37 weeks' gestation

\section{Risk of bias}

Bias

Random sequence generation (selection Low risk bias)

\section{Authors' judgement Support for judgement}

Randomly allocated in a ratio of 1:1 using random block sizes up to 20

\begin{tabular}{l|l|l}
\hline Allocation concealment (selection bias) $\quad$ Low risk $\quad$ Sealed opaque envelopes opened in sequential order.
\end{tabular}

Blinding of participants and personnel Unclear risk (performance bias)

All outcomes

Specific detail missing, but states same infusion, same timeline, same observation for both control and intervention In discussion, study authors identified problems with blinding of researcher and medical practitioner as potential threats

Blinding of outcome assessment (detection Unclear risk bias)

Specific detail missing, but states same infusion, same timeline, same observation for both control and intervention In discussion, study authors identified problems with blinding of researcher and medical practitioner as potential threats

Incomplete outcome data (attrition bias) Low risk All outcomes

Potential sample 505, of whom 284 were deemed eligible for inclusion in the trial. Of these, 13 refused and 47 were not offered

All 124 participants (62 in each arm) completed the trial. Intention-to-treat analysis.

Selective reporting (reporting bias)

Other bias
Unclear risk

Low risk
We did not assess the trial protocol.

No differences in age or gestation seen in baseline data. 


\begin{tabular}{|c|c|}
\hline Methods & RCT cross-over - using here only data from first part. \\
\hline Participants & $\begin{array}{l}\text { Inclusion criteria: women scheduled for attempted ECV with the fetal spine in the } \\
\text { midline (back-up or back-down) on US examination. } \mathrm{N}=26 \text {. All women approached } \\
\text { agreed to participate. } \\
\text { Exclusion criteria: oligohydramnios (AFI }<5 \mathrm{~cm} \text { ), fetal or uterine anomalies, ruptured } \\
\text { amniotic membranes, active labour, engagement of presenting part, fetal heart rate de- } \\
\text { celerations }\end{array}$ \\
\hline Interventions & $\begin{array}{l}\text { Intervention: vibroacoustic stimulation (B). } \\
\text { Fetal acoustic stimulation for } 1 \text { to } 3 \text { seconds with a Western Electric Division AT\&T } \\
\text { (Phoenix) model } 5 \mathrm{C} \text { electrolarynx over the fetal head, or over the nurse's upper arm } \\
\text { (dummy). Physician blinded by leaving the room during the intervention. } \mathrm{N}=12 \\
\text { Comparison: placebo. } \mathrm{N}=11 \text {. }\end{array}$ \\
\hline Outcomes & $\begin{array}{l}\text { Persistent midline spine position on US (stimulation } 1 / 13 \text {, control } 13 / 13 \text { ); failed ECV } \\
\text { attempt. Data on method of delivery not included because followed cross-over treatment }\end{array}$ \\
\hline Notes & $\begin{array}{l}2 \text { hospitals in Arizona, USA, } 1 \text { January } 1993 \text { to } 31 \text { December } 1994 \\
\text { After randomisation, } 1 \text { from the treatment group and } 2 \text { from the control group were } \\
\text { excluded because the breech was found to be deeply engaged in the pelvis during the } \\
\text { initial ECV attempt. None had changed position to the spine lateral position, and no } \\
\text { further attempts at ECV were made. In keeping with the pre-stated protocol for this } \\
\text { review, these women have been included in the outcomes as originally allocated } \\
\text { Those women in whom ECV failed were crossed over to the other intervention arm. } \\
\text { This review considers only data from the first intervention, according to the original } \\
\text { allocation Results of the 'cross-over' part of the study are not included }\end{array}$ \\
\hline
\end{tabular}

\section{Risk of bias}

\begin{tabular}{|c|c|c|}
\hline Bias & Authors' judgement & Support for judgement \\
\hline $\begin{array}{l}\text { Random sequence generation (selection } \\
\text { bias) }\end{array}$ & Low risk & Table of random numbers. \\
\hline Allocation concealment (selection bias) & Low risk & $\begin{array}{l}\text { Selection of sequential envelopes generated } \\
\text { by a table of random numbers and handed } \\
\text { out by research nurse }\end{array}$ \\
\hline $\begin{array}{l}\text { Blinding of participants and personnel } \\
\text { (performance bias) } \\
\text { All outcomes }\end{array}$ & Unclear risk & $\begin{array}{l}\text { Clinicians were blinded, but the nurse ap- } \\
\text { plying the stimulation and the women } \\
\text { could not be blinded }\end{array}$ \\
\hline $\begin{array}{l}\text { Blinding of outcome assessment (detection } \\
\text { bias) } \\
\text { All outcomes }\end{array}$ & Unclear risk & $\begin{array}{l}\text { Clinicians reported blinded, but the nurse } \\
\text { applying the stimulation and the women } \\
\text { could not be blinded }\end{array}$ \\
\hline
\end{tabular}

Interventions for helping to turn term breech babies to head first presentation when using external cephalic version (Review) 


\begin{tabular}{|c|c|c|}
\hline $\begin{array}{l}\text { Incomplete outcome data (attrition bias) } \\
\text { All outcomes }\end{array}$ & Low risk & $\begin{array}{l}3 \text { women }(12 \%) \text { ( } 1 \text { treatment and } 2 \text { con- } \\
\text { trol) excluded, as breech was deeply en- } \\
\text { gaged. This loss should be insufficient to } \\
\text { affect the comparison }\end{array}$ \\
\hline Selective reporting (reporting bias) & Unclear risk & We did not assess the trial protocol. \\
\hline Other bias & Unclear risk & $\begin{array}{l}\text { No baseline data are available for assess- } \\
\text { ment. }\end{array}$ \\
\hline
\end{tabular}

Kok 2008

\begin{tabular}{|c|c|}
\hline Methods & Multi-centre RCT. \\
\hline Participants & $\begin{array}{l}\text { Inclusion criteria: term singleton, breech presentation pregnancies. GA of } 36 \text { weeks } \\
\text { onwards. } \mathrm{N}=320 \text {. } \\
\text { Exclusion criteria: maternal exclusion: any contradiction to labour or vaginal birth, } \\
\text { scarred uterus other than transverse in the lower segment, known uterine anomalies, } \\
\text { placental abruption in the obstetric history, preeclampsia, maternal cardiac disease, third- } \\
\text { trimester bleeding. Fetal exclusion: IUGR (EFW }<5 \text { th percentile for GA assessed by } \\
\text { ultrasonography), fetal anomalies or an extended fetal head, oligohydramnios (defined } \\
\text { as an AFI } \leq 5 \mathrm{~cm} \text { ) and non-reassuring signs of fetal well-being }\end{array}$ \\
\hline Interventions & $\begin{array}{l}\text { Intervention: tocolytic: nifedipine - calcium channel blocker (A2) - oral. } \\
\text { Nifedipine ( } 2 \text { doses of } 10 \mathrm{mg} \text { ) orally. } \mathrm{N}=160 \text { but } 154 \text { analysed } \\
\text { Comparison: placebo: placebo capsules. } \mathrm{N}=160 \text { but } 156 \text { analysed. }\end{array}$ \\
\hline Outcomes & $\begin{array}{l}\text { Primary: successful ECV defined as a fetus in cephalic position } 30 \text { minutes after the ECV } \\
\text { procedure } \\
\text { Secondary: fetal presentation at birth, mode of birth and adverse maternal (major side ef- } \\
\text { fects due to medication, hypotension with fetal consequences, anaphylactic shock due to } \\
\text { the medication and any adverse cardiac events due to medication intake) and fetal events } \\
\text { (fetal death, emergency delivery, fetal bradycardia, premature rupture of the membranes } \\
\text { and placental abruption within } 24 \text { hours after the ECV procedure). Minor side effects: } \\
\text { nausea, dizziness and flushing and cessation of treatment because of side effects }\end{array}$ \\
\hline Notes & $\begin{array}{l}\text { Nifedipine group - } 2 \text { women excluded as they were less than } 39 \text { weeks' gestation, } 2 \\
\text { excluded as they were repeat versions, } 2 \text { women lost to follow-up } \\
\text { Placebo group - } 2 \text { women excluded as they were less than } 38 \text { weeks, } 2 \text { excluded as they } \\
\text { were repeat versions } \\
\text { Study reports no events for fetal death; emergency delivery less than } 24 \text { hours; placental } \\
\text { abruption less than } 24 \text { hours; premature rupture of membranes less than } 24 \text { hours; } \\
\text { maternal hypotension with fetal consequences; anaphylactic shock }\end{array}$ \\
\hline
\end{tabular}

\section{Risk of bias}




\begin{tabular}{|c|c|c|}
\hline $\begin{array}{l}\text { Random sequence generation (selection } \\
\text { bias) }\end{array}$ & Low risk & Computer blocks of 10 , stratified for centre and parity. \\
\hline Allocation concealment (selection bias) & Low risk & $\begin{array}{l}\text { Pharmacy prepared sealed opaque containers with study medi- } \\
\text { cation and kept an allocation list until completion of the study }\end{array}$ \\
\hline $\begin{array}{l}\text { Blinding of participants and personnel } \\
\text { (performance bias) } \\
\text { All outcomes }\end{array}$ & Low risk & $\begin{array}{l}\text { Double-blinded. All participants, nurses and doctors who per- } \\
\text { formed the ECV were blinded to the assignment }\end{array}$ \\
\hline $\begin{array}{l}\text { Blinding of outcome assessment (detection } \\
\text { bias) } \\
\text { All outcomes }\end{array}$ & Low risk & $\begin{array}{l}\text { Double-blinded. All participants, nurses and doctors who per- } \\
\text { formed the ECV were blinded to the assignment }\end{array}$ \\
\hline $\begin{array}{l}\text { Incomplete outcome data (attrition bias) } \\
\text { All outcomes }\end{array}$ & Low risk & $\begin{array}{l}6 \text { women were lost to follow-up or were excluded in the nifedip- } \\
\text { ine group, and } 4 \text { women in the control group }\end{array}$ \\
\hline Selective reporting (reporting bias) & Unclear risk & We did not assess the trial protocol. \\
\hline Other bias & Unclear risk & $\begin{array}{l}\text { Baseline characteristics were similar. Baseline characteristics (Ta- } \\
\text { ble } 1 \text { ) indicate generally good balance, although there appears } \\
\text { to be some imbalance in placental anterior localisation ( } 44 \text { vs } \\
55 \text { ). Some imbalances were seen in some of the ethnicity data } \\
\text { (Central African ( } 4 \text { vs } 10) \text { and Other (18 vs 9) }\end{array}$ \\
\hline
\end{tabular}

Mancuso 2000

\begin{tabular}{|c|c|}
\hline Methods & RCT. \\
\hline Participants & $\begin{array}{l}\text { Inclusion criteria: women undergoing ECV attempt. Age } 18 \text { years or greater, singleton } \\
\text { pregnancy, } 37 \text { weeks or more, breech or transverse presentation, intact membranes, EFW } \\
2000 \text { to } 4000 \text { g, reassuring fetal heart rate testing. } N=108 \\
\text { Exclusion criteria: placenta praevia, prior classical CS, third-trimester bleeding, AFI < } \\
5 \text { or }>25 \mathrm{~cm} \text {, known uterine malformation, suspected major fetal anomaly, active-phase } \\
\text { labour }\end{array}$ \\
\hline Interventions & $\begin{array}{l}\text { Intervention: regional analgesia }(C)+\text { tocolytic. } \\
\text { Lumbar epidural analgesia with } 3+10 \mathrm{~mL} 2 \% \text { lidocaine, with epinephrine test dose and } \\
\text { fentanyl } 100 \text { micrograms. } \mathrm{N}=54 \\
\text { Comparison: no regional analgesia + tocolytic. } \mathrm{N}=54 \text {. } \\
\text { All received Ringer's Lactate } 1500 \mathrm{~mL} \mathrm{IV} \text {, and terbutaline } 0.25 \mathrm{mg} \mathrm{SQ}\end{array}$ \\
\hline Outcomes & $\begin{array}{l}\text { Presentation after ECV attempt; presentation at birth; fetal bradycardia causing cessation } \\
\text { of ECV attempts; the way women gave birth }\end{array}$ \\
\hline Notes & Tripler Army Medical Centre, Honolulu, Hawaii, December 1994 to June 1998 \\
\hline
\end{tabular}

\section{Risk of bias}

Interventions for helping to turn term breech babies to head first presentation when using external cephalic version (Review) 


\begin{tabular}{l|l|l}
\hline Bias & Authors' judgement & Support for judgement \\
\hline $\begin{array}{l}\text { Random sequence generation (selection } \\
\text { bias) }\end{array}$ & Low risk & Computer-generated random numbers table. \\
\hline $\begin{array}{l}\text { Allocation concealment (selection bias) } \\
\text { Blinding of participants and personnel } \\
\text { (performance bias) } \\
\text { All outcomes }\end{array}$ & High risk & $\begin{array}{l}\text { L...with group assignments sealed in sequentially numbered } \\
\text { opaque envelopes randomisation }\end{array}$ \\
\hline $\begin{array}{l}\text { Blinding of outcome assessment (detection } \\
\text { bias) } \\
\text { All outcomes }\end{array}$ & High risk & It is not possible to blind people to epidurals. \\
\hline $\begin{array}{l}\text { Incomplete outcome data (attrition bias) } \\
\text { All outcomes }\end{array}$ & Low risk & It is not possible to blind people to epidurals. \\
\hline \begin{tabular}{l} 
Selective reporting (reporting bias) \\
\hline $\begin{array}{l}\text { Other bias }\end{array}$
\end{tabular} & Unclear risk & No exclusions or loss to follow-up. \\
\hline Wow risk & $\begin{array}{l}\text { Baseline data were similar between groups; no evidence of other } \\
\text { bias }\end{array}$ \\
\hline
\end{tabular}

\section{Marquette 1996}

\begin{tabular}{|c|c|}
\hline Methods & RCT. \\
\hline Participants & $\begin{array}{l}\text { Inclusion criteria: women with singleton breech presentation, } 36 \text { to } 41 \text { weeks' gestation, } \\
\text { reactive CTG, breech mobile on abdominal palpation. } \mathrm{N}=283 \\
\text { Exclusion criteria: impaired fetal growth (estimated weight }<10 \text { th percentile), oligohy- } \\
\text { dramnios (AFI < 5), placenta praevia, placental abruption, uterine scar other than low } \\
\text { transverse CS, active labour, ruptured membranes, fetal anomalies incompatible with } \\
\text { life, contraindication to vaginal delivery, contraindication to tocolysis }\end{array}$ \\
\hline Interventions & $\begin{array}{l}\text { Intervention: tocolytic: ritodrine - beta stimulant }(\mathrm{A} 1) \text { - parenteral. } \\
\text { IVI, for } 20 \text { minutes before and during ECV attempt, of ritodrine } 111 \text { micrograms/ } \\
\text { min or placebo. Maximum of } 3 \mathrm{ECV} \text { attempts as forward or backward flip. CTG was } \\
\text { repeated. } \mathrm{N}=138 \\
\text { Comparison: placebo. } \mathrm{N}=145\end{array}$ \\
\hline Outcomes & $\begin{array}{l}\text { Duration of infusion (tocolysis mean } 32.1 \text { (SD 1.04) vs control } 31.7 \text { (1.12) minutes); } \\
\text { unsuccessful ECV; CTG results (all reactive); time from ECV to birth (average } 2 \text { weeks); } \\
\text { maternal and fetal complications (maternal complications }<4 \% \text {, similar between groups) } \\
\text {; mode of birth; birthweight ( } 3370 \text { (39) vs } 3382 \text { (44) grams) }\end{array}$ \\
\hline
\end{tabular}




\section{Risk of bias}

Bias Authors' judgement Support for judgement

Random sequence generation (selection Unclear risk bias)

States random assignment of every 10 patients enrolled: 5 to ritodrine and 5 to control

\begin{tabular}{lll}
\hline Allocation concealment (selection bias) & Unclear risk $\quad$ No information provided.
\end{tabular}

Blinding of participants and personnel Low risk (performance bias)

Placebo and treatment made up in pharmacy in identical phials and administered IV in the same solution at the same rate

All outcomes

Blinding of outcome assessment (detection Low risk bias)

Placebo and treatment made up in pharmacy in identical phials and administered IV in the same solution at the same rate

All outcomes

\begin{tabular}{l|l|l}
$\begin{array}{l}\text { Incomplete outcome data (attrition bias) } \\
\text { All outcomes }\end{array}$ & Low risk & No exclusions or loss to follow-up reported. \\
\hline Selective reporting (reporting bias) & Unclear risk & We did not assess the trial protocol. \\
\hline Other bias & Unclear risk & $\begin{array}{l}\text { Ritodrine group had higher proportion of nulliparous women. } \\
\text { It is unclear whether this would impact the comparison of out- } \\
\text { comes }\end{array}$ \\
\hline
\end{tabular}

Munoz 2014

Methods

Participants 2-arm RCT. Individual women randomly assigned.

Dates of data collection: April 2010 to March 2011.

Setting: tertiary hospital in Spain with more than 3000 births a year

Inclusion criteria: women with non-cephalic presentation between 36 and 41 weeks' gestation (All non-labouring pregnant women at 36 to 41 weeks' gestation with a noncephalic presentation confirmed by ultrasound scan were invited to participate). $\mathrm{N}=60$ Exclusion criteria: fetal abnormalities, intrauterine fetal death, suspicion of fetal growth restriction, fetal weight above $3800 \mathrm{~g}$, maternal cardiovascular disease, American Society of Anesthesiologists class $>2$, severe hypertension, allergy to any trial medications, amniotic fluid index $<4 \mathrm{~cm}$, Doppler cerebroplacental ratio $>5$ th percentile, abnormal cardiotocographic recordings, contraindications to vaginal delivery, uterine abnormalities, coagulation disorders, Rhesus incompatibility, multiple gestation, rupture of membranes and/or placental abruption 
Interventions
Experimental intervention: remifentanil.

Remifentanil at $0.1 \mathrm{lg} / \mathrm{kg} / \mathrm{min}$, with rescue boluses on demand of $0.1 \mathrm{gg} / \mathrm{kg} / \mathrm{min}$ and a lockout period of 4 minutes. Given by patient-controlled pump.All women given IV infusion of ritodrine $200 \mathrm{lg} / \mathrm{min}$ for tocolysis. All women given $1 \mathrm{~g}$ paracetamol in 100 $\mathrm{mL}$ saline (IV) 5 minutes before ECV. $\mathrm{N}=31$

Control/Comparison intervention: placebo.

Study control solution at $0.1 \mathrm{lg} / \mathrm{kg} / \mathrm{min}$, with rescue boluses on demand of $0.1 \mathrm{lg} / \mathrm{kg} /$ min and a lockout period of 4 minutes. Given by patient-controlled pump. All women given IV infusion of ritodrine $200 \mathrm{lg} / \mathrm{min}$ for tocolysis. All women given $1 \mathrm{~g}$ paracetamol (IV) 5 minutes before ECV. $\mathrm{N}=29$

Outcomes

Pain score (numerical rating scale 0 to 10 , no pain to worst pain imaginable); success of ECV; CS; adverse events (nausea, vomiting, dizziness, etc); mode of birth; fetal bradycardia

Notes

Risk of bias

\begin{tabular}{lll}
\hline Bias & Authors' judgement & Support for judgement \\
\hline $\begin{array}{l}\text { Random sequence generation (selection } \\
\text { bias) }\end{array}$ & Low risk & $\begin{array}{l}\text { “...computer-generated } \\
\text { sequence...”. }\end{array}$ \\
\hline Allocation concealment (selection bias) & Low risk & $\begin{array}{l}\text { Hospital pharmacy prepared } 100 \mathrm{~mL} \text { in- } \\
\text { fusion bags that contained remifentanil }(1 \\
\text { mg) or saline, which were labelled with the } \\
\text { patient code and sent to the operative room }\end{array}$ \\
\hline
\end{tabular}

Blinding of participants and personnel Low risk (performance bias)

All outcomes

Blinding of outcome assessment (detection Low risk bias)

All outcomes

Incomplete outcome data (attrition bias) Low risk All outcomes
Women blind to allocation (placebo-controlled trial).

Anaesthesiologists, midwives and obstetricians were blinded to allocation group

\begin{tabular}{|l|l|l} 
& & $\begin{array}{l}\text { of the fetus to a cephalic presentation, and } \\
\text { one who declined to participate" } \\
\text { Obstetric data for } 2 \text { further women were } \\
\text { lost, but they were included in the statistical } \\
\text { analysis on an intention-to-treat basis }\end{array}$ \\
\hline Selective reporting (reporting bias) & Low risk & $\begin{array}{l}\text { Trial registration form (Valero 2010) lists } \\
\text { outcomes, all of which were reported in } \\
\text { main study publication (Munoz 2014). }\end{array}$
\end{tabular}


Munoz 2014

Other bias

Low risk

No imbalance in age; BMI; estimated fetal weight; ethnicity; parity; previous CS; presentation; placenta and amniotic fluid volume

Nor Azlin 2005

\begin{tabular}{l|l}
\hline Methods & RCT. \\
\hline Participants & Inclusion criteria: singleton term breech pregnancy at a tertiary hospital. $\mathrm{N}=60$. \\
\hline $\begin{array}{l}\text { Exclusion criteria: previous CS or other uterine scar, uterine malformation, antepartum } \\
\text { haemorrhage, hypertension, diabetes mellitus, IUGR, oligohydramnios, fetal anomalies, } \\
\text { early or active labour, contraindications to IV ritodrine, contraindication to vaginal } \\
\text { delivery }\end{array}$ \\
\hline
\end{tabular}

Interventions

Intervention: tocolytic: ritodrine - beta stimulant (A1) - parenteral.

Ritodrine (IV) $-0.4 \mathrm{mg} / \mathrm{mL}$ in $5 \%$ dextrose infused at $1.5 \mathrm{~mL} / \mathrm{min} . \mathrm{N}=30$ (nulliparous 22 and multiparous 8)

Comparison: placebo. $\mathrm{N}=30$ (nulliparous 23 and multiparous 7).

\begin{tabular}{l|l}
\hline Outcomes & Successful ECV. \\
\hline Notes & \\
\hline
\end{tabular}

Notes

Risk of bias

\begin{tabular}{|c|c|c|}
\hline Bias & Authors' judgement & Support for judgement \\
\hline $\begin{array}{l}\text { Random sequence generation (selection } \\
\text { bias) }\end{array}$ & Low risk & Computer random-number generator. \\
\hline Allocation concealment (selection bias) & Low risk & Sealed numbered opaque envelopes. \\
\hline $\begin{array}{l}\text { Blinding of participants and personnel } \\
\text { (performance bias) } \\
\text { All outcomes }\end{array}$ & Low risk & Obstetricians and women were blinded. \\
\hline $\begin{array}{l}\text { Blinding of outcome assessment (detection } \\
\text { bias) } \\
\text { All outcomes }\end{array}$ & Low risk & Obstetricians and women were blinded. \\
\hline $\begin{array}{l}\text { Incomplete outcome data (attrition bias) } \\
\text { All outcomes }\end{array}$ & Low risk & No exclusions or incomplete data. \\
\hline Selective reporting (reporting bias) & Unclear risk & We did not assess the trial protocol. \\
\hline Other bias & Unclear risk & More babies in the frank breech position in the ritodrine group \\
\hline
\end{tabular}


Nor Azlin 2008

\begin{tabular}{ll}
\hline Methods & RCT. \\
\hline Participants & $\begin{array}{l}\text { Inclusion criteria: singleton term pregnancies with a breech presentation. } \mathrm{N}=86 . \\
\text { Exclusion criteria: oligohydramnios, macrosomia, presence of a contraindication for } \\
\text { vaginal delivery, previous caesarean delivery, multiple pregnancy, hypertension in preg- } \\
\text { nancy, rhesus-negative mother, previous history of abruptio placenta, lethal fetal anomaly, } \\
\text { contraindication against nifedipine or terbutaline }\end{array}$ \\
\hline Interventions & $\begin{array}{l}\text { Intervention: tocolytic: nifedipine - calcium channel blocker (A2) - oral. } \\
\text { Oral nifedipine }(20 \mathrm{mg}) . \mathrm{N}=43 \text { (nulliparous 18, multiparous } 25) \\
\text { Comparison: tocolytic: terbutaline - beta stimulant (A1) - parenteral. } \\
\text { IV terbutaline }(50 \mu \mathrm{g}) . \mathrm{N}=43 \text { (nulliparous 21, multiparous 22) }(6 \text { lost to further follow- } \\
\text { up) }\end{array}$ \\
\hline Outcomes & $\begin{array}{l}\text { Successful ECV, difficult ECV, palpitations, hypotension, method of delivery, perinatal } \\
\text { morbidity }\end{array}$ \\
\hline Notes & 6 successful ECVs from the terbutaline group were lost to follow-up \\
\hline
\end{tabular}

\section{Risk of bias}

\section{Bias}

Random sequence generation (selection Low risk bias)
Sealed, opaque, numbered envelopes in sequence.

Clinicians doing ECV were blinded to the tocolytic drug, women were not blinded because 1 group had oral administration and the other IV. Clinicians doing the ECV were in control of the success rate and were blinded

Clinicians doing ECV were blinded to the tocolytic drug, women were not blinded because 1 group had oral administration and the other IV. Clinicians doing the ECV were in control of the success rate and were blinded

Incomplete outcome data (attrition bias) High risk All outcomes

Among those who had successful ECV, 6 from terbutaline group were lost to follow-up, so although all women were included in the assessment of the success of ECV, the outcome of CS is at risk of bias

\begin{tabular}{l|l} 
Selective reporting (reporting bias) Unclear risk & We did not assess the trial protocol.
\end{tabular}

Other bias Low risk
The study was not stopped early. Baseline characteristics were similar between groups in maternal age, GA, AFI, parity and type of breech presentation. No other biases were identified 
Reinhard 2012

Methods

Participants
RCT comparing 2 interventions (clinical hypnosis or NLP) (a control group receiving no intervention was used as a historical comparison - data for this group have not been included in the review). Single-centre, stratified by parity

ECVs, during which time neither hypnosis nor NLP was used. These data will not be
included
Setting: a tertiary university hospital in Germany. Johann Wolfgang Goethe University
Hospital in Frankfurt am Main
Inclusion criteria: pregnant women with a singleton fetus in a breech position at the
scheduled date of the ECV at or after $370 / 7$ ( 259 days) weeks' gestation, normal amniotic
fluid index, with advanced level of German language. $\mathrm{N}=80$
Exclusion criteria: women in active labour (regular uterine contractions and rupture of
membranes), contraindications for a vaginal birth (such as placenta praevia) and planned
birth by caesarean section even if the fetus turned to a cephalic position

Interventions

Experimental intervention: hypnosis.

20-Minute standardized clinical hypnosis intervention via head phones (Bose, QuietComfort 15) before ECV procedure was carried out. Hypnosis intervention was a voice recording of one of the trialists (a certified hypnotherapist who underwent training in the fundamentals of NLP). A relaxation induction was utilised, in which the therapist focused on breathing and concentrated on various parts of the body for trance deepening. $\mathrm{N}=42$

Control/Comparison intervention: neurolinguistic programming.

20-Minute standardised NLP intervention via head phones (Bose, QuietComfort 15) before ECV procedure was carried out. Hypnosis intervention was a voice recording of 1 of the trialists (a certified hypnotherapist who underwent training in the fundamentals of NLP). $\mathrm{N}=38$

ECV success; women's views (results reported as means derived from Likert 6-point scale)

Notes

We contacted the study author for more information re the NLP intervention and received additional information

\section{Risk of bias}

\begin{tabular}{|c|c|c|}
\hline Bias & Authors' judgement & Support for judgement \\
\hline $\begin{array}{l}\text { Random sequence generation (selection } \\
\text { bias) }\end{array}$ & Low risk & $\begin{array}{l}\text { Off-centre randomisation sequence based } \\
\text { on block randomisation was calculated and } \\
\text { assigned by the Institute of Biostatistics and } \\
\text { Mathematical Modeling }\end{array}$ \\
\hline
\end{tabular}

Allocation concealment (selection bias) Unclear risk

Blinding of participants and personnel Low risk (performance bias)

All outcomes
Allocation at the point of randomisation was not described.

Intervention was double-blinded, that is, the participant and the clinician who carried out the ECV procedure did not know 
Reinhard 2012 (Continued)

the kind of intervention

Blinding of outcome assessment (detection Low risk

Intervention was double-blinded, that is,

bias)

All outcomes the participant and the clinician who carried out the ECV procedure did not know the kind of intervention

Incomplete outcome data (attrition bias) Low risk

No loss to follow-up evident after randomiAll outcomes sation.

\begin{tabular}{lll}
\hline Selective reporting (reporting bias) & Unclear risk & We did not assess trial protocol. \\
\hline Other bias & Low risk & Other bias not apparent. \\
\hline
\end{tabular}

\section{Robertson 1987}

\begin{tabular}{|c|c|}
\hline Methods & Quasi-RCT \\
\hline Participants & $\begin{array}{l}\text { Inclusion criteria: breech presentation suitable for ECV at term ( } 37 \text { to } 41 \text { weeks). N = } \\
58 \\
\text { Exclusion criteria: oligohydramnios, estimated fetal weight }<2500 \mathrm{~g} \text { or }>4000 \mathrm{~g} \text {, non- } \\
\text { reactive NST }\end{array}$ \\
\hline Interventions & $\begin{array}{l}\text { Intervention: tocolytic: ritodrine - beta stimulant (A1) - parenteral. } \\
\text { Use of tocolysis (ritodrine infusion } 200 \text { micrograms per minute for } 20 \text { minutes) compared } \\
\text { with no tocolysis. All women had IV lines. Repeat version attempt with tocolysis was } \\
\text { successful in } 1 / 9 \text {, with initial failure in the control group (for immediate success rate, } \\
\text { this review considered only the initial attempt). } N=30 \\
\text { Comparison: no tocolytic. } N=28 \text {. }\end{array}$ \\
\hline Outcomes & Non-cephalic presentation at birth; CS; immediate ECV success \\
\hline Notes & Tacoma, Washington, USA. July 1984 to May 1987. \\
\hline
\end{tabular}

\section{Risk of bias}

\begin{tabular}{l|l|l}
\hline Bias & Authors' judgement & Support for judgement \\
\hline $\begin{array}{l}\text { Random sequence generation (selection } \\
\text { bias) }\end{array}$ & High risk & Allocated according to last digit of social security number. \\
\hline $\begin{array}{l}\text { Allocation concealment (selection bias) } \\
\begin{array}{l}\text { Blinding of participants and personnel } \\
\text { (performance bias) } \\
\text { All outcomes }\end{array}\end{array}$ & High risk & Allocated according to last digit of social security number. \\
\hline
\end{tabular}




\section{Robertson 1987 (Continued)}

\begin{tabular}{ll|l}
\hline $\begin{array}{l}\text { Blinding of outcome assessment (detection } \\
\text { bias) } \\
\text { All outcomes }\end{array}$ & High risk & No blinding. \\
\hline $\begin{array}{l}\text { Incomplete outcome data (attrition bias) } \\
\text { All outcomes }\end{array}$ & Low risk & $\begin{array}{l}3 \text { women lost to follow-up in the intervention group and } 5 \text { in } \\
\text { the control group. This seems unlikely to impact outcomes }\end{array}$ \\
\hline Selective reporting (reporting bias) & Unclear risk & We did not assess the trial protocol. \\
\hline Other bias & Low risk & $\begin{array}{l}\text { Groups were similar in age, parity, maternal weight, GA, EFW. } \\
\text { No other biases apparent }\end{array}$ \\
\hline
\end{tabular}

\section{Schorr 1997}

\begin{tabular}{|c|c|}
\hline Methods & RCT. \\
\hline Participants & $\begin{array}{l}\text { Inclusion criteria: breech presentation or transverse lie. } \mathrm{N}=69 \text {. } \\
\text { Exclusion criteria: placenta praevia, fetal compromise, fetal growth restriction, ruptured } \\
\text { membranes }\end{array}$ \\
\hline Interventions & $\begin{array}{l}\text { Intervention: regional analgesia }(\mathrm{C})+\text { tocolytic. } \\
\text { Epidural analgesia with } 2 \% \text { lidocaine with } 1: 200,000 \text { epinephrine }(\mathrm{N}=35) \text {; prehydration } \\
\text { with } 2000 \mathrm{~mL} \text { lactated Ringer's solution vs no epidural }(\mathrm{N}=34) \text {. All women received } \\
0.25 \mathrm{mg} \text { terbutaline } \mathrm{SQ} \text {. ECV attempted up to } 3 \text { times, with vaginal elevation of the } \\
\text { presenting part when necessary. } \mathrm{N}=35 \\
\text { Comparison: no regional analgesia + tocolytic. } \mathrm{N}=34 \text {. } \\
250 \mathrm{mg} \text { terbutaline given as adjunct. }\end{array}$ \\
\hline Outcomes & Successful ECV, complications, mode of birth, presentation at delivery \\
\hline
\end{tabular}

\section{Risk of bias}

\begin{tabular}{l|l|l}
\hline Bias & Authors' judgement & Support for judgement \\
\hline $\begin{array}{l}\text { Random sequence generation (selection } \\
\text { bias) }\end{array}$ & Low risk & $\begin{array}{l}\text { Computer-generated randomisation cards placed in permuted } \\
\text { blocks of 10 by Division of Biostatistics }\end{array}$ \\
\hline
\end{tabular}

\begin{tabular}{|c|c|c|}
\hline Allocation concealment (selection bias) & Low risk & $\begin{array}{l}\text { Allocation put in sealed opaque envelopes, and all investigators } \\
\text { participating in clinical aspects of the study were blinded to the } \\
\text { randomisation sequence }\end{array}$ \\
\hline
\end{tabular}

Blinding of participants and personnel High risk It is not possible to blind people to the use of epidurals. (performance bias)

All outcomes 


\begin{tabular}{l|l|l}
\hline $\begin{array}{l}\text { Blinding of outcome assessment (detection } \\
\text { bias) } \\
\text { All outcomes }\end{array}$ & High risk & It is not possible to blind people to the use of epidurals. \\
\hline $\begin{array}{l}\text { Incomplete outcome data (attrition bias) } \\
\text { All outcomes }\end{array}$ & Low risk & $\begin{array}{l}\text { Although 5 women declined randomisation, there seemed to be } \\
\text { no exclusions and no loss to follow-up }\end{array}$ \\
\hline $\begin{array}{l}\text { Selective reporting (reporting bias) } \\
\text { Other bias }\end{array}$ & Unclear risk & We did not assess the trial protocol. \\
\hline
\end{tabular}

\section{Stock 1993}

\begin{tabular}{l|l}
\hline Methods & RCT. \\
\hline Participants & $\begin{array}{l}\text { Inclusion criteria: breech presentation between } 36 \text { and } 42 \text { weeks with no contraindica- } \\
\text { tion to ECV. N }=63 .\end{array}$ \\
\hline $\begin{array}{l}\text { Exclusion criteria: diabetes, heart disease, thyrotoxicosis, ruptured membranes, multiple } \\
\text { pregnancy, uterine scar, placenta praevia, oligohydramnios, impaired fetal growth, nuchal } \\
\text { cord, placenta praevia }\end{array}$ \\
\hline
\end{tabular}

Interventions

Intervention 1: tocolytic: ritodrine - beta stimulant (A1) - parenteral.

Group B: ritodrine $0.3 \mathrm{mg}$ per minute infusion for 30 minutes and during the procedure, and placebo bolus injection. $\mathrm{N}=21$

Intervention 2: tocolytic: hexoprenaline - beta stimulant (A1) - parenteral.

Group C: placebo infusion and hexoprenaline 10 micrograms bolus injection. $\mathrm{N}=21$

Comparison: placebo.

Group A: placebo infusion and bolus injection. $\mathrm{N}=21$.

For the purposes of this review, which addresses the effectiveness of IV tocolysis for ECV rather than the evaluation of specific tocolytic agents, intervention 1 (group B) and intervention 2 (group C) have been combined

Nulliparous $=18$ in tocolytic groups and 9 in placebo group.

Multiparous $=24$ in tocolytic groups and 12 in placebo group

We have not set up a subgroup comparison of 1 beta stimulant vs another, so the data from this study on failed ECV for ritodrine $(7 / 21)$ vs hexoprenaline $(5 / 21)$ are not included as a direct comparison naline but not for ritodrine. Study authors decided not to continue the ritodrine/placebo arm of the trial to completion

\section{Risk of bias}


Stock 1993 (Continued)

\begin{tabular}{|c|c|c|}
\hline $\begin{array}{l}\text { Random sequence generation (selection } \\
\text { bias) }\end{array}$ & Unclear risk & $\begin{array}{l}\text { 'Each investigator had a separate randomisation sequence. These } \\
\text { were in sets of } 3 \text { to the } 3 \text { groups, stratified for parity.' Method } \\
\text { of randomisation not specified }\end{array}$ \\
\hline Allocation concealment (selection bias) & Unclear risk & No information provided. \\
\hline $\begin{array}{l}\text { Blinding of participants and personnel } \\
\text { (performance bias) } \\
\text { All outcomes }\end{array}$ & Low risk & $\begin{array}{l}\text { Placebo-controlled trial. Practitioners were blind to group allo- } \\
\text { cation, as were the women }\end{array}$ \\
\hline $\begin{array}{l}\text { Blinding of outcome assessment (detection } \\
\text { bias) } \\
\text { All outcomes }\end{array}$ & Low risk & Practitioners were blind to group allocation. \\
\hline $\begin{array}{l}\text { Incomplete outcome data (attrition bias) } \\
\text { All outcomes }\end{array}$ & Low risk & No evidence of exclusions of loss to follow-up. \\
\hline Selective reporting (reporting bias) & Unclear risk & We did not assess the trial protocol. \\
\hline Other bias & High risk & $\begin{array}{l}\text { No statistically significant differences between groups in terms } \\
\text { of parity, height, age or gestation at time of ECV (see Table } 2 \\
\text { on page 266). No differences between groups regarding fetal } \\
\text { biparietal diameter, abdominal circumference. Femur length or } \\
\text { AFI. Women in ritodrine group were significantly lighter than } \\
\text { those in the other } 2 \text { groups } \\
\text { Trial stopped early for benefit. }\end{array}$ \\
\hline
\end{tabular}

Sullivan 2009

\begin{tabular}{|c|c|}
\hline Methods & RCT. \\
\hline Participants & $\begin{array}{l}\text { Inclusion criteria: singleton breech presentations after } 36 \text { weeks' gestation. } \mathrm{N}=95 \text {. } \\
\text { Exclusion criteria: patients with contraindications to neuraxial anaesthesia, allergies to } \\
\text { study medications }\end{array}$ \\
\hline Interventions & $\begin{array}{l}\text { Intervention: systemic opioids }(\mathrm{E})+\text { tocolytic. } \\
\text { Systemic opioids }(50 \mu \mathrm{g} \text { fentanyl). } \mathrm{N}=47 \text {. } \\
\text { Comparison: regional analgesia }(\mathrm{C})+\text { tocolytic. } \\
\mathrm{CSE} \text { anaesthesia (bupivacaine } 2.5 \mathrm{mg} \text { and } 15 \mu \mathrm{g} \text { fentanyl followed by } 45 \mathrm{mg} \text { lidocaine } \\
\text { and } 15 \mu \mathrm{g} \text { epinephrine). } \mathrm{N}=48 \\
\text { Both groups received terbutaline. }\end{array}$ \\
\hline Outcomes & Successful ECV, hypotension, decelerations of FHR, persistent decelerations, CS \\
\hline Notes & 1 woman excluded after randomisation before ECV because of non-reassuring CTG \\
\hline
\end{tabular}

\section{Risk of bias}

Interventions for helping to turn term breech babies to head first presentation when using external cephalic version (Review) 
Sullivan 2009 (Continued)

\begin{tabular}{l|l|l}
\hline Bias & Authors' judgement & Support for judgement \\
\hline $\begin{array}{l}\text { Random sequence generation (selection } \\
\text { bias) }\end{array}$ & Low risk & Computer random-number table. \\
\hline \begin{tabular}{l} 
Allocation concealment (selection bias) \\
\hline $\begin{array}{l}\text { Blinding of participants and personnel } \\
\text { (performance bias) }\end{array}$
\end{tabular} & Low risk & Sequentially numbered opaque envelopes. \\
\hline $\begin{array}{l}\text { All outcomes } \\
\text { Blinding of outcome assessment (detection } \\
\text { bias) }\end{array}$ & High risk & No blinding. \\
\hline $\begin{array}{l}\text { All outcomes } \\
\text { All outcomes }\end{array}$ & No blinding. \\
\hline Selective reporting (reporting bias) & Unclear risk & We did not assess the trial protocol. \\
\hline Other bias & Low risk & $\begin{array}{l}\text { No significant differences between the 2 groups in age, parity, } \\
\text { GA, height, weight or obstetrician predicted difficulty of version. } \\
\text { Other biases not identified }\end{array}$ \\
\hline
\end{tabular}

\section{Tan 1989}

\begin{tabular}{ll}
\hline Methods & RCT. \\
\hline Participants & $\begin{array}{l}\text { Inclusion criteria: breech presentation beyond } 33 \text { weeks' gestation without contraindi- } \\
\text { cation to ECV. } \mathrm{N}=90 .\end{array}$ \\
& $\begin{array}{l}\text { Exclusion criteria: signs of growth restriction, vaginal bleeding in the third trimester, } \\
\text { toxaemia of pregnancy, labour, polyhydramnios, placenta praevia, previous CS scar, con- } \\
\text { tracted pelvis, fetal malformation and uterine malformation }\end{array}$ \\
\hline Interventions & $\begin{array}{l}\text { Intervention 1: tocolytic: salbutamol - beta stimulant (A1) - parenteral. } \\
\text { Group } 2 \text { received an IVI of salbutamol until maternal heart rate exceeded } 100 \text { beats per } \\
\text { minute for 30 minutes. } \mathrm{N}=30 \text { (nulliparous } 17, \text { multiparous } 13)\end{array}$ \\
$\begin{array}{l}\text { Intervention 2: tocolytic: salbutamol - beta stimulant (A1) - oral. } \\
\text { Group } 1 \text { received salbutamol } 4 \text { mg orally } 3 \text { times a day for at least } 1 \text { day. } \mathrm{N}=30 \\
\text { (nulliparous } 16, \text { multiparous } 14)\end{array}$ \\
$\begin{array}{l}\text { Comparison: placebo. } \\
\text { Group } 3 \text { received no salbutamol. } \mathrm{N}=30 \text { (nulliparous } 17, \text { multiparous } 13) \\
\text { Groups } 1 \text { and } 3 \text { received dummy IV lines }\end{array}$ \\
\hline
\end{tabular}

Outcomes

Immediate ECV success.

Interventions for helping to turn term breech babies to head first presentation when using external cephalic version (Review) 


\begin{tabular}{ll}
\hline Notes & Singapore. \\
& This study compared 2 different routes of administration (oral and IV) of a tocolytic \\
& drug to facilitate ECV. So it provides data only for tocolysis vs placebo, and the different \\
& routes of administration are considered in subgroups
\end{tabular}

\section{Risk of bias}

\begin{tabular}{l|l|l} 
Bias & Authors' judgement & Support for judgement \\
\hline $\begin{array}{l}\text { Random sequence generation (selection } \\
\text { bias) }\end{array}$ & Unclear risk & No information provided. \\
\hline Allocation concealment (selection bias) & High risk & $\begin{array}{l}2 \text { stacks of randomised cards divided according to parity with } \\
\text { each stack further subdivided by a colour code for gestation A } \\
\text { or B }\end{array}$ \\
\hline
\end{tabular}

Blinding of participants and personnel Low risk (performance bias)

All outcomes
States that clinicians were blinded to treatment and dummy IVs were inserted. Clinicians did not know parity or gestation. Women's status unclear, but clinicians more likely to be able to influence outcomes
Blinding of outcome assessment (detection Low risk bias)

All outcomes
States that clinicians were blinded to treatment and dummy IVs were inserted. Clinicians did not know parity or gestation. Women's status unclear, but clinicians more likely to be able to influence outcomes
Incomplete outcome data (attrition bias) Low risk All outcomes Unclear risk No exclusions apparent after randomisation and no loss to follow-up

\begin{tabular}{|c|c|c|}
\hline Selective reporting (reporting bias) & Unclear risk & We did not assess the trial protocol. \\
\hline Other bias & Unclear risk & $\begin{array}{l}\text { The } 3 \text { groups were similar in placental site, abdominal girth, } \\
\text { maternal weight, fetal birthweight and stratification of parity } \\
\text { and gestation across groups } \\
\text { Failed ECV: Time taken was significantly longer }(10.5+4.9 \text { vs } \\
5.6+3.9 \text {; P value }<0.001) \text { and onset of labour was significantly } \\
\text { earlier }(17.6+9.8 \text { vs } 25.2+14.9 \text { days; P value }<0.02) \text {, implying } \\
\text { that longer manipulation hastened the onset of labour by } 70 \%\end{array}$ \\
\hline
\end{tabular}

Vallikkannu 2014

\section{Methods}

Participants
RCT 2-arm (then cross-over for second attempt; data following cross-over have not been included in the review)

Dates of data collection: 18 Jan 2011 to 23 Dec 2012.

Setting: University Hospital, Kuala Lumpur, Malaysia. 6000 to 7000 births a year Inclusion criteria: women scheduled for ECV ( $\geq 36$ weeks' gestation).

Scheduled ECV, breech presentation or transverse lie, singleton gestation, gestational 

cardiotocogram. $\mathrm{N}=95$

Exclusion criteria: regular contractions were present, estimated fetal weight $<2 \mathrm{~kg}$, oligohydramnios (amniotic fluid index $<5 \mathrm{~cm}$ ), severe hypertension, recent antepartum haemorrhage, uterine scar, related allergy and any potential contraindication to vaginal birth

\begin{tabular}{|c|c|}
\hline Interventions & 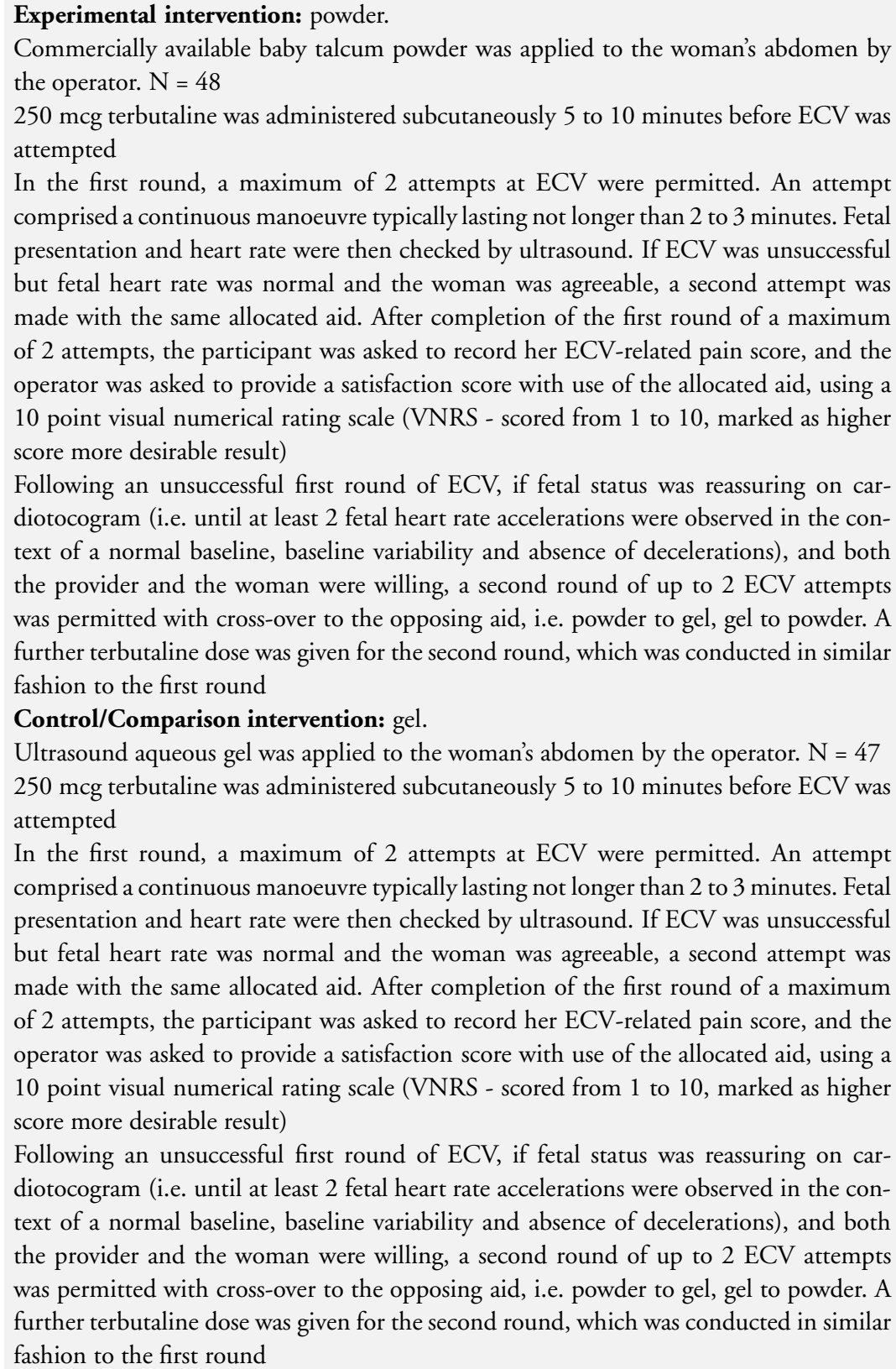 \\
\hline
\end{tabular}


Outcomes

Notes

Risk of bias
Self-reported pain; success of ECV; operator's VNRS satisfaction score (identical scale to the pain VNRS described above) with the agent used; significant post-ECV cardiotocogram anomaly; cephalic presentation at birth; caesarean (and indication); neonatal outcomes of Apgar score, umbilical cord arterial blood $\mathrm{pH}$ and base deficit and neonatal admission; gestational age at birth; blood loss at birth and birthweight; fetal or neonatal death; neonatal hypoxic-ischaemic encephalopathy and major abruptio placenta ECV was considered a success if cephalic presentation was demonstrated on ultrasound immediately after an attempt

\begin{tabular}{|c|c|c|}
\hline Bias & Authors' judgement & Support for judgement \\
\hline $\begin{array}{l}\text { Random sequence generation (selection } \\
\text { bias) }\end{array}$ & Low risk & $\begin{array}{l}\text { "...computer generated randomisation se- } \\
\text { quence obtained from http://www.ran- } \\
\text { dom.org..." }\end{array}$ \\
\hline Allocation concealment (selection bias) & Unclear risk & $\begin{array}{l}\text { "...randomisation envelopes were prepared } \\
\text { by an author (NV who was not involved in } \\
\text { recruitment) in a single block of } 100 \ldots \text { se- } \\
\text { quential opening of the lowest numbered } \\
\text { sealed opaque envelope remaining just be- } \\
\text { fore the start of ECV" } \\
5 \text { envelopes were not accounted for. }\end{array}$ \\
\hline $\begin{array}{l}\text { Blinding of participants and personnel } \\
\text { (performance bias) } \\
\text { All outcomes }\end{array}$ & High risk & $\begin{array}{l}\text { "Blinding of providers and patients to the } \\
\text { intervention was not attempted as it was } \\
\text { considered unachievable." It was not clear } \\
\text { whether staff were using their usual or pre- } \\
\text { ferred method (it was stated that talcum } \\
\text { powder had mainly been used, although } \\
\text { some staff had started to use gel for ECV) }\end{array}$ \\
\hline $\begin{array}{l}\text { Blinding of outcome assessment (detection } \\
\text { bias) } \\
\text { All outcomes }\end{array}$ & High risk & $\begin{array}{l}\text { Blinding was not attempted, as it was con- } \\
\text { sidered unachievable }\end{array}$ \\
\hline $\begin{array}{l}\text { Incomplete outcome data (attrition bias) } \\
\text { All outcomes }\end{array}$ & Low risk & $\begin{array}{l}48 \text { randomly assigned to powder and } 47 \text { to } \\
\text { gel. Recruitment ceased when all } 100 \text { num- } \\
\text { bered envelopes were used. } 5 \text { numbered en- } \\
\text { velopes could not be accounted for ( } 2 \text { allo- } \\
\text { cated to powder and } 3 \text { allocated to gel). All } \\
\text { participants received powder or gel as allo- } \\
\text { cated for their first round of ECV. Primary } \\
\text { analysis was per protocol }\end{array}$ \\
\hline
\end{tabular}

Interventions for helping to turn term breech babies to head first presentation when using external cephalic version (Review) 
Vallikkannu 2014 (Continued)

\begin{tabular}{|c|c|c|}
\hline Selective reporting (reporting bias) & Unclear risk & We did not assess the trial protocol. \\
\hline Other bias & Unclear risk & $\begin{array}{l}\text { No baseline imbalances in age; gestation; } \\
\text { parity; nulliparous; weight; height; BMI; } \\
\text { ethnicity; etc. When possible, we have used } \\
\text { the data related to the first attempt only, but } \\
\text { the assessment of pain seems to be pooled } \\
\text { in the published paper }\end{array}$ \\
\hline
\end{tabular}

Vani 2009

\begin{tabular}{ll}
\hline Methods & RCT. \\
\hline Participants & $\begin{array}{l}\text { Inclusion criteria: healthy women, singleton fetus in breech presentation, } 37 \text { to } 39 \text { weeks } \\
\text { with intact membranes, no signs of labour and a clinically EFW } 2 \text { to } 4 \text { kg. USS performed } \\
\text { to confirm breech presentation and to ascertain fetal neck position and location of the } \\
\text { placenta. } \mathrm{N}=114\end{array}$ \\
$\begin{array}{l}\text { Exclusion criteria: AFI outside range of } 5 \text { to } 25, \text { fetal hyperextended neck, placenta pre- } \\
\text { via, gross fetal anomalies, hypertension, gestational diabetes, antepartum haemorrhage, } \\
\text { uterine scar (from CS, myomectomy or perforation), uterine malformation allergy or } \\
\text { contraindication to salbutamol or contraindication to a trial of labour even if in cephalic } \\
\text { presentation }\end{array}$ \\
\hline
\end{tabular}

Interventions $\quad$ Intervention: tocolytic: salbutamol - beta stimulant (A1) - parenteral.

Salbutamol (IV dose of $0.1 \mathrm{mg}$ salbutamol with further boluses every 5 minutes). $\mathrm{N}=$ 57

Comparison: placebo. $\mathrm{N}=57$.

Outcomes

Successful ECV, palpitations, hypotension, fetal presentation at delivery, method of delivery, perinatal morbidity, Apgar scores

Notes

Risk of bias

Bias

Authors' judgement Support for judgement

Random sequence generation (selection Low risk bias)

Allocation concealment (selection bias) Low risk

Blinding of participants and personnel High risk (performance bias)

All outcomes
Sequence generated by a random-number generator.

Sealed numbered opaque envelopes prepared in blocks of 4 .

Open-label RCT and IV administration of tocolytic was not blinded 


\begin{tabular}{|c|c|c|}
\hline $\begin{array}{l}\text { Blinding of outcome assessment (detection } \\
\text { bias) } \\
\text { All outcomes }\end{array}$ & High risk & $\begin{array}{l}\text { Open-label RCT and IV administration of tocolytic was not } \\
\text { blinded }\end{array}$ \\
\hline $\begin{array}{l}\text { Incomplete outcome data (attrition bias) } \\
\text { All outcomes }\end{array}$ & Low risk & $\begin{array}{l}\text { No exclusions after randomisation and no loss to follow-up. All } \\
\text { women received their allocated treatment }\end{array}$ \\
\hline Selective reporting (reporting bias) & Unclear risk & We did not assess the trial protocol. \\
\hline Other bias & Unclear risk & $\begin{array}{l}\text { A significant difference was noted in the location of the placenta } \\
\text { between the } 2 \text { groups. Significantly more women in the tocolysis } \\
\text { group had a placenta attached to the fundus. Fewer women in the } \\
\text { intervention group had a placenta in the anterior upper segment } \\
\text { and more in the posterior upper segment, although statistical } \\
\text { significance is not reported. It is unclear whether this would have } \\
\text { an impact on outcomes } \\
\text { Post hoc multivariate logistic regression analyses incorporating } \\
\text { placental location and allocated treatment as independent co- } \\
\text { variables in the analysis with successful ECV and CS reported } \\
\text { separately as dependent outcomes. After control for placental } \\
\text { location in both models for successful ECV and CS salbutamol, } \\
\text { tocolysis remained significantly associated with increased ECV } \\
\text { success (adjusted OR 3.4; } 95 \% \text { CI } 1.4 \text { to } 8.2 \text {; decreased CS } \\
\text { adjusted OR 3.4; } 95 \% \text { CI } 0.14 \text { to } 0.79 \text { ) }\end{array}$ \\
\hline
\end{tabular}

Weiniger 2007

\begin{tabular}{ll}
\hline Methods & RCT. \\
\hline Participants & $\begin{array}{l}\text { Inclusion criteria: All eligible nulliparous women who requested ECV after } 37 \text { weeks } \\
\text { gestation during the period from September } 2002 \text { to May } 2006 \text { were approached for } \\
\text { recruitment before the ECV procedure. Inclusion criteria included American Society of } \\
\text { Anesthetists status I to II at } 37 \text { to } 40 \text { weeks' gestation, and no fetal abnormality. } \mathrm{N}=70 \\
\text { Exclusion criteria: women with a breech presenting fetus who requested elective cae- } \\
\text { sarean delivery, either after failed ECV at another institution or because they did not wish } \\
\text { to try ECV at all, were not included or followed up, and data regarding these women } \\
\text { were not collected. Women with any of the following were excluded: previous uterine } \\
\text { surgery or uterine anomaly, contraindication for vaginal delivery, contraindications for } \\
\text { regional analgesia, woman's refusal of regional analgesia, neuropathy, severe back pain } \\
\text { with neurological radiation, poor communication and morbid obesity (body mass index } \\
\left.>40 \mathrm{~kg} / \mathrm{m}^{2}\right) .\end{array}$ \\
\hline
\end{tabular}

Interventions

Intervention: regional analgesia $(\mathrm{C})+$ tocolytic.

Spinal analgesia (bupivacaine $7.5 \mathrm{mg}$ ). $\mathrm{N}=36$.

Comparison: no regional analgesia + tocolytic. $\mathrm{N}=34$.

Both groups received $50 \mathrm{mg}$ ritodrine or $20 \mathrm{mg}$ nifedipine sublingually 


\section{Risk of bias}

\begin{tabular}{|c|c|c|}
\hline Bias & Authors' judgement & Support for judgement \\
\hline $\begin{array}{l}\text { Random sequence generation (selection } \\
\text { bias) }\end{array}$ & Unclear risk & $\begin{array}{l}\text { Allocation cards randomly inserted into envelopes by a physician } \\
\text { not involved in the study }\end{array}$ \\
\hline Allocation concealment (selection bias) & Unclear risk & $\begin{array}{l}\text { Study allocation was by sequentially numbered sealed envelopes } \\
\text { containing a concealed allocation card designating the partici- } \\
\text { pant to receive (group S), or not receive (group N), spinal anal- } \\
\text { gesia. Allocation sequence was concealed until after enrolment, } \\
\text { and informed consent was obtained before study assignment of } \\
\text { the participant was revealed }\end{array}$ \\
\hline $\begin{array}{l}\text { Blinding of participants and personnel } \\
\text { (performance bias) } \\
\text { All outcomes }\end{array}$ & High risk & It is not possible to blind people to regional analgesia. \\
\hline $\begin{array}{l}\text { Blinding of outcome assessment (detection } \\
\text { bias) } \\
\text { All outcomes }\end{array}$ & High risk & It is not possible to blind people to regional analgesia. \\
\hline $\begin{array}{l}\text { Incomplete outcome data (attrition bias) } \\
\text { All outcomes }\end{array}$ & Low risk & $\begin{array}{l}2 \text { women in each group were excluded from the analysis ( } 1 \text { in } \\
\text { each group declined ECV or the intervention, and } 1 \text { protocol } \\
\text { violation was reported in each group). This was considered in- } \\
\text { sufficient to impact the analysis }\end{array}$ \\
\hline Selective reporting (reporting bias) & Unclear risk & We did not assess the trial protocol. \\
\hline Other bias & Unclear risk & $\begin{array}{l}\text { Women in the intervention group were significantly younger } \\
\text { than those in the control group, but other baseline characteris- } \\
\text { tics were similar between groups (height, weight, weight gain, } \\
\text { EFW, GA, amniotic fluid volume, placental position, fetal pre- } \\
\text { sentation, position of fetal spine, tocolytic used) }\end{array}$ \\
\hline
\end{tabular}

\section{Weiniger 2010}

\begin{tabular}{ll}
\hline Methods & RCT. \\
\hline Participants & $\begin{array}{l}\text { Inclusion criteria: Healthy multiparae at term requesting ECV for breech presentation, } \\
\text { without fetal or uterine anomaly, were enrolled after written informed consent, and } \\
\text { all eligible multiparae requesting ECV after } 37 \text { weeks' gestation were approached for } \\
\text { recruitment before the ECV. ASA status I to II, } 37 \text { to } 40 \text { complete weeks' gestation, }\end{array}$
\end{tabular}


no fetal abnormality (including IUGR), no contraindication for vaginal delivery or no contraindication for regional analgesia. $\mathrm{N}=64$

Exclusion criteria: previous CS, previous myomectomy with uterine cavity penetration or uterine anomaly, morbid obesity (body mass index $40 \mathrm{~kg} / \mathrm{m}^{2}$ ), AFI $7 \mathrm{~cm}$, neuropathy, severe back pain with radicular radiation, patient refusal of regional analgesia, poor communication or request for elective CS (after failed ECV at another institution or not wishing to attempt ECV)

Interventions

Intervention: regional analgesia $(\mathrm{C})+$ tocolytic.

Spinal analgesia (bupivacaine $7.5 \mathrm{mg}$ ). $\mathrm{N}=31$.

Comparison: no regional analgesia + tocolytic. $\mathrm{N}=33$.

Ritodrine (50 mg IV) used as muscle relaxant until April 2003, when it was replaced by nifedipine (20 mg orally)

\begin{tabular}{ll}
\hline Outcomes & Successful ECV. \\
\hline Notes & 1 woman's data not analysed. \\
\hline
\end{tabular}

Risk of bias

\begin{tabular}{|c|c|c|}
\hline Bias & Authors' judgement & Support for judgement \\
\hline $\begin{array}{l}\text { Random sequence generation (selection } \\
\text { bias) }\end{array}$ & Unclear risk & $\begin{array}{l}\text { "...concealed cards allocated at random by a physician not in- } \\
\text { volved in study enrolment..." }\end{array}$ \\
\hline
\end{tabular}

\begin{tabular}{|l|l|l} 
Allocation concealment (selection bias) & Unclear risk & $\begin{array}{l}\text { "Women were randomised using numbered sealed envelopes } \\
\text { containing concealed cards allocated at random by a physician } \\
\text { not involved in study enrolment" }\end{array}$ \\
\hline
\end{tabular}

Blinding of participants and personnel High risk The 2 experienced ECV-performing obstetricians were not (performance bias)

blinded. Women could not be blinded either

All outcomes

Blinding of outcome assessment (detection High risk bias)

No blinding attempted

All outcomes

Incomplete outcome data (attrition bias) Low risk All outcomes
1 woman (in analgesia group) refused ECV after randomisation. 1 woman randomly assigned to receive spinal analgesia did not receive the intended treatment, as the anaesthetist was unable to locate the dura (her ECV was unsuccessful, but she was analysed as intention-to-treat in the spinal analgesia group)

2 women with breech presentation in consecutive pregnancies were enrolled twice in the current study. A further analysis without these women was performed to exclude potential bias for the primary outcome. The success of ECV with spinal analgesia excluding the repeat data was 23 of $27(85.1 \%)$ vs 19 of 33 (57. $5 \%$ ) without analgesia (P value $<0.02$ )

None of this would be sufficient to have an impact on the analysis 
Weiniger 2010 (Continued)

\begin{tabular}{|c|c|c|}
\hline Selective reporting (reporting bias) & Unclear risk & We did not assess the trial protocol. \\
\hline Other bias & Unclear risk & $\begin{array}{l}\text { Similar maternal age, GA, weight at time of ECV and height. } \\
\text { Similar too in terms of breech in past pregnancy, EFW, AFI. } \\
\text { Study authors report there was no difference according to parity } \\
\text { in the rate of successful ECV within intention-to-treat groups. } \\
\text { However, it should be noted that for parity } 1,13 \text { were included } \\
\text { in the spinal analgesia group and } 21 \text { in the no analgesia group }\end{array}$ \\
\hline
\end{tabular}

Yanny 2000

\begin{tabular}{|c|c|}
\hline Methods & RCT. \\
\hline Participants & $\begin{array}{l}\text { Inclusion criteria: women with breech presentation choosing ECV, cardiotocograph } \\
\text { and US examination acceptable, failed initial ECV attempt without tocolysis. } \mathrm{N}=57\end{array}$ \\
\hline Interventions & $\begin{array}{l}\text { Intervention: tocolytic: glycerol trinitrate/nitroglycerine - nitric oxide donor (A3) - } \\
\text { sublingual } \\
\text { Glyceryl trinitrate sublingual spray } 800 \mu \mathrm{g} . \mathrm{N}=31 \text {. } \\
\text { Comparison: placebo. } \mathrm{N}=26 \text {. } \\
\text { Labelled sprays A and } \mathrm{B} \text {; repeat ECV attempt; if unsuccessful and uterus not relaxed, } \\
\text { salbutamol infusion and repeat ECV attempt }\end{array}$ \\
\hline Outcomes & $\begin{array}{l}\text { Side effects: maternal discomfort; blood pressure; pulse, after spray administration; ECV } \\
\text { success; uterine relaxation (poor } 8 / 30 \text { nitroglycerine vs } 9 / 25 \text { placebo, reasonable } 11 / 30 \\
\text { vs } 8 / 25 \text {, good } 7 / 30 \text { vs } 8 / 25 \text {, excellent } 4 / 30 \text { vs } 0 / 25 \text { ); salbutamol required ( } 13 / 31 \text { vs } 14 / \\
26 \text { ); dose of salbutamol }\end{array}$ \\
\hline
\end{tabular}

\section{Risk of bias}

Bias Authors' judgement Support for judgement

Random sequence generation (selection Low risk Computer-generated random numbers. bias)

Allocation concealment (selection bias) Low risk

Blinding of participants and personnel Unclear risk (performance bias)

All outcomes

Blinding of outcome assessment (detection Unclear risk bias)

All outcomes
Used opaque sealed envelopes, but no information as to whether they were sequentially numbered

No information provided.

No information provided. 


\begin{tabular}{l|l|l}
\hline $\begin{array}{l}\text { Incomplete outcome data (attrition bias) } \\
\text { All outcomes }\end{array}$ & Low risk & $\begin{array}{l}\text { No exclusions were reported after randomisation, and no loss to } \\
\text { follow-up }\end{array}$ \\
\hline Selective reporting (reporting bias) & Unclear risk & We did not assess the trial protocol. \\
\hline Other bias & Low risk & $\begin{array}{l}\text { Baseline characteristics for the women were similar between the } 2 \\
\text { groups in maternal age, parity, extended legs and liquor volume. } \\
\text { No other biases were apparent }\end{array}$ \\
\hline
\end{tabular}

AFI: amniotic fluid index.

BMI: body mass index.

$\mathrm{CI}$ : confidence interval.

CS: caesarean section.

CSE: combined spinal epidural.

CTG: cardiotocography.

ECV: external cephalic version.

EFW estimated fetal weight.

GA: gestational age.

IUGR: intrauterine growth restriction.

IV: intravenous.

IVI: intravenous infusion.

$\min (s)$ : minute(s).

NST: non-stress test.

OR: odds ratio.

RCT: randomised controlled trial.

SD: standard deviation.

SQ: subcutaneous.

US: ultrasound.

vs: versus.

A: Tocolytic drugs: A1 - beta stimulants; A2 - calcium channel blockers; A3 - nitric oxide donors.

B: Vibroacoustic stimulation.

C: Regional analgesia.

D: Amnioinfusion.

E: Systemic opioids.

\section{Characteristics of excluded studies [ordered by study ID]}

\begin{tabular}{ll}
\hline Study & Reason for exclusion \\
\hline Dockeray 1984 & $\begin{array}{l}\text { Non-randomised follow-up study comparing outcomes of patients who had an ECV vs patients who had a breech } \\
\text { vaginal delivery }\end{array}$ \\
\hline Guittier 2013 & $\begin{array}{l}\text { This was not a randomised trial. } 63 \text { women undergoing ECV under hypnosis between } 2010 \text { and } 2013 \text { were } \\
\text { compared with } 122 \text { women receiving standard care between } 2005 \text { and } 2008\end{array}$
\end{tabular}

Interventions for helping to turn term breech babies to head first presentation when using external cephalic version (Review) 
(Continued)

Wallace 1984 Non-randomised follow-up study after randomised trial of ECV with tocolysis

ECV: external cephalic version.

\section{Characteristics of studies awaiting assessment [ordered by study ID]}

Andarsio 2000

\begin{tabular}{|c|c|}
\hline Methods & RCT. \\
\hline Participants & Inclusion criteria: women undergoing ECV attempt. Unit: individual women. $\mathrm{N}=35$ women included \\
\hline Interventions & $\begin{array}{l}\text { Intervention: tocolysis: nitroglycerine - nitric oxide donor (A3) - no route reported } \\
\text { Nitroglycerine: only abstract available, no dose or route of administration given. } \mathrm{N}=18 \\
\text { Comparison: tocolysis: terbutaline - beta stimulant (A1) - no route reported. } \\
\text { Terbutaline: only abstract available, no dose or route of administration given. } \mathrm{N}=17\end{array}$ \\
\hline Outcomes & ECV success. \\
\hline Notes & $\begin{array}{l}\text { Preliminary abstract report only reviewed. This study was included in the previous publication (Cluver 2012), but } \\
\text { we cannot include in this update until we have information on the routes of administration used. We are writing to } \\
\text { study authors to request this information }\end{array}$ \\
\hline
\end{tabular}

Hollard 2003

\begin{tabular}{|c|c|}
\hline Methods & RCT. \\
\hline Participants & $\begin{array}{l}\text { Inclusion criteria: normal singleton breech pregnancy, gestational age } 36 \text { weeks or more, intact membranes, not in } \\
\text { labour. } \mathrm{N}=36\end{array}$ \\
\hline Interventions & $\begin{array}{l}\text { Intervention: regional analgesia }(\mathrm{C}) \text {. } \\
1000 \mathrm{~mL} \text { IVI prehydration and intrathecal injection of } 6 \mathrm{mg} 2 \% \text { lidocaine with } 15 \mathrm{mcg} \text { fentanyl. Followed by the } \\
\text { same protocol as comparison group. } \mathrm{N}=19 \\
\text { Comparison: no regional analgesia + tocolytic. } \\
0.25 \mathrm{mg} \text { SQ terbutaline and ECV attempted by a MFM physician. } \mathrm{N}=17\end{array}$ \\
\hline Outcomes & Maternal pain (reduced in spinal analgesia group) and satisfaction (no difference) on visual scale; ECV success \\
\hline Notes & $\begin{array}{l}\text { January } 1998 \text { to January } 2003 \text {. } \\
\text { It is unclear whether both groups received terbutaline or just the comparison group. We are writing to study authors } \\
\text { to clarify this and other details of the study }\end{array}$ \\
\hline
\end{tabular}


Tan 2008

\begin{tabular}{ll}
\hline Methods & Double-blind RCT. \\
\hline Participants & $\begin{array}{l}\text { Women with a singleton baby in the breech position. Gestation } \geq 36 \text { weeks (check for early confirmation of gestational } \\
\text { age), intact membranes and assuring fetal status on cardiotocograph. } \mathrm{N}=\text { at least } 103 \text { women }\end{array}$ \\
\hline Interventions & $250 \mu$ g or $500 \mu \mathrm{g}$ of bolus subcutaneous terbutaline followed by ECV 15 minutes later with a maximum of 2 attempts \\
\hline Outcomes & $\begin{array}{l}\text { Primary: immediate success rate of ECV; caesarean section; cephalic presentation at birth } \\
\text { Secondary: post-ECV cardiotocograph abnormalities; neonatal nursery admission; Apgar score at } 5 \text { minutes; umbilical } \\
\text { cord arterial blood, pH; adverse drug events; visual analogue scale satisfaction score with ECV; indication for operative } \\
\text { delivery }\end{array}$ \\
\hline Notes & Study reported as completed, but no information or data available as yet \\
\hline
\end{tabular}

ECV: external cephalic version.

IVI: intravenous infusion.

RCT: randomised controlled trial.

\section{Characteristics of ongoing studies [ordered by study ID]}

\section{Burgos 2012}

\begin{tabular}{l|l} 
Trial name or title & $\begin{array}{l}\text { Open randomised controlled trial to evaluate the efficacy and safety of remifentanil versus nitrous oxide in } \\
\text { external cephalic version at term in singleton pregnancy in breech presentation (REMIVER) }\end{array}$ \\
\hline Methods & Single-centre randomised parallel-group controlled trial. Analysis by intention-to-treat \\
\hline Participants & $\begin{array}{l}\text { Women } 18 \text { to } 65 \text { with term pregnancy, singleton pregnancy in breech position (estimated enrolment: } 180 \\
\text { women). Setting: hospital in Spain }\end{array}$ \\
\hline Interventions & Remifentanil vs inhaled nitrous oxide. \\
\hline Outcomes & Rate of successful ECV, analgesic effect, safety, caesarean rates, acceptability of procedures to the women \\
\hline Starting date & July 2012 (expected final data collection date: July 2013). \\
\hline Contact information & Jorge Burgos, jburgoss@sego.es \\
\hline Notes &
\end{tabular}


Passerini 2013

\begin{tabular}{l|l}
\hline Trial name or title & Maternal oral hydration and external cephalic version. \\
\hline Methods & Randomised trial. \\
\hline Participants & 164 pregnant women over 18 years of age with breech presentation at term \\
\hline $\begin{array}{l}\text { Interventions } \\
\text { Women in the intervention will be asked to drink } 2 \text { litres of water in } 2 \text { hours; the control group will receive } \\
\text { no intervention }\end{array}$ \\
\hline Outcomes & Successful external cephalic version, amniotic fluid volume, type of birth \\
\hline Starting date & October 2011 (expected final data collection date: January 2014) \\
\hline Contact information & virna.zobbi@unimib.it \\
\hline Notes & \\
\hline
\end{tabular}

ECV: external cephalic version. 
DATA AND ANALYSES

Comparison 1. Tocolytic drugs (A) vs placebo

\begin{tabular}{|c|c|c|c|c|}
\hline Outcome or subgroup title & $\begin{array}{l}\text { No. of } \\
\text { studies }\end{array}$ & $\begin{array}{c}\text { No. of } \\
\text { participants }\end{array}$ & Statistical method & Effect size \\
\hline $\begin{array}{l}1 \text { Cephalic presentation at birth } \\
\text { (primary) }\end{array}$ & 8 & & Risk Ratio (M-H, Random, 95\% CI) & Subtotals only \\
\hline $\begin{array}{l}1.1 \text { Beta stimulants - } \\
\text { parenteral }\end{array}$ & 5 & 459 & Risk Ratio (M-H, Random, 95\% CI) & $1.68[1.14,2.48]$ \\
\hline $\begin{array}{l}1.2 \text { Beta stimulants - oral or } \\
\text { sublingual }\end{array}$ & 0 & 0 & Risk Ratio (M-H, Random, 95\% CI) & $0.0[0.0,0.0]$ \\
\hline $\begin{array}{l}\text { 1.3 Calcium channel blockers } \\
\text { - oral or sublingual }\end{array}$ & 1 & 310 & Risk Ratio (M-H, Random, 95\% CI) & $1.13[0.87,1.48]$ \\
\hline $\begin{array}{l}1.4 \text { Nitric oxide donors - } \\
\text { parenteral }\end{array}$ & 1 & 125 & Risk Ratio (M-H, Random, 95\% CI) & $1.58[0.91,2.76]$ \\
\hline $\begin{array}{l}1.5 \text { Nitric oxide donors - oral } \\
\text { or sublingual }\end{array}$ & 1 & 99 & Risk Ratio (M-H, Random, 95\% CI) & $0.74[0.52,1.05]$ \\
\hline $\begin{array}{l}2 \text { Failure to achieve cephalic } \\
\text { vaginal birth (composite } \\
\text { outcome: caesarean section }+ \\
\text { vaginal breech birth) }\end{array}$ & 5 & & Risk Ratio (M-H, Random, 95\% CI) & Subtotals only \\
\hline $\begin{array}{l}2.1 \text { Beta stimulants - } \\
\text { parenteral }\end{array}$ & 4 & 399 & Risk Ratio (M-H, Random, 95\% CI) & $0.75[0.60,0.92]$ \\
\hline $\begin{array}{l}2.2 \text { Beta stimulants - oral or } \\
\text { sublingual }\end{array}$ & 0 & 0 & Risk Ratio (M-H, Random, 95\% CI) & $0.0[0.0,0.0]$ \\
\hline $\begin{array}{l}\text { 2.3 Calcium channel blockers } \\
\text { - oral or sublingual }\end{array}$ & 0 & 0 & Risk Ratio (M-H, Random, 95\% CI) & $0.0[0.0,0.0]$ \\
\hline $\begin{array}{l}2.4 \text { Nitric oxide donors - } \\
\text { parenteral }\end{array}$ & 0 & 0 & Risk Ratio (M-H, Random, 95\% CI) & $0.0[0.0,0.0]$ \\
\hline $\begin{array}{l}2.5 \text { Nitric oxide donors - oral } \\
\text { or sublingual }\end{array}$ & 1 & 99 & Risk Ratio (M-H, Random, 95\% CI) & $1.22[0.86,1.72]$ \\
\hline 3 Caesarean section (primary) & 8 & & Risk Ratio (M-H, Random, 95\% CI) & Subtotals only \\
\hline $\begin{array}{l}3.1 \text { Beta stimulants - } \\
\text { parenteral }\end{array}$ & 6 & 742 & Risk Ratio (M-H, Random, 95\% CI) & $0.77[0.67,0.88]$ \\
\hline $\begin{array}{l}3.2 \text { Beta stimulants - oral or } \\
\text { sublingual }\end{array}$ & 0 & 0 & Risk Ratio (M-H, Random, 95\% CI) & $0.0[0.0,0.0]$ \\
\hline $\begin{array}{l}\text { 3.3 Calcium channel blockers } \\
\text { - oral or sublingual }\end{array}$ & 1 & 310 & Risk Ratio (M-H, Random, 95\% CI) & $1.11[0.88,1.40]$ \\
\hline $\begin{array}{l}3.4 \text { Nitric oxide donors - } \\
\text { parenteral }\end{array}$ & 1 & 125 & Risk Ratio (M-H, Random, 95\% CI) & $0.83[0.67,1.02]$ \\
\hline $\begin{array}{l}3.5 \text { Nitric oxide donors - oral } \\
\text { or sublingual }\end{array}$ & 0 & 0 & Risk Ratio (M-H, Random, 95\% CI) & $0.0[0.0,0.0]$ \\
\hline 4 Fetal bradycardia (primary) & 3 & & Risk Ratio (M-H, Random, 95\% CI) & Subtotals only \\
\hline $\begin{array}{l}4.1 \text { Beta stimulants - } \\
\text { parenteral }\end{array}$ & 1 & 58 & Risk Ratio (M-H, Random, 95\% CI) & $2.81[0.12,66.17]$ \\
\hline $\begin{array}{l}\text { 4.2 Beta stimulants - oral or } \\
\text { sublingual }\end{array}$ & 0 & 0 & Risk Ratio (M-H, Random, 95\% CI) & $0.0[0.0,0.0]$ \\
\hline
\end{tabular}

Interventions for helping to turn term breech babies to head first presentation when using external cephalic version (Review) 


\begin{tabular}{|c|c|c|c|c|}
\hline $\begin{array}{l}\text { 4.3 Calcium channel blockers } \\
\text { - oral or sublingual }\end{array}$ & 1 & 310 & Risk Ratio (M-H, Random, 95\% CI) & $1.11[0.50,2.43]$ \\
\hline $\begin{array}{l}4.4 \text { Nitric oxide donors - } \\
\text { parenteral }\end{array}$ & 0 & 0 & Risk Ratio (M-H, Random, 95\% CI) & $0.0[0.0,0.0]$ \\
\hline $\begin{array}{l}4.5 \text { Nitric oxide donors - oral } \\
\text { or sublingual }\end{array}$ & 1 & 99 & Risk Ratio (M-H, Random, 95\% CI) & $0.39[0.08,1.93]$ \\
\hline 5 Failed external cephalic version & 13 & & Risk Ratio (M-H, Random, 95\% CI) & Subtotals only \\
\hline $\begin{array}{l}5.1 \text { Beta stimulants - } \\
\text { parenteral }\end{array}$ & 9 & 900 & Risk Ratio (M-H, Random, 95\% CI) & $0.70[0.60,0.82]$ \\
\hline $\begin{array}{l}5.2 \text { Beta stimulants - oral or } \\
\text { sublingual }\end{array}$ & 1 & 45 & Risk Ratio (M-H, Random, 95\% CI) & $1.0[0.56,1.79]$ \\
\hline $\begin{array}{l}\text { 5.3 Calcium channel blockers } \\
\text { - oral or sublingual }\end{array}$ & 1 & 310 & Risk Ratio (M-H, Random, 95\% CI) & $0.93[0.78,1.11]$ \\
\hline $\begin{array}{l}5.4 \text { Nitric oxide donors - } \\
\text { parenteral }\end{array}$ & 1 & 126 & Risk Ratio (M-H, Random, 95\% CI) & $0.86[0.70,1.06]$ \\
\hline $\begin{array}{l}5.5 \text { Nitric oxide donors - oral } \\
\text { or sublingual }\end{array}$ & 2 & 156 & Risk Ratio (M-H, Random, 95\% CI) & $1.04[0.55,1.96]$ \\
\hline $\begin{array}{l}6 \text { Difficult external cephalic } \\
\text { version }\end{array}$ & 1 & & Risk Ratio (M-H, Random, 95\% CI) & Subtotals only \\
\hline $\begin{array}{l}6.1 \text { Beta stimulants - } \\
\text { parenteral }\end{array}$ & 1 & 63 & Risk Ratio (M-H, Random, 95\% CI) & $0.5[0.16,1.54]$ \\
\hline $\begin{array}{l}6.2 \text { Beta stimulants - oral or } \\
\text { sublingual }\end{array}$ & 0 & 0 & Risk Ratio (M-H, Random, 95\% CI) & $0.0[0.0,0.0]$ \\
\hline $\begin{array}{l}\text { 6.3 Calcium channel blockers } \\
\text { - oral or sublingual }\end{array}$ & 0 & 0 & Risk Ratio (M-H, Random, 95\% CI) & $0.0[0.0,0.0]$ \\
\hline $\begin{array}{l}6.4 \text { Nitric oxide donors - } \\
\text { parenteral }\end{array}$ & 0 & 0 & Risk Ratio (M-H, Random, 95\% CI) & $0.0[0.0,0.0]$ \\
\hline $\begin{array}{l}\text { 6.5 Nitric oxide donors - oral } \\
\text { or sublingual }\end{array}$ & 0 & 0 & Risk Ratio (M-H, Random, 95\% CI) & $0.0[0.0,0.0]$ \\
\hline 7 Maternal palpitations & 3 & & Risk Ratio (M-H, Random, 95\% CI) & Subtotals only \\
\hline $\begin{array}{l}\text { 7.1 Beta stimulants - } \\
\text { parenteral }\end{array}$ & 1 & 114 & Risk Ratio (M-H, Random, 95\% CI) & $5.0[0.25,101.89]$ \\
\hline $\begin{array}{l}7.2 \text { Beta stimulants - oral or } \\
\text { sublingual }\end{array}$ & 0 & 0 & Risk Ratio (M-H, Random, 95\% CI) & $0.0[0.0,0.0]$ \\
\hline $\begin{array}{l}\text { 7.3 Calcium channel blockers } \\
\text { - oral or sublingual }\end{array}$ & 0 & 0 & Risk Ratio (M-H, Random, 95\% CI) & $0.0[0.0,0.0]$ \\
\hline $\begin{array}{l}7.4 \text { Nitric oxide donors - } \\
\text { parenteral }\end{array}$ & 1 & 117 & Risk Ratio (M-H, Random, 95\% CI) & $0.49[0.05,5.27]$ \\
\hline $\begin{array}{l}7.5 \text { Nitric oxide donors - oral } \\
\text { or sublingual }\end{array}$ & 1 & 99 & Risk Ratio (M-H, Random, 95\% CI) & $0.0[0.0,0.0]$ \\
\hline Maternal headaches & 2 & & Risk Ratio (M-H, Random, 95\% CI) & Subtotals only \\
\hline $\begin{array}{l}8.1 \text { Beta stimulants - } \\
\text { parenteral }\end{array}$ & 0 & 0 & Risk Ratio (M-H, Random, 95\% CI) & $0.0[0.0,0.0]$ \\
\hline $\begin{array}{l}8.2 \text { Beta stimulants - oral or } \\
\text { sublingual }\end{array}$ & 0 & 0 & Risk Ratio (M-H, Random, 95\% CI) & $0.0[0.0,0.0]$ \\
\hline $\begin{array}{l}\text { 8.3 Calcium channel blockers } \\
\text { - oral or sublingual }\end{array}$ & 0 & 0 & Risk Ratio (M-H, Random, 95\% CI) & $0.0[0.0,0.0]$ \\
\hline $\begin{array}{l}8.4 \text { Nitric oxide donors - } \\
\text { parenteral }\end{array}$ & 1 & 117 & Risk Ratio (M-H, Random, 95\% CI) & $18.68[1.11,313.77]$ \\
\hline $\begin{array}{l}8.5 \text { Nitric oxide donors - oral } \\
\text { or sublingual }\end{array}$ & 1 & 99 & Risk Ratio (M-H, Random, 95\% CI) & $10.29[2.55,41.56]$ \\
\hline
\end{tabular}


9 Maternal hypotension

9.1 Beta stimulants -

parenteral

9.2 Beta stimulants - oral or

sublingual

9.3 Calcium channel blockers

- oral or sublingual

9.4 Nitric oxide donors -

parenteral

9.5 Nitric oxide donors - oral

or sublingual

10 Operative vaginal birth

10.1 Beta stimulants parenteral

10.2 Beta stimulants - oral or sublingual

10.3 Calcium channel

blockers - oral or sublingual

10.4 Nitric oxide donors -

parenteral

10.5 Nitric oxide donors - oral or sublingual

11 Maternal mortality

11.1 Beta stimulants -

parenteral

11.2 Beta stimulants - oral or sublingual

11.3 Calcium channel

blockers - oral or sublingual

11.4 Nitric oxide donors -

parenteral

11.5 Nitric oxide donors - oral or sublingual

12 Maternal morbidity

12.1 Beta stimulants -

parenteral

12.2 Beta stimulants - oral or sublingual

12.3 Calcium channel

blockers - oral or sublingual

12.4 Nitric oxide donors parenteral

12.5 Nitric oxide donors - oral or sublingual

13 Perinatal mortality

13.1 Beta stimulants -

parenteral

13.2 Beta stimulants - oral or sublingual

13.3 Calcium channel

blockers - oral or sublingual
0

0

0

0

0

0

0

0

0

0

0

$$
0
$$

0

310
Risk Ratio (M-H, Random, 95\% CI) Risk Ratio (M-H, Random, 95\% CI)

Risk Ratio (M-H, Random, 95\% CI)

Risk Ratio (M-H, Random, 95\% CI)

Risk Ratio (M-H, Random, 95\% CI)

Risk Ratio (M-H, Random, 95\% CI)

Risk Ratio (M-H, Random, 95\% CI)

Risk Ratio (M-H, Random, 95\% CI)

Risk Ratio (M-H, Random, 95\% CI)

Risk Ratio (M-H, Random, 95\% CI)

Risk Ratio (M-H, Random, 95\% CI)

Risk Ratio (M-H, Random, 95\% CI)

Risk Ratio (M-H, Random, 95\% CI)

Risk Ratio (M-H, Random, 95\% CI)

Risk Ratio (M-H, Random, 95\% CI)

Risk Ratio (M-H, Random, 95\% CI)

Risk Ratio (M-H, Random, 95\% CI)

Risk Ratio (M-H, Random, 95\% CI)

Risk Ratio (M-H, Random, 95\% CI)

Risk Ratio (M-H, Random, 95\% CI)

Risk Ratio (M-H, Random, 95\% CI)
Risk Ratio (M-H, Random, 95\% CI)

Risk Ratio (M-H, Random, 95\% CI)

Risk Ratio (M-H, Random, 95\% CI)
Subtotals only

$0.0[0.0,0.0]$

$0.0[0.0,0.0]$

$0.0[0.0,0.0]$

$1.47[0.26,8.50]$

$5.88[0.73,47.07]$

Subtotals only

$0.0[0.0,0.0]$

$0.0[0.0,0.0]$

$0.34[0.09,1.22]$

$0.0[0.0,0.0]$

$0.0[0.0,0.0]$

Subtotals only $0.0[0.0,0.0]$

$0.0[0.0,0.0]$

$0.0[0.0,0.0]$

$0.0[0.0,0.0]$

$0.0[0.0,0.0]$

Subtotals only $0.0[0.0,0.0]$

$0.0[0.0,0.0]$

$0.0[0.0,0.0]$

$0.0[0.0,0.0]$

$0.0[0.0,0.0]$

Subtotals only $0.0[0.0,0.0]$

$0.0[0.0,0.0]$

$0.0[0.0,0.0]$ 
13.4 Nitric oxide donors -

0

parenteral

13.5 Nitric oxide donors - oral

or sublingual

14 Perinatal morbidity

14.1 Beta stimulants parenteral

14.2 Beta stimulants - oral or sublingual

14.3 Calcium channel blockers - oral or sublingual

14.4 Nitric oxide donors parenteral

14.5 Nitric oxide donors - oral or sublingual

15 Vaginal breech birth

15.1 Beta stimulants -

parenteral

15.2 Beta stimulants - oral or sublingual

15.3 Calcium channel

blockers - oral or sublingual

15.4 Nitric oxide donors parenteral

15.5 Nitric oxide donors - oral or sublingual

16 Apgar $<7$ at 5 minutes (not prespecified)

16.1 Beta stimulants -

parenteral

16.2 Beta stimulants - oral or sublingual

16.3 Calcium channel

blockers - oral or sublingual

16.4 Nitric oxide donors -

parenteral

16.5 Nitric oxide donors - oral or sublingual

17 Neonatal seizures (not prespecified)

17.1 Beta stimulants parenteral

17.2 Beta stimulants - oral or sublingual

17.3 Calcium channel

blockers - oral or sublingual

17.4 Nitric oxide donors parenteral

17.5 Nitric oxide donors - oral or sublingual

0

0

0

0

0

1

1

0

0

0

0
Risk Ratio (M-H, Random, 95\% CI)

Risk Ratio (M-H, Random, 95\% CI)

Risk Ratio (M-H, Random, 95\% CI)

Risk Ratio (M-H, Random, 95\% CI)

Risk Ratio (M-H, Random, 95\% CI)

Risk Ratio (M-H, Random, 95\% CI)

Risk Ratio (M-H, Random, 95\% CI)

Risk Ratio (M-H, Random, 95\% CI)

0

Risk Ratio (M-H, Random, 95\% CI)

0

Risk Ratio (M-H, Random, 95\% CI)

Risk Ratio (M-H, Random, 95\% CI)
Risk Ratio (M-H, Random, 95\% CI)

Risk Ratio (M-H, Random, 95\% CI)

Risk Ratio (M-H, Random, 95\% CI)

0

0

0

0

0

Risk Ratio (M-H, Random, 95\% CI)

Risk Ratio (M-H, Random, 95\% CI)

Risk Ratio (M-H, Random, 95\% CI)

Risk Ratio (M-H, Random, 95\% CI)

Risk Ratio (M-H, Random, 95\% CI)

Risk Ratio (M-H, Random, 95\% CI)

Risk Ratio (M-H, Random, 95\% CI)
$0.0[0.0,0.0]$

$0.0[0.0,0.0]$

Subtotals only

$0.0[0.0,0.0]$

$0.0[0.0,0.0]$

$0.0[0.0,0.0]$

$0.0[0.0,0.0]$

$0.0[0.0,0.0]$

Subtotals only

$1.0[0.30,3.28]$

$0.0[0.0,0.0]$

$0.0[0.0,0.0]$

$0.0[0.0,0.0]$

$0.0[0.0,0.0]$

Subtotals only

$0.0[0.0,0.0]$

$0.0[0.0,0.0]$

$0.0[0.0,0.0]$

$0.0[0.0,0.0]$

$0.0[0.0,0.0]$

Subtotals only

$0.0[0.0,0.0]$

$0.0[0.0,0.0]$

$0.0[0.0,0.0]$

$0.0[0.0,0.0]$

$0.0[0.0,0.0]$

Interventions for helping to turn term breech babies to head first presentation when using external cephalic version (Review) 


\begin{tabular}{|c|c|c|c|c|}
\hline $\begin{array}{l}18 \text { Admission to neonatal unit } \\
\text { (not prespecified) }\end{array}$ & 2 & & Risk Ratio (M-H, Random, 95\% CI) & Subtotals only \\
\hline $\begin{array}{l}18.1 \text { Beta stimulants - } \\
\text { parenteral }\end{array}$ & 2 & 238 & Risk Ratio (M-H, Random, 95\% CI) & $1.0[0.30,3.36]$ \\
\hline $\begin{array}{l}\text { 18.2 Beta stimulants - oral or } \\
\text { sublingual }\end{array}$ & 0 & 0 & Risk Ratio (M-H, Random, 95\% CI) & $0.0[0.0,0.0]$ \\
\hline $\begin{array}{l}\text { 18.3 Calcium channel } \\
\text { blockers - oral or sublingual }\end{array}$ & 0 & 0 & Risk Ratio (M-H, Random, 95\% CI) & $0.0[0.0,0.0]$ \\
\hline $\begin{array}{l}18.4 \text { Nitric oxide donors - } \\
\text { parenteral }\end{array}$ & 0 & 0 & Risk Ratio (M-H, Random, 95\% CI) & $0.0[0.0,0.0]$ \\
\hline $\begin{array}{l}18.5 \text { Nitric oxide donors - oral } \\
\text { or sublingual }\end{array}$ & 0 & 0 & Risk Ratio (M-H, Random, 95\% CI) & $0.0[0.0,0.0]$ \\
\hline 19 Birth trauma (not prespecified) & 1 & & Risk Ratio (M-H, Random, 95\% CI) & Subtotals only \\
\hline $\begin{array}{l}19.1 \text { Beta stimulants - } \\
\text { parenteral }\end{array}$ & 1 & 114 & Risk Ratio (M-H, Random, 95\% CI) & $0.0[0.0,0.0]$ \\
\hline $\begin{array}{l}\text { 19.2 Beta stimulants - oral or } \\
\text { sublingual }\end{array}$ & 0 & 0 & Risk Ratio (M-H, Random, 95\% CI) & $0.0[0.0,0.0]$ \\
\hline $\begin{array}{l}19.3 \text { Calcium channel } \\
\text { blockers - oral or sublingual }\end{array}$ & 0 & 0 & Risk Ratio (M-H, Random, 95\% CI) & $0.0[0.0,0.0]$ \\
\hline $\begin{array}{l}\text { 19.4 Nitric oxide donors - } \\
\text { parenteral }\end{array}$ & 0 & 0 & Risk Ratio (M-H, Random, 95\% CI) & $0.0[0.0,0.0]$ \\
\hline $\begin{array}{l}19.5 \text { Nitric oxide donors - oral } \\
\text { or sublingual }\end{array}$ & 0 & 0 & Risk Ratio (M-H, Random, 95\% CI) & $0.0[0.0,0.0]$ \\
\hline $\begin{array}{l}20 \text { Maternal flushing (not } \\
\text { prespecified) }\end{array}$ & 1 & & Risk Ratio (M-H, Random, 95\% CI) & Subtotals only \\
\hline $\begin{array}{l}20.1 \text { Beta stimulants - } \\
\text { parenteral }\end{array}$ & 0 & 0 & Risk Ratio (M-H, Random, 95\% CI) & $0.0[0.0,0.0]$ \\
\hline $\begin{array}{l}20.2 \text { Beta stimulants - oral or } \\
\text { sublingual }\end{array}$ & 0 & 0 & Risk Ratio (M-H, Random, 95\% CI) & $0.0[0.0,0.0]$ \\
\hline $\begin{array}{l}20.3 \text { Calcium channel } \\
\text { blockers - oral or sublingual }\end{array}$ & 1 & 310 & Risk Ratio (M-H, Random, 95\% CI) & $23.30[1.38,391.91]$ \\
\hline $\begin{array}{l}20.4 \text { Nitric oxide donors - } \\
\text { parenteral }\end{array}$ & 0 & 0 & Risk Ratio (M-H, Random, 95\% CI) & $0.0[0.0,0.0]$ \\
\hline $\begin{array}{l}20.5 \text { Nitric oxide donors - oral } \\
\text { or sublingual }\end{array}$ & 0 & 0 & Risk Ratio (M-H, Random, 95\% CI) & $0.0[0.0,0.0]$ \\
\hline
\end{tabular}

\section{Comparison 2. Tocolytic drug 1 (A) vs tocolytic drug 2 (A)}

\begin{tabular}{lcccr} 
Outcome or subgroup title & $\begin{array}{c}\text { No. of } \\
\text { studies }\end{array}$ & $\begin{array}{c}\text { No. of } \\
\text { participants }\end{array}$ & Statistical method & Effect size \\
\hline $\begin{array}{l}\text { 1 Cephalic presentation at birth } \\
\text { (primary) }\end{array}$ & 2 & & Risk Ratio (M-H, Random, 95\% CI) & Subtotals only \\
$\begin{array}{c}\text { 1.1 Calcium channel blockers } \\
\text { (A2) vs beta stimulants (A1) }\end{array}$ & 1 & 90 & Risk Ratio (M-H, Random, 95\% CI) & $0.62[0.39,0.98]$ \\
$\begin{array}{l}1.2 \text { Nitric oxide donors (A3) } \\
\text { vs beta stimulants (A1) }\end{array}$ & 1 & 74 & Risk Ratio (M-H, Random, 95\% CI) & $0.56[0.29,1.09]$ \\
\hline
\end{tabular}

Interventions for helping to turn term breech babies to head first presentation when using external cephalic version (Review) 
1.3 Nitric oxide donors (A3) vs calcium channel blockers

(A2)

2 Failure to achieve cephalic vaginal birth (composite outcome: caesarean section + vaginal breech birth)

2.1 Calcium channel blockers

(A2) vs beta stimulants (A1)

2.2 Nitric oxide donors (A3) vs beta stimulants (A1)

2.3 Nitric oxide donors (A3) vs calcium channel blockers

(A2)

3 Caesarean section (primary)

3.1 Calcium channel blockers (A2) vs beta stimulants (A1)

3.2 Nitric oxide donors (A3) vs beta stimulants (A1)

3.3 Nitric oxide donors (A3) vs calcium channel blockers

(A2)

4 Fetal bradycardia (primary)

4.1 Calcium channel blockers

(A2) vs beta stimulants (A1)

4.2 Nitric oxide donors (A3)

vs beta stimulants (A1)

4.3 Nitric oxide donors (A3)

vs calcium channel blockers

(A2)

5 Failed external cephalic version

5.1 Calcium channel blockers

(A2) vs beta stimulants (A1)

5.2 Nitric oxide donors (A3)

vs beta stimulants (A1)

5.3 Nitric oxide donors (A3) vs calcium channel blockers

(A2)

6 Difficult external cephalic

version

6.1 Calcium channel blockers

(A2) vs beta stimulants (A1)

6.2 Nitric oxide donors (A3)

vs beta stimulants (A1)

6.3 Nitric oxide donors (A3) vs calcium channel blockers

(A2)

7 Maternal palpitations

7.1 Calcium channel blockers (A2) vs beta stimulants (A1)
Subtotals only

$0.0[0.0,0.0]$

$1.13[0.88,1.47]$

$0.0[0.0,0.0]$

Subtotals only

Risk Ratio (M-H, Random, 95\% CI)

$1.28[1.03,1.59]$

$0.0[0.0,0.0]$

$0.0[0.0,0.0]$

Risk Ratio (M-H, Random, 95\% CI)

Risk Ratio (M-H, Random, 95\% CI)

Risk Ratio (M-H, Random, 95\% CI)

Subtotals only

$1.17[0.46,3.03]$

$1.06[0.16,7.10]$

$0.0[0.0,0.0]$

Subtotals only

Risk Ratio (M-H, Random, 95\% CI) 176

Risk Ratio (M-H, Random, 95\% CI)

$1.41[1.06,1.86]$

$1.48[1.13,1.94]$

$0.0[0.0,0.0]$

Risk Ratio (M-H, Random, 95\% CI)

Risk Ratio (M-H, Random, 95\% CI)

Subtotals only

$5.22[0.26,105.81]$

$0.0[0.0,0.0]$

$0.0[0.0,0.0]$

Risk Ratio (M-H, Random, 95\% CI)

Risk Ratio (M-H, Random, 95\% CI) 86
Subtotals only

$0.8[0.23,2.78]$ 
7.2 Nitric oxide donors (A3)

vs beta stimulants (A1)

7.3 Nitric oxide donors (A3)

vs calcium channel blockers

(A2)

8 Maternal headaches

8.1 Calcium channel blockers

(A2) vs beta stimulants (A1)

8.2 Nitric oxide donors (A3)

vs beta stimulants (A1)

8.3 Nitric oxide donors (A3)

vs calcium channel blockers

(A2)

9 Maternal hypotension

9.1 Calcium channel blockers

(A2) vs beta stimulants (A1)

9.2 Nitric oxide donors (A3)

vs beta stimulants (A1)

9.3 Nitric oxide donors (A3)

vs calcium channel blockers

(A2)

10 Operative vaginal birth

10.1 Calcium channel

blockers (A2) vs beta stimulants

(A1)

10.2 Nitric oxide donors (A3)

vs beta stimulants (A1)

10.3 Nitric oxide donors (A3)

vs calcium channel blockers

(A2)

11 Maternal mortality

11.1 Calcium channel

blockers (A2) vs beta stimulants

(A1)

11.2 Nitric oxide donors (A3)

vs beta stimulants (A1)

11.3 Nitric oxide donors (A3)

vs calcium channel blockers

(A2)

12 Maternal morbidity

12.1 Calcium channel

blockers (A2) vs beta stimulants

(A1)

12.2 Nitric oxide donors (A3)

vs beta stimulants (A1)

12.3 Nitric oxide donors (A3)

vs calcium channel blockers

(A2)

13 Perinatal mortality
Risk Ratio (M-H, Random, 95\% CI)

Risk Ratio (M-H, Random, 95\% CI)

Risk Ratio (M-H, Random, 95\% CI)

Risk Ratio (M-H, Random, 95\% CI)

Risk Ratio (M-H, Random, 95\% CI)

Risk Ratio (M-H, Random, 95\% CI)

Risk Ratio (M-H, Random, 95\% CI)

Risk Ratio (M-H, Random, 95\% CI)

Risk Ratio (M-H, Random, 95\% CI)

Risk Ratio (M-H, Random, 95\% CI)

0

0

0

Risk Ratio (M-H, Random, 95\% CI)

Risk Ratio (M-H, Random, 95\% CI)

Risk Ratio (M-H, Random, 95\% CI)

Risk Ratio (M-H, Random, 95\% CI)

0

0

0

Risk Ratio (M-H, Random, 95\% CI)

$0 \quad$ Risk Ratio (M-H, Random, 95\% CI)

Risk Ratio (M-H, Random, 95\% CI)

Risk Ratio (M-H, Random, 95\% CI)

0

0

0

Risk Ratio (M-H, Random, 95\% CI)

0

Risk Ratio (M-H, Random, 95\% CI)

0

0

Risk Ratio (M-H, Random, 95\% CI)
$0.53[0.10,2.71]$

$0.0[0.0,0.0]$

Subtotals only

$0.0[0.0,0.0]$

$3.52[1.05,11.76]$

$0.0[0.0,0.0]$

Subtotals only

$0.0[0.0,0.0]$

$3.17[0.35,29.06]$

$0.0[0.0,0.0]$

Subtotals only

$0.0[0.0,0.0]$

$0.0[0.0,0.0]$

$0.0[0.0,0.0]$

Subtotals only

$0.0[0.0,0.0]$

$0.0[0.0,0.0]$

$0.0[0.0,0.0]$

Subtotals only

$0.0[0.0,0.0]$

$0.0[0.0,0.0]$

$0.0[0.0,0.0]$

Subtotals only

Interventions for helping to turn term breech babies to head first presentation when using external cephalic version (Review) 
13.1 Calcium channel

blockers (A2) vs beta stimulants

(A1)

13.2 Nitric oxide donors (A3)

0

vs beta stimulants (A1)

13.3 Nitric oxide donors (A3)

0

vs calcium channel blockers

(A2)

14 Perinatal morbidity

14.1 Calcium channel

blockers (A2) vs beta stimulants

(A1)

14.2 Nitric oxide donors (A3)

vs beta stimulants (A1)

14.3 Nitric oxide donors (A3)

vs calcium channel blockers

(A2)

15 Vaginal breech birth (not prespecified)

15.1 Calcium channel

blockers (A2) vs beta stimulants

(A1)

15.2 Nitric oxide donors (A3)

vs beta stimulants (A1)

15.3 Nitric oxide donors (A3)

vs calcium channel blockers

(A2)

16 Apgar $<7$ at 5 minutes (not prespecified)

16.1 Calcium channel

blockers (A2) vs beta stimulants

(A1)

16.2 Nitric oxide donors (A3)

vs beta stimulants (A1)

16.3 Nitric oxide donors (A3) vs calcium channel blockers

(A2)

17 Neonatal seizures (not prespecified)

17.1 Calcium channel

blockers (A2) vs beta stimulants

(A1)

17.2 Nitric oxide donors (A3)

vs beta stimulants (A1)

17.3 Nitric oxide donors (A3) vs calcium channel blockers (A2)

18 Admissions to neonatal unit (not prespecified)
0

Risk Ratio (M-H, Random, 95\% CI)

$0.0[0.0,0.0]$

0

Risk Ratio (M-H, Random, 95\% CI)

$0.0[0.0,0.0]$

$0.0[0.0,0.0]$

Subtotals only

$0.0[0.0,0.0]$

$0.0[0.0,0.0]$

$0.0[0.0,0.0]$

Subtotals only

$0.0[0.0,0.0]$

$0.0[0.0,0.0]$

$0.0[0.0,0.0]$

Risk Ratio (M-H, Random, 95\% CI)

Risk Ratio (M-H, Random, 95\% CI)

Subtotals only

$0.0[0.0,0.0]$

$0.0[0.0,0.0]$

$0.0[0.0,0.0]$

Subtotals only

$0.0[0.0,0.0]$

Risk Ratio (M-H, Random, 95\% CI)

$0.0[0.0,0.0]$

$0.0[0.0,0.0]$

Risk Ratio (M-H, Random, 95\% CI)

Risk Ratio (M-H, Random, 95\% CI)
$0.0[0.0,0.0]$ 
18.1 Calcium channel

blockers (A2) vs beta stimulants

(A1)

18.2 Nitric oxide donors (A3)

vs beta stimulants (A1)

18.3 Nitric oxide donors (A3)

vs calcium channel blockers

(A2)

19 Birth trauma (not prespecified)

19.1 Calcium channel

blockers (A2) vs beta stimulants

(A1)

19.2 Nitric oxide donors (A3)

vs beta stimulants (A1)

19.3 Nitric oxide donors (A3)

vs calcium channel blockers

(A2)

20 Maternal flushing (not

prespecified)

20.1 Calcium channel

blockers (A2) vs beta stimulants

(A1)

20.2 Nitric oxide donors (A3)

vs beta stimulants (A1)

20.3 Nitric oxide donors (A3)

vs calcium channel blockers

(A2)
$0.0[0.0,0.0]$

0

Risk Ratio (M-H, Random, 95\% CI)

$0.0[0.0,0.0]$

$0.0[0.0,0.0]$

Subtotals only

$0.0[0.0,0.0]$

Risk Ratio (M-H, Random, 95\% CI)

Risk Ratio (M-H, Random, 95\% CI)

$0.0[0.0,0.0]$

$0.0[0.0,0.0]$

Risk Ratio (M-H, Random, 95\% CI)

Risk Ratio (M-H, Random, 95\% CI)

Subtotals only

$0.0[0.0,0.0]$

Risk Ratio (M-H, Random, 95\% CI)

$0.0[0.0,0.0]$

Risk Ratio (M-H, Random, 95\% CI)

Risk Ratio (M-H, Random, 95\% CI)

$0.0[0.0,0.0]$

\section{Comparison 3. Vibroacoustic stimulation (B) vs placebo}

\begin{tabular}{|c|c|c|c|c|}
\hline Outcome or subgroup title & $\begin{array}{l}\text { No. of } \\
\text { studies }\end{array}$ & $\begin{array}{c}\text { No. of } \\
\text { participants }\end{array}$ & Statistical method & Effect size \\
\hline $\begin{array}{l}1 \text { Cephalic presentation at birth } \\
\text { (primary) }\end{array}$ & 0 & 0 & Risk Ratio (M-H, Random, 95\% CI) & $0.0[0.0,0.0]$ \\
\hline $\begin{array}{l}2 \text { Failure to achieve cephalic } \\
\text { vaginal birth (composite } \\
\text { outcome: caesarean section }+ \\
\text { vaginal breech birth) }\end{array}$ & 0 & 0 & Risk Ratio (M-H, Random, 95\% CI) & $0.0[0.0,0.0]$ \\
\hline 3 Caesarean section (primary) & 0 & 0 & Risk Ratio (M-H, Random, 95\% CI) & $0.0[0.0,0.0]$ \\
\hline 4 Fetal bradycardia (primary) & 0 & 0 & Risk Ratio (M-H, Random, 95\% CI) & $0.0[0.0,0.0]$ \\
\hline 5 Failed external cephalic version & 1 & 23 & Risk Ratio (M-H, Random, 95\% CI) & $0.09[0.01,0.60]$ \\
\hline $\begin{array}{l}6 \text { Difficult external cephalic } \\
\text { version }\end{array}$ & 0 & 0 & Risk Ratio (M-H, Random, 95\% CI) & $0.0[0.0,0.0]$ \\
\hline 7 Maternal palpitations & 0 & 0 & Risk Ratio (M-H, Random, 95\% CI) & $0.0[0.0,0.0]$ \\
\hline 8 Maternal headaches & 0 & 0 & Risk Ratio (M-H, Random, 95\% CI) & $0.0[0.0,0.0]$ \\
\hline 9 Maternal hypotension & 0 & 0 & Risk Ratio (M-H, Random, 95\% CI) & $0.0[0.0,0.0]$ \\
\hline 10 Operative vaginal birth & 0 & 0 & Risk Ratio (M-H, Random, 95\% CI) & $0.0[0.0,0.0]$ \\
\hline 11 Maternal mortality & 0 & 0 & Risk Ratio (M-H, Random, 95\% CI) & $0.0[0.0,0.0]$ \\
\hline
\end{tabular}




0
0
0

\section{Comparison 6. Regional analgesia (with or without tocolysis) vs no intervention of regional analgesia (with or without tocolysis)}

\begin{tabular}{|c|c|c|c|c|}
\hline Outcome or subgroup title & $\begin{array}{l}\text { No. of } \\
\text { studies }\end{array}$ & $\begin{array}{c}\text { No. of } \\
\text { participants }\end{array}$ & Statistical method & Effect size \\
\hline $\begin{array}{l}1 \text { Cephalic presentation at birth } \\
\text { (primary) }\end{array}$ & 3 & & Risk Ratio (M-H, Random, 95\% CI) & Subtotals only \\
\hline 1.1 Regional analgesia alone & 0 & 0 & Risk Ratio (M-H, Random, 95\% CI) & $0.0[0.0,0.0]$ \\
\hline vs no intervention & & & & \\
\hline $\begin{array}{l}1.2 \text { Regional analgesia }+ \\
\text { tocolysis vs tocolysis }\end{array}$ & 3 & 279 & Risk Ratio (M-H, Random, 95\% CI) & $1.44[0.78,2.66]$ \\
\hline $\begin{array}{l}2 \text { Failure to achieve cephalic } \\
\text { vaginal birth (composite } \\
\text { outcome: caesarean section }+ \\
\text { vaginal breech birth) }\end{array}$ & 0 & 0 & Risk Ratio (M-H, Fixed, 95\% CI) & $0.0[0.0,0.0]$ \\
\hline 3 Caesarean section (primary) & 3 & & Risk Ratio (M-H, Random, 95\% CI) & Subtotals only \\
\hline $\begin{array}{l}3.1 \text { Regional analgesia alone } \\
\text { vs no intervention }\end{array}$ & 0 & 0 & Risk Ratio (M-H, Random, 95\% CI) & $0.0[0.0,0.0]$ \\
\hline $\begin{array}{l}3.2 \text { Regional analgesia }+ \\
\text { tocolysis vs tocolysis }\end{array}$ & 3 & 279 & Risk Ratio (M-H, Random, 95\% CI) & $0.74[0.40,1.37]$ \\
\hline 4 Fetal bradycardia (primary) & 2 & & Risk Ratio (M-H, Random, 95\% CI) & Subtotals only \\
\hline $\begin{array}{l}\text { 4.1 Regional analgesia alone } \\
\text { vs no intervention }\end{array}$ & 0 & 0 & Risk Ratio (M-H, Random, 95\% CI) & $0.0[0.0,0.0]$ \\
\hline $\begin{array}{l}4.2 \text { Regional analgesia }+ \\
\text { tocolysis vs tocolysis }\end{array}$ & 2 & 210 & Risk Ratio (M-H, Random, 95\% CI) & $1.48[0.62,3.57]$ \\
\hline 5 Failed external cephalic version & 6 & & Risk Ratio (M-H, Random, 95\% CI) & Subtotals only \\
\hline $\begin{array}{l}5.1 \text { Regional analgesia alone } \\
\text { vs no intervention }\end{array}$ & 1 & 141 & Risk Ratio (M-H, Random, 95\% CI) & $0.89[0.70,1.14]$ \\
\hline $\begin{array}{l}5.2 \text { Regional analgesia }+ \\
\text { tocolysis vs tocolysis }\end{array}$ & 5 & 409 & Risk Ratio (M-H, Random, 95\% CI) & $0.61[0.43,0.86]$ \\
\hline $\begin{array}{l}6 \text { Difficult external cephalic } \\
\text { version }\end{array}$ & 0 & & Risk Ratio (M-H, Random, 95\% CI) & Subtotals only \\
\hline $\begin{array}{l}\text { 6.1 Regional analgesia alone } \\
\text { vs no intervention }\end{array}$ & 0 & 0 & Risk Ratio (M-H, Random, 95\% CI) & $0.0[0.0,0.0]$ \\
\hline $\begin{array}{l}6.2 \text { Regional analgesia + } \\
\text { tocolysis vs tocolysis }\end{array}$ & 0 & 0 & Risk Ratio (M-H, Random, 95\% CI) & $0.0[0.0,0.0]$ \\
\hline 7 Maternal palpitations & 0 & & Risk Ratio (M-H, Random, 95\% CI) & Subtotals only \\
\hline $\begin{array}{l}7.1 \text { Regional analgesia alone } \\
\text { vs no intervention }\end{array}$ & 0 & 0 & Risk Ratio (M-H, Random, 95\% CI) & $0.0[0.0,0.0]$ \\
\hline $\begin{array}{l}7.2 \text { Regional analgesia }+ \\
\text { tocolysis vs tocolysis }\end{array}$ & 0 & 0 & Risk Ratio (M-H, Random, 95\% CI) & $0.0[0.0,0.0]$ \\
\hline 8 Maternal headaches & 0 & & Risk Ratio (M-H, Random, 95\% CI) & Subtotals only \\
\hline
\end{tabular}


8.1 Regional analgesia alone vs no intervention

8.2 Regional analgesia + tocolysis vs tocolysis

9 Maternal hypotension

9.1 Regional analgesia alone vs no intervention

9.2 Regional analgesia + tocolysis vs tocolysis

10 Operative vaginal birth

10.1 Regional analgesia alone vs no intervention

10.2 Regional analgesia + tocolysis vs tocolysis

11 Maternal mortality

11.1 Regional analgesia alone vs no intervention

11.2 Regional analgesia + tocolysis vs tocolysis

12 Maternal morbidity

12.1 Regional analgesia alone vs no intervention

12.2 Regional analgesia + tocolysis vs tocolysis

13 Perinatal morbidity

13.1 Regional analgesia alone vs no intervention

13.2 Regional analgesia + tocolysis vs tocolysis

14 Perinatal mortality

14.1 Regional analgesia alone vs no intervention

14.2 Regional analgesia + tocolysis vs tocolysis

15 Placental abruption (not prespecified)

15.1 Regional analgesia alone vs no intervention

15.2 Regional analgesia + tocolysis vs tocolysis

16 Maternal discomfort (not prespecified)

16.1 Regional analgesia alone vs no intervention

16.2 Regional analgesia + tocolysis vs tocolysis
$0.0[0.0,0.0]$

0

0

Risk Ratio (M-H, Random, 95\% CI)

$0.0[0.0,0.0]$

Risk Ratio (M-H, Random, 95\% CI)

0

Risk Ratio (M-H, Random, 95\% CI)

280

Risk Ratio (M-H, Random, 95\% CI)

Risk Ratio (M-H, Random, 95\% CI)

0

Risk Ratio (M-H, Random, 95\% CI)

0

Risk Ratio (M-H, Random, 95\% CI)

Risk Ratio (M-H, Random, 95\% CI)

0

Risk Ratio (M-H, Random, 95\% CI)

0

Risk Ratio (M-H, Random, 95\% CI)

Risk Ratio (M-H, Random, 95\% CI)

0

Risk Ratio (M-H, Random, 95\% CI)

0

Risk Ratio (M-H, Random, 95\% CI)

Risk Ratio (M-H, Random, 95\% CI)

0

Risk Ratio (M-H, Random, 95\% CI)

0

Risk Ratio (M-H, Random, 95\% CI)

Risk Ratio (M-H, Random, 95\% CI)

0

Risk Ratio (M-H, Random, 95\% CI)

0

Risk Ratio (M-H, Random, 95\% CI)

Risk Ratio (M-H, Random, 95\% CI)

0

Risk Ratio (M-H, Random, 95\% CI)

102

Risk Ratio (M-H, Random, 95\% CI)

Risk Ratio (M-H, Random, 95\% CI)

0

Risk Ratio (M-H, Random, 95\% CI)

171
Subtotals only

$0.0[0.0,0.0]$

$11.58[1.53,87.50]$

Subtotals only

$0.0[0.0,0.0]$

$0.0[0.0,0.0]$

Subtotals only $0.0[0.0,0.0]$

$0.0[0.0,0.0]$

Subtotals only $0.0[0.0,0.0]$

$0.0[0.0,0.0]$

Subtotals only $0.0[0.0,0.0]$

$0.0[0.0,0.0]$

Subtotals only $0.0[0.0,0.0]$

$0.0[0.0,0.0]$

Subtotals only

$0.0[0.0,0.0]$

$0.35[0.01,8.31]$

Subtotals only

$0.0[0.0,0.0]$

$0.19[0.03,1.04]$

Interventions for helping to turn term breech babies to head first presentation when using external cephalic version (Review) 


\begin{tabular}{|c|c|c|c|c|}
\hline Outcome or subgroup title & $\begin{array}{l}\text { No. of } \\
\text { studies }\end{array}$ & $\begin{array}{c}\text { No. of } \\
\text { participants }\end{array}$ & Statistical method & Effect size \\
\hline $\begin{array}{l}1 \text { Cephalic presentation at birth } \\
\text { (primary) }\end{array}$ & 0 & 0 & Risk Ratio (M-H, Random, 95\% CI) & $0.0[0.0,0.0]$ \\
\hline $\begin{array}{l}2 \text { Failure to achieve cephalic } \\
\text { vaginal birth (composite } \\
\text { outcome: caesarean section }+ \\
\text { vaginal breech birth) }\end{array}$ & 0 & 0 & Risk Ratio (M-H, Random, 95\% CI) & $0.0[0.0,0.0]$ \\
\hline 3 Fetal bradycardia (primary) & 1 & 60 & Risk Ratio (M-H, Random, 95\% CI) & $0.31[0.09,1.04]$ \\
\hline 4 Caesarean section (primary) & 1 & 60 & Risk Ratio (M-H, Random, 95\% CI) & $0.99[0.63,1.57]$ \\
\hline 5 Failed external cephalic version & 1 & 60 & Risk Ratio (M-H, Random, 95\% CI) & $0.77[0.47,1.26]$ \\
\hline $\begin{array}{l}6 \text { Difficult external cephalic } \\
\text { version }\end{array}$ & 0 & 0 & Risk Ratio (M-H, Random, 95\% CI) & $0.0[0.0,0.0]$ \\
\hline 7 Maternal palpitations & 0 & 0 & Risk Ratio (M-H, Random, 95\% CI) & $0.0[0.0,0.0]$ \\
\hline 8 Maternal headaches & 0 & 0 & Risk Ratio (M-H, Random, 95\% CI) & $0.0[0.0,0.0]$ \\
\hline 9 Maternal hypotension & 0 & 0 & Risk Ratio (M-H, Random, 95\% CI) & $0.0[0.0,0.0]$ \\
\hline 10 Operative vaginal birth & 1 & 60 & Risk Ratio (M-H, Random, 95\% CI) & $0.94[0.20,4.27]$ \\
\hline 11 Maternal mortality & 0 & 0 & Risk Ratio (M-H, Random, 95\% CI) & $0.0[0.0,0.0]$ \\
\hline 12 Maternal morbidity & 0 & 0 & Risk Ratio (M-H, Random, 95\% CI) & $0.0[0.0,0.0]$ \\
\hline 13 Perinatal mortality & 0 & 0 & Risk Ratio (M-H, Random, 95\% CI) & $0.0[0.0,0.0]$ \\
\hline 14 Perinatal morbidity & 0 & 0 & Risk Ratio (M-H, Random, 95\% CI) & $0.0[0.0,0.0]$ \\
\hline $\begin{array}{l}15 \text { Pain score (0-10 scale, lowest } \\
\text { best) (non-prespecified) }\end{array}$ & 1 & 60 & Mean Difference (IV, Fixed, 95\% CI) & $-1.8[-3.04,-0.56]$ \\
\hline $\begin{array}{l}16 \text { Maternal satisfaction } \\
\text { score (lower score worst) } \\
\text { (non-prespecified) }\end{array}$ & 1 & 60 & Mean Difference (IV, Fixed, 95\% CI) & $2.60[1.25,3.95]$ \\
\hline $\begin{array}{l}17 \text { Nausea and vomiting } \\
\text { (non-prespecified) }\end{array}$ & 1 & 60 & Risk Ratio (M-H, Fixed, 95\% CI) & $0.31[0.03,2.83]$ \\
\hline 18 Dizziness (non-prespecified) & 1 & 60 & Risk Ratio (M-H, Fixed, 95\% CI) & $0.31[0.01,7.38]$ \\
\hline 19 Drowsiness (non-prespecified) & 1 & 60 & Risk Ratio (M-H, Fixed, 95\% CI) & $2.81[0.12,66.40]$ \\
\hline
\end{tabular}

Comparison 18. Systemic opioids (E) vs regional anaesthesia (C)

\begin{tabular}{|c|c|c|c|c|}
\hline Outcome or subgroup title & $\begin{array}{l}\text { No. of } \\
\text { studies }\end{array}$ & $\begin{array}{c}\text { No. of } \\
\text { participants }\end{array}$ & Statistical method & Effect size \\
\hline $\begin{array}{l}1 \text { Cephalic presentation at birth } \\
\text { (primary) }\end{array}$ & 0 & 0 & Risk Ratio (M-H, Random, 95\% CI) & $0.0[0.0,0.0]$ \\
\hline $\begin{array}{l}2 \text { Failure to achieve cephalic } \\
\text { vaginal birth (composite } \\
\text { outcome: caesarean section }+ \\
\text { vaginal breech birth) }\end{array}$ & 1 & 95 & Risk Ratio (M-H, Random, 95\% CI) & $1.18[0.90,1.54]$ \\
\hline 3 Caesarean section (primary) & 1 & 95 & Risk Ratio (M-H, Random, 95\% CI) & $1.18[0.90,1.54]$ \\
\hline 4 Fetal bradycardia (primary) & 1 & 94 & Risk Ratio (M-H, Random, 95\% CI) & $0.71[0.24,2.09]$ \\
\hline 5 Failed external cephalic version & 1 & 95 & Risk Ratio (M-H, Random, 95\% CI) & $1.29[0.93,1.80]$ \\
\hline
\end{tabular}




\begin{tabular}{lllll}
$\begin{array}{l}\text { 6 Difficult external cephalic } \\
\text { version }\end{array}$ & 0 & 0 & Risk Ratio (M-H, Random, 95\% CI) & $0.0[0.0,0.0]$ \\
7 Maternal palpitations & 0 & 0 & Risk Ratio (M-H, Random, 95\% CI) & $0.0[0.0,0.0]$ \\
8 Maternal headaches & 0 & 0 & Risk Ratio (M-H, Random, 95\% CI) & $0.0[0.0,0.0]$ \\
9 Maternal hypotension & 0 & 0 & Risk Ratio (M-H, Random, 95\% CI) & $0.0[0.0,0.0]$ \\
10 Operative vaginal birth & 0 & 0 & Risk Ratio (M-H, Random, 95\% CI) & $0.0[0.0,0.0]$ \\
11 Maternal mortality & 0 & 0 & Risk Ratio (M-H, Random, 95\% CI) & $0.0[0.0,0.0]$ \\
12 Maternal morbidity & 0 & 0 & Risk Ratio (M-H, Random, 95\% CI) & $0.0[0.0,0.0]$ \\
13 Perinatal mortality & 0 & 0 & Risk Ratio (M-H, Random, 95\% CI) & $0.0[0.0,0.0]$ \\
14 Perinatal morbidity & 0 & 0 & Risk Ratio (M-H, Random, 95\% CI) & $0.0[0.0,0.0]$ \\
\hline
\end{tabular}

Comparison 21. Tocolytics vs placebo - nullips vs multips

\begin{tabular}{lccll} 
Outcome or subgroup title & $\begin{array}{c}\text { No. of } \\
\text { studies }\end{array}$ & $\begin{array}{c}\text { No. of } \\
\text { participants }\end{array}$ & \multicolumn{1}{c}{ Statistical method } & Effect size \\
\hline $\begin{array}{l}\text { 1 Cephalic presentation at birth } \\
\text { (primary) }\end{array}$ & 2 & 249 & Risk Ratio (M-H, Random, 95\% CI) & $1.89[0.98,3.62]$ \\
$\quad$ 1.1 Nullips & 2 & 170 & Risk Ratio (M-H, Random, 95\% CI) & $2.13[1.02,4.45]$ \\
1.2 Multips & 2 & 79 & Risk Ratio (M-H, Random, 95\% CI) & $2.02[0.45,9.15]$ \\
2 Caesarean section (primary) & 2 & 249 & Risk Ratio (M-H, Random, 95\% CI) & $0.84[0.74,0.95]$ \\
2.1 Nullips & 2 & 170 & Risk Ratio (M-H, Random, 95\% CI) & $0.85[0.75,0.97]$ \\
2.2 Multips & 2 & 79 & Risk Ratio (M-H, Random, 95\% CI) & $0.67[0.38,1.17]$ \\
3 Fetal bradycardia (primary) & 0 & 0 & Risk Ratio (M-H, Random, 95\% CI) & $0.0[0.0,0.0]$ \\
3.1 Nullips & 0 & 0 & Risk Ratio (M-H, Random, 95\% CI) & $0.0[0.0,0.0]$ \\
3.2 Multips & 0 & 0 & Risk Ratio (M-H, Random, 95\% CI) & $0.0[0.0,0.0]$ \\
4 Failed external cephalic version & 6 & 513 & Risk Ratio (M-H, Random, 95\% CI) & $0.78[0.66,0.92]$ \\
$\quad$ 4.1 Nullips & 6 & 323 & Risk Ratio (M-H, Random, 95\% CI) & $0.85[0.76,0.95]$ \\
4.2 Multips & 6 & 190 & Risk Ratio (M-H, Random, 95\% CI) & $0.60[0.38,0.95]$ \\
\hline
\end{tabular}

Comparison 22. Tocolytic (nifedipine) vs tocolytic (terbutaline) - nullips vs multips

\begin{tabular}{|c|c|c|c|c|}
\hline Outcome or subgroup title & $\begin{array}{l}\text { No. of } \\
\text { studies }\end{array}$ & $\begin{array}{c}\text { No. of } \\
\text { participants }\end{array}$ & Statistical method & Effect size \\
\hline $\begin{array}{l}1 \text { Cephalic presentation at birth } \\
\text { (primary) }\end{array}$ & 0 & 0 & Risk Ratio (M-H, Random, 95\% CI) & $0.0[0.0,0.0]$ \\
\hline 1.1 Nullips & 0 & 0 & Risk Ratio (M-H, Random, 95\% CI) & $0.0[0.0,0.0]$ \\
\hline 1.2 Multips & 0 & 0 & Risk Ratio (M-H, Random, 95\% CI) & $0.0[0.0,0.0]$ \\
\hline 2 Caesarean section (primary) & 0 & 0 & Risk Ratio (M-H, Random, 95\% CI) & $0.0[0.0,0.0]$ \\
\hline 2.1 Nullips & 0 & 0 & Risk Ratio (M-H, Random, 95\% CI) & $0.0[0.0,0.0]$ \\
\hline 2.2 Multips & 0 & 0 & Risk Ratio (M-H, Random, 95\% CI) & $0.0[0.0,0.0]$ \\
\hline 3 Fetal bradycardia (primary) & 0 & 0 & Risk Ratio (M-H, Random, 95\% CI) & $0.0[0.0,0.0]$ \\
\hline 3.1 Nullips & 0 & 0 & Risk Ratio (M-H, Random, 95\% CI) & $0.0[0.0,0.0]$ \\
\hline 3.2 Multips & 0 & 0 & Risk Ratio (M-H, Random, 95\% CI) & $0.0[0.0,0.0]$ \\
\hline 4 Failed ECV & 1 & 86 & Risk Ratio (M-H, Random, 95\% CI) & $1.38[0.90,2.13]$ \\
\hline 4.1 Nullips & 1 & 39 & Risk Ratio (M-H, Random, 95\% CI) & $1.60[0.83,3.10]$ \\
\hline
\end{tabular}


4.2 Multips

4.3 Caesarean section

(primary)
47

Risk Ratio (M-H, Random, 95\% CI)

$1.23[0.69,2.19]$

Risk Ratio (M-H, Random, 95\% CI)

$0.0[0.0,0.0]$

Comparison 23. Hypnosis vs neurolinguistic programming

\begin{tabular}{|c|c|c|c|c|}
\hline Outcome or subgroup title & $\begin{array}{l}\text { No. of } \\
\text { studies }\end{array}$ & $\begin{array}{l}\text { No. of } \\
\text { participants }\end{array}$ & Statistical method & Effect size \\
\hline $\begin{array}{l}1 \text { Cephalic presentation at birth } \\
\text { (primary) }\end{array}$ & 0 & & Risk Ratio (M-H, Random, 95\% CI) & Subtotals only \\
\hline $\begin{array}{l}2 \text { Failure to achieve cephalic } \\
\text { vaginal birth (composite } \\
\text { outcome: caesarean section + } \\
\text { vaginal breech birth) }\end{array}$ & 0 & 0 & Risk Ratio (M-H, Random, 95\% CI) & $0.0[0.0,0.0]$ \\
\hline 3 Caesarean section (primary) & 0 & & Risk Ratio (M-H, Random, 95\% CI) & Subtotals only \\
\hline 4 Fetal bradycardia (primary) & 0 & & Risk Ratio (M-H, Random, 95\% CI) & Subtotals only \\
\hline 5 Failed external cephalic version & 1 & 80 & Risk Ratio (M-H, Random, 95\% CI) & $1.08[0.74,1.57]$ \\
\hline $\begin{array}{l}6 \text { Difficult external cephalic } \\
\text { version }\end{array}$ & 0 & & Risk Ratio (M-H, Random, 95\% CI) & Subtotals only \\
\hline 7 Maternal palpitations & 0 & & Risk Ratio (M-H, Random, 95\% CI) & Subtotals only \\
\hline 8 Maternal headaches & 0 & & Risk Ratio (M-H, Random, 95\% CI) & Subtotals only \\
\hline 9 Maternal hypotension & 0 & & Risk Ratio (M-H, Random, 95\% CI) & Subtotals only \\
\hline 10 Operative vaginal birth & 0 & & Risk Ratio (M-H, Random, 95\% CI) & Subtotals only \\
\hline 11 Maternal mortality & 0 & & Risk Ratio (M-H, Random, 95\% CI) & Subtotals only \\
\hline 12 Maternal morbidity & 0 & & Risk Ratio (M-H, Random, 95\% CI) & Subtotals only \\
\hline 13 Perinatal mortality & 0 & & Risk Ratio (M-H, Random, 95\% CI) & Subtotals only \\
\hline 14 Perinatal morbidity & 0 & & Risk Ratio (M-H, Random, 95\% CI) & Subtotals only \\
\hline $\begin{array}{l}15 \text { Good pain relief (higher scores } \\
\text { better) (non-prespecified) }\end{array}$ & 1 & 80 & Mean Difference (IV, Fixed, 95\% CI) & $-0.10[-0.87,0.67]$ \\
\hline
\end{tabular}

\section{Comparison 24. Talcum powder vs gel}

\begin{tabular}{|c|c|c|c|c|}
\hline Outcome or subgroup title & $\begin{array}{l}\text { No. of } \\
\text { studies }\end{array}$ & $\begin{array}{c}\text { No. of } \\
\text { participants }\end{array}$ & Statistical method & Effect size \\
\hline $\begin{array}{l}1 \text { Cephalic presentation at birth } \\
\text { (primary) }\end{array}$ & 0 & & Risk Ratio (M-H, Random, 95\% CI) & Subtotals only \\
\hline $\begin{array}{l}2 \text { Failure to achieve cephalic } \\
\text { vaginal birth (composite } \\
\text { outcome: caesarean section }+ \\
\text { vaginal breech birth) }\end{array}$ & 0 & 0 & Risk Ratio (M-H, Random, 95\% CI) & $0.0[0.0,0.0]$ \\
\hline 3 Caesarean section (primary) & 0 & & Risk Ratio (M-H, Random, 95\% CI) & Subtotals only \\
\hline 4 Fetal bradycardia (primary) & 0 & & Risk Ratio (M-H, Random, 95\% CI) & Subtotals only \\
\hline $\begin{array}{l}5 \text { Failed external cephalic version } \\
\text { (after first round of attempts) }\end{array}$ & 1 & 95 & Risk Ratio (M-H, Random, 95\% CI) & $1.26[0.84,1.89]$ \\
\hline
\end{tabular}




\begin{tabular}{llll}
$\begin{array}{l}\text { 6 Difficult external cephalic } \\
\text { version }\end{array}$ & 0 & Risk Ratio (M-H, Random, 95\% CI) & Subtotals only \\
7 Maternal palpitations & 0 & Risk Ratio (M-H, Random, 95\% CI) & Subtotals only \\
8 Maternal headaches & 0 & Risk Ratio (M-H, Random, 95\% CI) & Subtotals only \\
9 Maternal hypotension & 0 & Risk Ratio (M-H, Random, 95\% CI) & Subtotals only \\
10 Operative vaginal birth & 0 & Risk Ratio (M-H, Random, 95\% CI) & Subtotals only \\
11 Maternal mortality & 0 & Risk Ratio (M-H, Random, 95\% CI) & Subtotals only \\
12 Maternal morbidity & 0 & Risk Ratio (M-H, Random, 95\% CI) & Subtotals only \\
13 Perinatal mortality & 0 & Risk Ratio (M-H, Random, 95\% CI) & Subtotals only \\
14 Perinatal morbidity & 0 & Risk Ratio (M-H, Random, 95\% CI) & Subtotals only \\
\hline
\end{tabular}

\section{Analysis I.I. Comparison I Tocolytic drugs (A) vs placebo, Outcome I Cephalic presentation at birth (primary).}

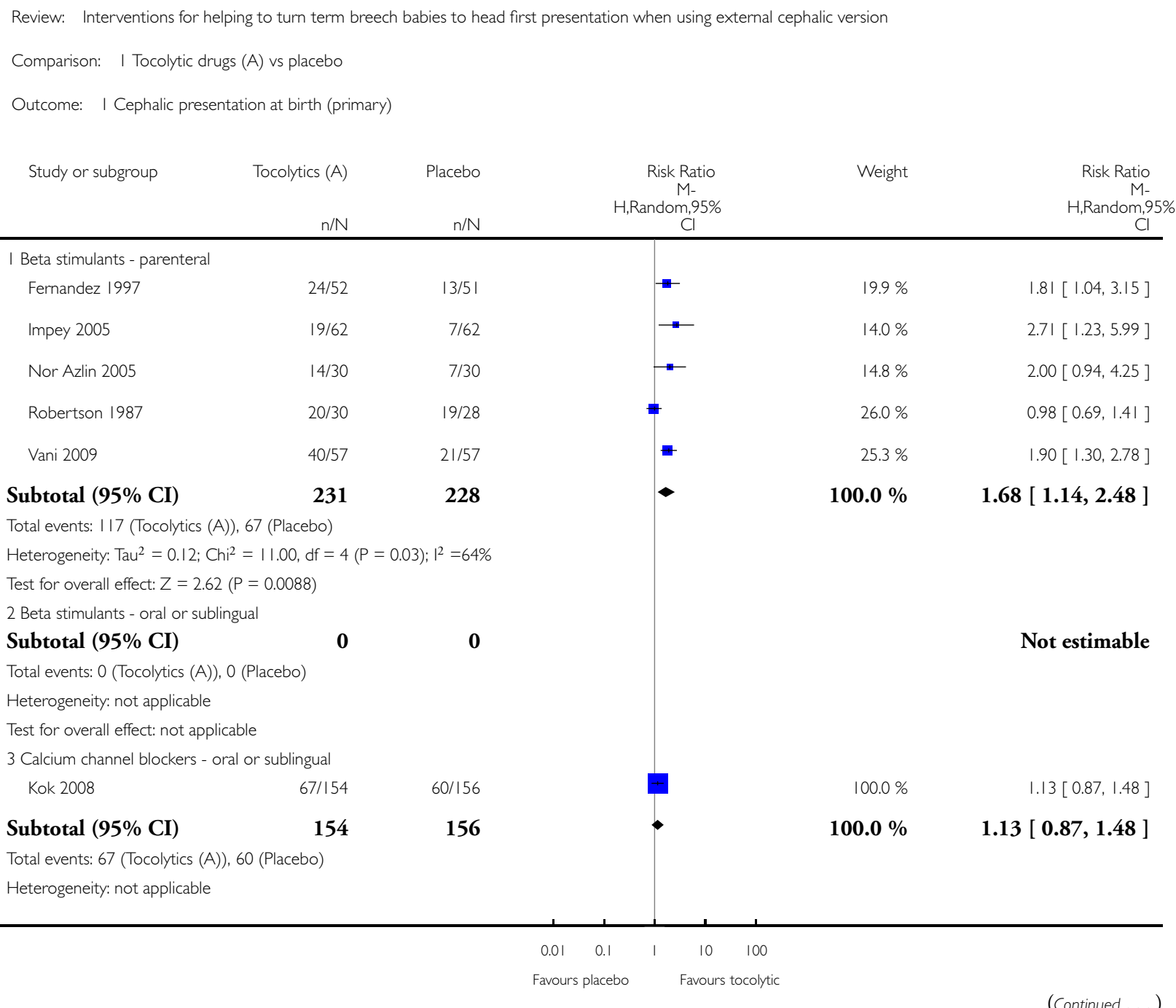

Interventions for helping to turn term breech babies to head first presentation when using external cephalic version (Review) 


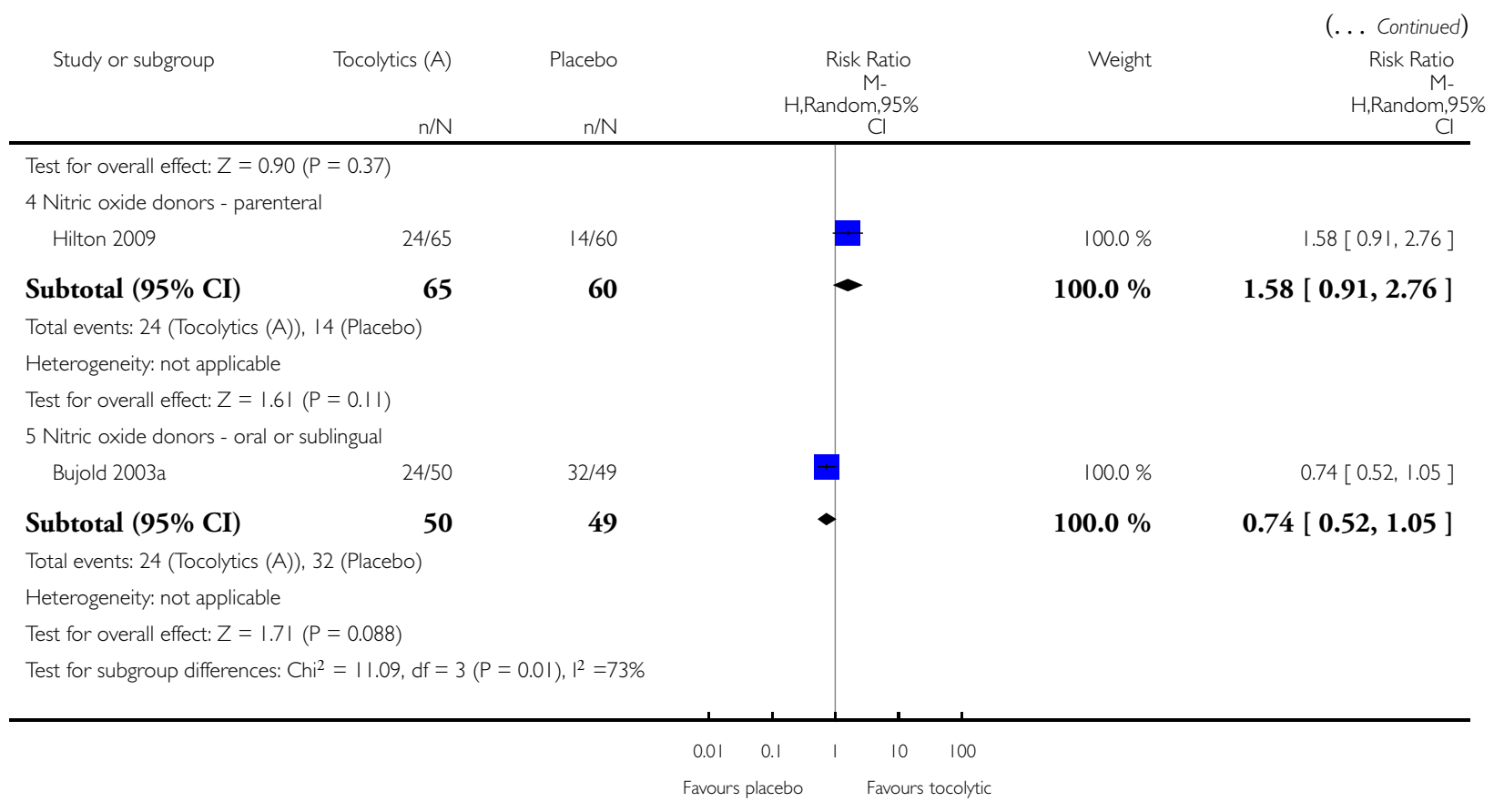


Analysis I.2. Comparison I Tocolytic drugs (A) vs placebo, Outcome 2 Failure to achieve cephalic vaginal birth (composite outcome: caesarean section + vaginal breech birth).

Review: Interventions for helping to turn term breech babies to head first presentation when using external cephalic version

Comparison: I Tocolytic drugs (A) vs placebo

Outcome: 2 Failure to achieve cephalic vaginal birth (composite outcome: caesarean section + vaginal breech birth)

$\begin{array}{llll}\text { Study or subgroup } & \text { Tocolytics (A) Risk Ratio } & \text { Placebo } & \text { Weight }\end{array}$ H,Random,95\% H,Random,95\%

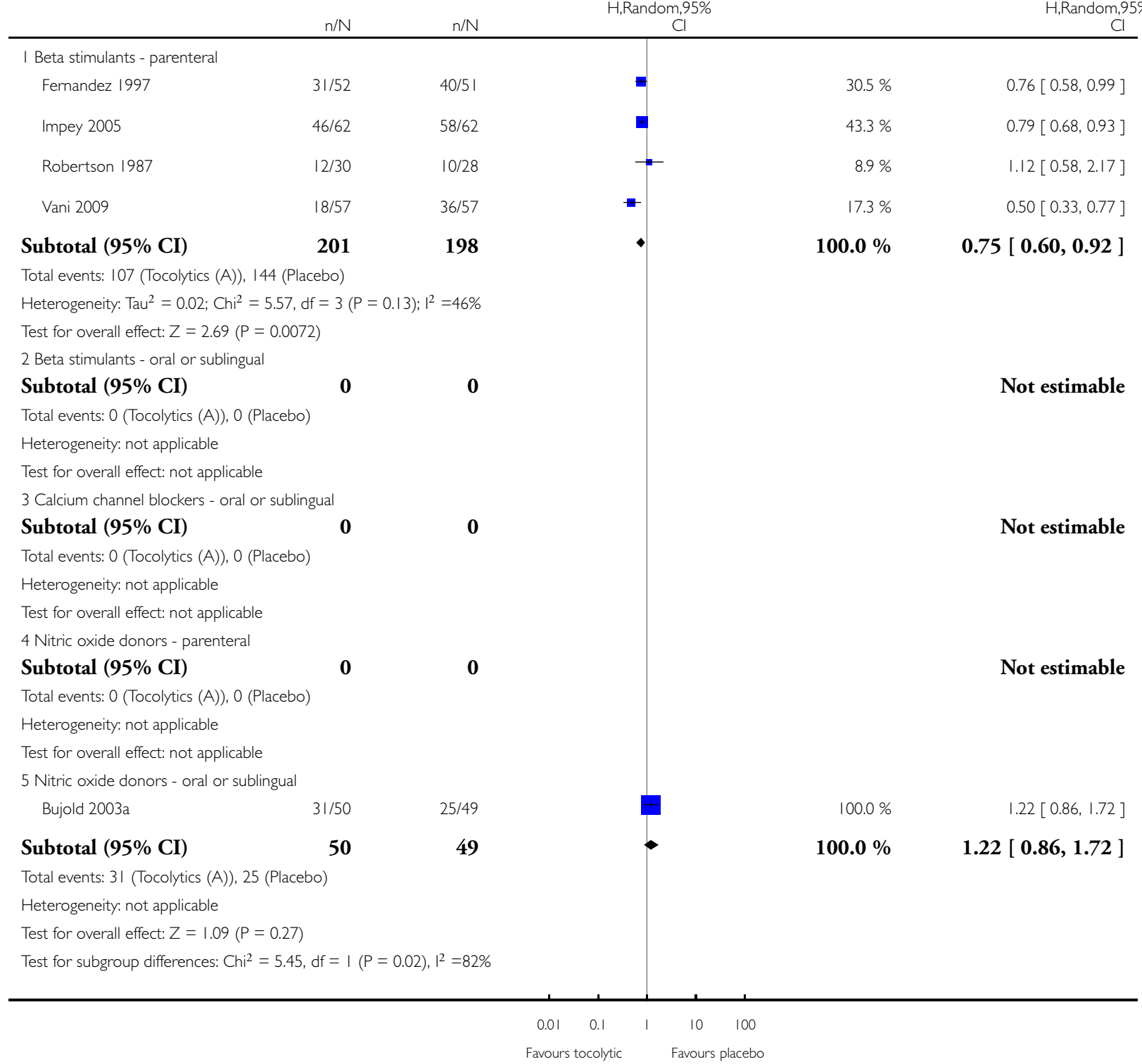

Interventions for helping to turn term breech babies to head first presentation when using external cephalic version (Review) 
Analysis I.3. Comparison I Tocolytic drugs (A) vs placebo, Outcome 3 Caesarean section (primary).

Review: Interventions for helping to turn term breech babies to head first presentation when using external cephalic version

Comparison: I Tocolytic drugs (A) vs placebo

Outcome: 3 Caesarean section (primary)

\begin{tabular}{|c|c|c|c|c|c|}
\hline Study or subgroup & Tocolytics (A) & Placebo & $\begin{array}{c}\text { Risk Ratio } \\
\text { M- } \\
\text { H,Random,95\% } \\
\text { Cl }\end{array}$ & Weight & $\begin{array}{c}\text { Risk Ratio } \\
\text { M- } \\
\text { H,Random,95\% } \\
\text { Cl }\end{array}$ \\
\hline \multicolumn{6}{|c|}{ I Beta stimulants - parenteral } \\
\hline Fernandez 1997 & $30 / 52$ & $39 / 51$ & 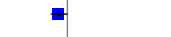 & $18.7 \%$ & $0.75[0.57,1.00]$ \\
\hline Impey 2005 & $41 / 62$ & $53 / 62$ & $\mathbf{m}$ & $28.0 \%$ & $0.77[0.63,0.95]$ \\
\hline Marquette 1996 & $76 / 138$ & $94 / 145$ & $\mathbf{E}$ & $30.2 \%$ & $0.85[0.70,1.03]$ \\
\hline Nor Azlin 2005 & $17 / 30$ & $23 / 30$ & $\rightarrow$ & $12.0 \%$ & $0.74[0.51,1.07]$ \\
\hline Robertson 1987 & $8 / 30$ & $5 / 28$ & +1 & $2.0 \%$ & $1.49[0.55,4.03]$ \\
\hline Vani 2009 & $18 / 57$ & $36 / 57$ & - & $9.3 \%$ & $0.50[0.33,0.77]$ \\
\hline
\end{tabular}

Subtotal $(95 \% \mathrm{CI})$

$369 \quad 373$

Total events: 190 (Tocolytics (A)), 250 (Placebo)

Heterogeneity: $\operatorname{Tau}^{2}=0.01 ; \mathrm{Chi}^{2}=6.65, \mathrm{df}=5(P=0.25) ; \mathrm{I}^{2}=25 \%$

Test for overall effect: $Z=3.71(P=0.00021)$

2 Beta stimulants - oral or sublingual

Subtotal (95\% CI)

$\mathbf{0}$

$\mathbf{0}$

Total events: 0 (Tocolytics (A)), 0 (Placebo)

Heterogeneity: not applicable

Test for overall effect: not applicable

3 Calcium channel blockers - oral or sublingual

Kok 2008

$79 / 154 \quad 72 / 156$

-

$100.0 \%$

$0.77[0.67,0.88$ ]

Subtotal (95\% CI)

154

156

$100.0 \%$

I.I $[0.88,1.40]$

Total events: 79 (Tocolytics (A)), 72 (Placebo)

Heterogeneity: not applicable

Test for overall effect: $Z=0.90(P=0.37)$

4 Nitric oxide donors - parenteral

Hilton 2009

Subtotal (95\% CI)

60

Total events: 44 (Tocolytics (A)), 49 (Placebo)

Heterogeneity: not applicable

Test for overall effect: $Z=1.78(P=0.075)$

5 Nitric oxide donors - oral or sublingual

Subtotal (95\% CI)

$\mathbf{0}$

Total events: 0 (Tocolytics (A)), 0 (Placebo)

Heterogeneity: not applicable

Test for overall effect: not applicable

Test for subgroup differences: $\mathrm{Chi}^{2}=7.39, \mathrm{df}=2(\mathrm{P}=0.02), \mathrm{I}^{2}=73 \%$

$100.0 \%$

$0.83[0.67,1.02]$

Not estimable

Interventions for helping to turn term breech babies to head first presentation when using external cephalic version (Review) 


\section{Analysis I.4. Comparison I Tocolytic drugs (A) vs placebo, Outcome 4 Fetal bradycardia (primary).}

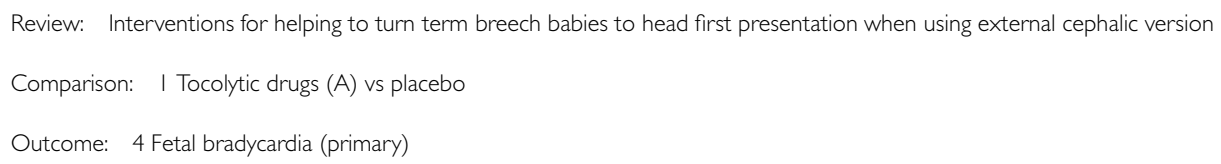

Total events: I (Tocolytics (A)), 0 (Placebo)

Heterogeneity: not applicable

Test for overall effect: $Z=0.64(P=0.52)$

2 Beta stimulants - oral or sublingual

Subtotal $(95 \% \mathrm{CI})$

$\mathbf{0}$

$\mathbf{0}$

Total events: 0 (Tocolytics (A)), 0 (Placebo)

Heterogeneity: not applicable

Test for overall effect: not applicable

3 Calcium channel blockers - oral or sublingual

$$
\text { Kok } 2008 \quad \text { 12/154 }
$$

Subtotal (95\% CI)

Total events: 12 (Tocolytics (A)), I I (Placebo)

Heterogeneity: not applicable

Test for overall effect: $Z=0.25(P=0.80)$

4 Nitric oxide donors - parenteral

\section{Subtotal (95\% CI)}

Total events: 0 (Tocolytics (A)), 0 (Placebo)

Heterogeneity: not applicable

Test for overall effect: not applicable

5 Nitric oxide donors - oral or sublingual Bujold 2003a

Subtotal (95\% CI)

Total events: 2 (Tocolytics (A)), 5 (Placebo)

Heterogeneity: not applicable

Test for overall effect: $Z=1.15(P=0.25)$

Test for subgroup differences: $\mathrm{Chi}^{2}=1.78, \mathrm{df}=2(\mathrm{P}=0.4 \mathrm{I}), \mathrm{I}^{2}=0.0 \%$

156

$\mathbf{0}$

49
Weight

$$
\begin{array}{r}
\text { Risk Ratio } \\
\text { M- } \\
\text { H,Random,95\% }
\end{array}
$$

$100.0 \%$

$2.81[0.12,66.17]$

\section{8}
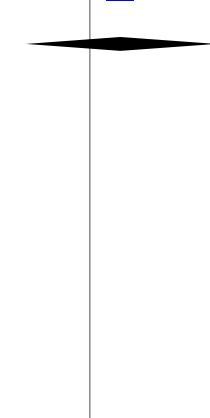

$100.0 \%$

$2.81[0.12,66.17$ ]

Not estimable

$100.0 \%$

I.II [0.50, 2.43]

$100.0 \%$

$1.11[0.50,2.43$ ]

Not estimable

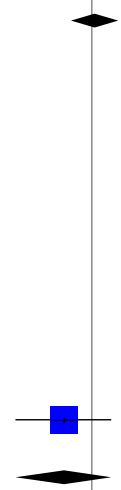

$100.0 \%$

$0.39[0.08,1.93]$ 


\section{Analysis I.5. Comparison I Tocolytic drugs (A) vs placebo, Outcome 5 Failed external cephalic version.}

Review: Interventions for helping to turn term breech babies to head first presentation when using external cephalic version

Comparison: I Tocolytic drugs (A) vs placebo

Outcome: 5 Failed external cephalic version

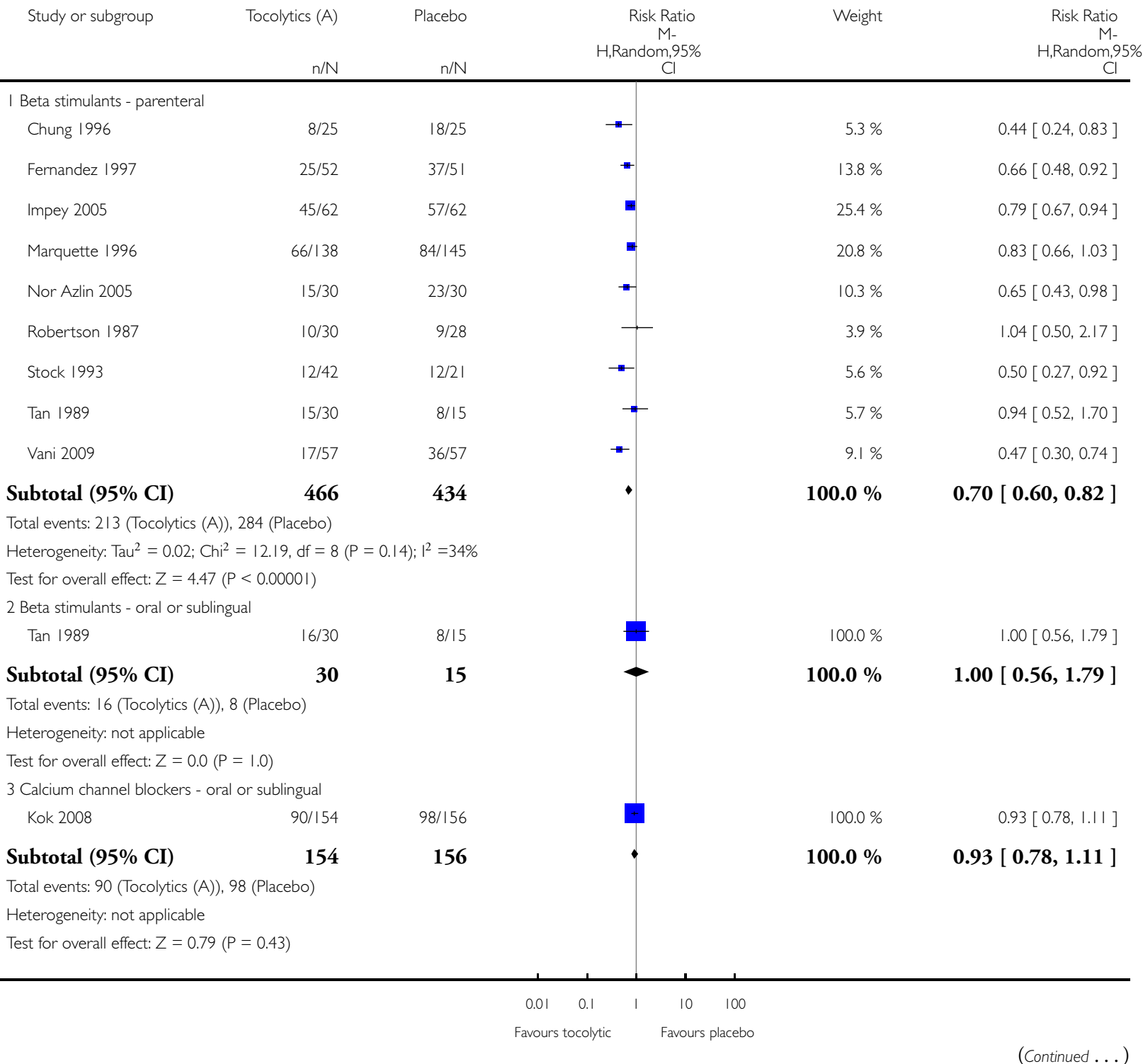




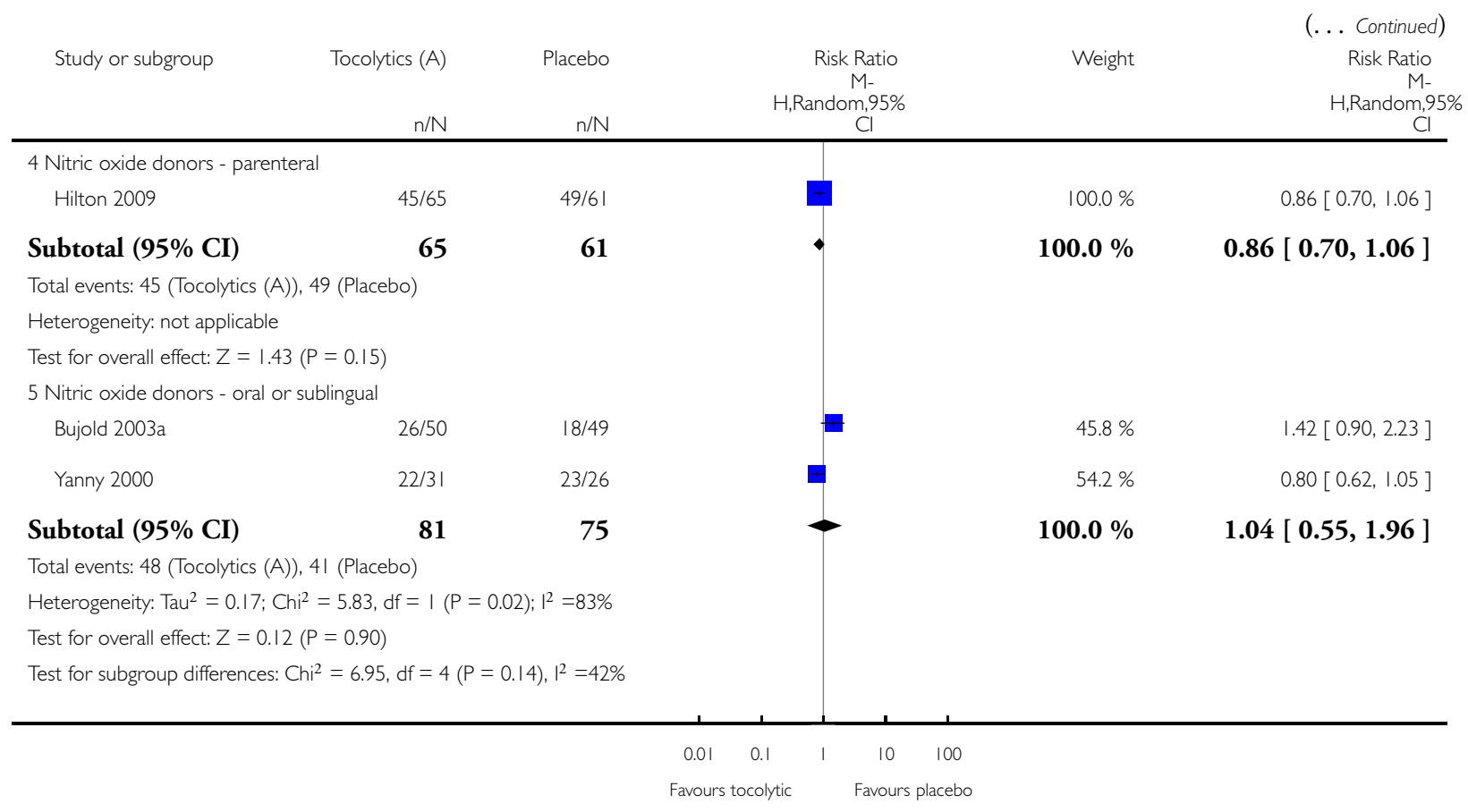


Analysis I.6. Comparison I Tocolytic drugs (A) vs placebo, Outcome 6 Difficult external cephalic version.

Review: Interventions for helping to turn term breech babies to head first presentation when using external cephalic version

Comparison: I Tocolytic drugs (A) vs placebo

Outcome: 6 Difficult external cephalic version

Study or subgroup Tocolytics (A) Placebo

Risk Ratio

H,Random, $95 \%$

Weight

Risk Ratio

H,Random,95\%

$\mathrm{n} / \mathrm{N}$

$\mathrm{n} / \mathrm{N}$

Cl

I Beta stimulants - parenteral

Stock 1993

$5 / 42$

$5 / 21$

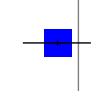

Subtotal (95\% CI)

42

21

$100.0 \%$

$0.50[0.16,1.54]$

Total events: 5 (Tocolytics (A)), 5 (Placebo)

Heterogeneity: not applicable

Test for overall effect: $Z=1.21(P=0.23)$

2 Beta stimulants - oral or sublingual

Subtotal (95\% CI)

$\mathbf{0}$

Total events: 0 (Tocolytics (A)), 0 (Placebo)

Heterogeneity: not applicable

Test for overall effect: not applicable

3 Calcium channel blockers - oral or sublingual

Subtotal (95\% CI)

$\mathbf{0}$

Total events: 0 (Tocolytics (A)), 0 (Placebo)

Heterogeneity: not applicable

Test for overall effect: not applicable

4 Nitric oxide donors - parenteral

Subtotal (95\% CI)

$\mathbf{0}$

Total events: 0 (Tocolytics (A)), 0 (Placebo)

Heterogeneity: not applicable

Test for overall effect: not applicable

5 Nitric oxide donors - oral or sublingual

Subtotal (95\% CI)

$\mathbf{0}$

$\mathbf{0}$

Total events: 0 (Tocolytics (A)), 0 (Placebo)

Heterogeneity: not applicable

Test for overall effect: not applicable

Test for subgroup differences: Not applicable

Not estimable

$100.0 \%$

$0.50[0.16,1.54$ ]

Not estimable

Not estimable

Not estimable 


\section{Analysis I.7. Comparison I Tocolytic drugs (A) vs placebo, Outcome 7 Maternal palpitations.}

Review: Interventions for helping to turn term breech babies to head first presentation when using external cephalic version

Comparison: I Tocolytic drugs (A) vs placebo

Outcome: 7 Maternal palpitations

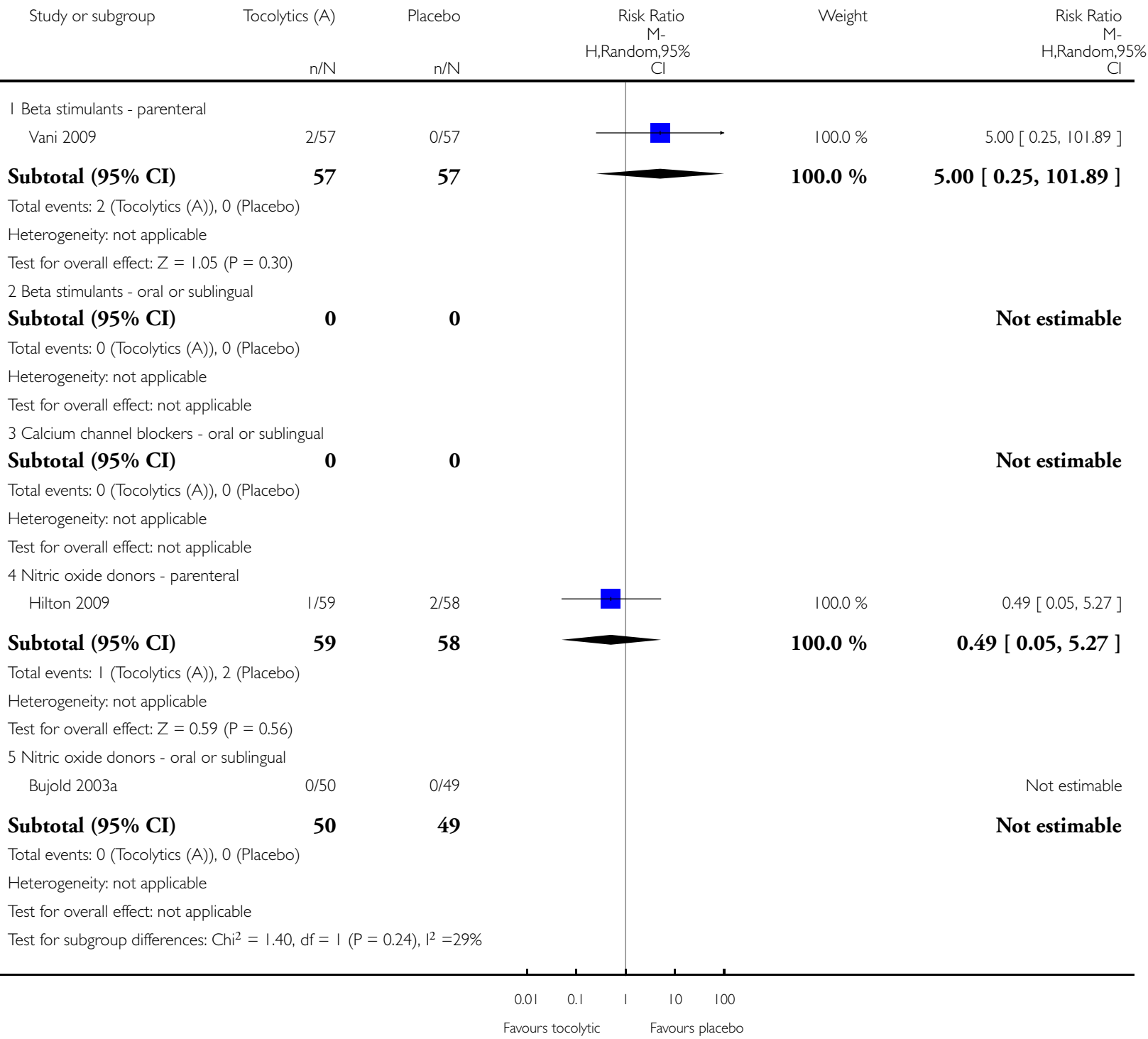




\section{Analysis I.8. Comparison I Tocolytic drugs (A) vs placebo, Outcome 8 Maternal headaches.}

Review: Interventions for helping to turn term breech babies to head first presentation when using external cephalic version

Comparison: I Tocolytic drugs (A) vs placebo

Outcome: 8 Maternal headaches

Placebo

Risk Ratio

$M-$

H,Random, $95 \%$

Weight

Risk Ratio

H,Random, $95 \%$

I Beta stimulants - parenteral
Subtotal (95\% CI)

Total events: 0 (Tocolytics (A)), 0 (Placebo)

$n / N \quad n / N$

$\mathrm{Cl}$

Heterogeneity: not applicable

Test for overall effect: not applicable

2 Beta stimulants - oral or sublingual

Subtotal (95\% CI)

\section{0}

$\mathbf{0}$

0

Not estimable

Total events: 0 (Tocolytics (A)), 0 (Placebo)

Heterogeneity: not applicable

Test for overall effect: not applicable

3 Calcium channel blockers - oral or sublingual

Subtotal (95\% CI)

0

Total events: 0 (Tocolytics (A)), 0 (Placebo)

Heterogeneity: not applicable

Test for overall effect: not applicable

4 Nitric oxide donors - parenteral

$\mathbf{0}$

Not estimable

Subtotal (95\% CI)

$59 \quad 58$

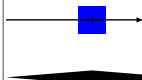

$100.0 \%$

$18.68[1.11,313.77]$

Total events: 9 (Tocolytics (A)), 0 (Placebo)

Heterogeneity: not applicable

Test for overall effect: $Z=2.03(P=0.042)$

5 Nitric oxide donors - oral or sublingual

$$
\text { Bujold 2003a }
$$

Subtotal $(95 \%$ CI $)$

50

49

Total events: 21 (Tocolytics (A)), 2 (Placebo)

Heterogeneity: not applicable

Test for overall effect: $Z=3.27(P=0.0011)$

Test for subgroup differences: $\mathrm{Chi}^{2}=0.14, \mathrm{df}=\mathrm{I}(\mathrm{P}=0.7 \mathrm{I}), \mathrm{I}^{2}=0.0 \%$

$100.0 \%$ 


\section{Analysis I.9. Comparison I Tocolytic drugs (A) vs placebo, Outcome 9 Maternal hypotension.}

Review: Interventions for helping to turn term breech babies to head first presentation when using external cephalic version

Comparison: I Tocolytic drugs (A) vs placebo

Outcome: 9 Maternal hypotension

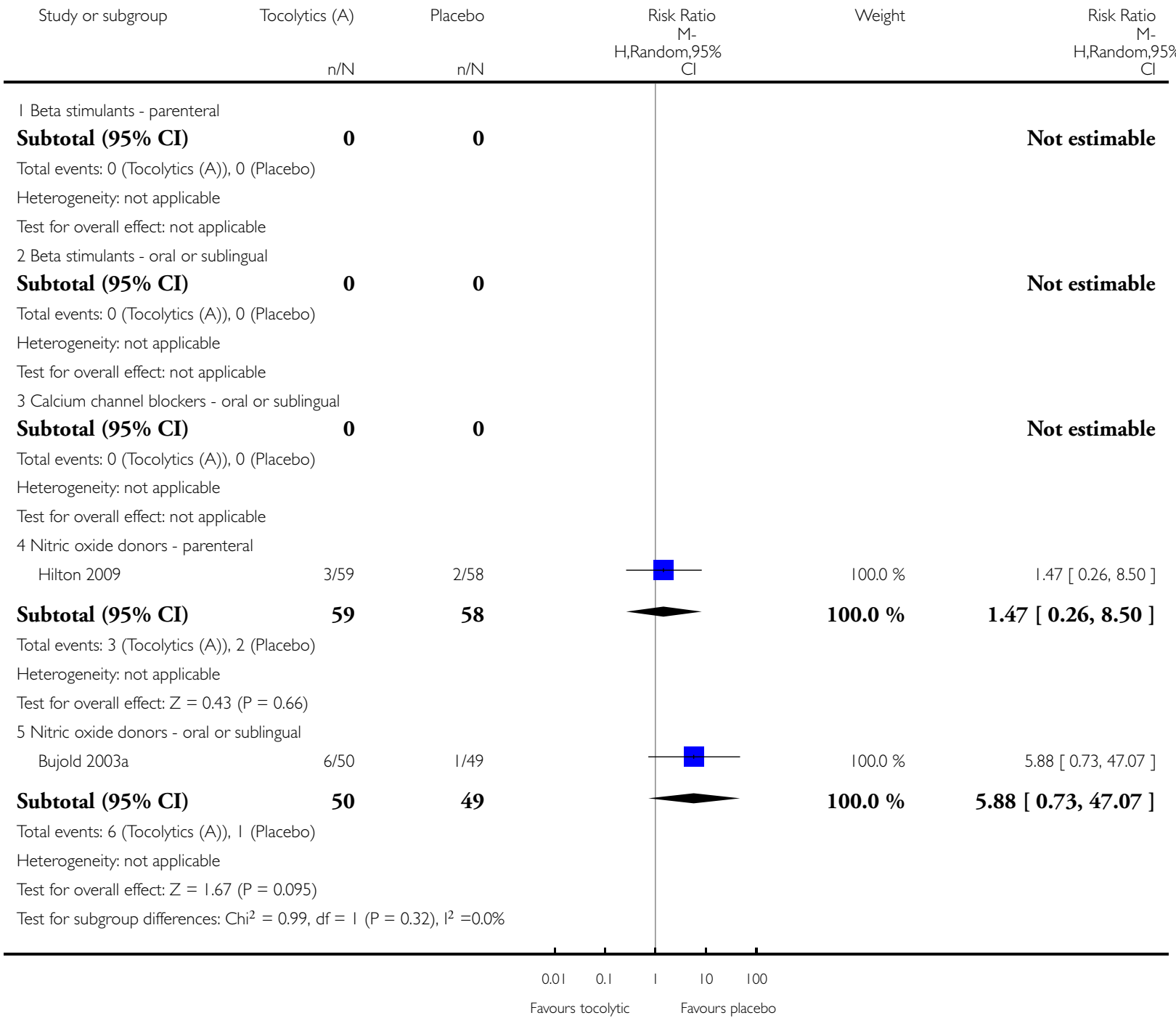


Analysis I.I0. Comparison I Tocolytic drugs (A) vs placebo, Outcome 10 Operative vaginal birth.

Review: Interventions for helping to turn term breech babies to head first presentation when using external cephalic version

Comparison: I Tocolytic drugs (A) vs placebo

Outcome: 10 Operative vaginal birth

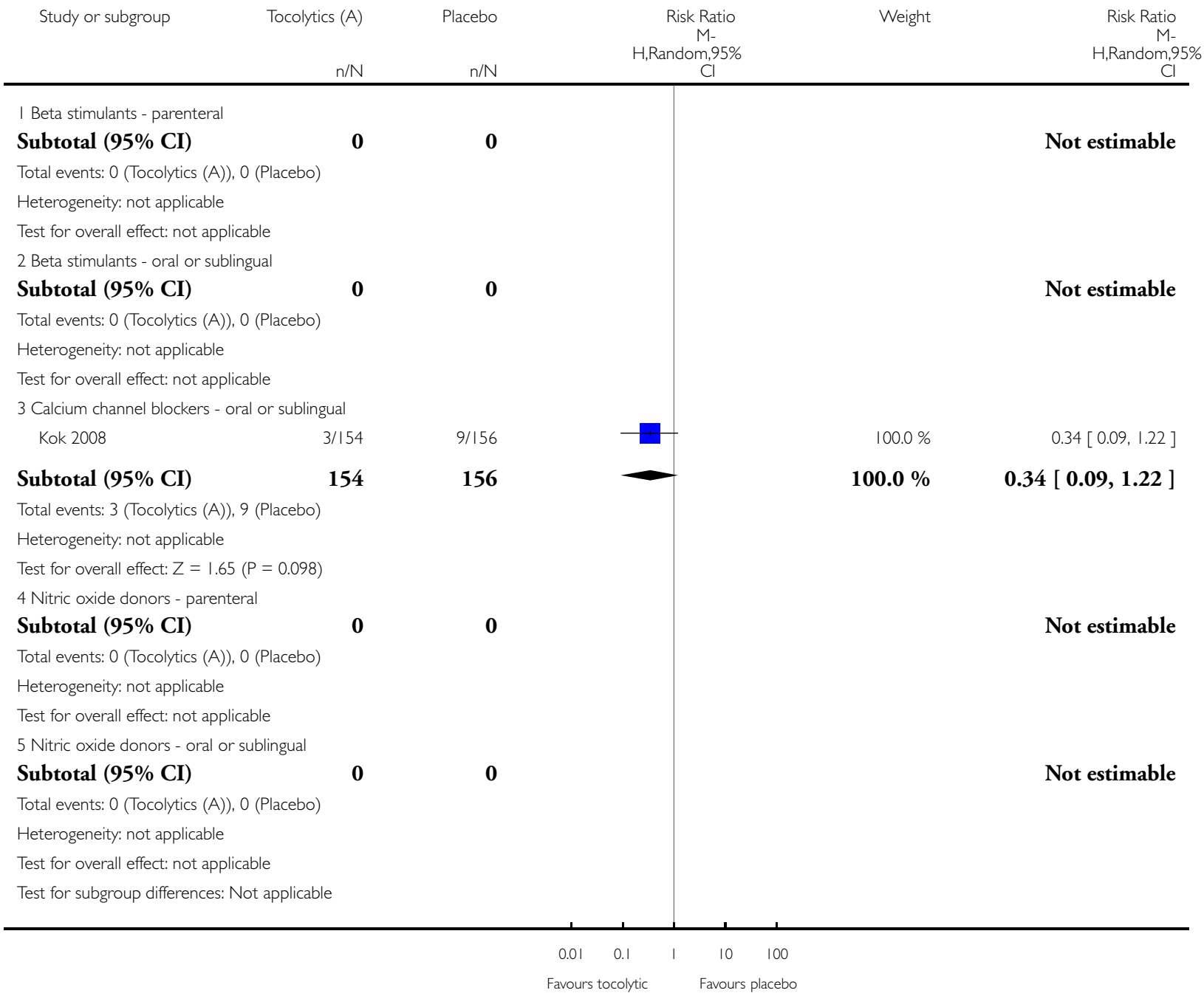




\section{Analysis I.13. Comparison I Tocolytic drugs (A) vs placebo, Outcome I3 Perinatal mortality.}

Review: Interventions for helping to turn term breech babies to head first presentation when using external cephalic version

Comparison: I Tocolytic drugs (A) vs placebo

Outcome: 13 Perinatal mortality

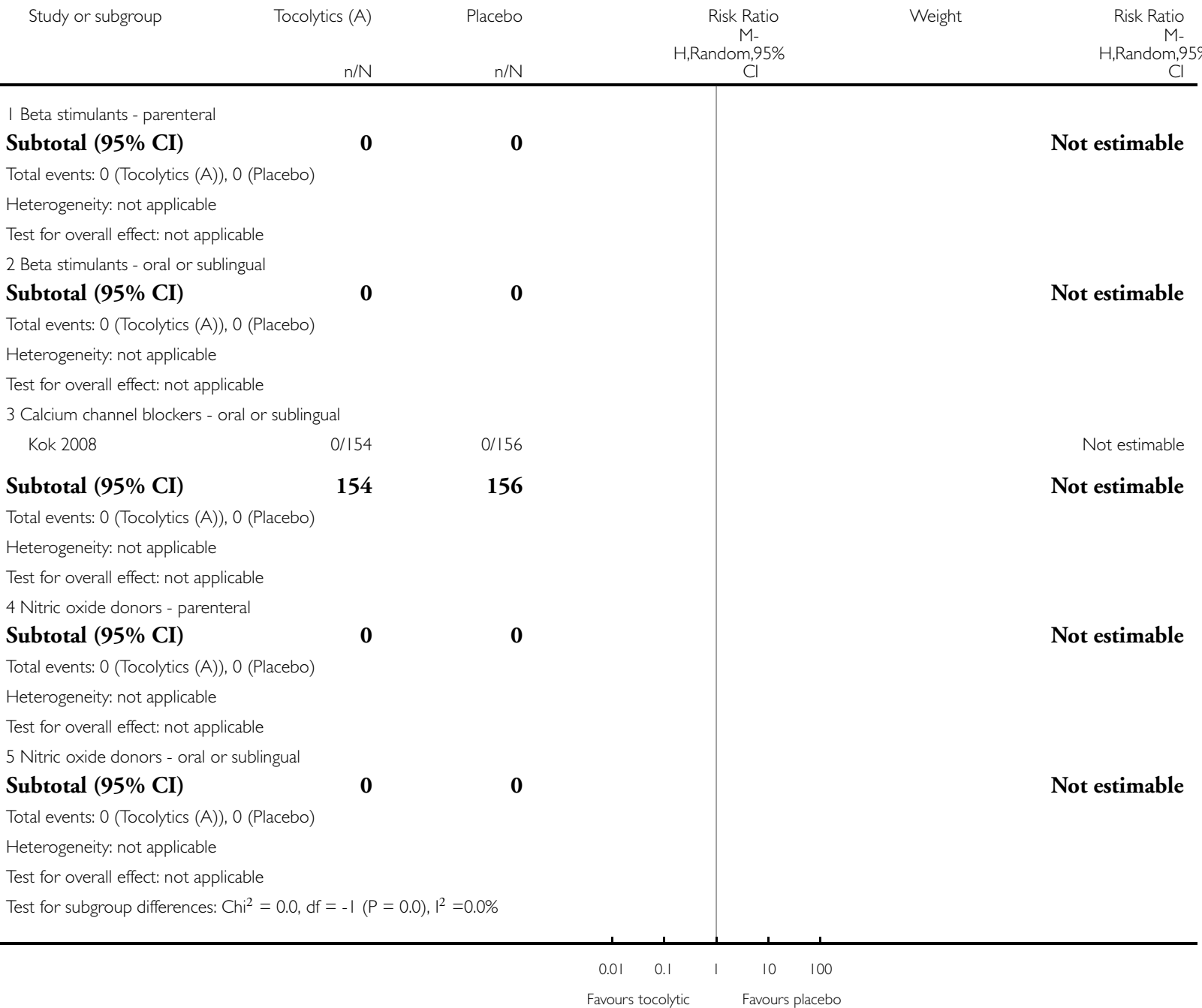




\section{Analysis I.I5. Comparison I Tocolytic drugs (A) vs placebo, Outcome I5 Vaginal breech birth.}

Review: Interventions for helping to turn term breech babies to head first presentation when using external cephalic version

Comparison: I Tocolytic drugs (A) vs placebo

Outcome: 15 Vaginal breech birth

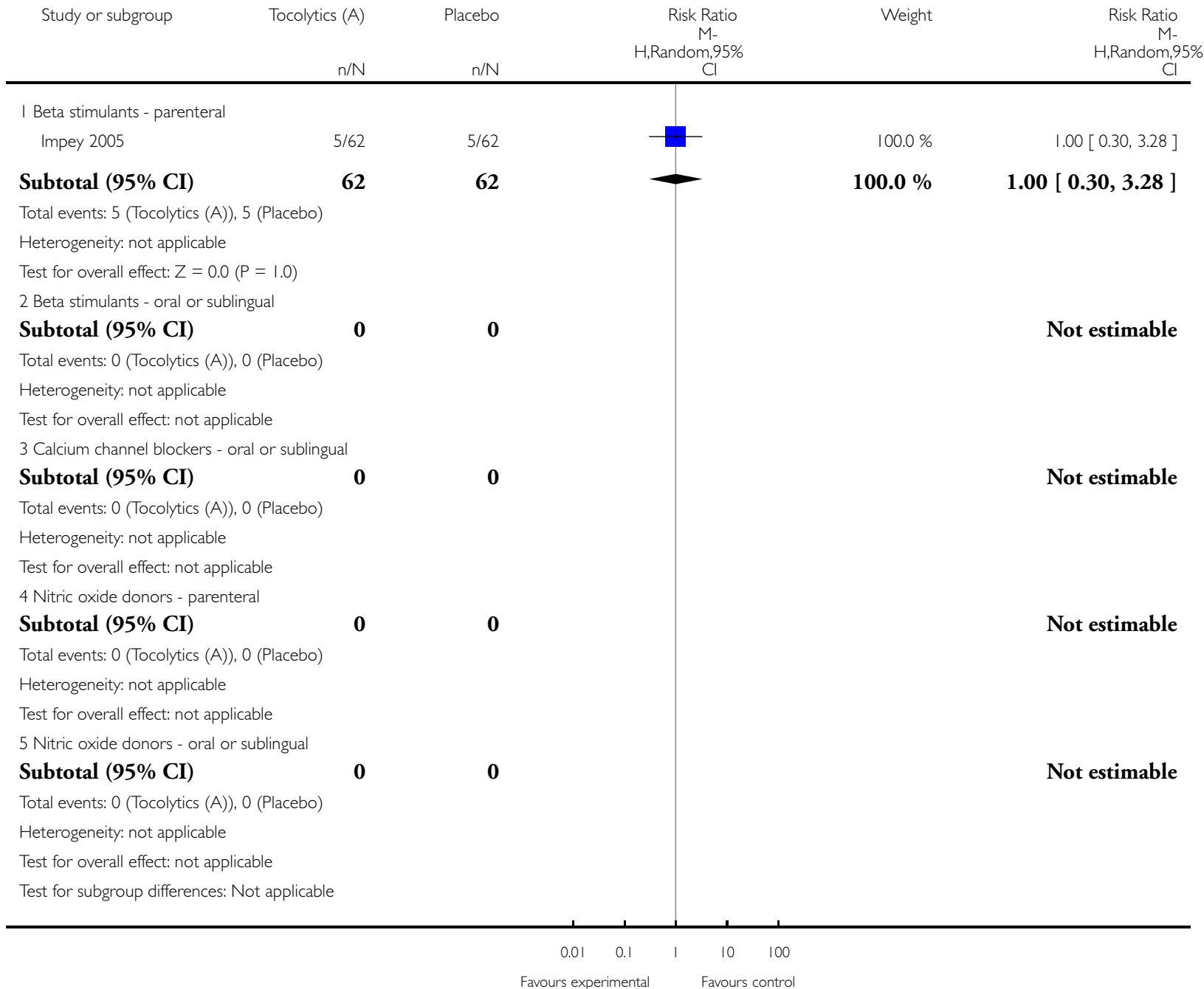




\section{Analysis I.16. Comparison I Tocolytic drugs (A) vs placebo, Outcome 16 Apgar $<7$ at 5 minutes (not prespecified).}

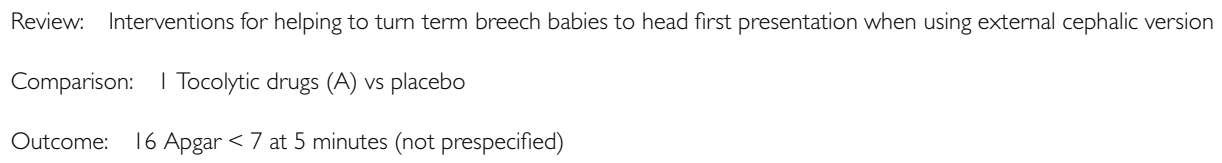

Subtotal (95\% CI)

114

Total events: 0 (Tocolytics (A)), 0 (Placebo)

Heterogeneity: not applicable

Test for overall effect: not applicable

2 Beta stimulants - oral or sublingual

Subtotal (95\% CI)

Total events: 0 (Tocolytics (A)), 0 (Placebo)

Heterogeneity: not applicable

Test for overall effect: not applicable

3 Calcium channel blockers - oral or sublingual

Subtotal (95\% CI)

Total events: 0 (Tocolytics (A)), 0 (Placebo)

Heterogeneity: not applicable

Test for overall effect: not applicable

4 Nitric oxide donors - parenteral

\section{Subtotal (95\% CI)}

$\mathbf{0}$

$\mathbf{0}$

Total events: 0 (Tocolytics (A)), 0 (Placebo)

Heterogeneity: not applicable

Test for overall effect: not applicable

5 Nitric oxide donors - oral or sublingual

Subtotal (95\% CI)

Total events: 0 (Tocolytics (A)), 0 (Placebo)

Heterogeneity: not applicable

Test for overall effect: not applicable

Test for subgroup differences: $C h i^{2}=0.0, \mathrm{df}=-\mathrm{I}(\mathrm{P}=0.0), \mathrm{I}^{2}=0.0 \%$

Not estimable

Not estimable

Not estimable

Not estimable 
Analysis I.I7. Comparison I Tocolytic drugs (A) vs placebo, Outcome I7 Neonatal seizures (not prespecified).

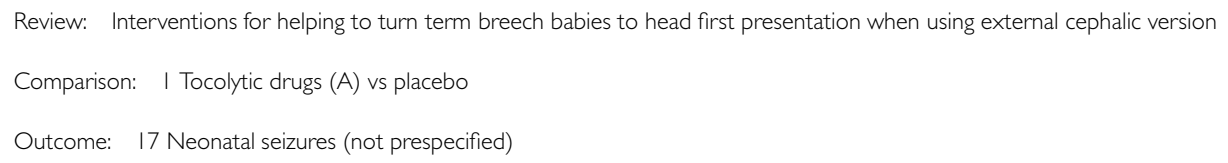

Subtotal (95\% CI)

Total events: 0 (Tocolytics (A)), 0 (Placebo)

Heterogeneity: not applicable

Test for overall effect: not applicable

2 Beta stimulants - oral or sublingual

Subtotal (95\% CI)

Not estimable

Total events: 0 (Tocolytics (A)), 0 (Placebo)

Heterogeneity: not applicable

Test for overall effect: not applicable

3 Calcium channel blockers - oral or sublingual

Subtotal (95\% CI)

\section{$\mathbf{0}$}

Not estimable

Total events: 0 (Tocolytics (A)), 0 (Placebo)

Heterogeneity: not applicable

Test for overall effect: not applicable

4 Nitric oxide donors - parenteral

Subtotal (95\% CI)

$\mathbf{0}$

$\mathbf{0}$

Not estimable

Total events: 0 (Tocolytics (A)), 0 (Placebo)

Heterogeneity: not applicable

Test for overall effect: not applicable

5 Nitric oxide donors - oral or sublingual

Subtotal $(95 \% \mathrm{CI})$

0

o

Total events: 0 (Tocolytics (A)), 0 (Placebo)

Heterogeneity: not applicable

Test for overall effect: not applicable

Test for subgroup differences: $\mathrm{Chi}^{2}=0.0, \mathrm{df}=-\mathrm{I}(\mathrm{P}=0.0), \mathrm{I}^{2}=0.0 \%$

Not estimable

Not estimable 


\section{Analysis I.18. Comparison I Tocolytic drugs (A) vs placebo, Outcome I8 Admission to neonatal unit (not prespecified).}

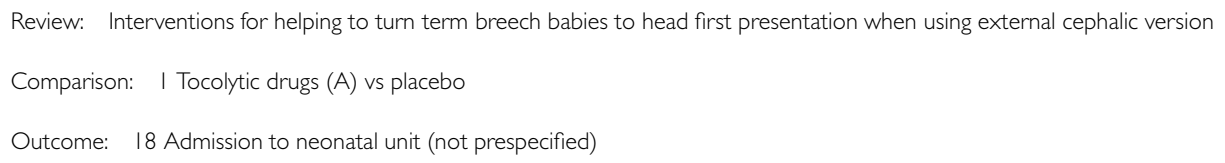

162

$3 / 57 \quad 3 / 57$

Subtotal (95\% CI)

Total events: 5 (Tocolytics (A)), 5 (Placebo)

Heterogeneity: $\mathrm{Tau}^{2}=0.0 ; \mathrm{Chi}^{2}=0.0, \mathrm{df}=$ I $(\mathrm{P}=1.00) ; \mathrm{I}^{2}=0.0 \%$

Test for overall effect: $Z=0.0(P=1.0)$

2 Beta stimulants - oral or sublingual

Subtotal (95\% CI)

Total events: 0 (Tocolytics (A)), 0 (Placebo)

Heterogeneity: not applicable

Test for overall effect: not applicable

3 Calcium channel blockers - oral or sublingual

Subtotal (95\% CI)

0

Total events: 0 (Tocolytics (A)), 0 (Placebo)

Heterogeneity: not applicable

Test for overall effect: not applicable

4 Nitric oxide donors - parenteral

Subtotal (95\% CI)

$\mathbf{0}$

Total events: 0 (Tocolytics (A)), 0 (Placebo)

Heterogeneity: not applicable

Test for overall effect: not applicable

5 Nitric oxide donors - oral or sublingual

Subtotal (95\% CI)

$\mathbf{0}$

Total events: 0 (Tocolytics (A)), 0 (Placebo)

Heterogeneity: not applicable

Test for overall effect: not applicable

Test for subgroup differences: Not applicable

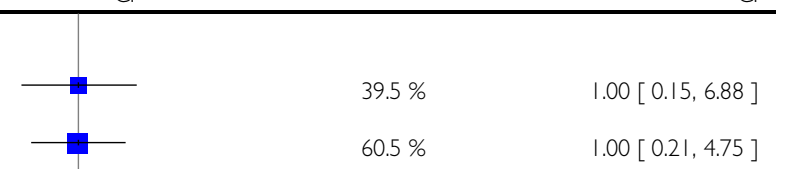

$100.0 \%$

$1.00[0.30,3.36]$

Not estimable

Not estimable

Not estimable

Not estimable 


\section{Analysis I.19. Comparison I Tocolytic drugs (A) vs placebo, Outcome I9 Birth trauma (not prespecified).}

Review: Interventions for helping to turn term breech babies to head first presentation when using external cephalic version

Comparison: I Tocolytic drugs (A) vs placebo

Outcome: 19 Birth trauma (not prespecified)

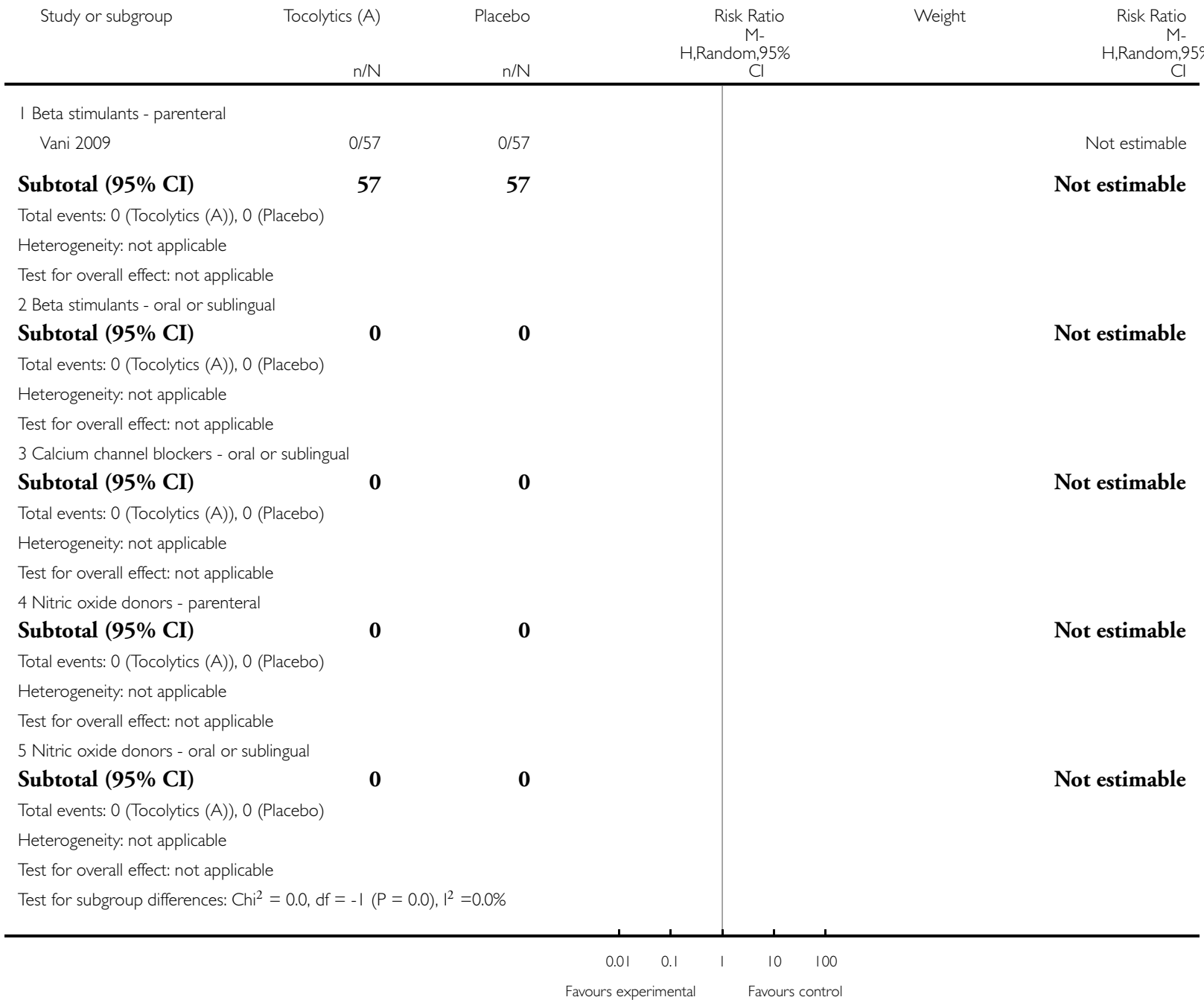




\section{Analysis I.20. Comparison I Tocolytic drugs (A) vs placebo, Outcome 20 Maternal flushing (not}

prespecified).

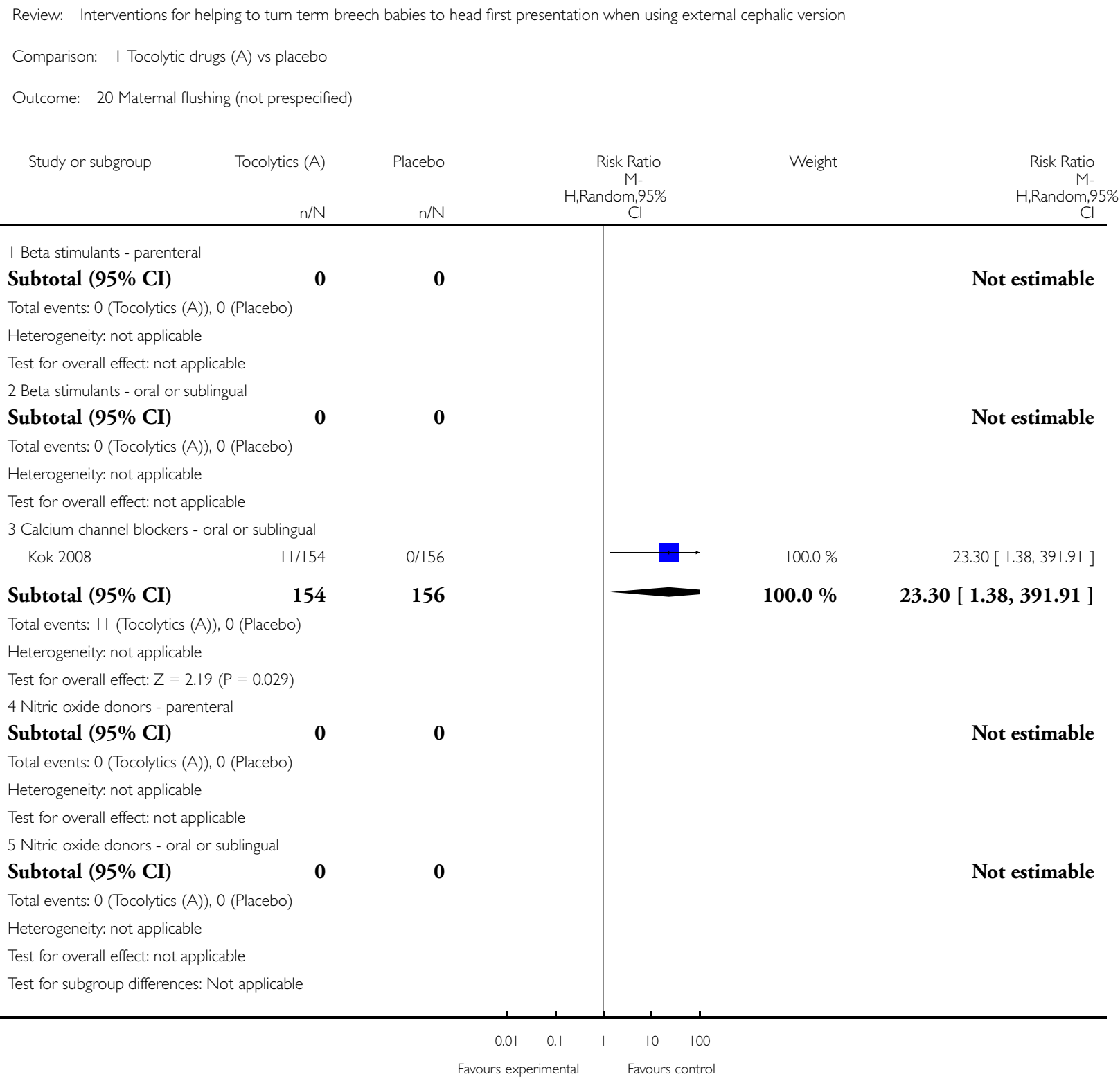




\section{Analysis 2.I. Comparison 2 Tocolytic drug I (A) vs tocolytic drug 2 (A), Outcome I Cephalic presentation} at birth (primary).

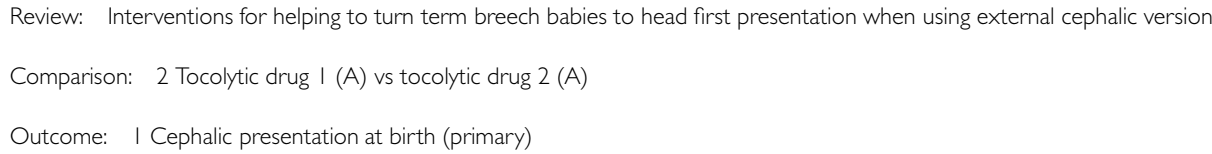

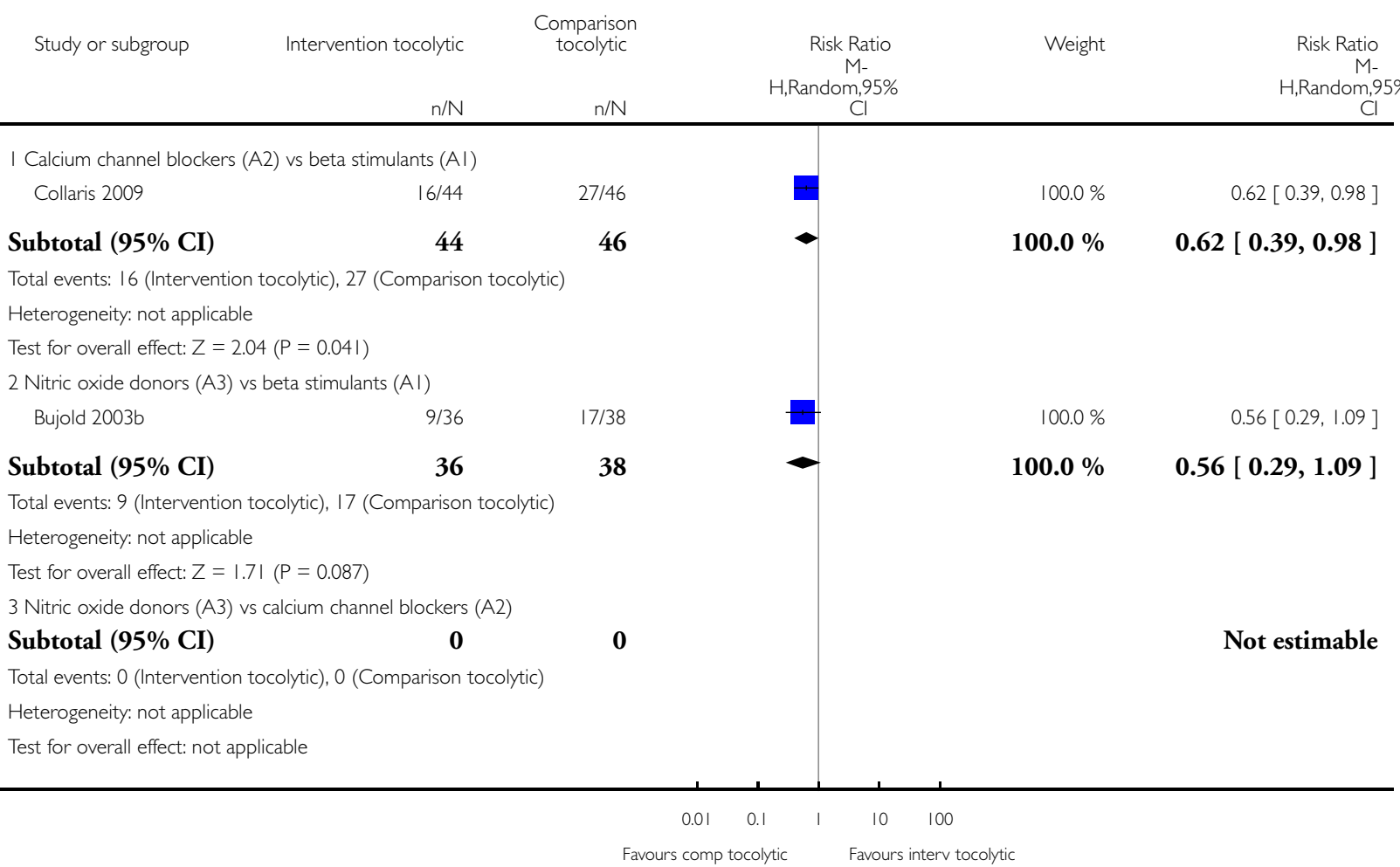


Analysis 2.2. Comparison 2 Tocolytic drug I (A) vs tocolytic drug 2 (A), Outcome 2 Failure to achieve cephalic vaginal birth (composite outcome: caesarean section + vaginal breech birth).

Review: Interventions for helping to turn term breech babies to head first presentation when using external cephalic version

Comparison: 2 Tocolytic drug I (A) vs tocolytic drug 2 (A)

Outcome: 2 Failure to achieve cephalic vaginal birth (composite outcome: caesarean section + vaginal breech birth)

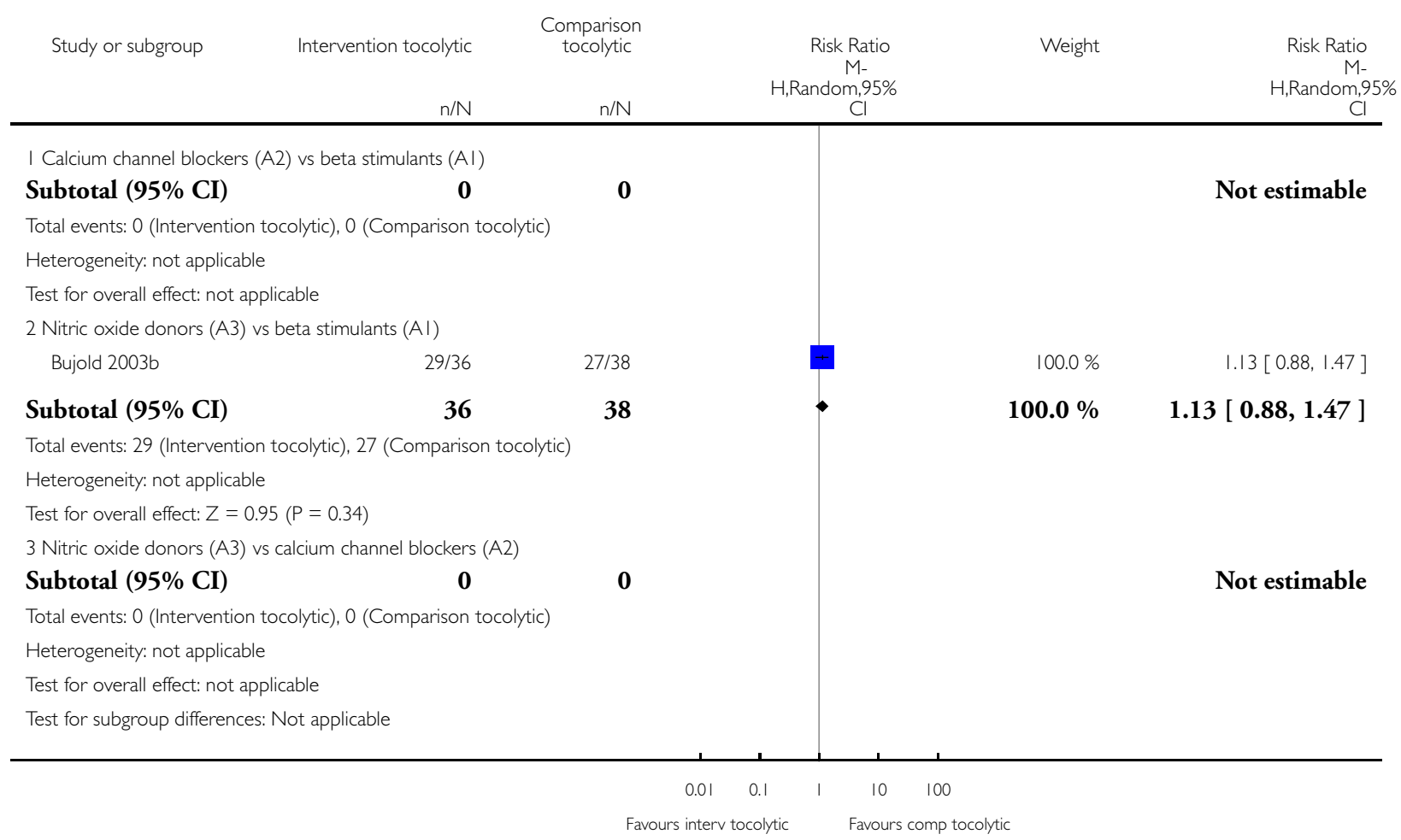


Analysis 2.3. Comparison 2 Tocolytic drug I (A) vs tocolytic drug 2 (A), Outcome 3 Caesarean section (primary).

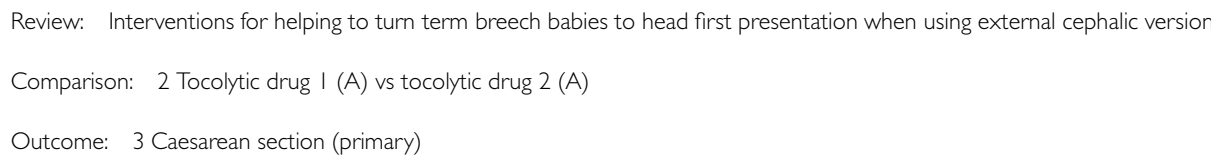

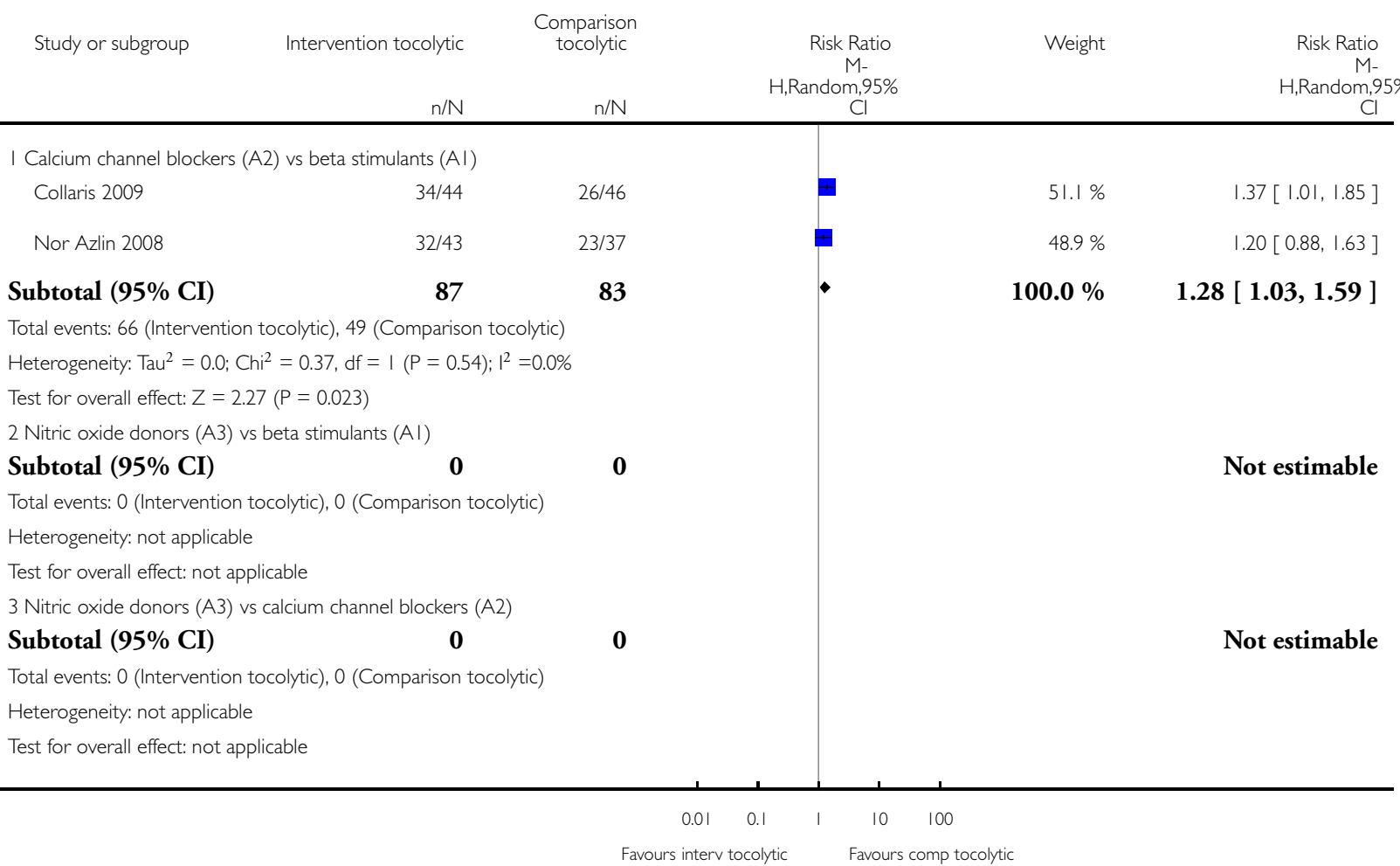




\section{Analysis 2.4. Comparison 2 Tocolytic drug I (A) vs tocolytic drug 2 (A), Outcome 4 Fetal bradycardia}

(primary).

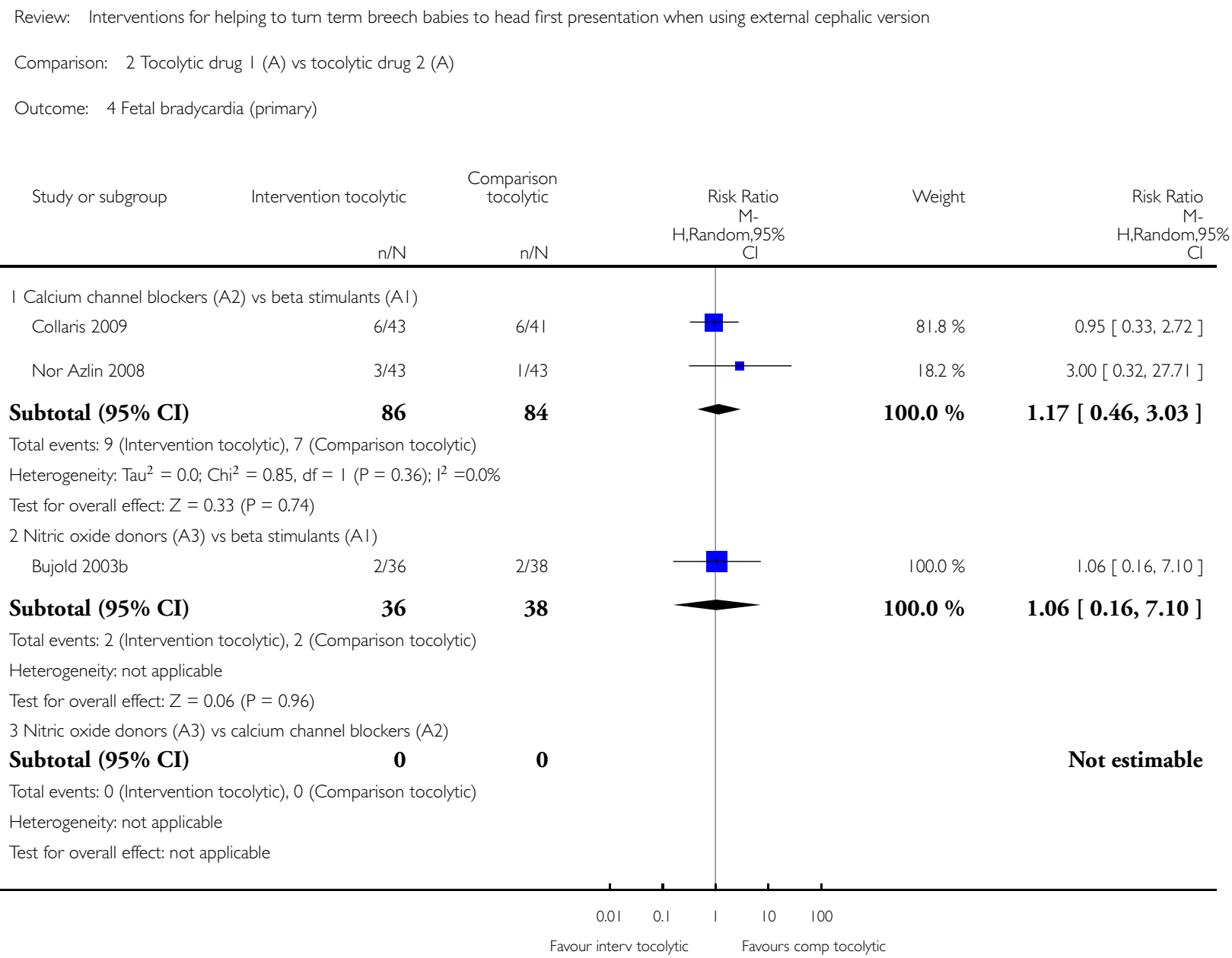




\section{Analysis 2.5. Comparison 2 Tocolytic drug I (A) vs tocolytic drug 2 (A), Outcome 5 Failed external cephalic}

version.

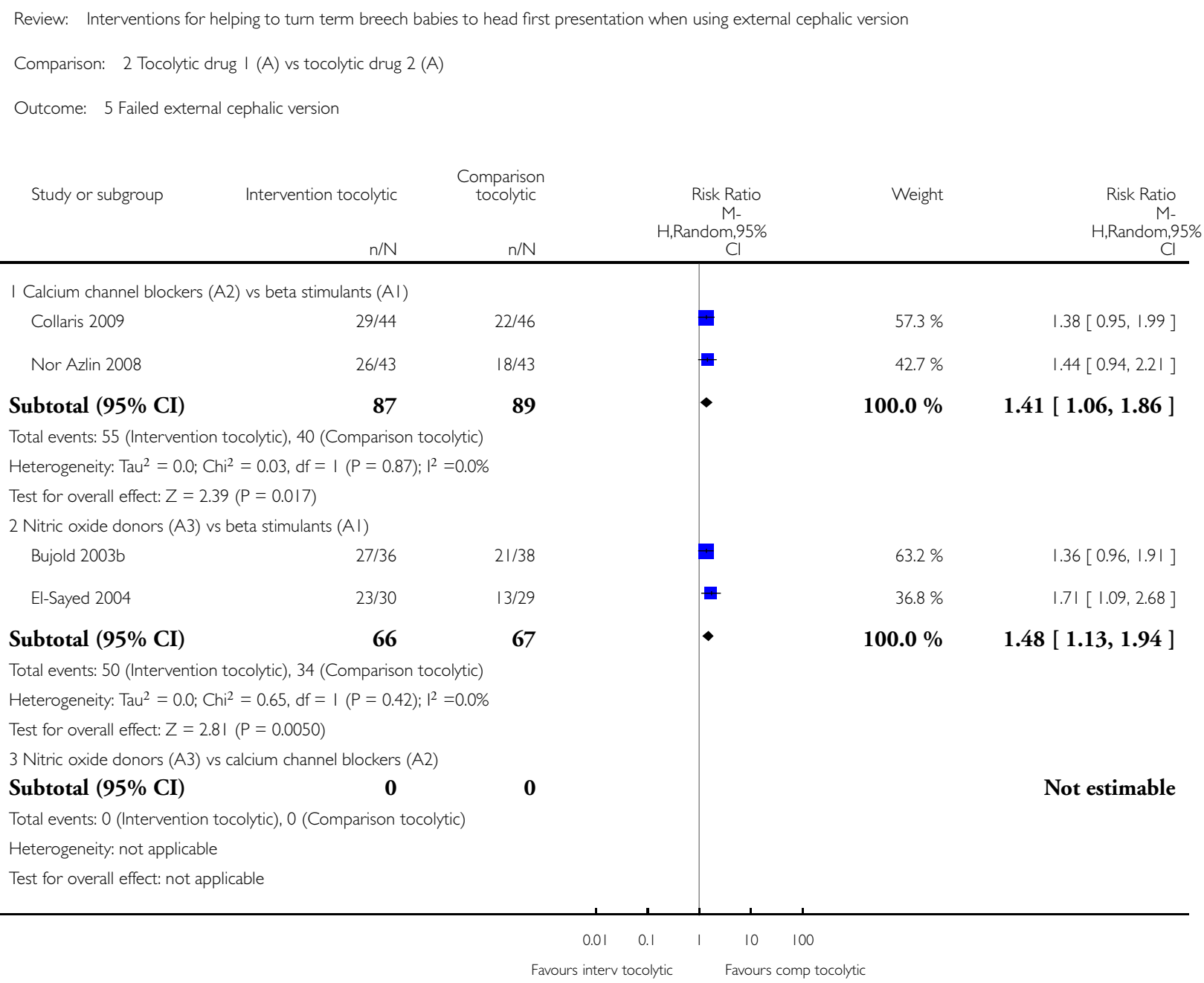


Analysis 2.6. Comparison 2 Tocolytic drug I (A) vs tocolytic drug 2 (A), Outcome 6 Difficult external cephalic version.

Review: Interventions for helping to turn term breech babies to head first presentation when using external cephalic version

Comparison: 2 Tocolytic drug I (A) vs tocolytic drug 2 (A)

Outcome: 6 Difficult external cephalic version

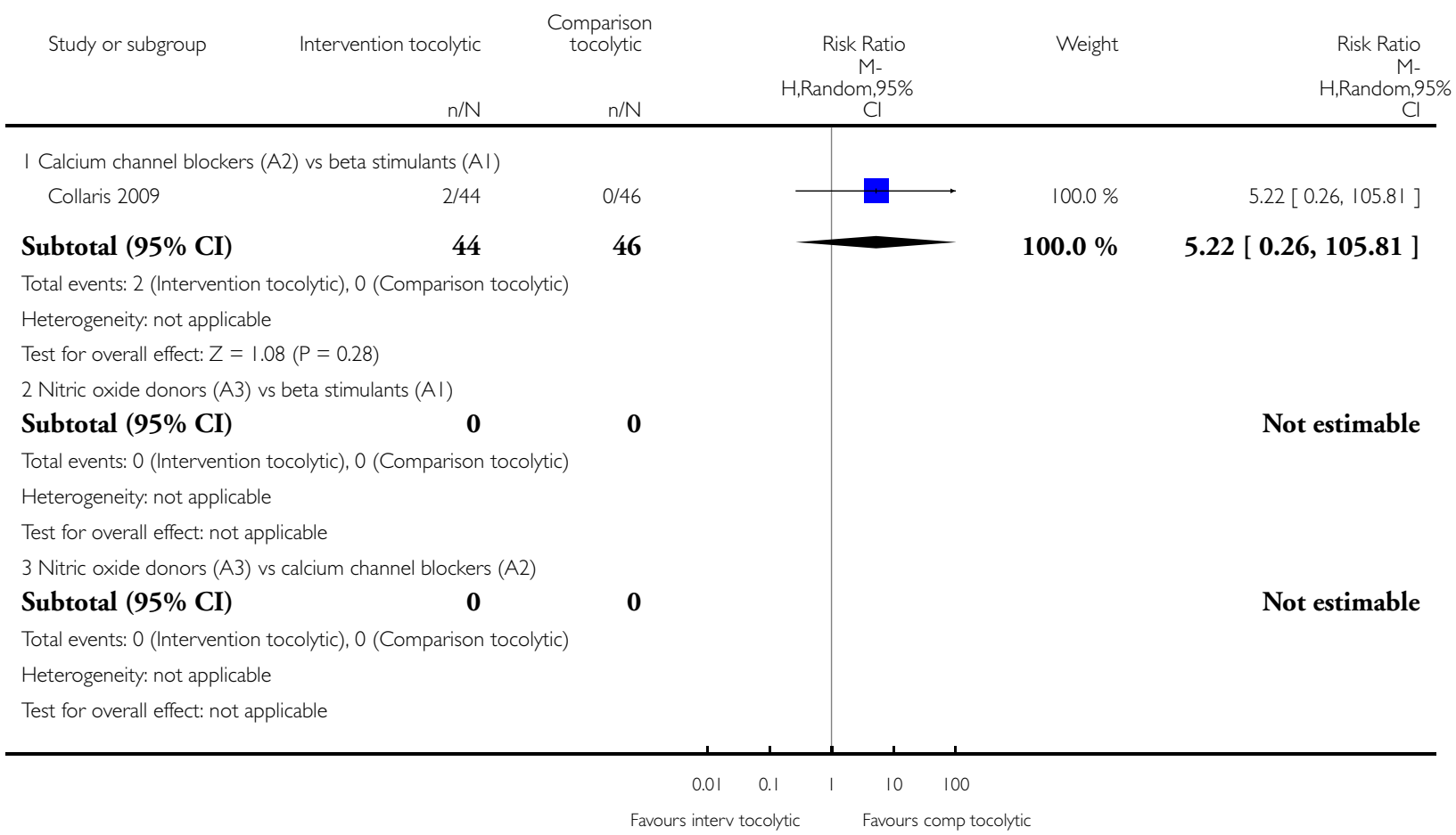




\section{Analysis 2.7. Comparison 2 Tocolytic drug I (A) vs tocolytic drug 2 (A), Outcome 7 Maternal palpitations.}

Review: Interventions for helping to turn term breech babies to head first presentation when using external cephalic version

Comparison: 2 Tocolytic drug I (A) vs tocolytic drug 2 (A)

Outcome: 7 Maternal palpitations

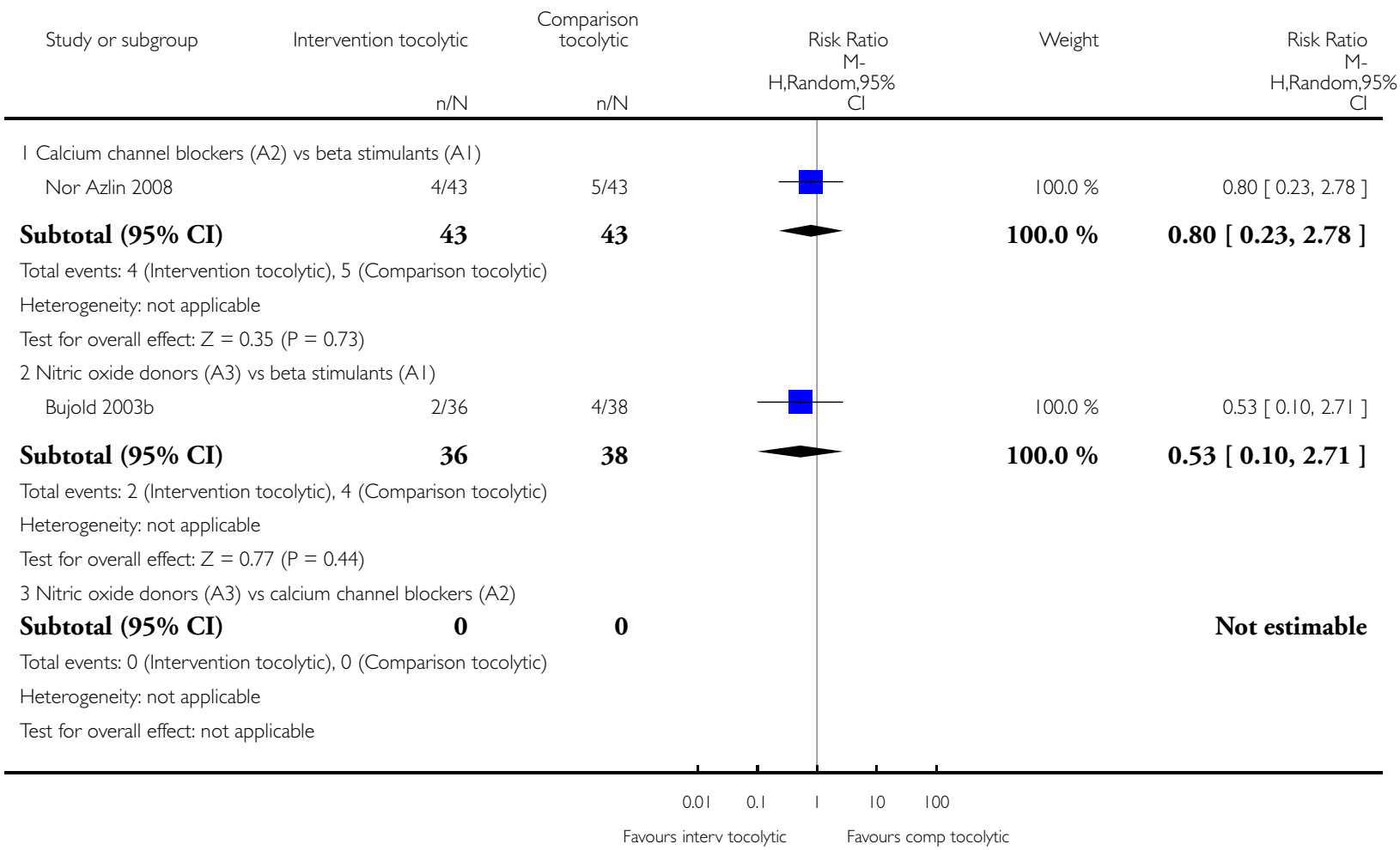




\section{Analysis 2.8. Comparison 2 Tocolytic drug I (A) vs tocolytic drug 2 (A), Outcome 8 Maternal headaches.}

Review: Interventions for helping to turn term breech babies to head first presentation when using external cephalic version

Comparison: 2 Tocolytic drug I (A) vs tocolytic drug 2 (A)

Outcome: 8 Maternal headaches Comparison
Study or subgroup $\quad$ Intervention tocolytic

Risk Ratio M-

I Calcium channel blockers (A2) vs beta stimulants (A I)
Subtotal (95\% CI)

0

Total events: 0 (Intervention tocolytic), 0 (Comparison tocolytic)

Heterogeneity: not applicable

Test for overall effect: not applicable

2 Nitric oxide donors (A3) vs beta stimulants (AI)

Bujold 2003b

36

Subtotal (95\% CI)

Total events: 10 (Intervention tocolytic), 3 (Comparison tocolytic)

Heterogeneity: not applicable

Test for overall effect: $Z=2.04(P=0.04 \mathrm{I})$

3 Nitric oxide donors (A3) vs calcium channel blockers (A2)

Subtotal (95\% CI)

Total events: 0 (Intervention tocolytic), 0 (Comparison tocolytic)

Heterogeneity: not applicable

Test for overall effect: not applicable $\mathbf{0}$

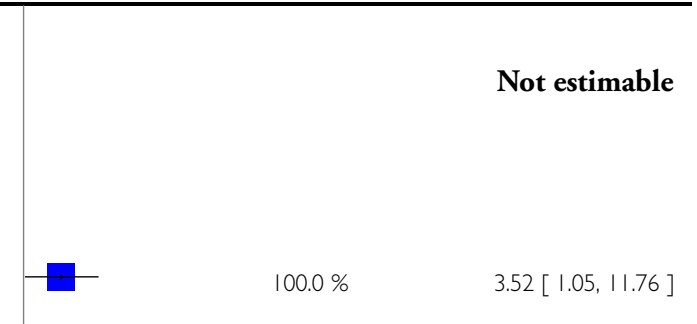

38

$100.0 \%$
0

Not estimable 


\section{Analysis 2.9. Comparison 2 Tocolytic drug I (A) vs tocolytic drug 2 (A), Outcome 9 Maternal hypotension.}

Review: Interventions for helping to turn term breech babies to head first presentation when using external cephalic version

Comparison: 2 Tocolytic drug I (A) vs tocolytic drug 2 (A)

Outcome: 9 Maternal hypotension

- Comparison

$\mathrm{n} / \mathrm{N} \quad \mathrm{n} / \mathrm{N}$

\begin{tabular}{|c|}
\hline $\begin{array}{c}\text { Risk Ratio } \\
\text { M- } \\
\text { H,Random,95\% }\end{array}$ \\
\hline
\end{tabular}

I Calcium channel blockers (A2) vs beta stimulants (A I)

Subtotal (95\% CI)

$\mathbf{0}$

Not estimable

Total events: 0 (Intervention tocolytic), 0 (Comparison tocolytic)

Heterogeneity: not applicable

Test for overall effect: not applicable

2 Nitric oxide donors (A3) vs beta stimulants (AI)

Bujold 2003b

$3 / 36$

36

Subtotal (95\% CI)

Total events: 3 (Intervention tocolytic), I (Comparison tocolytic)

Heterogeneity: not applicable

Test for overall effect: $Z=1.02(P=0.31)$

3 Nitric oxide donors (A3) vs calcium channel blockers (A2)

Subtotal (95\% CI)

Total events: 0 (Intervention tocolytic), 0 (Comparison tocolytic)

Heterogeneity: not applicable

Test for overall effect: not applicable

$\begin{array}{cccc}0.01 \quad 0.1 & 1 & 10 \quad 100 \\ \text { Favours interv tocolytic } & \text { Favours comp tocolytic }\end{array}$


Analysis 2.16. Comparison 2 Tocolytic drug I (A) vs tocolytic drug 2 (A), Outcome 16 Apgar $<$ at 5 minutes (not prespecified).

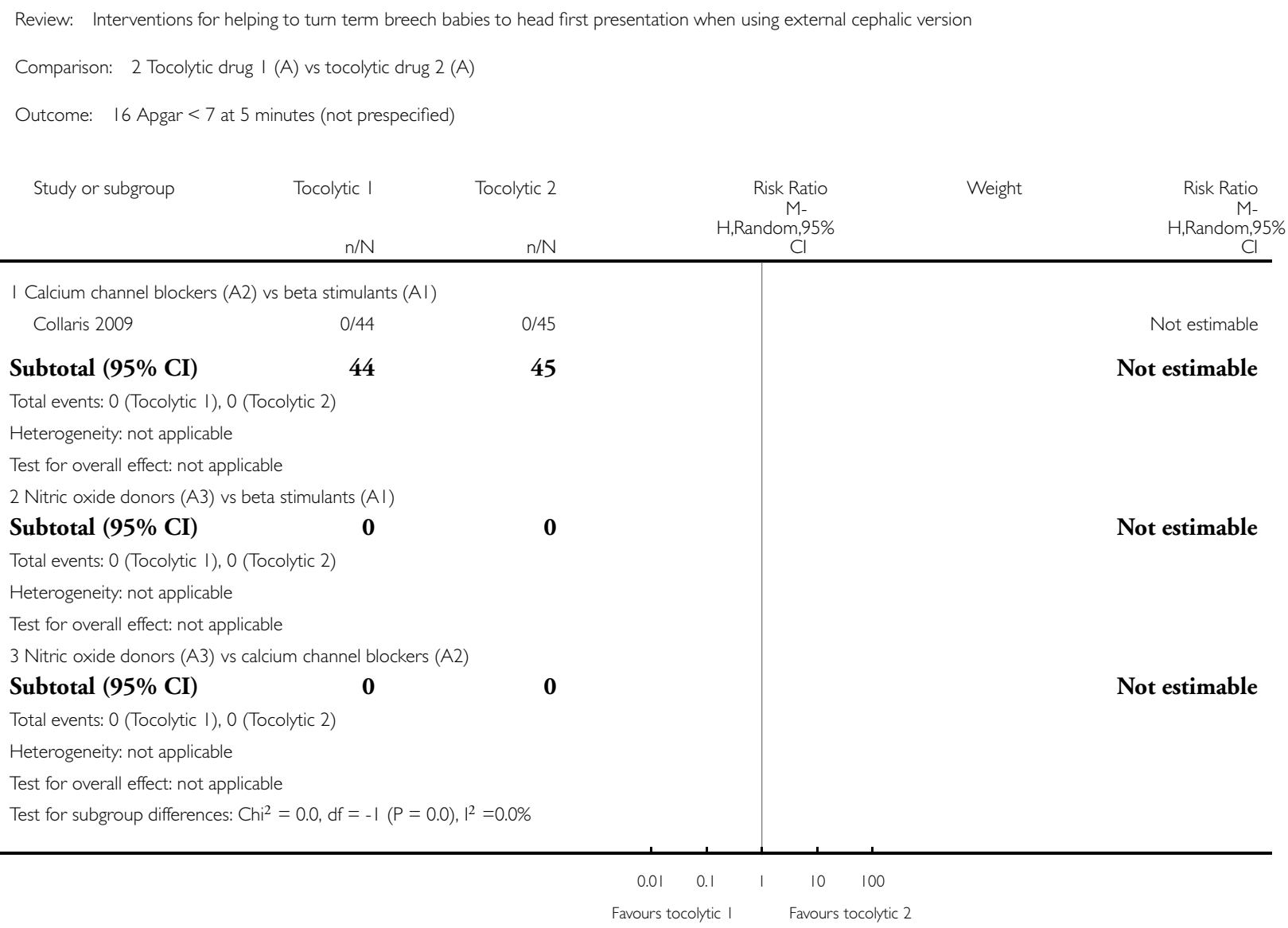




\section{Analysis 2.18. Comparison 2 Tocolytic drug I (A) vs tocolytic drug 2 (A), Outcome 18 Admissions to}

neonatal unit (not prespecified).

Review: Interventions for helping to turn term breech babies to head first presentation when using external cephalic version

Comparison: 2 Tocolytic drug I (A) vs tocolytic drug 2 (A)

Outcome: 18 Admissions to neonatal unit (not prespecified)

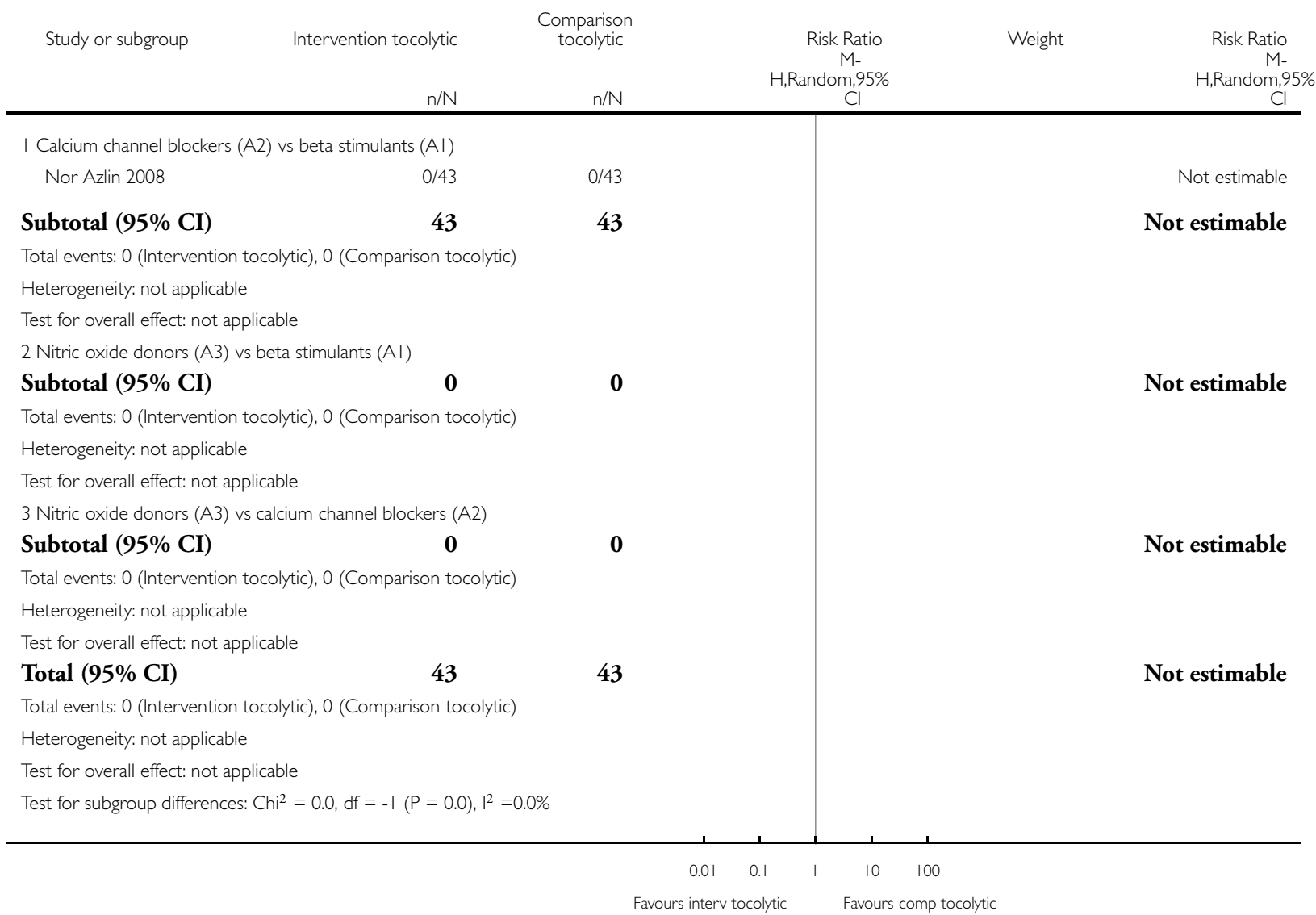


Analysis 3.5. Comparison 3 Vibroacoustic stimulation (B) vs placebo, Outcome 5 Failed external cephalic version.

Review: Interventions for helping to turn term breech babies to head first presentation when using external cephalic version

Comparison: 3 Vibroacoustic stimulation (B) vs placebo

Outcome: 5 Failed external cephalic version

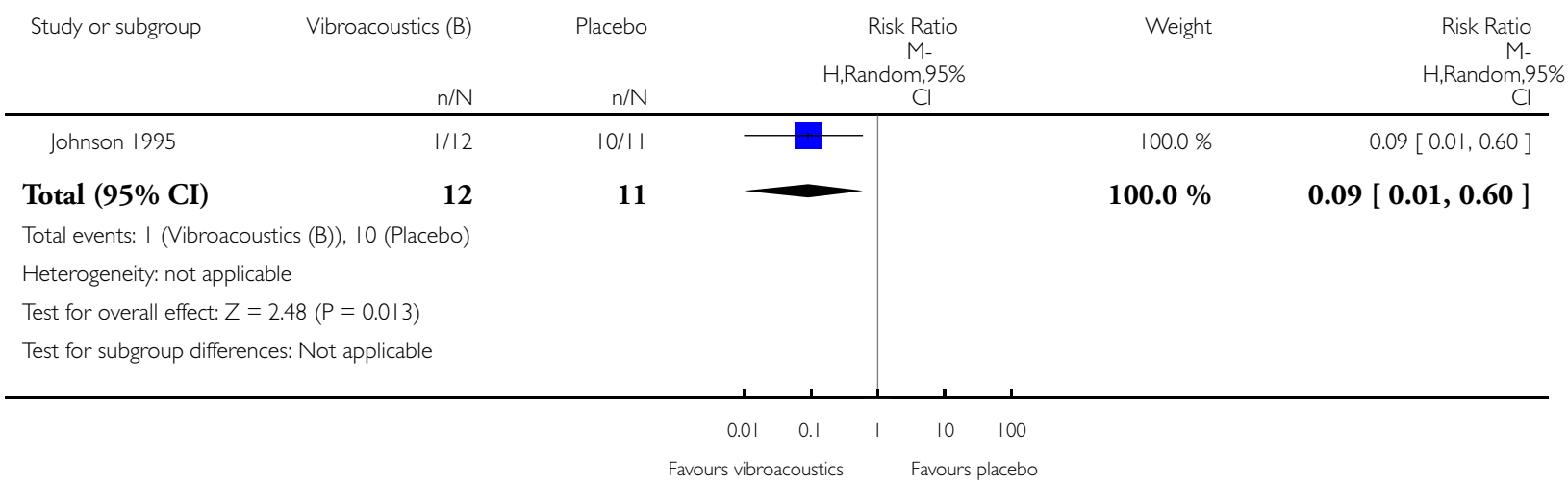


Analysis 6.1. Comparison 6 Regional analgesia (with or without tocolysis) vs no intervention of regional analgesia (with or without tocolysis), Outcome I Cephalic presentation at birth (primary).

Review: Interventions for helping to turn term breech babies to head first presentation when using external cephalic version

Comparison: 6 Regional analgesia (with or without tocolysis) vs no intervention of regional analgesia (with or without tocolysis)

Outcome: I Cephalic presentation at birth (primary)

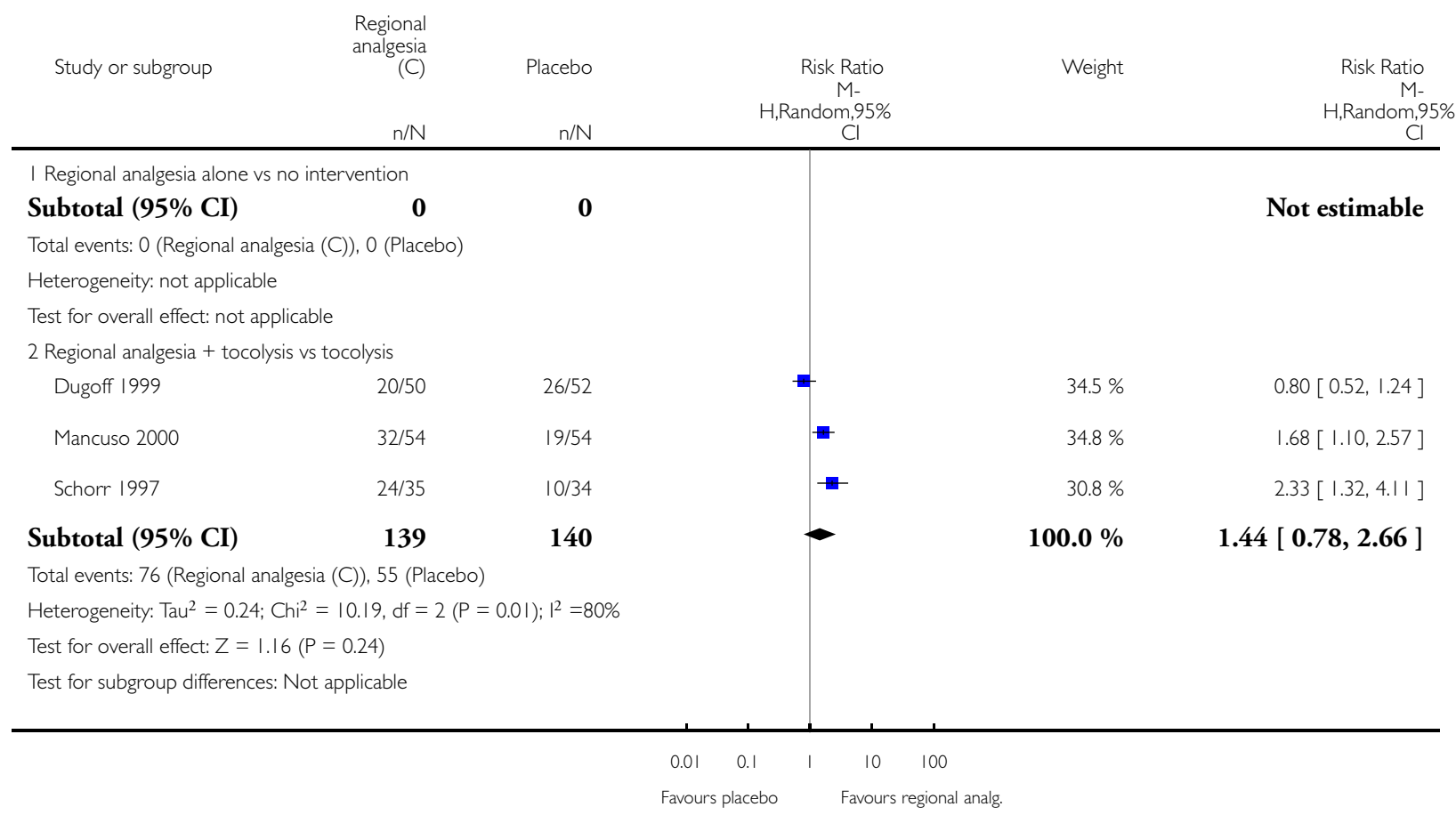


Analysis 6.3. Comparison 6 Regional analgesia (with or without tocolysis) vs no intervention of regional analgesia (with or without tocolysis), Outcome 3 Caesarean section (primary).

Review: Interventions for helping to turn term breech babies to head first presentation when using external cephalic version

Comparison: 6 Regional analgesia (with or without tocolysis) vs no intervention of regional analgesia (with or without tocolysis)

Outcome: 3 Caesarean section (primary)

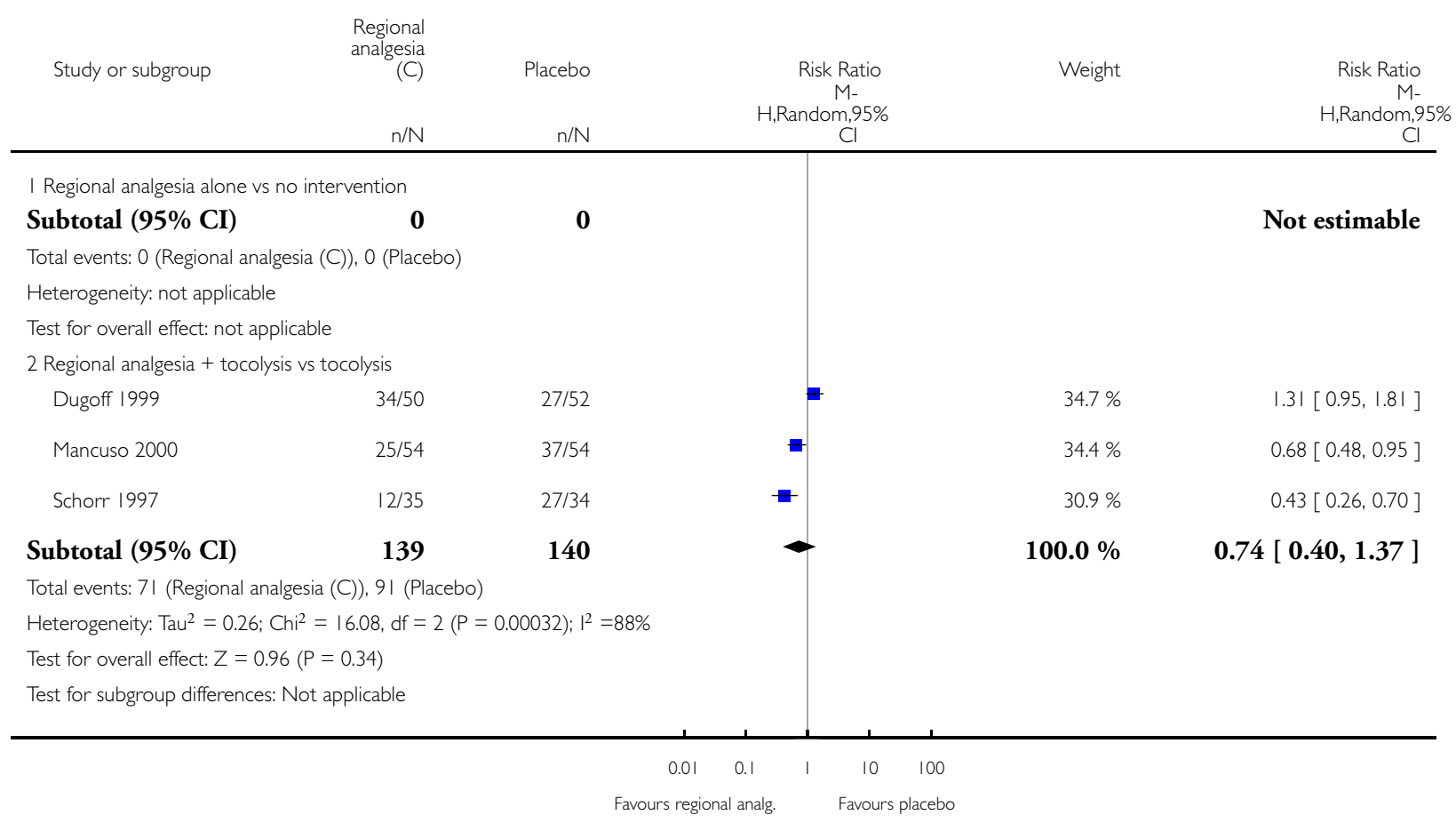


Analysis 6.4. Comparison 6 Regional analgesia (with or without tocolysis) vs no intervention of regional analgesia (with or without tocolysis), Outcome 4 Fetal bradycardia (primary).

Review: Interventions for helping to turn term breech babies to head first presentation when using external cephalic version

Comparison: 6 Regional analgesia (with or without tocolysis) vs no intervention of regional analgesia (with or without tocolysis)

Outcome: 4 Fetal bradycardia (primary)

\begin{tabular}{|c|c|c|c|c|c|c|}
\hline Study or subgroup & $\begin{array}{r}\text { Regional } \\
\text { analgesia } \\
(\mathrm{C}) \\
\mathrm{n} / \mathrm{N} \\
\end{array}$ & $\begin{array}{r}\text { Placebo } \\
n / N \\
\end{array}$ & & $\begin{array}{c}\text { Risk Ratio } \\
\text { M- } \\
\text { H,Random,95\% } \\
\text { Cl }\end{array}$ & Weight & $\begin{array}{c}\text { Risk Ratio } \\
\text { M- } \\
\text { H,Random,95\% } \\
\text { Cl } \\
\end{array}$ \\
\hline \multicolumn{7}{|c|}{ I Regional analgesia alone vs no intervention } \\
\hline Subtotal (95\% CI) & $\mathbf{0}$ & $\mathbf{0}$ & & & & Not estimable \\
\hline \multicolumn{7}{|c|}{ Total events: 0 (Regional analgesia (C)), 0 (Placebo) } \\
\hline \multicolumn{7}{|c|}{ Heterogeneity: not applicable } \\
\hline \multicolumn{7}{|c|}{ Test for overall effect: not applicable } \\
\hline \multicolumn{7}{|c|}{2 Regional analgesia + tocolysis vs tocolysis } \\
\hline Dugoff 1999 & $11 / 50$ & $6 / 52$ & & & $76.1 \%$ & $1.91[0.76,4.76]$ \\
\hline Mancuso 2000 & $2 / 54$ & $3 / 54$ & & $\longrightarrow$ & $23.9 \%$ & $0.67[0.12,3.83]$ \\
\hline Subtotal (95\% CI) & 104 & 106 & & - & $100.0 \%$ & $1.48[0.62,3.57]$ \\
\hline \multicolumn{7}{|c|}{ Total events: 13 (Regional analgesia (C)), 9 (Placebo) } \\
\hline \multicolumn{7}{|c|}{ Heterogeneity: Tau $^{2}=0.05 ;$ Chi $^{2}=1.09, d f=I(P=0.30) ; I^{2}=8 \%$} \\
\hline \multicolumn{7}{|c|}{ Test for overall effect: $Z=0.88(P=0.38)$} \\
\hline \multicolumn{7}{|c|}{ Test for subgroup differences: Not applicable } \\
\hline & & & 0.01 & 10 & 100 & \\
\hline & & & s regic & Favours & acebo & \\
\hline
\end{tabular}


Analysis 6.5. Comparison 6 Regional analgesia (with or without tocolysis) vs no intervention of regional analgesia (with or without tocolysis), Outcome 5 Failed external cephalic version.

Review: Interventions for helping to turn term breech babies to head first presentation when using external cephalic version

Comparison: 6 Regional analgesia (with or without tocolysis) vs no intervention of regional analgesia (with or without tocolysis)

Outcome: 5 Failed external cephalic version

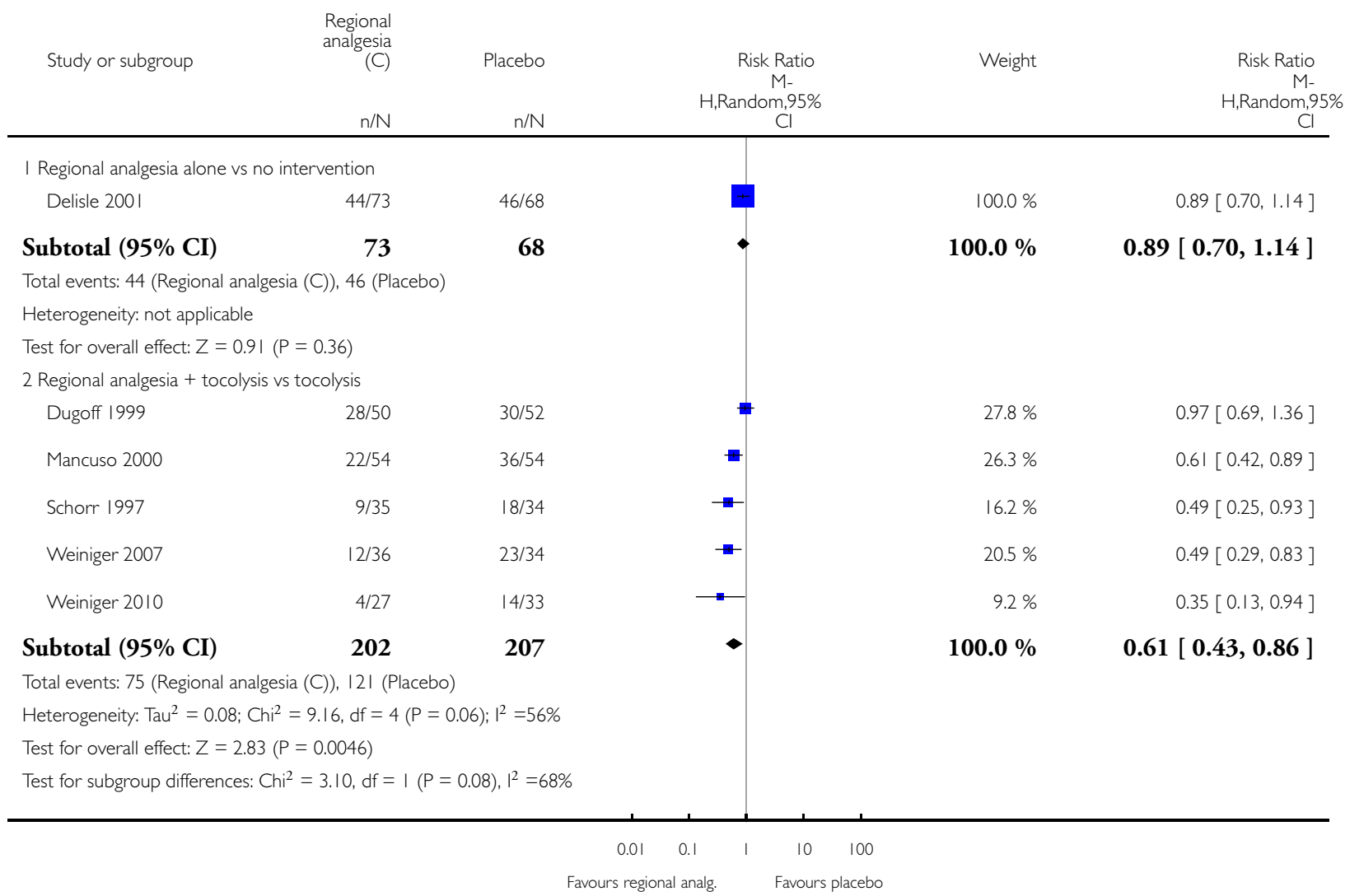


Analysis 6.9. Comparison 6 Regional analgesia (with or without tocolysis) vs no intervention of regional analgesia (with or without tocolysis), Outcome 9 Maternal hypotension.

Review: Interventions for helping to turn term breech babies to head first presentation when using external cephalic version

Comparison: 6 Regional analgesia (with or without tocolysis) vs no intervention of regional analgesia (with or without tocolysis)

Outcome: 9 Maternal hypotension

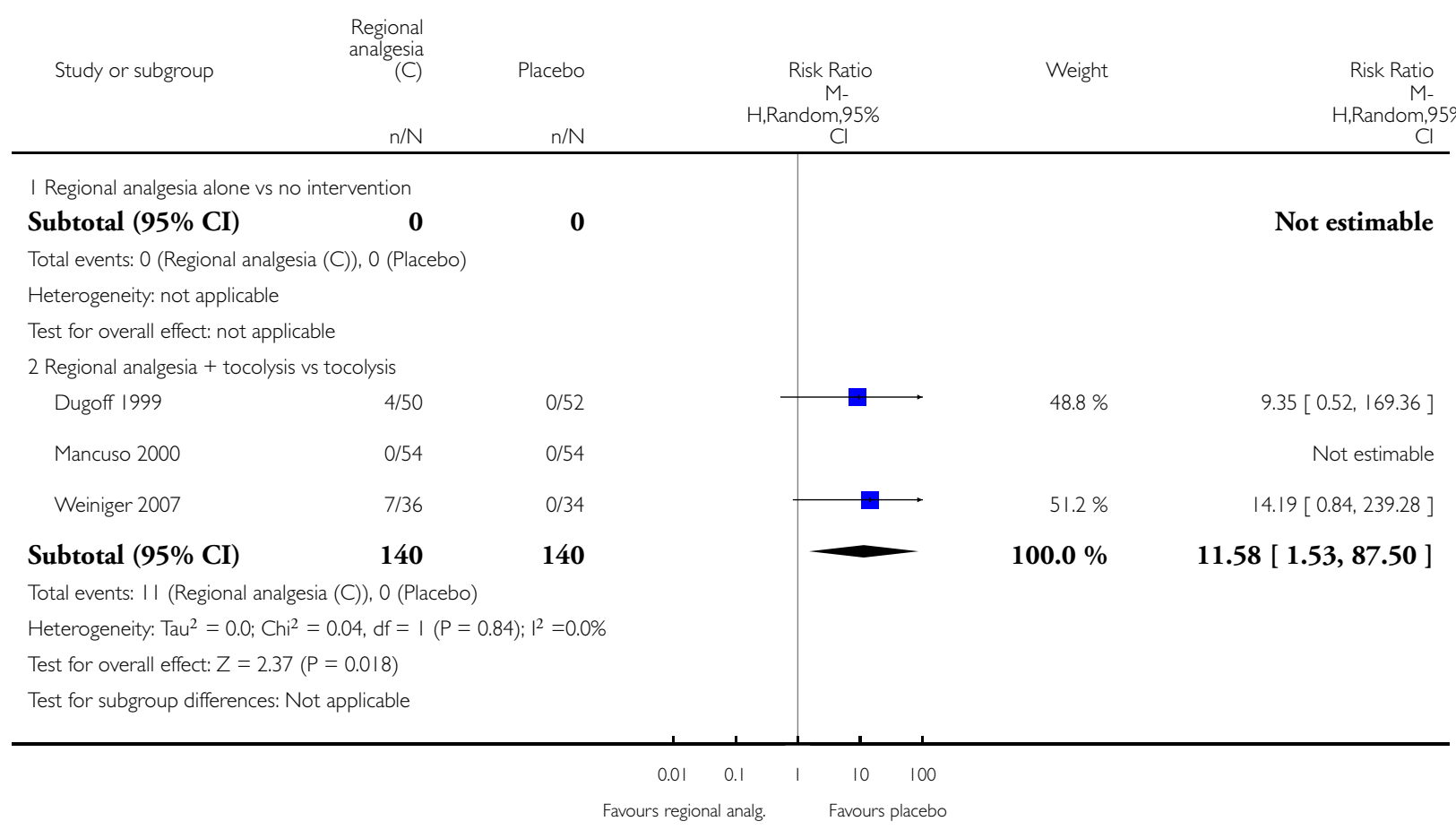


Analysis 6.15. Comparison 6 Regional analgesia (with or without tocolysis) vs no intervention of regional analgesia (with or without tocolysis), Outcome 15 Placental abruption (not prespecified).

Review: Interventions for helping to turn term breech babies to head first presentation when using external cephalic version

Comparison: 6 Regional analgesia (with or without tocolysis) vs no intervention of regional analgesia (with or without tocolysis)

Outcome: 15 Placental abruption (not prespecified)

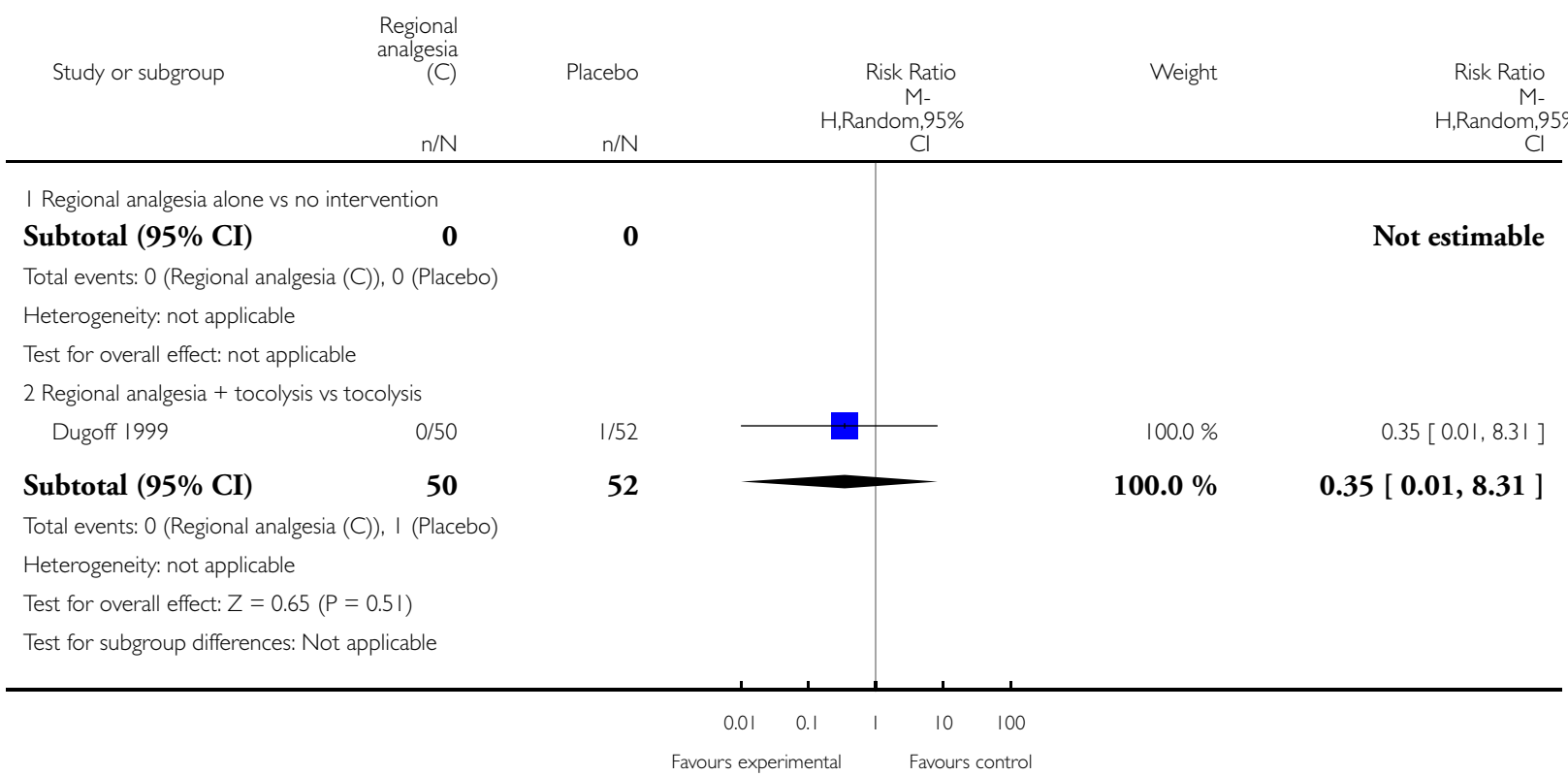


Analysis 6.16. Comparison 6 Regional analgesia (with or without tocolysis) vs no intervention of regional analgesia (with or without tocolysis), Outcome 16 Maternal discomfort (not prespecified).

Review: Interventions for helping to turn term breech babies to head first presentation when using external cephalic version

Comparison: 6 Regional analgesia (with or without tocolysis) vs no intervention of regional analgesia (with or without tocolysis)

Outcome: 16 Maternal discomfort (not prespecified)

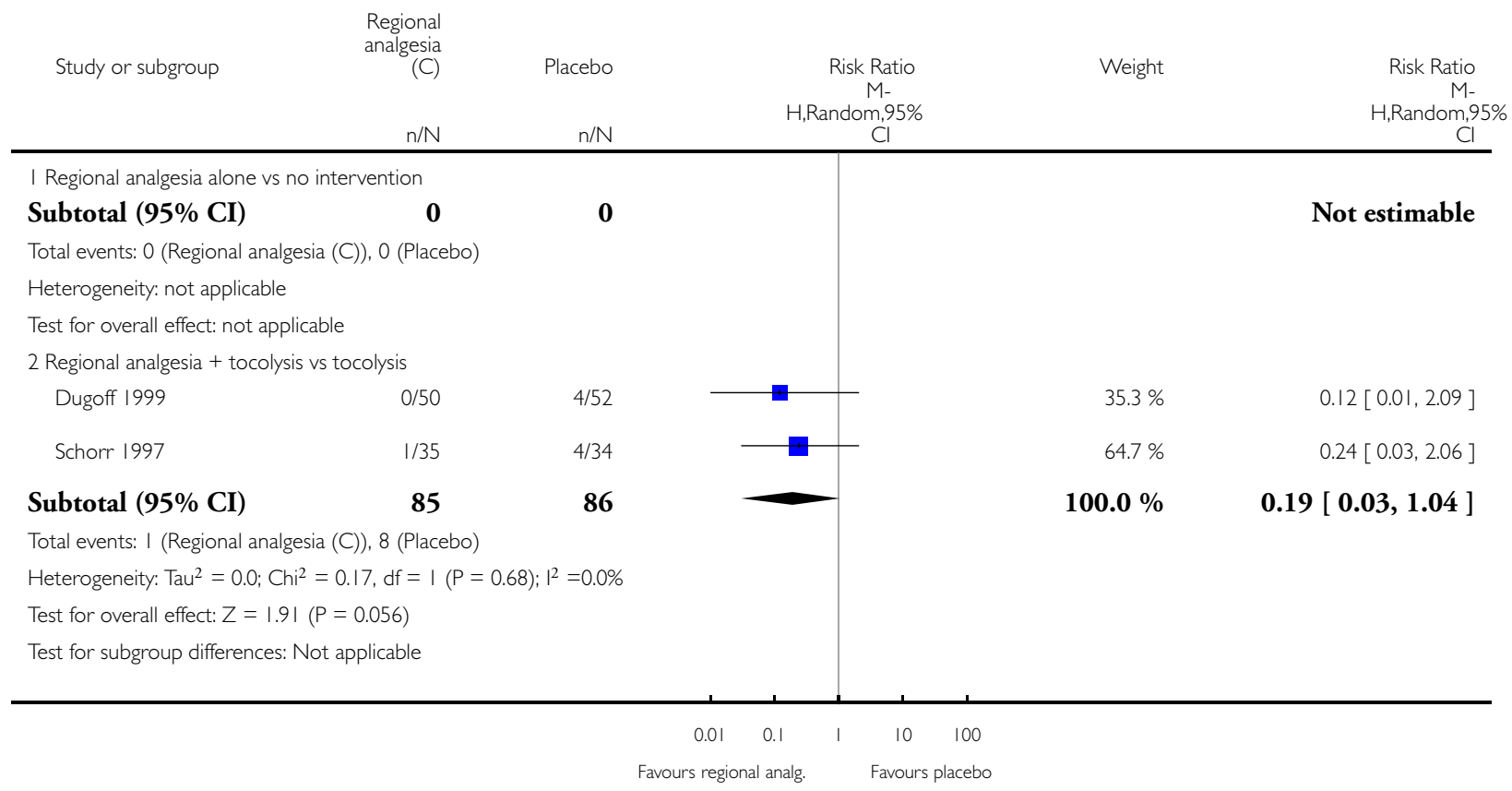


Analysis I5.3. Comparison I Systemic opioids (E) vs placebo, Outcome 3 Fetal bradycardia (primary).

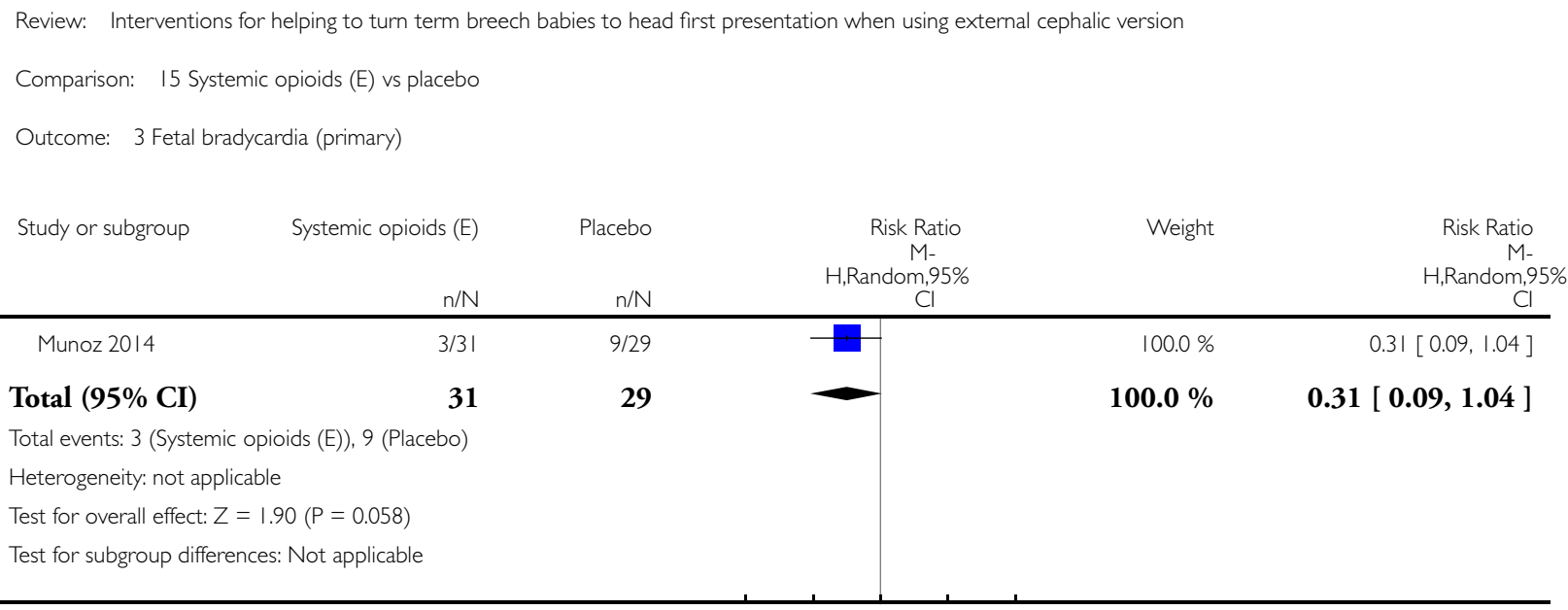

$\begin{array}{ccccc}0.01 & 0.1 & 1 & 10 & 100 \\ \text { Favours experimental } & & \text { Favours control }\end{array}$

\section{Analysis 15.4. Comparison I5 Systemic opioids (E) vs placebo, Outcome 4 Caesarean section (primary).}

Review: Interventions for helping to turn term breech babies to head first presentation when using external cephalic version

Comparison: 15 Systemic opioids (E) vs placebo

Outcome: 4 Caesarean section (primary)

\begin{tabular}{|c|c|c|c|c|c|}
\hline Study or subgroup & Systemic opioids (E) & $\begin{array}{r}\text { Placebo } \\
\text { n/N }\end{array}$ & $\begin{array}{r}\text { Risk Ratio } \\
\text { M- } \\
\text { H,Random,95\% } \\
\text { Cl }\end{array}$ & Weight & $\begin{array}{c}\text { Risk Ratio } \\
\text { M- } \\
\text { H,Random,95\% } \\
\mathrm{Cl} \\
\end{array}$ \\
\hline Munoz 2014 & $17 / 31$ & $16 / 29$ & 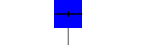 & $100.0 \%$ & $0.99[0.63,1.57]$ \\
\hline Total $(95 \% \mathrm{CI})$ & 31 & 29 & - & $100.0 \%$ & $0.99[0.63,1.57]$ \\
\hline \multicolumn{6}{|c|}{ Total events: 17 (Systemic opioids (E)), 16 (Placebo) } \\
\hline \multicolumn{6}{|c|}{ Heterogeneity: not applicable } \\
\hline \multicolumn{6}{|c|}{ Test for overall effect: $Z=0.03(P=0.98)$} \\
\hline Test for subgroup dif & : Not applicable & & & & \\
\hline
\end{tabular}




\section{Analysis 15.5. Comparison I5 Systemic opioids (E) vs placebo, Outcome 5 Failed external cephalic version.}

Review: Interventions for helping to turn term breech babies to head first presentation when using external cephalic version

Comparison: 15 Systemic opioids (E) vs placebo

Outcome: 5 Failed external cephalic version

\begin{tabular}{|c|c|c|c|c|c|}
\hline Study or subgroup & Systemic opioids (E) & Placebo & $\begin{array}{r}\text { Risk Ratio } \\
\text { M- } \\
\mathrm{H} \text {,Random,95\% } \\
\mathrm{Cl}\end{array}$ & Weight & $\begin{array}{c}\text { Risk Ratio } \\
\text { M- } \\
\text { H,Random,95\% } \\
\text { Cl }\end{array}$ \\
\hline Munoz 2014 & $|4 / 3|$ & $17 / 29$ & & $100.0 \%$ & $0.77[0.47,1.26]$ \\
\hline Total (95\% CI) & 31 & 29 & $<$ & $100.0 \%$ & $0.77[0.47,1.26]$ \\
\hline \multicolumn{6}{|c|}{ Total events: 14 (Systemic opioids (E)), 17 (Placebo) } \\
\hline \multicolumn{6}{|c|}{ Heterogeneity: not applicable } \\
\hline \multicolumn{6}{|c|}{ Test for overall effect: $Z=1.04(P=0.30)$} \\
\hline Test for subgroup dif & Not applicable & & & & \\
\hline
\end{tabular}

$\begin{array}{ccccc}0.01 & 0.1 & 1 & 10 & 100 \\ \text { Favours experimental } & & \text { Favours control }\end{array}$

\section{Analysis 15.10. Comparison I5 Systemic opioids (E) vs placebo, Outcome 10 Operative vaginal birth.}

Review: Interventions for helping to turn term breech babies to head first presentation when using external cephalic version

Comparison: 15 Systemic opioids (E) vs placebo

Outcome: 10 Operative vaginal birth

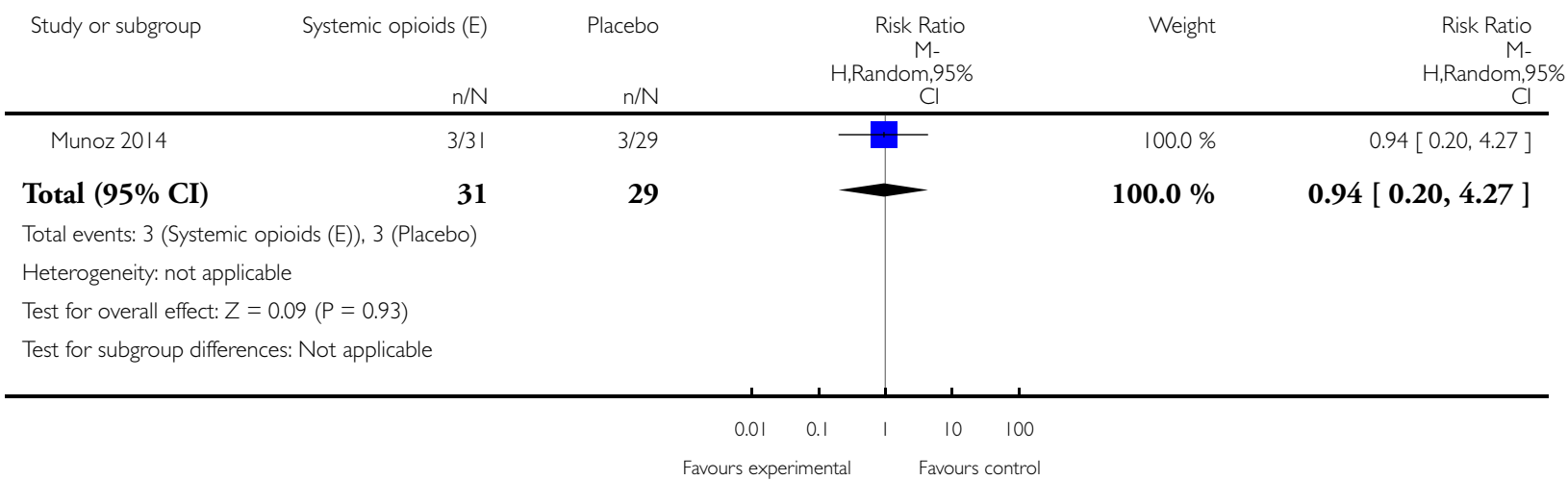




\section{Analysis I5.I5. Comparison I5 Systemic opioids (E) vs placebo, Outcome I5 Pain score (0-I 0 scale, lowest best) (non-prespecified).}

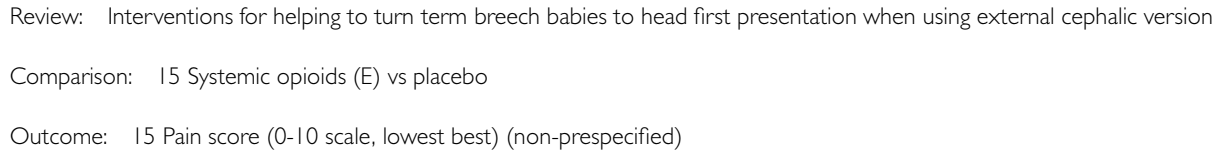

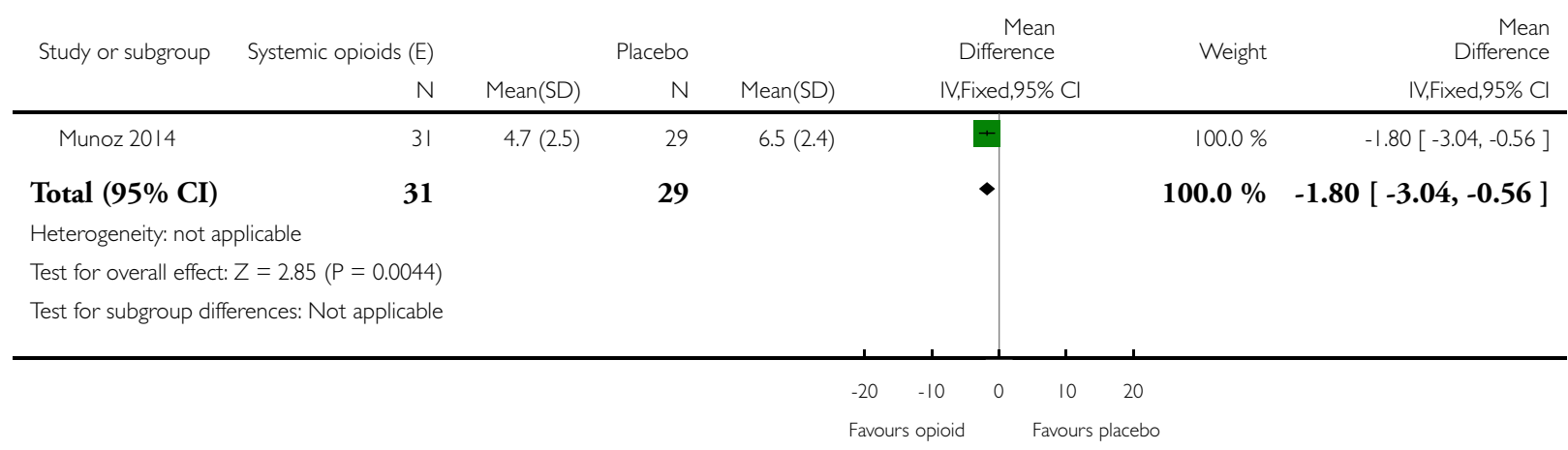

\section{Analysis 15.16. Comparison I5 Systemic opioids (E) vs placebo, Outcome 16 Maternal satisfaction score} (lower score worst) (non-prespecified).

Review: Interventions for helping to turn term breech babies to head first presentation when using external cephalic version

Comparison: 15 Systemic opioids (E) vs placebo

Outcome: 16 Maternal satisfaction score (lower score worst) (non-prespecified)

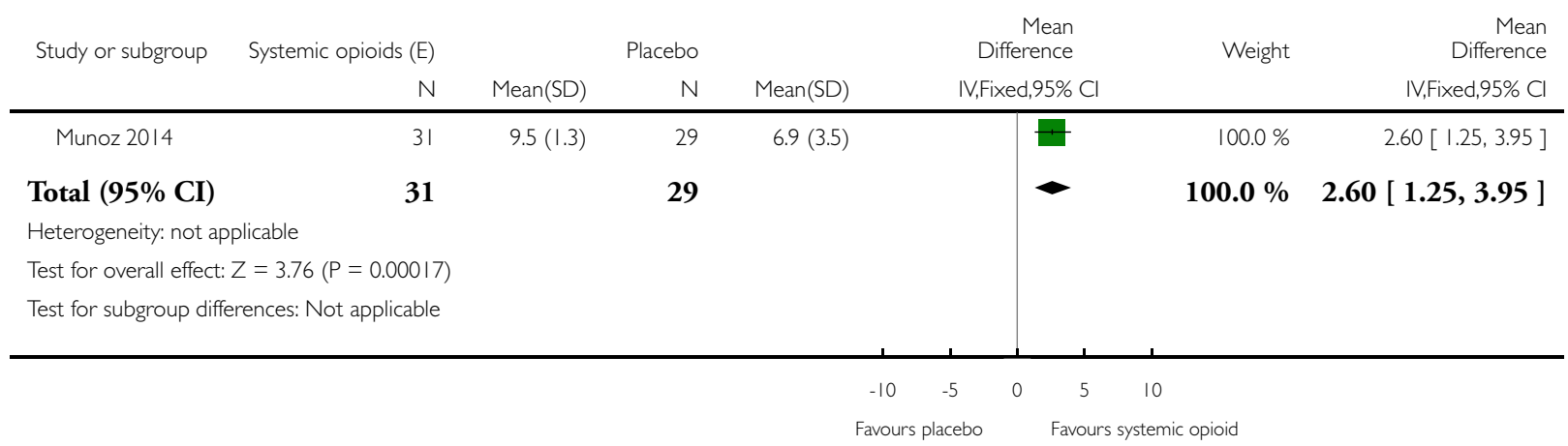




\section{Analysis 15.17. Comparison I5 Systemic opioids (E) vs placebo, Outcome I7 Nausea and vomiting (non-} prespecified).

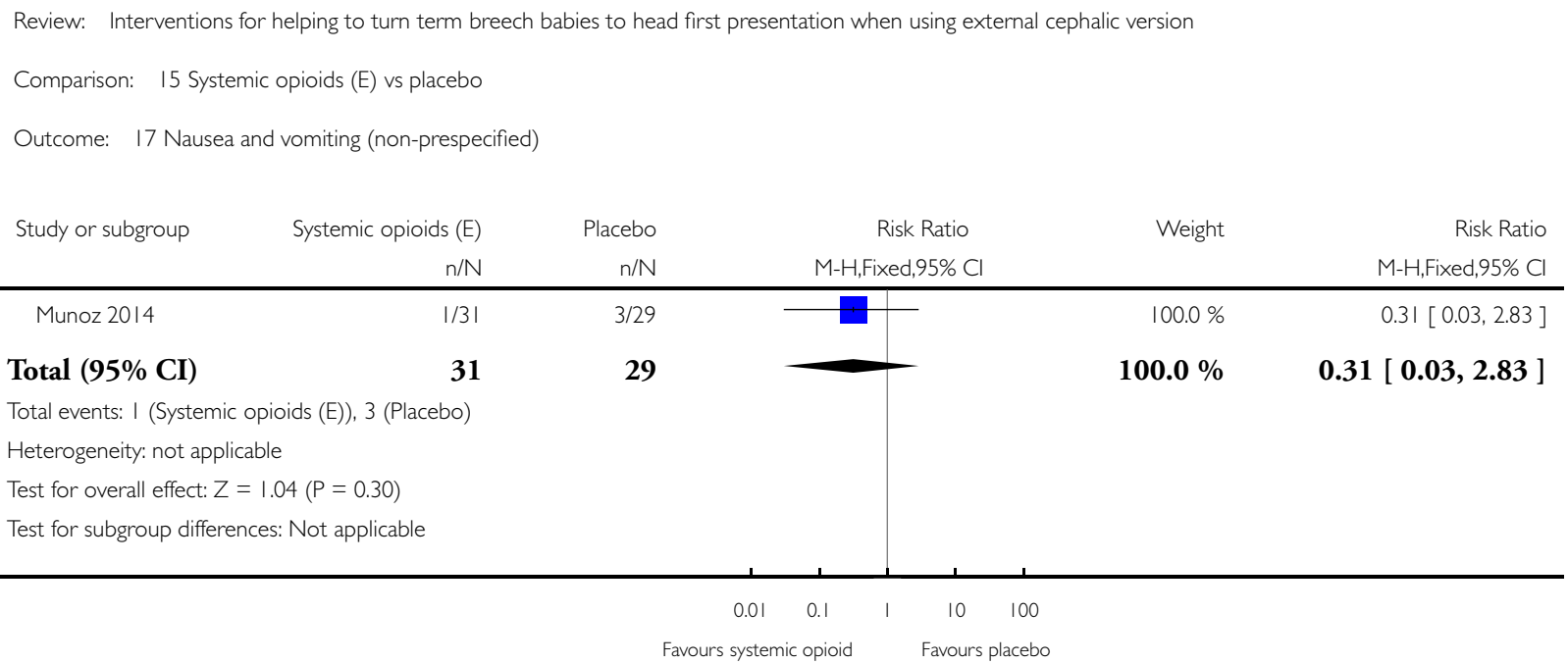

\section{Analysis 15.18. Comparison I5 Systemic opioids (E) vs placebo, Outcome 18 Dizziness (non-prespecified).}

Review: Interventions for helping to turn term breech babies to head first presentation when using external cephalic version

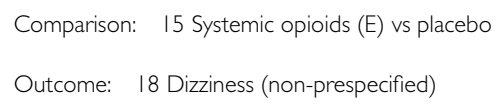

\begin{tabular}{|c|c|c|c|c|}
\hline & $\mathrm{n} / \mathrm{N}$ & $n / N$ & M-H,Fixed,95\% Cl & M-H,Fixed,95\% Cl \\
\hline Munoz 2014 & $0 / 31$ & $1 / 29$ & $\begin{array}{l}+1 \\
+2\end{array}$ & $0.31[0.01,7.38]$ \\
\hline
\end{tabular}

Total $(95 \% \mathrm{CI})$

31

29

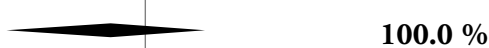

$0.31[0.01,7.38]$

Total events: 0 (Systemic opioids (E)), I (Placebo)

Heterogeneity: not applicable

Test for overall effect: $Z=0.72(P=0.47)$

Test for subgroup differences: Not applicable

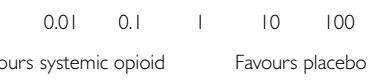




\section{Analysis 15.19. Comparison 15 Systemic opioids (E) vs placebo, Outcome 19 Drowsiness (non-prespecified).}

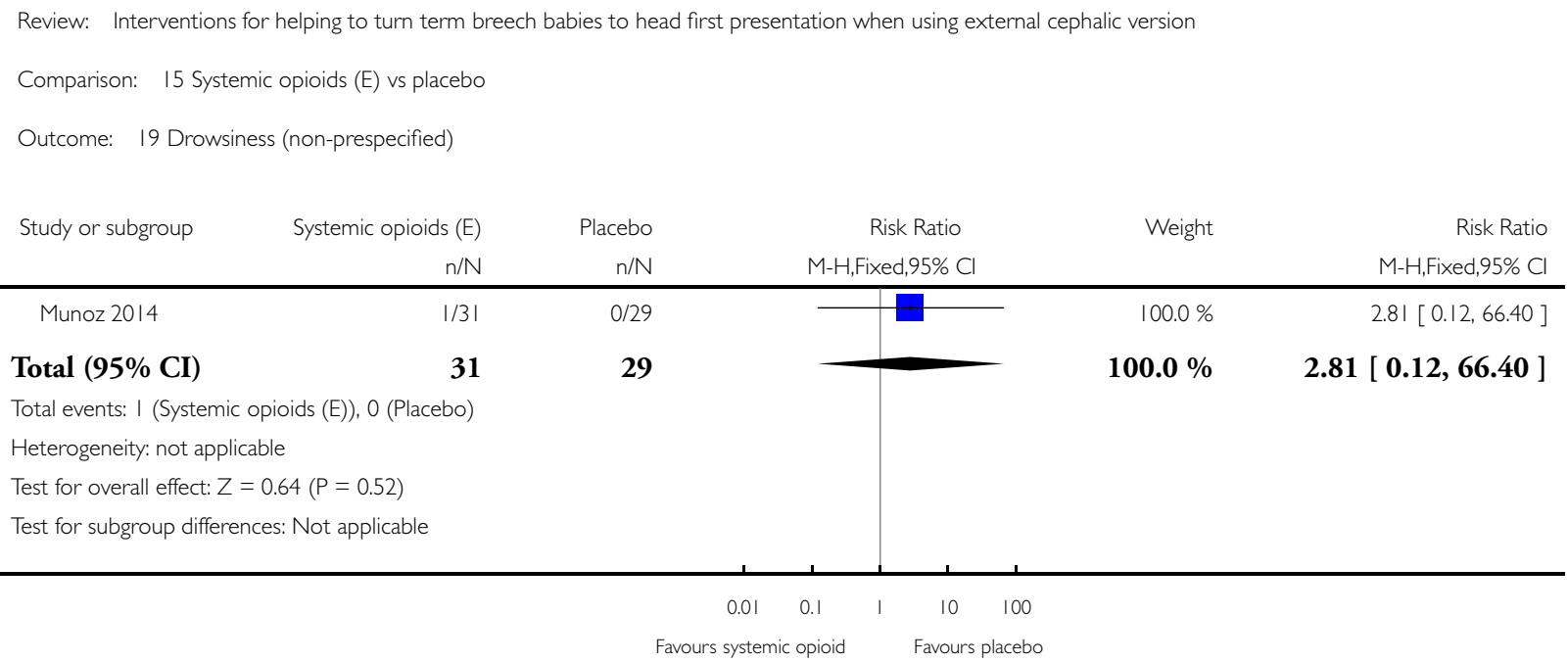

\footnotetext{
Analysis 18.2. Comparison I8 Systemic opioids (E) vs regional anaesthesia (C), Outcome 2 Failure to achieve cephalic vaginal birth (composite outcome: caesarean section + vaginal breech birth).

Review: Interventions for helping to turn term breech babies to head first presentation when using external cephalic version

Comparison: 18 Systemic opioids (E) vs regional anaesthesia (C)

Outcome: 2 Failure to achieve cephalic vaginal birth (composite outcome: caesarean section + vaginal breech birth)

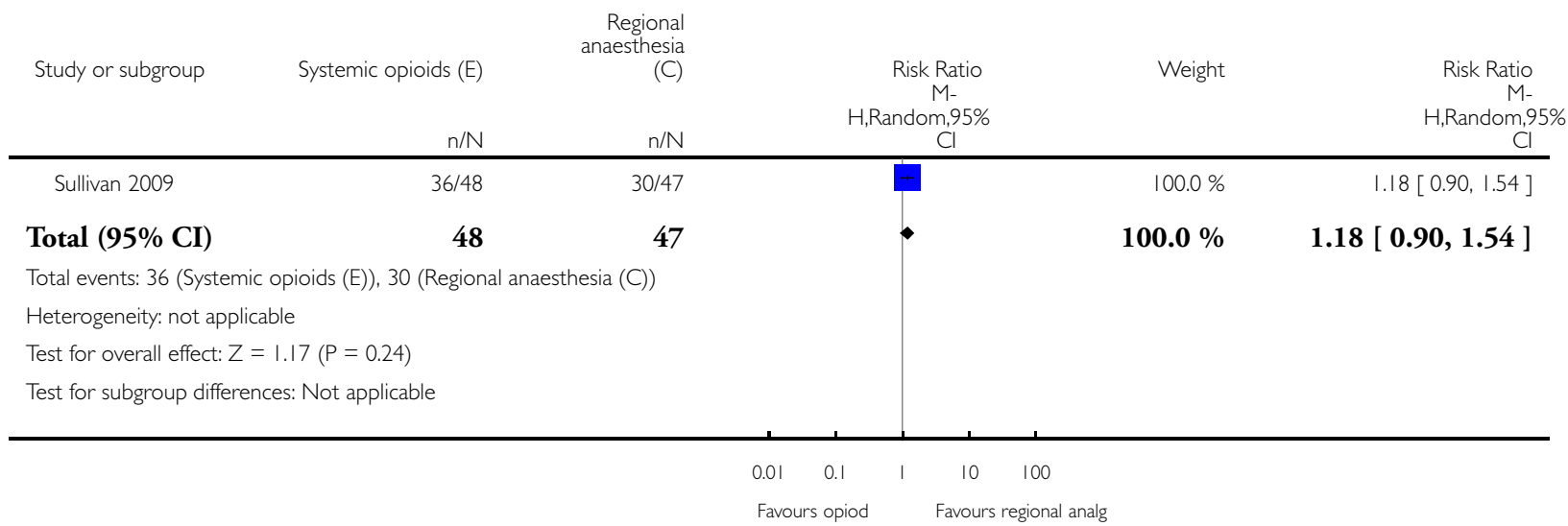


Analysis 18.3. Comparison I 8 Systemic opioids (E) vs regional anaesthesia (C), Outcome 3 Caesarean section (primary).

Review: Interventions for helping to turn term breech babies to head first presentation when using external cephalic version

Comparison: 18 Systemic opioids (E) vs regional anaesthesia (C)

Outcome: 3 Caesarean section (primary)

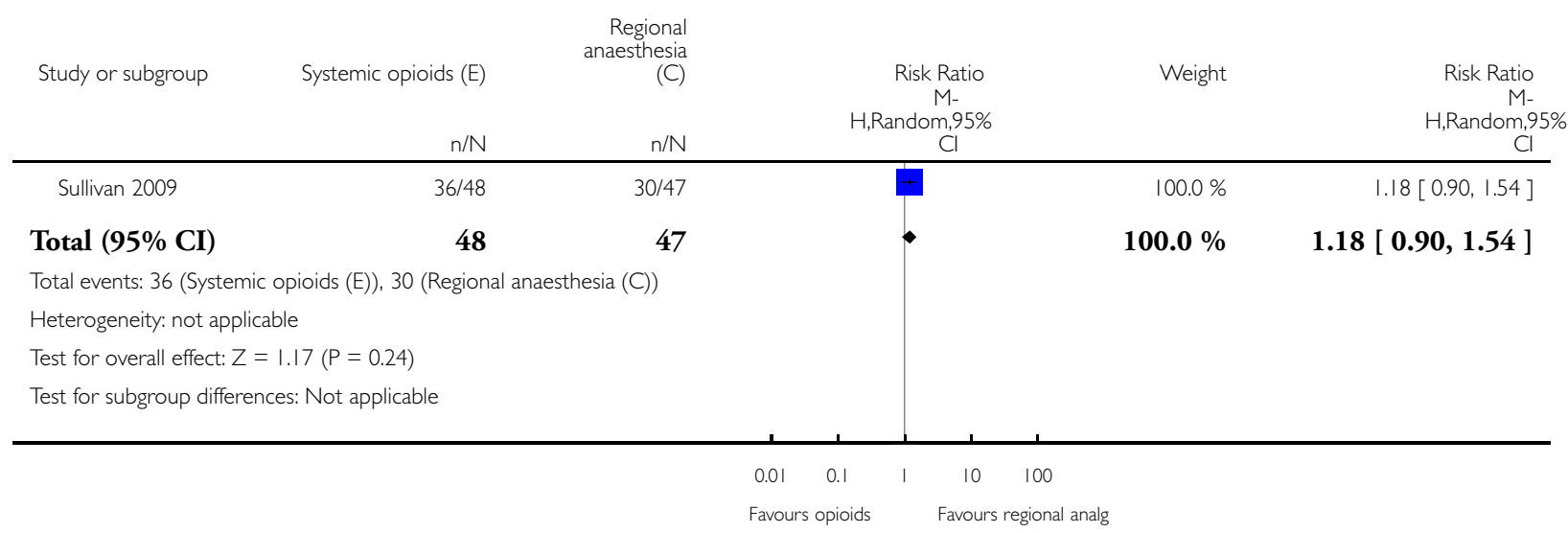


Analysis 18.4. Comparison I8 Systemic opioids (E) vs regional anaesthesia (C), Outcome 4 Fetal bradycardia (primary).

Review: Interventions for helping to turn term breech babies to head first presentation when using external cephalic version

Comparison: 18 Systemic opioids (E) vs regional anaesthesia (C)

Outcome: 4 Fetal bradycardia (primary)

\begin{tabular}{|c|c|c|c|c|c|c|}
\hline Study or subgroup & $\begin{array}{r}\text { Systemic opioids (E) } \\
\text { n/N }\end{array}$ & $\begin{array}{r}\text { Regional } \\
\text { anaesthesia } \\
(\mathrm{C}) \\
\mathrm{n} / \mathrm{N}\end{array}$ & & $\begin{array}{r}\text { Risk Ratio } \\
\text { M- } \\
\text { H,Random,95\% } \\
\text { Cl } \\
\end{array}$ & Weight & $\begin{array}{c}\text { Risk Ratio } \\
\text { M- } \\
\text { H,Random,95\% } \\
\text { Cl }\end{array}$ \\
\hline Sullivan 2009 & $5 / 47$ & $7 / 47$ & & & $100.0 \%$ & $0.71[0.24,2.09]$ \\
\hline Total $(95 \% \mathrm{CI})$ & 47 & 47 & & & $100.0 \%$ & $0.71[0.24,2.09]$ \\
\hline \multicolumn{7}{|c|}{ Total events: 5 (Systemic opioids (E)), 7 (Regional anaesthesia (C)) } \\
\hline \multicolumn{7}{|c|}{ Heterogeneity: not applicable } \\
\hline \multicolumn{7}{|c|}{ Test for overall effect: $Z=0.61(P=0.54)$} \\
\hline \multicolumn{7}{|c|}{ Test for subgroup differences: Not applicable } \\
\hline & & & 0.01 & 10 & 100 & \\
\hline \multicolumn{7}{|c|}{ Favours opioids $\quad$ Favours regional anaes } \\
\hline
\end{tabular}


Analysis 18.5. Comparison I 8 Systemic opioids (E) vs regional anaesthesia (C), Outcome 5 Failed external cephalic version.

Review: Interventions for helping to turn term breech babies to head first presentation when using external cephalic version

Comparison: 18 Systemic opioids (E) vs regional anaesthesia (C)

Outcome: 5 Failed external cephalic version

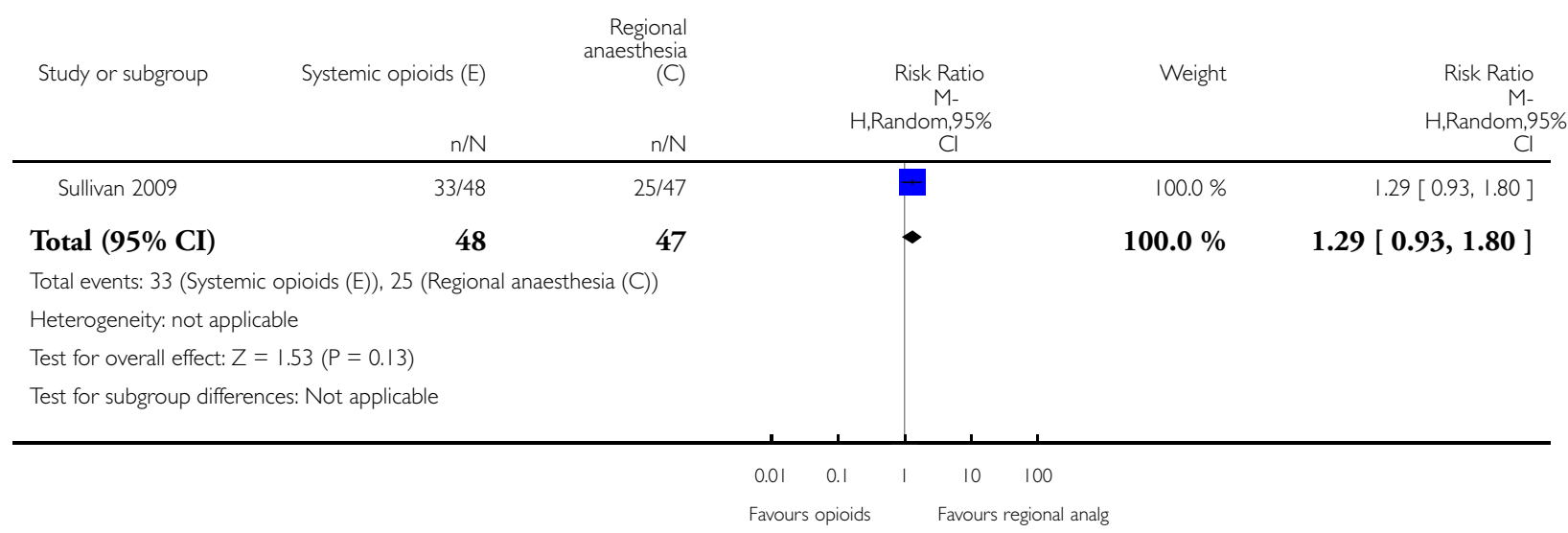




\section{Analysis 21.1. Comparison 21 Tocolytics vs placebo - nullips vs multips, Outcome I Cephalic presentation at birth (primary).}

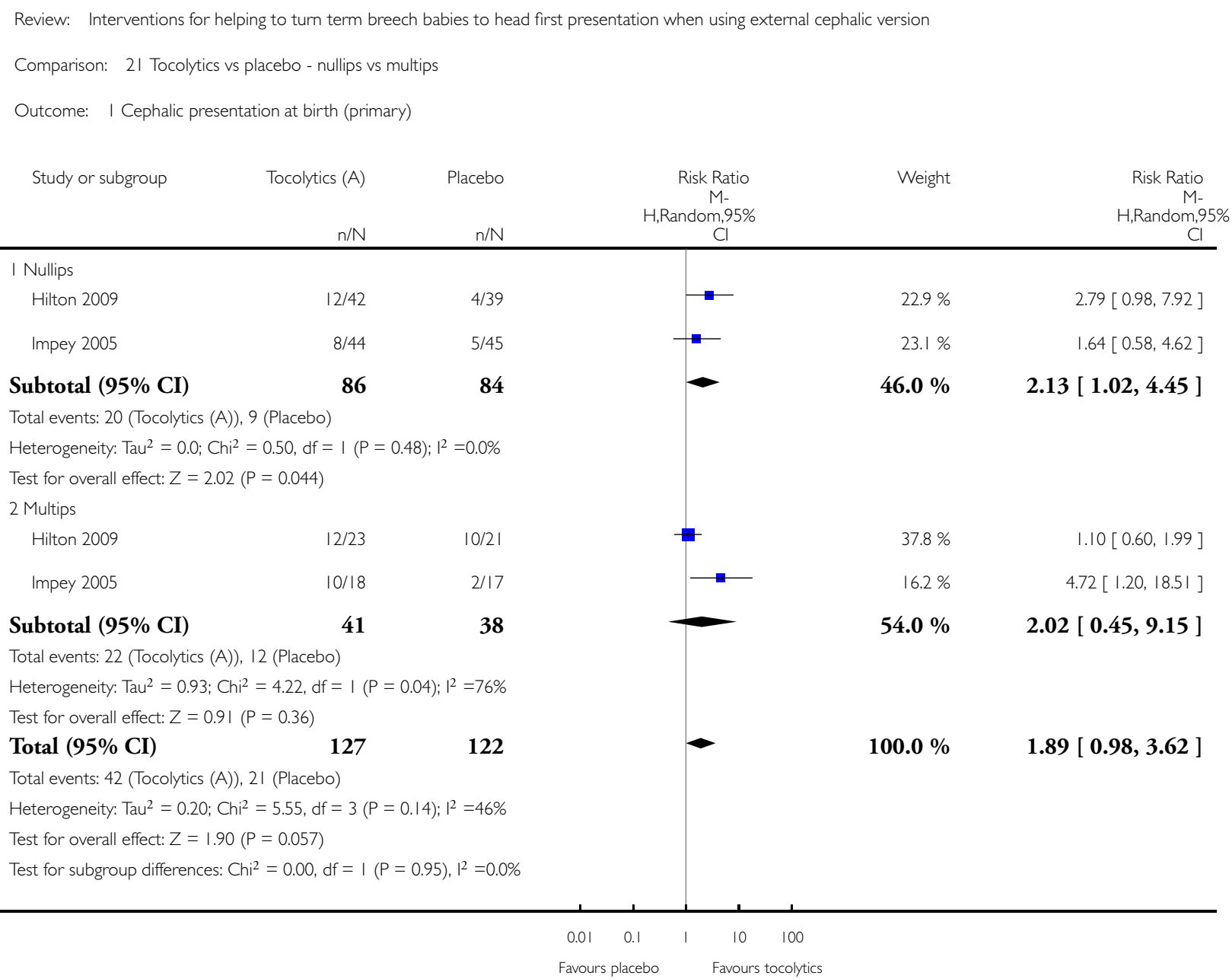


Analysis 21.2. Comparison 21 Tocolytics vs placebo - nullips vs multips, Outcome 2 Caesarean section (primary).

\begin{tabular}{|c|c|c|c|c|c|}
\hline \multicolumn{6}{|c|}{ Comparison: 21 Tocolytics vs placebo - nullips vs multips } \\
\hline \multicolumn{6}{|c|}{ Outcome: 2 Caesarean section (primary) } \\
\hline Study or subgroup & Tocolytics (A) & $\begin{array}{r}\text { Placebo } \\
n / N \\
\end{array}$ & $\begin{array}{c}\text { Risk Ratio } \\
\text { M- } \\
\text { H,Random,95\% } \\
\mathrm{Cl} \\
\end{array}$ & Weight & $\begin{array}{c}\text { Risk Ratio } \\
\text { M- } \\
\text { H,Random,95\% } \\
\mathrm{Cl}\end{array}$ \\
\hline \multicolumn{6}{|l|}{ I Nullips } \\
\hline Hilton 2009 & $32 / 42$ & $36 / 39$ & $\mathbf{m}$ & $41.6 \%$ & $0.83[0.68,1.00]$ \\
\hline Impey 2005 & $35 / 44$ & $41 / 45$ & ت & $49.5 \%$ & $0.87[0.73,1.04]$ \\
\hline Subtotal $(95 \% \mathrm{CI})$ & 86 & 84 & • & $91.1 \%$ & $0.85[0.75,0.97]$ \\
\hline \multicolumn{6}{|c|}{ Total events: 67 (Tocolytics (A)), 77 (Placebo) } \\
\hline \multicolumn{6}{|c|}{ Heterogeneity: $\mathrm{Tau}^{2}=0.0 ; \mathrm{Ch}^{2}=0.18, \mathrm{df}=\mathrm{I}(\mathrm{P}=0.67) ; \mathrm{I}^{2}=0.0 \%$} \\
\hline \multicolumn{6}{|c|}{ Test for overall effect: $Z=2.44(P=0.015)$} \\
\hline \multicolumn{6}{|l|}{2 Multips } \\
\hline Hilton 2009 & $12 / 23$ & $|3 / 2|$ & $\rightarrow$ & $5.9 \%$ & $0.84[0.50,1.41]$ \\
\hline Impey 2005 & $6 / 18$ & $12 / 17$ & $\rightarrow$ & $3.0 \%$ & $0.47[0.23,0.97]$ \\
\hline Subtotal (95\% CI) & 41 & 38 & - & $8.9 \%$ & $0.67[0.38,1.17]$ \\
\hline \multicolumn{6}{|c|}{ Total events: 18 (Tocolytics (A)), 25 (Placebo) } \\
\hline \multicolumn{6}{|c|}{ Heterogeneity: $\mathrm{Tau}^{2}=0.07 ; \mathrm{Chi}^{2}=1.67, \mathrm{df}=1(P=0.20) ; \mathrm{I}^{2}=40 \%$} \\
\hline \multicolumn{6}{|c|}{ Test for overall effect: $Z=1.41(P=0.16)$} \\
\hline Total $(95 \%$ CI $)$ & 127 & 122 & - & $100.0 \%$ & $0.84[0.74,0.95]$ \\
\hline \multicolumn{6}{|c|}{ Total events: 85 (Tocolytics (A)), 102 (Placebo) } \\
\hline \multicolumn{6}{|c|}{ Heterogeneity: $\mathrm{Tau}^{2}=0.00 ; \mathrm{Chi}^{2}=3.03, \mathrm{df}=3(\mathrm{P}=0.39) ; \mathrm{I}^{2}=1 \%$} \\
\hline \multicolumn{6}{|c|}{ Test for overall effect: $Z=2.81$ ( $P=0.0049)$} \\
\hline \multicolumn{6}{|c|}{ Test for subgroup differences: Chi $^{2}=0.68, d f=I(P=0.4 I), I^{2}=0.0 \%$} \\
\hline
\end{tabular}


Analysis 21.4. Comparison 21 Tocolytics vs placebo - nullips vs multips, Outcome 4 Failed external cephalic version.

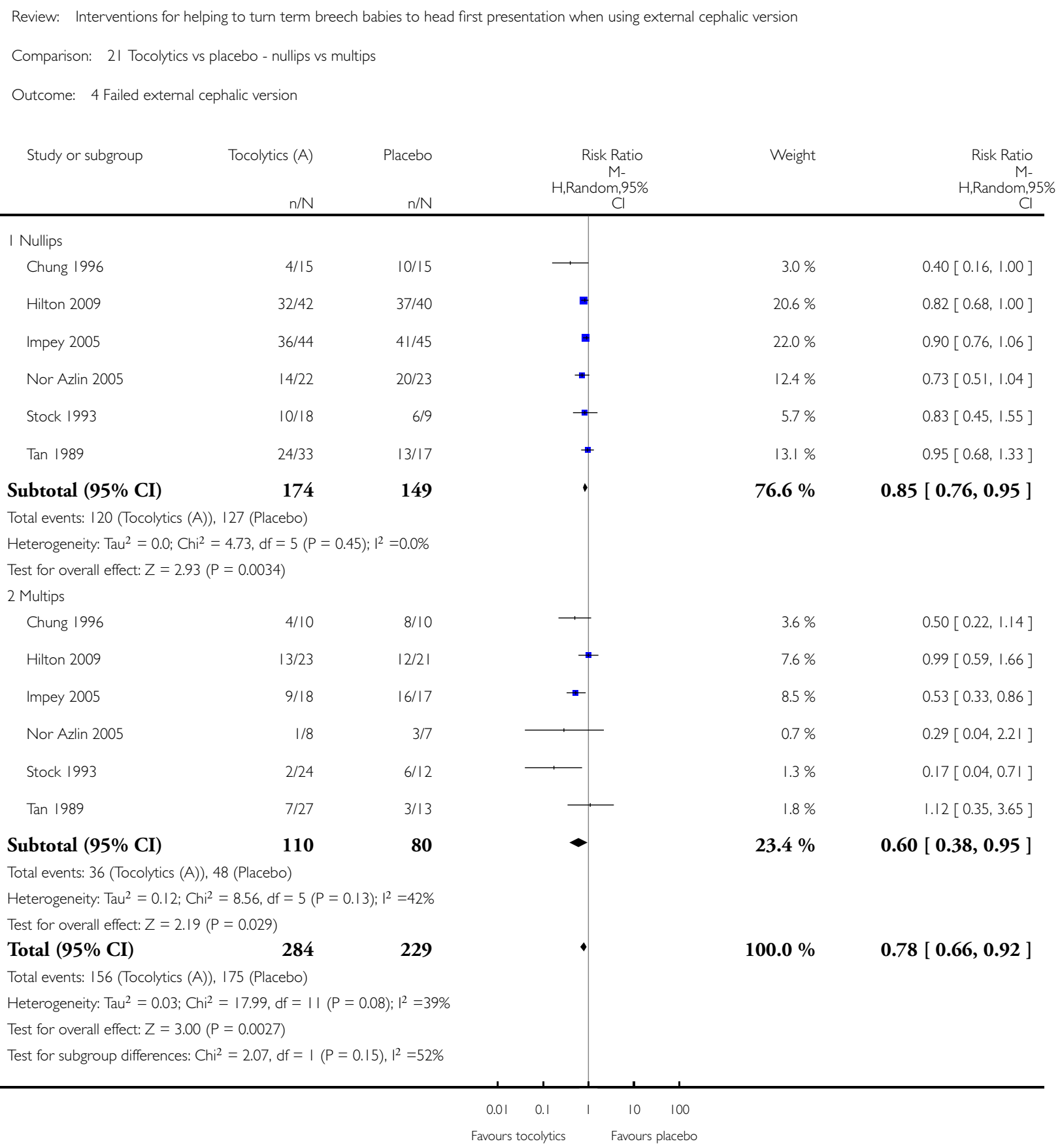




\section{Analysis 22.4. Comparison 22 Tocolytic (nifedipine) vs tocolytic (terbutaline) - nullips vs multips, Outcome}

4 Failed ECV.

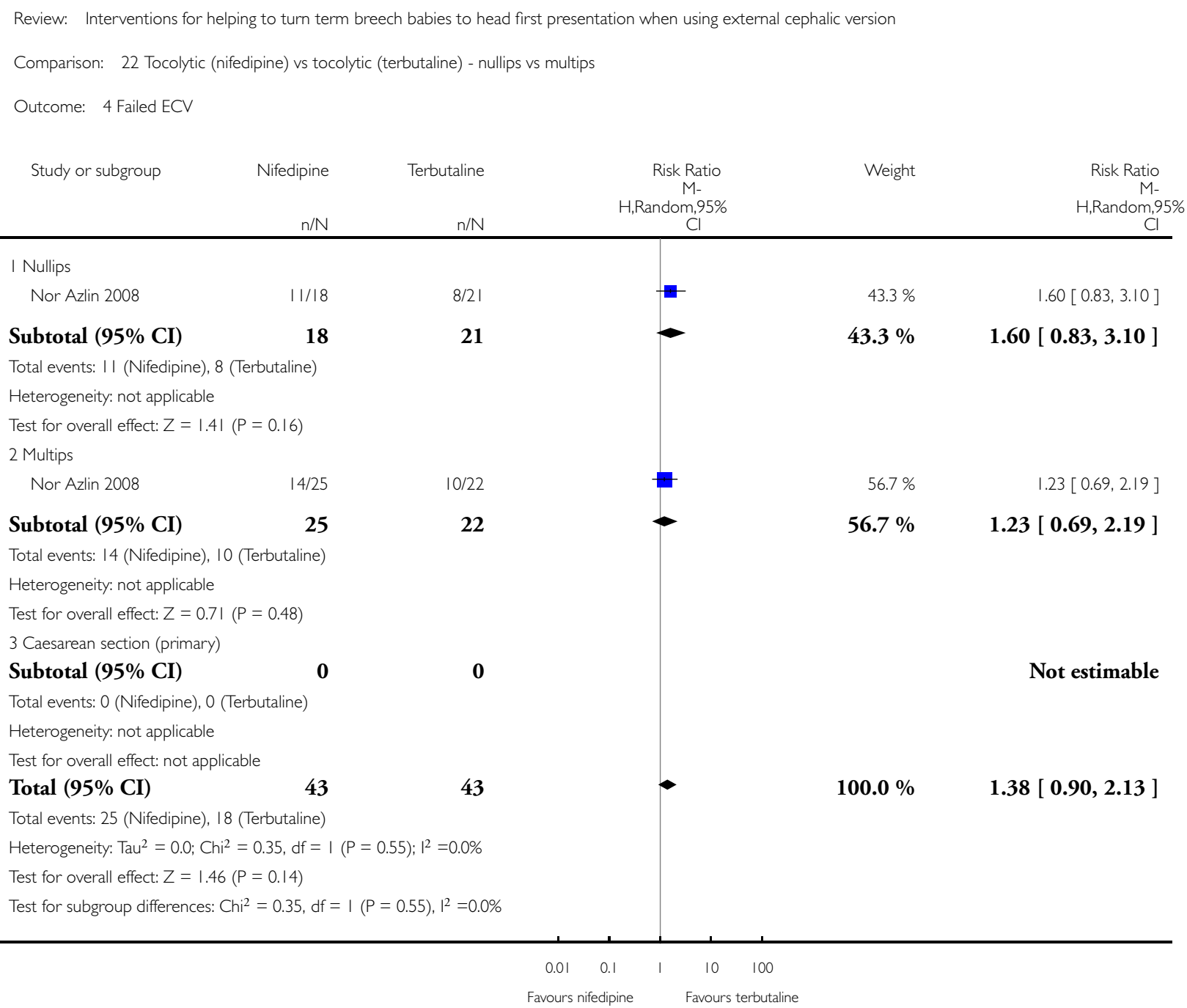




\section{Analysis 23.5. Comparison 23 Hypnosis vs neurolinguistic programming, Outcome 5 Failed external}

cephalic version.

Review: Interventions for helping to turn term breech babies to head first presentation when using external cephalic version

Comparison: 23 Hypnosis vs neurolinguistic programming

Outcome: 5 Failed external cephalic version

Neuro-
linguistic

$\begin{array}{lr}\text { linguistic } \\ \text { Study or subgroup } \quad \text { Hypnosis } & \text { programm }\end{array}$

$\begin{array}{ccc} & \mathrm{n} / \mathrm{N} & \mathrm{n} / \mathrm{N}\end{array}$

$\mathrm{n} / \mathrm{N}$

$21 / 38$

42

38

Total (95\% CI)

38

Total events: 25 (Hypnosis), 2 I (Neuro-linguistic programm)

Heterogeneity: not applicable

Test for overall effect: $Z=0.38(P=0.70)$

Test for subgroup differences: Not applicable

\begin{tabular}{|c|c|c|}
\hline $\begin{array}{c}\text { Risk Ratio } \\
\text { M- } \\
\text { H,Random,95\% } \\
\text { Cl }\end{array}$ & Weight & $\begin{array}{c}\text { Risk Ratio } \\
\text { M- } \\
\text { H,Random,95\% } \\
\text { Cl }\end{array}$ \\
\hline & $100.0 \%$ & $1.08[0.74,1.57]$ \\
\hline & $100.0 \%$ & $1.08[0.74,1.57]$ \\
\hline
\end{tabular}

Analysis 23.15. Comparison 23 Hypnosis vs neurolinguistic programming, Outcome 15 Good pain relief (higher scores better) (non-prespecified).

Review: Interventions for helping to turn term breech babies to head first presentation when using external cephalic version

Comparison: 23 Hypnosis vs neurolinguistic programming

Outcome: 15 Good pain relief (higher scores better) (non-prespecified)

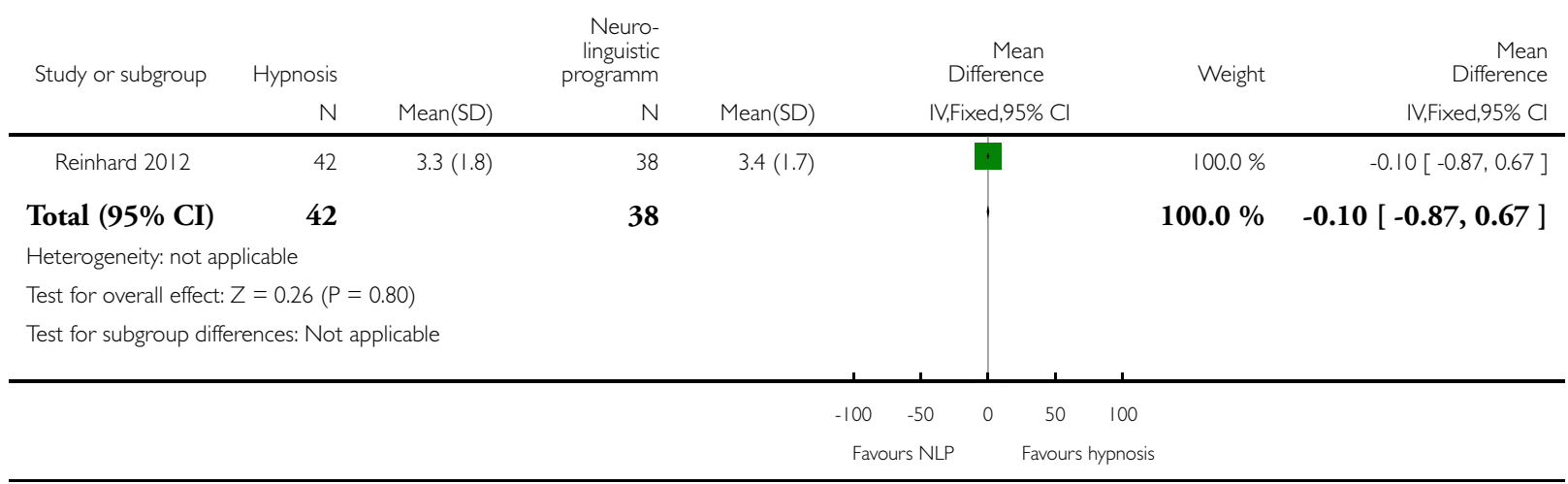

Interventions for helping to turn term breech babies to head first presentation when using external cephalic version (Review)

Copyright (C) 2016 The Cochrane Collaboration. Published by John Wiley \& Sons, Ltd. 


\section{Analysis 24.5. Comparison 24 Talcum powder vs gel, Outcome 5 Failed external cephalic version (after first round of attempts).}

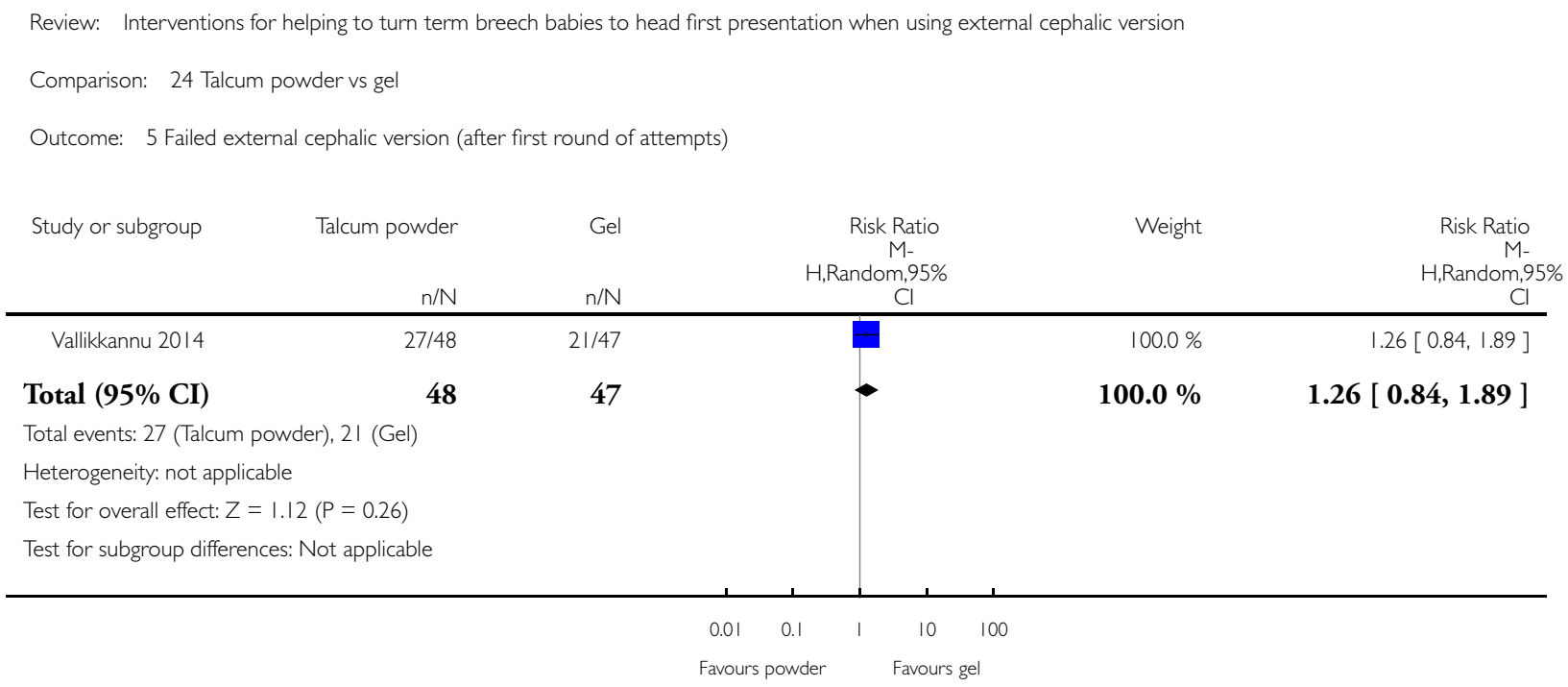

\section{WHAT'S NEW}

Last assessed as up-to-date: 30 September 2014.

\begin{tabular}{|c|c|c|}
\hline Date & Event & Description \\
\hline 9 March 2016 & Amended & $\begin{array}{l}\text { We have corrected a typographical error in Analysis } 6.1 \text { (in relation to Schorr 1997). This edit does not } \\
\text { affect the analysis/results or conclusions of this review }\end{array}$ \\
\hline
\end{tabular}




\section{H IS TOR Y}

Protocol first published: Issue 3, 1996

Review first published: Issue 3, 1996

\begin{tabular}{lll}
\hline Date & Event & Description \\
\hline 30 September 2014 & New search has been performed & $\begin{array}{l}\text { We have updated the search and identified 6 new stud- } \\
\text { ies. We have included 3 new trials in the review (Munoz } \\
\text { 2014; Reinhard 2012; Vallikkannu 2014), excluded } \\
1 \text { study (Guittier 2013) and identified 2 trial regis- } \\
\text { trations for ongoing studies (Burgos 2012; Passerini } \\
2013)\end{array}$ \\
\hline
\end{tabular}

30 September 2014 New citation required but conclusions have not changed

Overall results are similar to those reported in the previous version of the review. A new author joined the review team to assist with the update. We have incorporated a summary of findings table

30 September 2011 New search has been performed

Search updated: 10 new trials added to review We have moved Andarsio 2000 from categorisation as an 'Included study' to 'Awaiting classification' because we need to know the route of administration of the drug before we can include data on subgroups in the updated review. We are trying to obtain this information

19 May $2011 \quad$ New citation required and conclusions have changed

Beta stimulants are now recommended for facilitating external cephalic version at term, but data on adverse effects were insufficient. Data on calcium channel blockers and nitric acid donors were insufficient to provide good evidence

New authors helped update this review

\begin{tabular}{ll|l}
\hline 1 October 2009 & Amended & $\begin{array}{l}\text { Search updated: 19 reports added to Studies awaiting } \\
\text { classification }\end{array}$ \\
\hline 3 November 2008 & Amended & Converted to new review format \\
\hline 31 March 2004 & New search has been performed & $\begin{array}{l}\text { One new trial added to studies awaiting classification } \\
\text { (Hollard 2003) }\end{array}$ \\
\hline
\end{tabular}

30 September 2003 New citation required and conclusions have changed

With inclusion of Bujold 2003a and Bujold 2003b, we have changed the recommendation regarding nitroglycerine

30 September 2003 New search has been performed

Search updated. 2 new trials included (Bujold 2003a; Bujold 2003b) 


\section{CONTRIBUTIONSOFAUTHORS}

G. Justus Hofmeyr (JH) prepared the original version of the review. Gill Gyte (GG) and JH revised the review in 2004. Cathy Cluver (CC), JH, Marlene Sinclair (MS) and GG revised the review in 2011, and CC and MS undertook data extraction. JH, CC and GG entered and checked data. CC, JH, MS and Therese Dowswell (TD) revised the review in 2014. TD and GG undertook data extraction and checked the data entered. CC, JH and GG are responsible for editing the review and maintaining it.

\section{DECLARATIONSOF INTEREST}

TD is paid by the UK NHS to work on a range of Cochrane Reviews. The Funders have no influence on the content or conclusions of the reviews I work on. I have received payment from NIHR for my work on this and other reviews.

GJH receives royalties for two chapters authored in UpToDate.

\section{SOURCES OF SUPPORT}

\section{Internal sources}

- University of the Witwatersrand, South Africa.

- University of Fort Hare, South Africa.

- The University of Liverpool, UK.

\section{External sources}

- South African Medical Research Council, South Africa.

- UNDP/UNFPA/WHO/World Bank (HRP), Switzerland.

- National Institute for Health Research (NIHR), UK.

NIHR Cochrane Programme Grant Project: 13/89/05 - Pregnancy and childbirth systematic reviews to support clinical guidelines

\section{DIFFERENCES BETWEEN PROTOCOLANDREVIEW}

We have allocated all outcomes to be primary or secondary outcomes. We have included further interventions examined in recent trials in addition to those originally prespecified in the protocol. We have added an outcome - cephalic vaginal birth not achieved (caesarean section + vaginal breech births) - to enhance consistency with the findings of other related reviews. Additional outcomes are reported that were not specified in the protocol: vaginal breech birth, Apgar less than seven at five minutes, neonatal seizures, admission to neonatal unit, birth trauma, flushing in women, placental abruption, maternal discomfort, pain scores, maternal satisfaction with the procedure and maternal side effects (nausea and vomiting, dizziness and drowsiness).

\section{NDEX TERMS}




\section{Medical Subject Headings (MeSH)}

Analgesia, Obstetrical [methods]; Breech Presentation [* prevention \& control]; Calcium Channel Blockers [therapeutic use]; Delivery, Obstetric; Nitroglycerin [therapeutic use]; Randomized Controlled Trials as Topic; Tocolysis [ ${ }^{*}$ methods]; Tocolytic Agents [therapeutic use]; Version, Fetal [ ${ }^{*}$ methods]; Vibration [therapeutic use]

\section{MeSH check words}

Female; Humans; Pregnancy 